VICTOR TAKAZI KATAYAMA

QUANTIFICAÇÃO DA PRODUÇÃO DE LODO DE ESTAÇÕES DE TRATAMENTO DE ÁGUA DE CICLO COMPLETO: UMA ANÁLISE CRÍTICA 



\section{QUANTIFICAÇÃO DA PRODUÇÃO DE LODO DE ESTAÇÕES DE TRATAMENTO DE ÁGUA DE CICLO COMPLETO: UMA ANÁLISE CRÍTICA}

Dissertação apresentada à Escola Politécnica da Universidade de São Paulo para obtenção do título de Mestre em Engenharia

Área de concentração: Engenharia Hidráulica

Orientador: Prof ${ }^{\mathrm{a}}$. LivreDocentre Dione Mari Morita 



\section{QUANTIFICAÇÃO DA PRODUÇÃO DE LODO DE ESTAÇÕES DE TRATAMENTO DE ÁGUA DE CICLO COMPLETO: UMA ANÁLISE CRÍTICA}

Dissertação apresentada à Escola Politécnica da Universidade de São Paulo para obtenção do título de Mestre em Engenharia

Área de concentração: Engenharia Hidráulica

Orientador: Prof ${ }^{a}$. LivreDocentre Dione Mari Morita 
FICHA CATALOGRÁFICA

Katayama, Victor Takazi

Quantificação da produção de lodo de estações de tratamento de água de ciclo completo: uma análise crítica / V.T.

Katayama. -- São Paulo, 2012. $139 \mathrm{p}$.

Dissertação (Mestrado) - Escola Politécnica da Universidade de São Paulo. Departamento de Engenharia Hidráulica e Ambiental.

1. Lodo (Produção; Estimativa) 2. Tratamento de água 3. Saneamento I. Universidade de São Paulo. Escola Politécnica. Departamento de Engenharia Hidráulica e Ambiental II. t. 


\section{AGRADECIMENTOS}

À professora Dione Mari Morita, pela paciência infinita e pelo punho firme no mar revolto.

Aos companheiros de trincheira Fernando Aidar, Marcus Vinícius, Lara Lessa, Lina Ledesma, Felipe Avancine, Fábio Lofrano, Manoel de Toledo e Carolina Yabroudi: os frutos virão.

À professora Linda Lee Ho, pela condução através do vale das sombras da Estatística.

Aos meus precursores Caroline Montes e Thadeu Hiroshi, pela dádiva dos dados. 

Truth is the daughter of time, not authority. (Francis Bacon) 



\section{RESUMO}

Grande parte do lodo gerado em ETAs no Brasil ainda é disposta em rios ou em aterros sanitários. Contudo, principalmente em grandes centros urbanos, condições de licenciamento ambiental restritivas e custos logísticos crescentes tem levantado interesse em usos benéficos para esse resíduo. Um obstáculo para a mudança de paradigma recai no fato de que muito raramente operadores e projetistas de ETAs nacionais conseguirem prever, com algum grau de confiabilidade, a massa e volume de resíduos produzidos pelo tratamento da água bruta. Geralmente, usa-se para esse fim fórmulas empíricas, que relacionam a produção de lodo à concentração de sólidos em suspensão totais (SST) na água bruta e à dosagem de produtos químicos.

Os objetivos deste trabalho são: comparar o desempenho de dois dos principais métodos quantitativos de estimativa de produção de lodo - o método de fórmulas empíricas, e o do balanço de massa; investigar a prática disseminada de se estimar a concentração de sólidos em suspensão totais na água bruta por meio de modelos de regressão linear com a turbidez como variável independente; e delinear condições para a aplicação dessa correlação. Foram utilizados dados de seis ETAs de ciclo completo operadas pela SABESP (ABV, Alto Cotia, Cubatão, Guaraú, Franca e Presidente Prudente), além de dados de monitoramento de 130 estações de monitoramento de águas superficiais da CETESB.

Os resultados sugerem que a identificação de correlações significativas entre concentração de SST e turbidez é elusiva, e não constitui tarefa trivial. Do universo de 130 estações da CETESB, somente 7 apresentaram correlação significativa; das ETAs, somente Presidente Prudente. Modelos de regressão alternativos utilizando outras variáveis (cor, vazão média mensal e mês), combinadas com a turbidez ou isoladamente, foram desenvolvidos. Somente a inclusão do mês como variável categórica foi capaz de aumentar o poder explicativo do modelo baseado exclusivamente na turbidez, sugerindo que a relação entre turbidez e concentração de SST é variável sazonalmente.

Mediante a comparação com balanços de massa, foram identificados alguns fatores que afetam o poder de predição da fórmula empírica desenvolvida pela American Water Works Association, algumas vezes de maneira drástica. Em geral, conclui-se que o uso de fórmulas empíricas - principalmente em conjunto com modelos de regressão entre concentração de SST e turbidez - possa não ser recomendável.

Palavras-chave: produção de lodo; quantificação de lodo; tratamento de água; água para abastecimento; ETA. 



\begin{abstract}
Most of the water treatment plant (WTP) residuals generated in Brazil is still discharged in water bodies, or disposed of in landfills. However, especially in large urban areas, ever stringent conditions for environmental permits e rising logistical costs have put into focus beneficial uses for those residuals. A major obstacle for paradigm change in that aspect lies in the fact that very rarely water treatment plant operators and designers are able to predict - with some degree of certainty - the mass and volume of residuals produced by the treatment process. Usually, empirical formulas are used for that end, which relates the residuals production rate to the concentration of total suspended solids (TSS) in the raw water, and the chemicals dose.
\end{abstract}

The objectives of this work are: to compare the performance of two of the main quantitative estimation methods for residuals production - the empirical formulas and the mass balance; to investigate the widespread practice of estimating the concentration of TSS using turbidity as a surrogate; and to identify the conditions under which such procedure is acceptable. For that end, data from six WTPs operated by SABESP (ABV, Alto Cotia, Cubatão, Guaraú, Franca e Presidente Prudente), plus 130 surface water monitoring stations operated by CETESB, was analyzed. Alternative regression models, employing other independent variables (color, average monthly flow and month) singly or in combination with turbidity, were developed. Only the inclusion of the month as a categorical variable was capable of enhancing the explaining power of the turbidity model, suggesting that the relation between turbidity and TSS concentration is seasonally variable.

The results suggest that identification of such significant correlations between TSS concentration and turbidity is elusive at best, and doesn't amount to a trivial task. Out of the universe of 130 monitoring stations, in only 7 a good degree of correlation was found; of the WTPs, that was the case only in Presidente Prudente.

Through the comparison with the mass balances, some factors that affect the predictive power of the American Water Works Association - sometimes drastically a were identified. In general, it is concluded that the use of empirical formulas especially when combined with turbidity and TSS concentration regression models may not be recommended.

Keywords: water treatment plant residuals; residuals production; residuals quantification; drinking water; WTP. 



\section{LISTA DE FIGURAS}

Figura 3.1 - Variação dos valores de sólidos secos por mês obtidos pelas fórmulas empíricas e pela verificação in loc.

Figura 3.2 - Efeito do diâmetro e natureza de partículas em suspensão no meio líquido na atenuação da luz..

Figura 3.3 - Relação entre o coeficiente de espalhamento específico $b^{*}$ e o diâmetro efetivo $d_{\mathrm{ef}}$ obtido para amostras coletas em rio e reservatório.

Figura 3.4 - Gráfico de dispersão de turbidez e concentração de sedimentos em suspensão obtido para o estuário de Elkhorn Slough.

Figura 3.5 - Imagens das membranas usadas para filtração de amostras coletadas em Elkhorn Slough durante o procedimento de determinação da concentração de sedimentos em suspensão.

Figura 3.6 - Relação entre vazão e coeficiente angular da reta de regressão obtida por Pfannkuche e Schmidt (2003) para amostras coletadas no rio Elbe (Alemanha).

Figura 3.7 - Valores medidos $\log _{10}$ CSS versus valores calculados a partir de correlação com $\log _{10} T u$, obtidos por Williamson e Crawford (2010) em estudo regional no estado de Kentucky..

Figura 3.8 - Unidades básicas de organização de um floco de coagulaçãofloculação.

Figura 3.9 - Relação entre teor de água ligada e dimensão fractal em três dimensões de flocos produzidos com sulfato de alumínio e cloreto férrico.

Figura 3.10 - Dimensão fractal de flocos de caulinita coagulados por diferentes mecanismos de coagulação e sob diferentes gradientes de velocidade, utilizando-se sulfato de alumínio como coagulante e polímero como auxiliar de floculação.

Figura 3.11 - Balanço de massa nos decantadores e filtros de ETAs de ciclo completo. 
Figura 3.12 - Valores médios de SST e SD ao longo das ETAs.

Figura 4.1 - Volumes de controle considerados no Balanço de massa obtido para ETA Alto Cotia

Figura 4.2 - Balanço de massa das ETAs ABV, Guaraú, Presidente Prudente e Franca

Figura 4.3 - Balanço de massa da ETA Cubatão 46

Figura 5.1 - Boxplots dos valores medidos das variáveis (a) SST, (b) turbidez, (c) cor e (d), COT, discriminados por ETA.

Figura 5.2 - Séries de valores de turbidez, cor e concentração de SST medidos na água bruta da ETA PPR, e precipitação média dos meses das medições.

Figura 5.3 - Frequência acumulada de valores de $\mathrm{R}^{2}$ das regressões lineares em função da turbidez obtidas para os pontos de monitoramento selecionados, assumindo-se modelo com e sem constante.

Figura 5.4 - Frequência acumulada de valores de $\mathrm{R}^{2}$ das regressões lineares em função da turbidez, obtidas para os pontos de monitoramento selecionados.

Figura 5.5 - Possíveis outliers nos dados de 6 pontos de monitoramento, marcados em vermelho.

Figura 5.6 - Valores extremos com alta alavanca e alta influência nos dados dos pontos de monitoramento LENS02500 e STAN04400.

Figura 5.7 - Gráfico de dispersão de todos os pares de valores de turbidez e concentração de SST, na forma logarítmica.

Figura 5.8 - Boxplot da concentração de SST e vazão média mensal do ponto de monitoramento MOGU02900.

Figura 5.9 - Frequência acumulada de $R^{2}$ para modelo de regressão simples, baseado na turbidez, e modelo interativo de turbidez e mês. Foram omitidos dados de pontos de monitoramento para os quais o modelo interativo não foi obtido ou retornou valores negativos de $\mathrm{R}^{2}$. 
Figura 5.10 - Gráfico de dispersão de concentração de SST e turbidez para medidos nas ETAs (a), e detalhe para o intervalo de turbidez $\leq 25$ UNT (b)......67

Figura 5.11 - Gráfico de dispersão de concentração de SST e cor para medidos nas ETAs (a), e detalhe para o intervalo de cor $\leq 250 \cup \mathrm{C}(\mathrm{b})$.

Figura 5.12 - Comparação da produção de lodo estimada pela fórmula empírica da AWWA (1999) para a ETA FRA supondo-se três ou nenhuma água ligada aos precipitados de $\mathrm{Fe}(\mathrm{OH})_{3}$

Figura 5.13 - Para a ETA ALC: (A) Comparação entre produção de lodo obtida por balanço de massa e pela aplicação da fórmula empírica da AWWA (1999); (B) gráfico de dispersão de produção de lodo medida (pelo balanço de massa) e estimada (pela fórmula empírica) - barras de erros correspondem a um desvio padrão; (C) Gráfico de dispersão de turbidez e dosagem de coagulante; (D) Série temporal de medições de turbidez e dosagem de coagulante.

Figura 5.14- Para a ETA CUB: (A) Comparação entre produção de lodo obtida por balanço de massa e pela aplicação da fórmula empírica da AWWA (1999); (B) gráfico de dispersão de produção de lodo medida (pelo balanço de massa) e estimada (pela fórmula empírica) - barras de erros correspondem a um desvio padrão; (C) Gráfico de dispersão de turbidez e dosagem de coagulante; (D) Série temporal de medições de turbidez e dosagem de coagulante.

Figura 5.15 - Para a ETA FRA: (A) Comparação entre produção de lodo obtida por balanço de massa e pela aplicação da fórmula empírica da AWWA (1999); (B) gráfico de dispersão de produção de lodo medida (pelo balanço de massa) e estimada (pela fórmula empírica) - barras de erros correspondem a um desvio padrão; (C) Gráfico de dispersão de turbidez e dosagem de coagulante; (D) Série temporal de medições de turbidez e dosagem de coagulante. .76

Figura 5.16 - Para a ETA GUA: (A) Comparação entre produção de lodo obtida por balanço de massa e pela aplicação da fórmula empírica da AWWA (1999); (B) gráfico de dispersão de produção de lodo medida (pelo balanço de massa) e estimada (pela fórmula empírica) - barras de 
erros correspondem a um desvio padrão; (C) Gráfico de dispersão de turbidez e dosagem de coagulante; (D) Série temporal de medições de turbidez e dosagem de coagulante.

Figura 5.17 - Para a ETA PPR: (A) Comparação entre produção de lodo obtida por balanço de massa e pela aplicação da fórmula empírica da AWWA (1999); (B) gráfico de dispersão de produção de lodo medida (pelo balanço de massa) e estimada (pela fórmula empírica) - barras de erros correspondem a um desvio padrão; (C) Gráfico de dispersão de turbidez e dosagem de coagulante; (D) Série temporal de medições de turbidez e dosagem de coagulante.

Figura 5.18 - Gráfico de dispersão das concentrações de SST e SD na água bruta das diversas ETAs.

Figura 5.19 - Distribuição de probabilidade dos desvios entre produção estimada e medida de lodo nas ETAs ALC, CUB, FRA e PPR.

Figura 5.20 - Desvios entre produção estimada e produzida de lodo para as ETAs ALC, CUB, FRA e PPR.

Figura 5.21 - Gráfico de dispersão da produção de lodo medida e estimada para as diversas ETAs com exceção da ETA GUA, com a reta 1:1 (equivalente

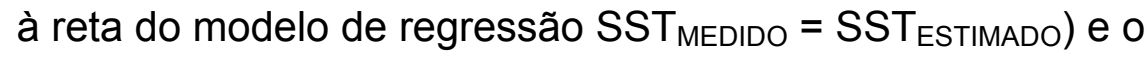
respectivo intervalo de confiança $(\alpha=0,05)$. .83

Figura 5.22 - Gráfico de dispersão de turbidez e dosagem de sulfato de alumínio para as ETAs ALC, CUB, GUA, FRA e PPR, além de outras 108 ETAs operadas pela SABESP. 


\section{LISTA DE TABELAS}

Tabela 3.1 - Características de lodos de ETA, em termos de parâmetros convencionais

Tabela 3.2 - Características de lodos de ETA, em termos de parâmetros nãoconvencionais

Tabela 3.3 - Compostos orgânicos detectados em lodos de ETA por Stackelberg et al (2007).

Tabela 3.4 - Métodos aprovados pelo USGS para medição de turbidez. 20

Tabela 4.1 - Conjunto de variáveis avaliadas por tipo de água amostrada e para cada tipologia de ETA

Tabela 5.1 - Pontos de monitoramento com $R^{2} \geq 0,8$, e respectivos valores da quantidade de dados ( $n$ ) e coeficiente do modelo de regressão (b). ...51

Tabela 5.2 - Pontos de monitoramento com $R^{2} \geq 0,8$ após remoção de possíveis outliers, e respectivos valores da quantidade de dados ( $\mathrm{n}$ ) e coeficiente do modelo de regressão (b). .55

Tabela 5.3 - Valores de $R^{2}$ obtidos para modelos de regressão linear simples baseados na variável cor real.

Tabela 5.4 - Valores do coeficiente de determinação obtidos para diferentes modelos de regressão multilinear envolvendo as variáveis cor real e turbidez.

Tabela 5.5 - Valores de $R^{2}$ obtidos pelos modelos aditivos e interativos de vazão e turbidez.

Tabela 5.6 - Valores de $\mathrm{R}^{2}$ obtidos para o modelo de regressão baseado na turbidez para ambientes lênticos.

Tabela 5.7 - Coeficientes dos termos mensais do modelo SST Turbidez $\times$ Mês ..65

Tabela $5.8-\mathrm{N}^{\circ}$ de medições, coeficiente de determinação, e coeficiente das regressões lineares da forma SST $=b_{1}{ }^{*}$ Turbidez de cada ETA estudada. 
Tabela $5.9-\mathrm{N}^{\circ}$ de medições, coeficiente de determinação, e coeficientes das regressões lineares da forma SST $=b_{1}{ }^{*}$ Turbidez $+b_{0}$ de cada ETA estudada.

Tabela $5.10-\mathrm{N}^{\circ}$ de medições e coeficientes de determinação obtidos para modelos de regressão linear da concentração de SST em função das varáveis cor real e COT, e para modelos interativo e aditivo dependentes de tanto turbidez e quanto cor. Coeficientes para modelo baseado na turbidez e mostrado para comparação.

Tabela $5.11-\mathrm{N}^{\circ}$ de medições, coeficiente de determinação, e coeficientes das regressões lineares SST $=b_{1}{ }^{*}$ Cor $+b_{0}$ de cada ETA estudada 69

Tabela 5.12 - Estatísticas dos desvios da produção de lodo medida em relação à produção estimada pela fórmula empírica. 


\section{LISTA DE SÍMBOLOS}

Sólidos em suspensão totais

SD

Sólidos dissolvidos

CSS

Concentração de sedimentos em suspensão

$\mathrm{Tu}$

Turbidez

W

Produção diária de lodo

P

Produção de lodo por volume de água tratada

b

Coeficiente de espalhamento

$b^{*}$

Coeficiente de espalhamento específico

Q

Eficiência de espalhamento

$Q_{\text {ef }}$

Eficiência de espalhamento efetivo

AP

Área projetada por partícula no plano perpendicular ao feixe de luz

$\mathrm{V}_{\mathrm{p}}$

Volume da partícula

V

Volume da suspensão de partículas

$\lambda$

Comprimento de onda da luz

$\mathrm{m}$

Índice de refração complexo

d

Diâmetro da partícula

$d_{\text {ef }}$

Diâmetro da partícula efetivo

$\rho$

Massa específica

$N(d)$

Número de partículas com diâmetro d

Mlodo

Massa de lodo total gerada na estação

$M_{\text {dec }}$

Massa de lodo gerada nos decantadores

$M_{\text {fil }}$

Massa de lodo gerada nos filtros

$\mathrm{Q}_{\mathrm{ab}}$

Vazão de água bruta 


$\begin{array}{ll}Q_{a r} & \text { Vazão de retorno } \\ Q_{d d} & \text { Vazão de descarga do decantador } \\ Q_{d f} & \text { Vazão de água de lavagem dos filtros } \\ C_{a c} & \text { Concentração de SST na água coagulada } \\ C_{a f} & \text { Concentração de SST na água floculada } \\ C_{a d} & \text { Concentração de SST na água decantada } \\ C_{d d} & \text { Concentração de SST na água de descarga dos decantadores } \\ C_{d f} & \text { Concentração de SST na água de descarga dos filtros } \\ C_{d d} & \text { Concentração de SST na água de descarga dos decantadores } \\ C_{r} & \text { Concentração de SST na água de retorno } \\ C_{a t} & \text { Concentração de SST na água tratada } \\ n & \text { Tamanho da amostra } \\ \mathrm{b}_{\mathrm{i}} & \text { Coeficiente do modelo de regressão }\end{array}$




\section{SUMÁRIO}

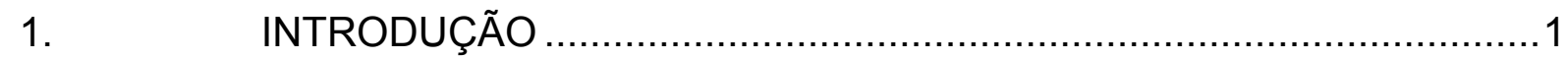

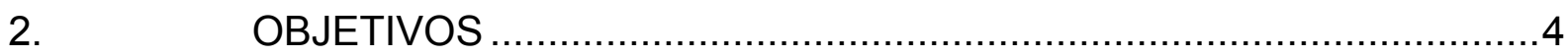

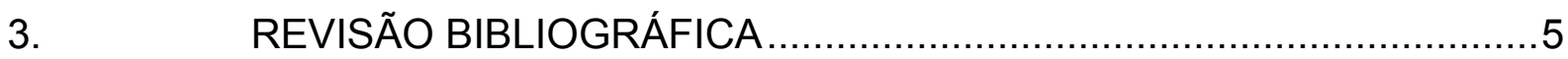

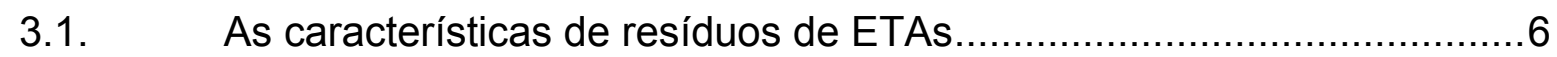

3.2. Quantificação de lodo de ETA......................................................14

3.2.1. Quantificação de lodo em projetos de ETAs novas............................15

3.2.2. Quantificação de lodo em projetos de ETAs existentes .......................35

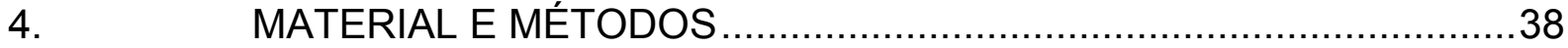

5. apresentação e discussão dos RESULTADOS ………………….....47

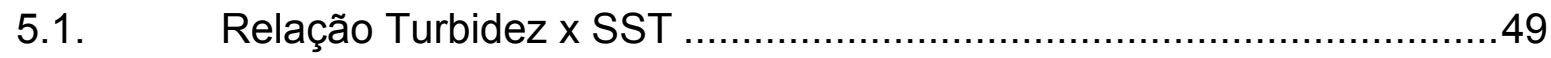

5.1.1. Dados da rede de monitoramento da CETESB ................................49

5.1.2. Dados das medições realizadas na água bruta das ETAs ...................66

5.2. Balanço de massa e fórmulas empíricas........................................70

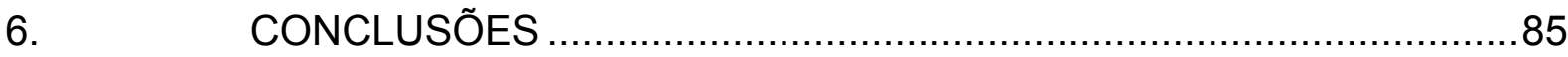

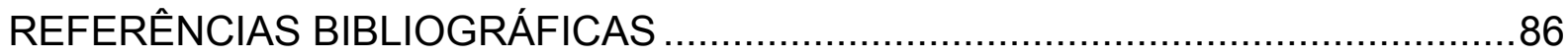

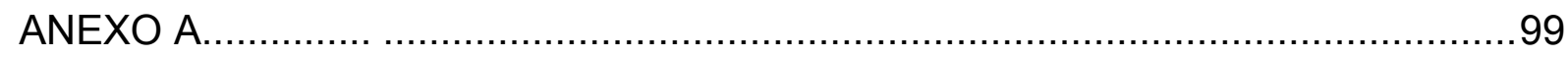

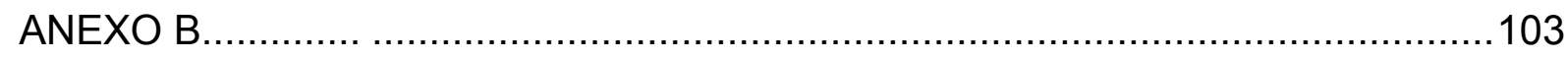

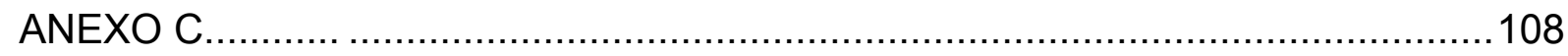

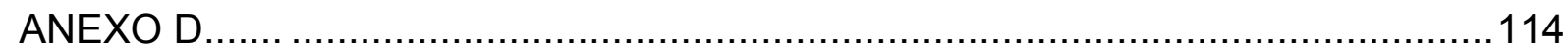






\section{INTRODUÇÃO}

Lodos de estações de tratamento de água (ETAs) de ciclo completo são resíduos sólidos que, tipicamente, contêm compostos húmicos e minerais precipitados da água bruta em conjunto com os hidróxidos de alumínio ou ferro oriundos dos produtos químicos usados como coagulantes e auxiliares de coagulação.

Embora a maioria dos países desenvolvidos já tenha adequado seus sistemas para tratar e dispor desses lodos, atualmente, nos países subdesenvolvidos ou em desenvolvimento, um grande número de estações de tratamento de água ainda lança esse material diretamente nos cursos d'água. Apesar de haver resultados contraditórios em relação à toxicidade do lodo à biota aquática, outros impactos ambientais significativos têm levado os órgãos ambientais a exigirem das concessionárias de saneamento a implantação de alternativas de disposição desse resíduo (ZHAO; BABATUNDE, 2007; ANDREOLI; PINTO, 2001). Muitas vezes, os projetos de estações de tratamento simplesmente ignoram a forma de destinação desse material, que acaba sendo gerenciado em situação emergencial pelos operadores, com altos custos financeiros e ambientais, que, no Brasil, só tendem a aumentar conforme a prestação de serviços de abastecimento de água tratada aproxima-se da universalidade.

No Brasil, tradicionalmente, os lodos são dispostos das seguintes formas:

- lançamento em rios, não indicado devido à escassez de mananciais, assoreamento dos corpos d'água, piora na qualidade da água e impactos adversos sobre a vida aquática;

- disposição em aterros sanitários, método caro, que requer grandes áreas e pode contribuir para a contaminação do solo e da água subterrânea;

- tratamento em conjunto com o esgoto doméstico, que pode sobrecarregar a estação de tratamento de esgoto (ETE) ou causar problemas operacionais se esta não tiver sido projetada para tal finalidade. Além disso, transfere o problema de disposição de lodo da ETA para a ETE.

Vem emergindo em tempos recentes o princípio da ecologia industrial (KOREVAAR, 2004), e com ele a tendência de considerar o lodo como um produto - que, como tal, 
poderia ser reciclado ou reutilizado -, e mesmo de se abandonar o termo "lodo", que seria o jargão do saneamento para "rejeito" e pejorativo, não refletindo a potencial utilidade deste resíduo (AWWA, 1999). Assim, com a previsão de aumento contínuo na produção mundial de lodos de ETAs e em consonância com legislações ambientais cada vez mais restritivas e que privilegiam a prevenção da poluição em geral, diversas formas de usos benéficos de lodo têm sido investigadas em substituição aos métodos de disposição convencionais (ZHAO; BABATUNDE, 2007). Idéias interessantes e viáveis têm surgido em países da Europa, no Japão e na Austrália, os mais engajados na pesquisa destas novas alternativas. Nestes países, foram testadas aplicações do lodo em áreas degradadas e agrícolas e em processos industriais como produção de cimento, alumínio e peças cerâmicas. Com algumas ressalvas, quase todas as experiências mostraram-se viáveis e eficientes, muitas vezes trazendo economia significativa, principalmente quando usadas como alternativas para substituir a disposição em aterros sanitários. Os maiores problemas encontrados estão associados à presença de material tóxico no resíduo; à dificuldade de adaptação dos diversos agentes envolvidos no processo (indústria, agricultor, etc); a problemas com transporte (distância, volume de lodo, custo) e a dificuldades para adequar o lodo às necessidades do uso a que se pretende (CORNWELL, 2006).

No Brasil, são ainda restritas e incipientes as experiências realizadas no equacionamento dos problemas concernentes ao lodo de estações de tratamento de água. Grande parte do lodo gerado ainda é disposta em rios e poucas estações têm se preocupado com o tratamento e disposição do resíduo. Essa situação, além de condenável do ponto de vista ambiental, é insustentável também do ponto de vista legal, em vista do fato de que, sendo lodos de ETA classificados como resíduos sólidos pela NBR 10004 (ABNT, 2004), seu lançamento in natura no meio ambiente é vedado pela Política Nacional de Resíduos Sólidos, disposta pela Lei $n^{\circ} 12305$ (BRASIL, 2010).

- Contribui para essa situação o fato de que muito raramente operadores e projetistas de ETAs nacionais conseguirem prever, com algum grau de confiabilidade, a massa e volume de resíduos produzidos pelo tratamento da água bruta; a se julgar pela realidade das estações do Estado de São Paulo, as linhas de 
tratamento dos resíduos são sistematicamente mal dimensionadas, geralmente resultando em sistemas disfuncionais, inadequados tanto para o processamento do resíduo em material para algum uso benéfico, ou para sua disposição adequada.

Di Bernardo e Dantas (2005) e Kawamura (2000) recomendam que a melhor prática para o dimensionamento dos sistemas de tratamento de lodos seja baseada na realização de testes em estações-piloto - ou, no mínimo ensaios em escala de laboratório -, por ao menos um ano, com a água bruta do manancial a ser explorado pela futura ETA, para se averiguar qual será o resultado dos processos de tratamento em termos de produção de lodo. Devido aos custos de se aderir a essa prática, muitos projetos são realizados tomando-se como parâmetro estimativas de produção de resíduos obtidas através de fórmulas empíricas, que relacionam a geração de resíduos à dosagem de produtos químicos e à quantidade de sólidos em suspensão afluentes à ETA. Apesar de terem base lógica sólida, essas fórmulas são dependentes de premissas que - como em modelos matemáticos em geral - se manifestam na forma de valores de constantes e coeficientes. Os valores para essas constantes e coeficientes fornecidas pelos manuais de projeto não tem validade universal, e podem não serem aplicáveis a uma dada condição de projeto; não obstante, frequentemente acabam sendo usadas sem critério, com péssimos resultados práticos.

A motivação deste trabalho é explorar quais são as fragilidades dessa maneira de se estimar a geração de lodo por uma ETA e buscar soluções, de modo a aperfeiçoar sua aplicação e, assim, contribuir para formas de gerenciamento modernas e responsáveis dos resíduos de ETAs. 


\section{OBJETIVOS}

O objetivo deste trabalho foi investigar os métodos disponíveis para estimar a quantidade de resíduos produzidos em estações de tratamento de água de ciclo completo, e avaliar potenciais aperfeiçoamentos que podem ser feitos na prática de sua aplicação. Mais especificamente, almejou-se:

- Comparar o desempenho de dois dos principais métodos quantitativos de estimativa de produção de lodo - o método das fórmulas empíricas, e o do balanço de massa;

- Investigar a prática disseminada de se estimar a concentração de sólidos em suspensão totais na água bruta por meio de correlação com a turbidez;

- Delinear condições para a aplicação dessa correlação. 


\section{REVISÃO BIBLIOGRÁFICA}

As ETAs para abastecimento público transformam a água bruta captada em mananciais superficiais -- normalmente inadequada para consumo humano -- em água potável, e podem ser classificadas em (RICHTER, 2001):

- De ciclo completo (coagulação, floculação, decantação, filtração, desinfecção): tem finalidade básica de remoção de cor/turbidez e organismos patogênicos. Utiliza, geralmente, sulfato de alumínio ou cloreto férrico como coagulante primário.

- de abrandamento: tem finalidade básica de remoção de dureza, através da precipitação do carbonato de cálcio e/ou de magnésio, pelo acréscimo de cal.

O tratamento convencional ou de ciclo completo é o mais utilizado no Brasil (CORDEIRO, 1999). Para que ele seja bem-sucedido é necessária a aplicação de produtos químicos, como sais de ferro ou de alumínio, os quais, através de suas cargas, são capazes de provocar a desestabilização dessas partículas. A coagulação para remoção de cor e turbidez é realizada predominantemente no mecanismo de varredura - pela formação de hidróxidos de alumínio ou ferro visando à formação de flocos com boas características de sedimentabilidade. Após a formação dos flocos, é necessária sua remoção para clarificação da água. Esta operação é realizada nos decantadores, onde esse material sedimentado fica retido durante um certo período de tempo. A água decantada contendo parte dos flocos que não sedimentaram é encaminhada aos filtros para a clarificação final. Assim, produz-se água para abastecimento e geram-se como resíduos os lodos acumulados no fundo dos decantadores e a água de lavagem dos filtros (CORDEIRO,1999). 


\subsection{As características de resíduos de ETAs}

Godbold et al. (2003) apud Andrade (2005) definem "lodo" como todo resíduo proveniente do tratamento para produzir água potável a partir da água bruta. Segundo os autores, o termo "resíduo sólido" é mais adequado do que o termo "lodo", porque o último tende a possuir uma conotação negativa, quando considerado para aplicações de reúso/reciclagem. Este resíduo é composto basicamente de impurezas removidas da água em conjunto com os produtos químicos de tratamento utilizados, e, tipicamente, compreende até $5 \%$ da produção anual da ETA. Por sua vez, Richter (2001) considera que lodo de ETA é o resíduo constituído de água e sólidos em suspensão originalmente presentes na fonte de abastecimento, acrescidos de produtos resultantes dos reagentes aplicados à água nos processos de tratamento, bem como suas impurezas.

O volume e massa de resíduos produzidos por uma ETA são determinados, entre outros fatores, principalmente pela qualidade da água de captação (dada pela sua turbidez ou concentração de sólidos); a tecnologia de tratamento empregada; as metas de tratamento (níveis de turbidez e dureza a serem atingidos pelo tratamento); e a maneira pela qual as ETAs são operadas (CORNWELL et al, 2006; DI BERNARDO; DANTAS, 2005). Em cada unidade na qual ocorre a remoção de sólidos da fase líquida, o princípio de remoção, o procedimento operacional e o tipo de produto químico adicionado (eventualmente mais que um) interagem para produzir resíduos em volumes e massas diferentes. Por exemplo, apesar de uma ETA de ciclo completo gerar em termos mássicos maior parte de seus resíduos nos decantadores, em termos volumétricos essa geração é dominada pelos filtros, que demandam maior quantidade de água para sua lavagem.

No entanto, as características químicas dos resíduos do tratamento da água são determinadas pela qualidade dos produtos químicos usados durante o tratamento. $O$ lodo de sulfato de alumínio é um fluído não-newtoniano, gelatinoso, cuja fração de sólidos é constituída de hidróxido de alumínio, partículas inorgânicas, colóides e resíduos orgânicos, inclusive bactérias e outros organismos removidos no processo de coagulação/floculação/sedimentação. Estes lodos sedimentam com relativa facilidade, porém sua baixa compressibilidade resulta em grande volume e baixo 
teor de sólidos. O lodo proveniente do uso de coagulantes férricos tem características e constituição semelhantes, porém ao invés de hidróxido de alumínio, tem-se hidróxido de ferro (RICHTER, 2001).

Já o lodo formado no processo de abrandamento por cal é constituído principalmente de carbonato de cálcio e é praticamente isento de matéria orgânica. Sua composição inclui $75 \%$ de $\mathrm{CaCO}_{3}, 6 \%$ de sílica como $\mathrm{SiO}_{2}, 7 \%$ de carbono total, $3 \%$ de alumínio como $\mathrm{Al}_{2} \mathrm{O}_{3}$ e $2 \%$ de magnésio como MgO (RICHTER, 2001). Não obstante, a composição, a massa e o volume variam com a dureza removida e outras características físico-químicas da água bruta; o eventual uso de coagulante de alumínio ou de ferro pode aumentar consideravelmente o volume de lodo produzido.

Convencionalmente, lodos de ETA são caracterizados por variáveis tais quais: teor de sólidos, $\mathrm{pH}$, metais, nitrogênio, fósforo total, etc. As características dos lodos levantadas por alguns autores estão indicadas nas Tabelas 3.1 e 3.2. Contudo, conforme as circunstâncias, alguns outros parâmetros menos convencionais podem ser empregados. Por exemplo, Stackelberg et al (2007) determinaram os teores de fármacos, pesticidas, hidrocarbonetos aromáticos polinucleares (HAPs) e outros compostos orgânicos no lodo (Tabela 3.3).

Outros parâmetros, de natureza física, tais como filtrabilidade, resistência específica, sedimentabilidade, compressibilidade, tamanho e distribuição de partículas, são fundamentais na definição do método de remoção de água para redução de volume e na fixação do tipo de equipamento e condições de funcionamento para tratamento. Segundo Vesilind (1988), a filtrabilidade e a sedimentabilidade são características físicas do lodo que dependem do teor de sólidos, dosagem de coagulante e outros compostos presentes em sua massa. A primeira pode ser medida pelo parâmetro resistência específica, definida como sendo o diferencial de pressão necessário para produzir uma vazão unitária de filtrado de viscosidade unitária através de uma torta (lodo) de massa unitária (base seca); já a sedimentabilidade depende do volume e peso dos flocos formados. A compressibilidade é função do tamanho das partículas e de sua deformação pela pressão aplicada. 
Tabela 3.1 - Características de lodos de ETA, em termos de parâmetros convencionais

\begin{tabular}{|c|c|c|c|c|c|c|c|}
\hline \multirow[b]{2}{*}{ PARÂMETROS } & \multicolumn{7}{|c|}{ AUTOR } \\
\hline & BARBOSA (2000) & RICHTER (2001) & $\begin{array}{c}\text { ISAAC } \\
\text { et al } \\
(2002 \mathrm{a})\end{array}$ & $\begin{array}{l}\text { PAULSRUD et } \\
\text { al (2002) }\end{array}$ & $\begin{array}{l}\text { GODBOLD et al } \\
\text { (2003) }\end{array}$ & $\begin{array}{l}\text { CHAO } \\
(2005)\end{array}$ & $\begin{array}{c}\text { SOTERO- } \\
\text { SANTOS et al } \\
(2007)\end{array}$ \\
\hline $\mathrm{pH}$ & $\begin{array}{c}6,2-9,8^{(2)} \\
6,8-10,6^{(3)}\end{array}$ & $\begin{array}{c}6-8^{(2)} \\
7,4-9,5^{(3)}\end{array}$ & $7,8^{(5)}$ & $6,9-8,4$ & $5,5-7,5$ & $5,8-6,1$ & $6,8-7,4$ \\
\hline Sólidos totais & $\begin{array}{c}29595-52345^{(2)} \\
2132-5074^{(3)} \\
(\mathrm{mg} / \mathrm{L})\end{array}$ & $\begin{array}{c}0,1-4^{(2)} \\
0,25-3,5^{(3)} \\
2-25^{(4)} \\
(\%)\end{array}$ & $\begin{array}{r}480^{(5)} \\
(\mathrm{mg} / \mathrm{L})\end{array}$ & $\begin{array}{l}0,06-18,5 \\
(\%)\end{array}$ & $\begin{array}{c}0,1-27^{(2)} \\
1,85-17,6^{(3)} \\
(\% \mathrm{~m} / \mathrm{m})\end{array}$ & $\begin{array}{l}1114- \\
25826 \\
(\mathrm{mg} / \mathrm{L})\end{array}$ & $\begin{array}{c}2132-5074 \\
(\mathrm{mg} / \mathrm{L})\end{array}$ \\
\hline $\begin{array}{l}\text { Sólidos voláteis } \\
\text { (\% dos sólidos totais -\% } \\
\text { st) }\end{array}$ & $\begin{array}{l}24,96-25,35^{(2)} \\
23,57-29,17^{(3)}\end{array}$ & $\begin{array}{c}20-35^{(2)} \\
5,1-14,1^{(3)}\end{array}$ & $33^{(5)}$ & $37,5-67,5$ & $10-35$ & - & $\begin{array}{c}622-1196 \\
(\mathrm{mg} / \mathrm{L})\end{array}$ \\
\hline Alcalinidade & $\begin{array}{c}68,48-93,60^{(2)} \\
54,08-81,32^{(3)} \\
(\mathrm{mgCaCO} / \mathrm{L})\end{array}$ & - & $3,70^{(5)}$ & $\begin{array}{c}0,25-1,76 \\
\text { (\% Ca em st) }\end{array}$ & - & - & - \\
\hline Ferro & $\begin{array}{c}130500-392500^{(3)} \\
124000-299500^{(2)} \\
(\mathrm{mgFe} / \mathrm{kg})\end{array}$ & - & $\begin{array}{c}>113,1^{(5)} \\
(\mathrm{mg} / \mathrm{L})\end{array}$ & - & $\begin{array}{c}6,5^{(2)} \\
19-38^{(3)}(\% \mathrm{st})\end{array}$ & - & $\begin{array}{c}145500- \\
392500 \\
(\mathrm{mgFe} / \mathrm{kg})\end{array}$ \\
\hline
\end{tabular}

LEGENDA

(1) - síntese da caracterização de lodo de decantadores realizados por diversos autores

(2) - resíduo de tratamento com sulfato de alumínio

(3) - resíduo de tratamento com cloreto férrico

(4) - resíduo do processo de abrandamento por cal

(5) - água de lavagem dos filtros 
Tabela 3.2 - Características de lodos de ETA, em termos de parâmetros não-convencionais

\begin{tabular}{|c|c|c|c|c|c|c|}
\hline \multirow[b]{2}{*}{ PARÂMETRO } & \multicolumn{6}{|c|}{ AUTOR } \\
\hline & $\begin{array}{l}\text { ISAAC et al } \\
(2002)^{(5)}\end{array}$ & $\begin{array}{l}\text { PAULSRUD et } \\
\text { al (2002) }\end{array}$ & $\begin{array}{l}\text { GODBOLD et } \\
\text { al (2003) }\end{array}$ & $\begin{array}{l}\text { CHAO } \\
(2005)\end{array}$ & $\begin{array}{l}\text { MAKRIS et } \\
\text { al(2006] }\end{array}$ & $\begin{array}{l}\text { SOTERO- } \\
\text { SANTOS et al } \\
\text { (2007) }\end{array}$ \\
\hline $\mathrm{Al}$ & 5,48 (mgAl/L) & - & $\begin{array}{c}4-11^{(2)} \\
4,5-10,5^{(3)} \\
(\% \mathrm{st})\end{array}$ & $\begin{array}{c}40000- \\
63689 \\
(\mathrm{mgAl} / \mathrm{kg})\end{array}$ & 110 (g/kg) & $\begin{array}{c}57730- \\
162165 \\
\text { (mgAl/kg) }\end{array}$ \\
\hline $\mathrm{Zn}$ & 1,55 (mgZn/L) & $\begin{array}{c}66-296 \\
\text { (mgZn/kg st) }\end{array}$ & $\begin{array}{c}0,011-0,086 \\
\text { (\% st) }\end{array}$ & $\begin{array}{l}0,1-0,9 \\
(\mathrm{mgZn} / \mathrm{L})\end{array}$ & $<0,0027(\mathrm{mg} / \mathrm{L})$ & $\begin{array}{c}29-125 \\
(\mathrm{mgZn} / \mathrm{kg})\end{array}$ \\
\hline $\mathrm{Cd}$ & $25,76(\mathrm{mgCd} / \mathrm{L})$ & $\begin{array}{c}0,06-1,2 \\
(\mathrm{mgCd} / \mathrm{kg} \mathrm{st})\end{array}$ & $\begin{array}{c}<0,005^{(2)} \\
<0,0001- \\
0,0006^{(3)} \\
(\% \mathrm{st})\end{array}$ & $\begin{array}{c}0,01-0,02 \\
(\mathrm{mgCd} / \mathrm{L})\end{array}$ & $<0,0083(\mathrm{mg} / \mathrm{L})$ & - \\
\hline $\mathrm{Ni}$ & 0,373 (mgNi/L) & $\begin{array}{c}3,4-39,7 \\
(\mathrm{mgNi} / \mathrm{kg} \mathrm{st})\end{array}$ & $\begin{array}{c}0,0018 \text { - } \\
0,0125 \text { (\% st) }\end{array}$ & - & $<0,0810(\mathrm{mg} / \mathrm{L})$ & $\begin{array}{c}78-90 \\
(\mathrm{mgCd} / \mathrm{kg})\end{array}$ \\
\hline $\mathrm{Mn}$ & $\begin{array}{c}1,002 \\
(\mathrm{mgMn} / \mathrm{L})\end{array}$ & - & $\begin{array}{c}<0,005-5^{(2)} \\
0,06-0,81^{(3)} \\
(\% s t)\end{array}$ & - & $0,41(\mathrm{mg} / \mathrm{L})$ & $\begin{array}{l}366-1415 \\
(\mathrm{mgMn} / \mathrm{kg})\end{array}$ \\
\hline $\mathrm{Cu}$ & $0,028(\mathrm{mgCu} / \mathrm{L})$ & $\begin{array}{c}<10-110 \\
(\mathrm{mgCu} / \mathrm{kg} \mathrm{st})\end{array}$ & $\begin{array}{c}0,003-0,0087 \\
\text { (\%st) }\end{array}$ & $\begin{array}{l}0,1-0,7 \\
(\mathrm{mgCu} / \mathrm{L})\end{array}$ & $<0,0468(\mathrm{mg} / \mathrm{L})$ & $\begin{array}{c}24-61 \\
(\mathrm{mgCu} / \mathrm{kg})\end{array}$ \\
\hline $\mathrm{Cr}$ & $\begin{array}{c}<0,004 \\
(\mathrm{mgCr} / \mathrm{L})\end{array}$ & $\begin{array}{c}<5,8-33 \\
(\mathrm{mgCr} / \mathrm{kg} \mathrm{st})\end{array}$ & $\begin{array}{c}<0,0002- \\
0,0125 \text { (\% st) }\end{array}$ & - & $<0,0084(\mathrm{mg} / \mathrm{L})$ & $\begin{array}{c}38-44 \\
(\mathrm{mgCr} / \mathrm{kg})\end{array}$ \\
\hline $\mathrm{Pb}$ & 0,03 (mgPb/L) & $\begin{array}{c}6,4-29,4 \\
(\mathrm{mgPb} / \mathrm{kg} \mathrm{st})\end{array}$ & $\begin{array}{c}0,0013 \text { - } \\
0,0084 \text { (\% st) }\end{array}$ & $\begin{array}{c}<0,01 \\
(\mathrm{mgPb} / \mathrm{L})\end{array}$ & $<0,0546(\mathrm{mg} / \mathrm{L})$ & $\begin{array}{c}48-75 \\
(\mathrm{mgPb} / \mathrm{kg})\end{array}$ \\
\hline As & $<0,02(\mathrm{mgAs} / \mathrm{L})$ & - & $\begin{array}{c}<0,04^{(2)} \\
0,001-0,002^{(3)} \\
1 \% \mathrm{st})\end{array}$ & - & $<0,0253(\mathrm{mg} / \mathrm{L})$ & - \\
\hline $\mathrm{Hg}$ & - & $\begin{array}{c}0,01-0,46 \\
(\mathrm{mgHg} / \mathrm{kg} \mathrm{st})\end{array}$ & $\begin{array}{c}<0,00005- \\
0,00006 \text { (\% st) }\end{array}$ & - & 0,55 (mg/L) & - \\
\hline Si & - & - & - & - & - & - \\
\hline СOT & - & - & $\begin{array}{l}7,72(\% \mathrm{~m} / \mathrm{m} \\
\text { C) }\end{array}$ & & - & - \\
\hline
\end{tabular}

LEGENDA

(1) - síntese da caracterização de lodo de decantadores realizados por diversos autores;

(2) - resíduo de tratamento com sulfato de alumínio; (3) - resíduo de tratamento com cloreto férrico;

(4) - resíduo do processo de abrandamento por cal; (5) - água de lavagem dos filtros 
Tabela 3.3 - Compostos orgânicos detectados em lodos de ETA por Stackelberg et al (2007).

\begin{tabular}{|c|c|c|}
\hline \multirow[b]{2}{*}{ Nome do composto } & \multicolumn{2}{|c|}{ Concentração nos sólidos ( $\mu \mathrm{g} / \mathrm{kg})$} \\
\hline & decantador & $\begin{array}{c}\text { água de lavagem dos filtros } \\
\text { (areia e CAP) }\end{array}$ \\
\hline \multicolumn{3}{|l|}{ Fármacos } \\
\hline Carbamazepina & 54 & 359 \\
\hline Fluoxetina & 49,5 & 58,6 \\
\hline \multicolumn{3}{|c|}{ Surfactantes e metabólitos } \\
\hline Octilfenol dietoxilado & 65 & -- \\
\hline Nonilfenol dietoxilado & 1940 & 785 \\
\hline 4-Nonilfenol & 185 & 160 \\
\hline \multicolumn{3}{|l|}{ Retardantes de chama } \\
\hline TPP & 27,5 & 27 \\
\hline TBEP & 525 & 545 \\
\hline TDIP & 109 & 84,5 \\
\hline Bisfenol A & 19 & ND \\
\hline TBP & 14,5 & 7,5 \\
\hline \multicolumn{3}{|l|}{ HAPs } \\
\hline Antraceno & 30,5 & 31,5 \\
\hline Fluoranteno & 215 & 205 \\
\hline Fenantreno & 135 & 145 \\
\hline Pireno & 136 & 99,5 \\
\hline Benzo[a]pireno & 48,5 & 15 \\
\hline Naftalenp & 27,5 & 39,5 \\
\hline 2-Metilnaftaleno & 20 & 22 \\
\hline 1-Metilnaftaleno & 18,6 & 17,5 \\
\hline 2,6-Dimetilnaftaleno & 19,3 & 14 \\
\hline \multicolumn{3}{|l|}{ Fragrâncias } \\
\hline $\mathrm{HHCB}$ & 41,5 & 39 \\
\hline AHTN & 92 & 83 \\
\hline Skatol & 129,5 & 53,5 \\
\hline \multicolumn{3}{|l|}{ Hormônios } \\
\hline b-Sitosterol & 4000 & 2900 \\
\hline b-Stigmastanol & 1270 & 650 \\
\hline Colesterol & 7100 & 6050 \\
\hline
\end{tabular}


Tabela 3.3 (Continuação)

\begin{tabular}{lcc}
\hline \multirow{2}{*}{ Nome do composto } & \multicolumn{2}{c}{ Concentração nos sólidos $(\mu \mathrm{g} / \mathrm{kg}$ ) } \\
\cline { 2 - 3 } & decantador & $\begin{array}{c}\text { água de lavagem dos filtros } \\
\text { (areia e CAP) }\end{array}$ \\
\hline Pesticidas & 34,5 & 36,5 \\
Carbazol & 11 & 17 \\
DEET & 186,5 & 59 \\
Indol & & \\
Outros & 170 & 200 \\
Antraquinona & 170 & 215 \\
Benzofenona & 305 & 195 \\
4-Cresol & 3,9 & 3,45 \\
Tetracloroetileno & 12 & 6,5 \\
Isoforona & 27 & 15,5 \\
Triclosan & &
\end{tabular}

Fonte: STACKELBERG et al, 2007.

Alternativas de usos benéficos dos resíduos de ETA têm objetivado grandes estudos nos últimos anos. O lodo de ETA é um resíduo gerado em grande volume, e cujas formas de disposição tradicionais - em aterros sanitários ou em corpos d'água - tem originado impactos ambientais sérios e não são condizentes com os princípios de minimização, reúso, reaproveitamento e reciclagem dos resíduos, que regem o gerenciamento de resíduos sólidos moderno. Muitos estudos indicam possíveis usos benéficos para o lodo de ETA, os quais dependem das características do lodo, assim como da qualidade da água bruta de origem e do tipo de coagulantes e outros compostos químicos adicionados. Diversas formas de usos benéficos para o lodo de ETA já foram propostas, em diversos níveis de maturidade tecnológica, entre as quais:

- Recuperação de áreas degradadas: O resíduo de ETA pode ser usado na recuperação do solo, a fim de reabilitá-lo para o crescimento de plantas, em áreas susceptíveis ou já comprometidas por processos erosivos, como por exemplo, locais que foram utilizados pela atividade de mineração nas quais é necessária a remoção do solo de superfície (CORNWELL et al., 2000). 
- Agricultura: Segundo vários autores (CORNWELL et al., 2000; GODBOLD et al., 2003), a aplicação de lodos de ETAs na agricultura não provoca impactos significativos ao crescimento das espécies vegetais, sendo relatados os seguintes benefícios: melhoria da estrutura, ajuste do $\mathrm{pH}$, adição de traços de minerais, aumento da capacidade de retenção de umidade e aeração do solo; e os seguintes pontos desfavoráveis: a tendência do ferro do resíduo de capturar o fósforo disponível para a planta e do alumínio causar problema de toxicidade para a mesma, caso o pH do solo não seja mantido em valores iguais ou inferiores a 6,5 (CORNWELL et al., 2000; GODBOLD et al., 2003 apud ANDRADE, 2005).

- Remoção de fósforo de efluentes de estações de tratamento biológico de esgotos: no descarte de lodo de estações de tratamento de água - ETAs, que utilizam sulfato de alumínio, são desprezadas toneladas de produtos químicos, que poderiam ser recicladas e utilizadas como insumo para remoção de fósforo de efluentes de estações de tratamento de esgotos, ETEs (CHAO; YABROUDI; MORITA, 2011).

- Incorporação na fabricação de cimento: os materiais comumente utilizados na fabricação do cimento são calcário, xisto e argila. O calcário corresponde cerca de 70 a $80 \%$ do material bruto utilizado, porém com baixas concentrações de sílica, ferro e alumínio (AWWA, 1999). Para solucionar esta deficiência, são adicionados xisto, argila, minério de ferro e bauxita. Os lodos de ETAs de ciclo completo normalmente contêm todos esses elementos citados anteriormente e, por isso, eles podem ser introduzidos no processo de fabricação do cimento na fase de pré-homogeneização das matérias-primas. O teor de sólidos necessário para esta aplicação é de no mínimo $50 \%$. As principais características de lodos de ETAs, que comprometem a qualidade do produto,ou até mesmo inviabilizam a sua utilização na fabricação de cimento, são: presença de altas concentrações de matéria orgânica, antracito ou carvão ativado, sulfato, permanganato de potássio e metais pesados (CORNWELL, 2006); 
- Utilização na fabricação de tijolos: as características físicas e químicas de lodos de ETAs são, muitas vezes, similares às dos materiais utilizados na fabricação de tijolos: argilas. As grandes quantidades de lodos gerados em ETAs podem diminuir a quantidade de argila utilizada na fabricação de tijolos, aumentando a vida útil das jazidas naturais. Lodos contendo hidróxidos de ferro atribuem ao tijolo uma coloração avermelhada, desejada pelos fabricantes (CORNWELL, 2006). Segundo Cornwell et al. (2000), a umidade contida no lodo de ETA é muito importante para o seu manuseio e incorporação no processo de obtenção de materiais cerâmicos, por isso os fabricantes preferem lodos com teor de sólidos superior a $20 \%$. Quanto mais a distribuição granulométrica do lodo for similar à da argila, melhor sua aplicabilidade. Por isso, a presença de areia e de pó de carvão no lodo de ETA pode provocar alterações no comportamento do material cerâmico, como causar expansão e fissuras ao produto final, porque a areia e o pó de carvão são constituídos de partículas de tamanhos consideravelmente maiores que as das argilas. Entretanto, deve-se salientar que certa quantidade de carvão é adicionada na massa antes dela passar por misturadores na etapa de homogeneização (ANDRADE, 2005).

- Inibição da formação de sulfetos: experiências realizadas na Holanda indicam que lodos de coagulantes a base de ferro podem ser usados para o controle de geração de sulfetos em redes de esgotos, digestores de ETEs e outros processos nos quais ocorram condições anaeróbias propícias à redução do enxofre, em substituição a soluções convencionais, como a aplicação direta de cloreto férrico. No caso de redes de coleta de esgotos e digestores anaeróbios, Cornwell e Koppers (1990) reportam que a dosagem de até $31 \mathrm{mg} / \mathrm{L}$ reduziu a geração de $\mathrm{H}_{2} \mathrm{~S}$ em até $95 \%$.

- Compostagem e fabricação de solo para jardinagem: lodos de ETA podem ser compostados em conjunto com resíduos sólidos, provendo umidade, metais-traço e - principalmente - servindo de agente estruturante para as pilhas de composto. Na produção de solo para jardinagem, exerce o mesmo papel, substituindo outros materiais empregados, como bentonita, areia e calcário (CORNWELL, 2006). 
- Substrato de wetlands construídas: estudos de bancada indicam que lodos de sulfato de alumínio desaguados podem servir de substrato para sistemas de wetlands construídas, servindo tanto de suporte para o desenvolvimento de biofilmes quanto para remoção de fósforo por adsorção (BABATUNDE et al, 2011; ZHAO; ZHAO; BABATUNDE, 2009).

Apesar de tecnicamente factível, o uso benéfico do lodo de ETA esbarra em diversos obstáculos, entre os quais a presença potencial de materiais tóxicos no resíduo (que pode provocar desconfiança por parte dos órgãos ambientais e criar dificuldades de licenciamento), a falta de sinergia entre os diversos atores envolvidos no processo, e a uma logística de transporte nem sempre favorável (ANDRADE, 2005). No Brasil, soma-se aos obstáculos aos usos benéficos, citados anteriormente, a quantificação correta da produção dos resíduos, tanto presente quanto futura.

\subsection{Quantificação de lodo de ETA}

A quantificação do lodo gerado na ETA é fundamental para planejar a operação das unidades geradoras, de tratamento e avaliar a sua destinação. Segundo Di Bernardo e Dantas (2005), para estações ainda em fase de projeto é desejável a realização de jar tests ou ensaios em estações piloto por no mínimo um ano para a estimativa mais precisa de como as características da água bruta e sua variabilidade se traduzirão em produção de lodo, dadas as condições de projeto da ETA. Alternativamente, fórmulas empíricas podem ser usadas para obtenção de estimativas menos precisas.

No que diz respeito a ETAs já existentes, além de fórmulas empíricas, há outros dois métodos de quantificação de lodo possíveis: balanço de massa e determinação direta em campo. A pertinência de cada um dos três deve ser avaliada caso a caso, e, preferencialmente, mais de um deve ser empregado ao mesmo tempo, de modo a permitir verificações cruzadas entre eles (CORNWELL, 2006). 


\subsubsection{Quantificação de lodo em projetos de ETAs novas}

Diversas fórmulas empíricas foram desenvolvidas, que permitem obter uma aproximação mais grosseira da geração de lodo, relacionando variáveis (que são ou parâmetros de projeto da própria ETA, ou inferíveis de dados de monitoramento préexistentes), com outras que possuem valores publicados na literatura. Dado o custo e tempo de execução tanto da alternativa dos jar tests quanto da estação-piloto, essas fórmulas tornaram-se muito populares no Brasil. A seguir, são listadas algumas, com base em levantamentos da literatura.

Todas as equações partem do mesmo princípio conceitual e diferem, de modo sutil, somente na escolha de algumas das variáveis independentes. Em geral, assume-se que os sólidos gerados pelo tratamento da água possuam duas componentes: a primeira é constituída pela fração dos sólidos da água bruta, que é removida no tratamento, e é quantificada pela concentração de sólidos em suspensão totais (SST). Esses sólidos são considerados não reativos e preservam sua massa durante a remoção. No caso de ETAs com processos de abrandamento por precipitação química, incluem-se nessa categoria os precipitados dos cátions causadores da dureza.

O segundo componente advém dos produtos adicionados à água bruta como parte do tratamento, que se precipitam, são adsorvidos ou são insolúveis, e, portanto, saem da solução: coagulantes à base de sais metálicos, polímeros, carvão ativado em pó, e - no caso estações de abrandamento por precipitação química - a cal e o carbonato de sódio, por exemplo.

\section{AMERICAN WATER WORK ASSOCIATION - AWWA (1978)}

$$
P=3,5 \times 10^{-3} \times \mathrm{Tu}^{0,66}
$$

Onde: $\quad \mathrm{P}$ - produção de sólidos ( $\mathrm{kg}$ de matéria seca $/ \mathrm{m}^{3}$ de água bruta tratada)

Tu - turbidez da água bruta (UT) 
WATER RESEARCH CENTRE - DILLON (1996)

$$
P=(S S+0,07 \times C+H+A) \times 10^{-3}
$$

Onde: $\quad \mathrm{P}$ - produção de sólidos ( $\mathrm{kg}$ de matéria seca/m3 de água bruta tratada)

SS - sólidos em suspensão na água bruta $(\mathrm{mg} / \mathrm{L})$

$\mathrm{C}$ - cor na água bruta (UC)

$\mathrm{H}$ - hidróxido coagulante $(\mathrm{mg} / \mathrm{L})$

A - outros aditivos, tal como o polímero (mg/L).

ASSOCIATION FRANCAISE POUR L'ETUDE DES EAUX - AFEE (1983)

$$
P=(1,2 \times \mathrm{Tu}+0,07 \times C+0,17 \times \mathrm{D}+\mathrm{A}) \times 10^{-3}
$$

Onde: $\quad \mathrm{P}$ - produção de sólidos ( $\mathrm{kg}$ de matéria seca $/ \mathrm{m}^{3}$ de água bruta tratada)

Tu - turbidez da água bruta (uT)

$\mathrm{C}$ - cor aparente da água bruta (uC)

$D$ - dosagem de sulfato de alumínio $(\mathrm{mg} / \mathrm{L})$

A - outros aditivos, tal como o polímero (mg/L).

\section{CORNWELL (1987)}

$\mathrm{W}=86,4 \times \mathrm{Q} \times(2 \times \mathrm{Ca}+2,6 \times \mathrm{Mg}+0,44 \times \mathrm{DSAl}+2,9 \times \mathrm{DFe}+\mathrm{SST}+\mathrm{A}) \times 10^{-3}$

Onde: $\quad$ W - produção de sólidos (kg/dia)

$\mathrm{Q}$ - vazão de água bruta $(\mathrm{L} / \mathrm{s})$

$\mathrm{Ca}$ - dureza cálcica removida $\left(\mathrm{mg} / \mathrm{L} \mathrm{CaCO}_{3}\right)$

$\mathrm{Mg}$ - dureza do magnésio removida $\left(\mathrm{mg} / \mathrm{L} \mathrm{CaCO}_{3}\right)$

DSAI - dosagem de sulfato de alumínio com 17,17\% de $\mathrm{Al}_{2} \mathrm{O}_{3}$ (mgSAl/L)

$\mathrm{DFe}$ - dosagem de cloreto férrico, medido em Fe (mgFe/L)

SST - sólidos em suspensão na água bruta (mgSST/L)

$A$ - outros aditivos (mg/L)

Dcal - Dosagem de cal (mg/L) 
KAWAMURA (1991)

$$
P=\left(D \times F c_{1}\right)+\left(T_{u} \times \mathrm{Fc}_{2}\right)
$$

Onde: $\mathrm{P}$ - produção de sólidos ( $\mathrm{g}$ de matéria seca $/ \mathrm{m}^{3}$ de água bruta tratada)

$\mathrm{D}$ - dosagem de sulfato de alumínio ( $\mathrm{mg} / \mathrm{L})$

$\mathrm{Fc}_{1}$ - fator que depende do número de moléculas de água associadas a cada molécula de sulfato de alumínio. Usualmente varia entre 0,23 a 0,26.

$\mathrm{Tu}$ - turbidez da água bruta (UT)

$\mathrm{Fc}_{2}$ - razão entre a concentração de sólidos em suspensão totais presentes na água bruta e turbidez da mesma. Geralmente na faixa de 1,0 a 2,0.

\section{AMERICAN WATER WORK ASSOCIATION - AWWA (1999)}

Considerando o uso de sulfato de alumínio e o mecanismo de varredura:

$$
W=86,4 \times Q \times(4,89 \times D A I+S S T+D p+D c a p+0,1 \times \text { Dcal }) \times 10^{-3}
$$

Onde: $\quad \mathrm{W}$ - produção de SST (kg massa seca/dia)

$\mathrm{Q}$ - vazão de água bruta a ser tratada (L/s)

$\mathrm{DAl}$ - dosagem de sulfato de alumínio, medido em $\mathrm{Al}(\mathrm{mgAl} / \mathrm{L})$

Dp - dosagem de polímero seco ( $\mathrm{mg} / \mathrm{L}$ )

SST - sólidos em suspensão na água bruta (mgSST/L)

Dcap - dosagem de dureza cálcica removida $\left(\mathrm{mg} / \mathrm{L} \mathrm{CaCO}_{3}\right)$

Dcal - dosagem de cal (mg/L)

Considerando o uso de cloreto férrico anidro:

$$
W=86,4 \times Q \times(2,9 \times D F e+S S T+D p+D c a p+0,1 \times \text { Dcal }) \times 10^{-3}
$$

Onde: $\quad \mathrm{W}$ - produção de SST (kg massa seca /dia)

$\mathrm{Q}$ - vazão de água bruta a ser tratada (L/s)

$\mathrm{DFe}$ - dosagem de ferro ( $\mathrm{mgFe} / \mathrm{L}$ )

Dp - dosagem de polímero seco ( $\mathrm{mg} / \mathrm{L}$ )

SST - sólidos em suspensão na água bruta (mgSST/L)

Dcap - dosagem de dureza cálcica removida $\left(\mathrm{mg} / \mathrm{L} \mathrm{CaCO}_{3}\right)$

Dcal - dosagem de cal (mg/L) 
Saron e Leite (2001) estudaram a diferença entre os resultados das eqs. 1, 2, 3, 4 e 5, aplicando valores médios mensais do ano de 2000 da ETA Guaraú às variáveis de cada uma das equações. Os resultados mostrados na Figura 3.1 deixam claro o desvio expressivo entre a produção de resíduos calculada e a efetivamente medida, principalmente para os meses chuvosos; também é visível que durante o período chuvoso as discrepâncias entre os valores obtidos por cada equação aumentam.

Essas divergências são associadas às premissas assumidas pelas fórmulas, ou, mais apropriadamente, à maneira pela qual essas premissas são traduzidas matematicamente. Nesse aspecto, duas delas merecem particular atenção: a primeira é o uso - por algumas das fórmulas -- de funções dependentes da turbidez para se estimar a concentração de SST na água bruta; a segunda diz respeito à quantidade de águas ligadas às partículas sólidas formadas pelo processo de coagulação e floculação. Ambas serão discutidas com mais detalhe a seguir.

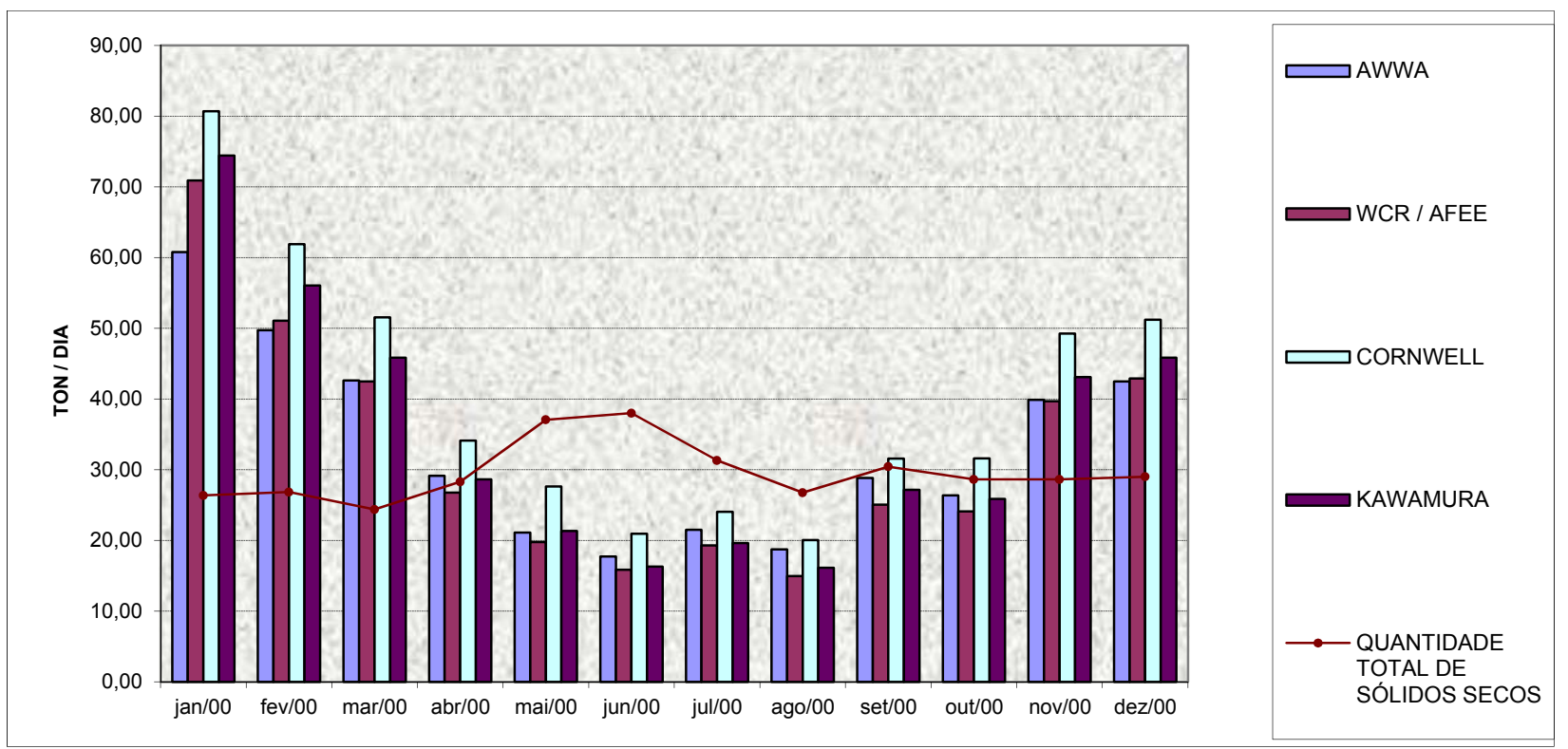

Figura 3.1 - Variação dos valores de sólidos secos por mês obtidos pelas fórmulas empíricas e pela verificação in loc. Fonte: Saron; Leite, 2001. 


\subsubsection{Relações entre turbidez e SST}

A estimação da concentração de SST por meio da turbidez foi introduzida nas fórmulas empíricas (e.g. eqs. 3 e 5) devido às evidentes vantagens práticas da medição de turbidez - para a qual sondas automáticas de alta taxa de aquisição de dados são disponíveis, a um custo relativamente baixo - em relação à determinação de SST, cujo processo é manual e comparativamente muito mais trabalhoso, principalmente para águas com baixa concentração de sólidos, para as quais a filtração de grandes volumes de amostra se faz necessária - razão pela qual não é constitui análise de rotina em ETAs (CORNWELL, 2006).

Contudo, a tradução de concentração de sólidos em turbidez é mediada por complexos fenômenos ópticos e afetada por diversas propriedades das partículas que compõe os sólidos. Por essa razão, a modelagem de uma exclusivamente em função à outra é inerentemente sujeita a interferências, em parte associada a própria natureza da grandeza turbidez, conforme será discutido à seguir.

\section{Considerações teóricas sobre a turbidez e o espalhamento de luz}

Antes de qualquer discussão sobre a correlação entre turbidez e concentração de sólidos, é preciso definir o que é turbidez e seu significado físico. A Organização Internacional para Padronização (ISO, no acrônimo em inglês) define a turbidez como "a redução da transparência de um líquido, causada pela presença de matéria não dissolvida" (ISO, 1999). Em termos físicos, a turbidez é uma medida do grau de espalhamento que a luz sofre ao passar por um líquido. Sua medição, em geral, baseia-se no posicionamento de fotodetectores, de modo a interceptar feixes de luz gerados por uma fonte de luz e espalhados em um intervalo angular específico, pela amostra de líquido. O sinal do sensor é comparado com o sinal obtido pelo espalhamento da luz por um padrão. Apesar de diversas configurações óticas serem possíveis, a maior parte dos métodos padronizados consagrados emprega a nefelometria (no qual a posição angular central do detector é de $90^{\circ}$ ), e a formazina como padrão de calibração (SADAR, 2004), conforme mostrado na Tabela 3.4.

Por depender da comparação com um padrão arbitrário, a turbidez nefelométrica é considerada somente um indicador relativo do fênomeno físico do espalhamento da 
luz, e não é uma grandeza prontamente relacionável de forma quantitativa com outras por meio de princípios físicos. A propriedade física ao qual a turbidez se relaciona é o coeficiente de espalhamento, b, que dá a fração de fótons espalhados em qualquer direção pelas partículas em suspensão por unidade de distância percorrida pelo feixe de luz. Apesar de diversos estudos reportarem que geralmente a turbidez nefelométrica correlaciona-se de modo significativo com o coeficiente de espalhamento (e.g. KIRK, 1980; EFFLER, 1988; PENG et al, 2009), as unidades dessas duas grandezas não são conversíveis com base em considerações puramente teóricas (DAVIES-COLLEY, 2001).

Tabela 3.4 - Métodos aprovados pelo USGS para medição de turbidez.

\begin{tabular}{|c|c|c|c|c|}
\hline Característica & $\begin{array}{c}\text { Método USEPA } \\
180.1 \\
\text { (nonratio } \\
\text { mode) }\end{array}$ & $\begin{array}{c}\text { Método ISO } \\
7027 \\
\text { (radiação difusa) }\end{array}$ & $\begin{array}{l}\text { Método ISO } \\
7027 \\
\text { (radiação } \\
\text { atenuada) }\end{array}$ & $\begin{array}{l}\text { Método 2130B } \\
\text { Standard } \\
\text { Methods }\end{array}$ \\
\hline Uso dos dados & $\begin{array}{c}\text { água de } \\
\text { abastecimento }\end{array}$ & $\begin{array}{c}\text { água de } \\
\text { abastecimento }\end{array}$ & água residuária & $\begin{array}{c}\text { água de } \\
\text { abastecimento }\end{array}$ \\
\hline $\begin{array}{l}\text { Intervalo de } \\
\text { aplicabilidade }\end{array}$ & 0 - 40 UNT & 0 - 40 UTF & 40 - 4000 UAF & 0 - 4000 UNT \\
\hline Fonte de luz & $\begin{array}{l}\text { Lâmpada de } \\
\text { tungstênio }\end{array}$ & Fotodiodo & Fotodiodo & $\begin{array}{l}\text { Lâmpada de } \\
\text { tungstênio }\end{array}$ \\
\hline $\begin{array}{l}\text { Comprimento de } \\
\text { onda }\end{array}$ & $400-600 \mathrm{~nm}$ & $860 \mathrm{~nm}$ & $860 \mathrm{~nm}$ & $400-600 \mathrm{~nm}$ \\
\hline $\begin{array}{l}\text { Largura de banda } \\
\text { espectral }\end{array}$ & $\begin{array}{c}\text { não } \\
\text { especificada }\end{array}$ & $60 \mathrm{~nm}$ & $60 \mathrm{~nm}$ & $60 \mathrm{~nm}$ \\
\hline $\begin{array}{l}\text { Orientação do } \\
\text { detector e ângulo } \\
\text { de medição }\end{array}$ & $90^{\circ}+/-30^{\circ}$ & $90^{\circ}+/-2,5^{\circ}$ & $90^{\circ}+/-2,5^{\circ}$ & $90^{\circ}+/-30^{\circ}$ \\
\hline Ângulo de abertura & $\begin{array}{c}\text { não } \\
\text { especificado }\end{array}$ & $20-30^{\circ}$ & $20-30^{\circ}$ & não especificado \\
\hline Percurso ótico & menos de $10 \mathrm{~cm}$ & menos de $10 \mathrm{~cm}$ & menos de $10 \mathrm{~cm}$ & menos de $10 \mathrm{~cm}$ \\
\hline Padrão primário & Formazina & Formazina & Formazina & Formazina \\
\hline $\begin{array}{l}\text { Padrões } \\
\text { secundários }\end{array}$ & $\begin{array}{c}\text { microesferas de } \\
\text { polímero }\end{array}$ & $\begin{array}{c}\text { microesferas de } \\
\text { polímero }\end{array}$ & $\begin{array}{l}\text { microesferas, } \\
\text { cubos ou } \\
\text { filamentos de } \\
\text { polímero }\end{array}$ & $\begin{array}{c}\text { microesferas de } \\
\text { polímero }\end{array}$ \\
\hline
\end{tabular}

Obs.: UNT - Unidades Nefelométricas de Turbidez; UTF - Unidades de Turbidez de Formazina; UAF - Unidades de Atenuação de Formazina

Fonte: Ziegler, 2002. 
Quantitativamente, a relação entre a concentração de sólidos e o espalhamento da luz (em um dado comprimento de onda) não é trivial ou imediata - a relação entre a massa de sólidos e seu efeito em termos das propriedades óticas da suspensão é dependente de diversos atributos da população das partículas que constituem a massa de sólidos.

De acordo com Kirk (1994), são quatro os atributos fundamentais: concentração numérica, distribuição granulométrica, composição e forma. Para uma partícula individual, esses atributos se relacionam com o coeficiente de espalhamento (denotado pela letra b) segundo a eq. 8 (KIRK, 1994). Os efeitos de espalhamento são aditivos e, portanto, para uma suspensão de diversas partículas, o valor global de b é dado pela somatória dos valores individuais das partículas (eq. 9).

$$
\begin{gathered}
b(\lambda)=\frac{Q(m, \lambda, d) \cdot A P}{V_{P}} \\
b(\lambda)=\frac{1}{V} \sum_{i=1}^{N} Q_{b, i}\left(m_{i}, \lambda, d_{i}\right) \cdot A P_{i}
\end{gathered}
$$

Onde: $b(\lambda)$ é coeficiente de espalhamento $\left(\mathrm{m}^{-1}\right)$ do volume de líquido em relação à luz com comprimento de onda $\lambda ; V_{P}$ é o volume da partícula individual; $V$ é o volume de suspensão de partículas; $Q_{b, i}$ é a eficiência de espalhamento da partícula i; $m_{i}, d_{i} e$ $\mathrm{AP}_{\mathrm{i}}$ são, respectivamente, índice de refração complexo, diâmetro e área projetada da partícula i; N é o tamanho da população de partículas.

A eficiência de espalhamento indica o quanto cada unidade de área projetada da partícula - isto é, a área da seção ortogonal ao feixe incidente de luz - contribuirá em termos de espalhamento; isto é a razão entre área projetada efetiva em termos de espalhamento e área geométrica da partícula, Devido a efeitos de difração, esse coeficiente pode ser superior à unidade, e assume valores entre 2 e 3 para aquelas partículas geralmente encontradas em suspensão em corpo d'água naturais (BABIN et al,2003; BOWERS et al, 2009; PENG; EFFLER, 2012; PENG et al, 2009; PENG et al, 2007).

Dividindo-se o coeficiente pela concentração de partículas, obtém-se o coeficiente de espalhamento específico $b^{*}(\lambda)$, que mede a quantidade de espalhamento produzida por uma unidade de concentração de partículas, e é a grandeza que é 
eventualmente refletida pela correlação entre turbidez e concentração de SST (eq. 10) (BOHREN; HUFFMAN, 2007).

$$
b^{*}(\lambda)=\frac{b(\lambda)}{S S T}=\frac{\sum_{i=1}^{N} Q_{b, i}\left(m_{i}, \lambda, d_{i}\right) \cdot A P_{i}}{\sum_{i}^{N} \rho_{i} \cdot V P_{i}}
$$

A literatura reporta ampla variação temporal e espacial de b* em rios, reservatórios e águas oceânicas. Dentre os diversos fatores implícitos e explícitos, a distribuição granulométrica e a composição das partículas são aqueles aos quais frequentemente se atribui tais variações (BABIN et al,2003; BOWERS et al, 2009; DAVIES-COLLEY, 2001; PENG; EFFLER, 2012; PENG et al, 2009; PENG et al, 2007; STRAMSKI et al, 2004).

O impacto da natureza das partículas é ilustrado na Figura 3.2, na qual são mostrados os perfis de distribuição de b* calculados por Davies-Colley et al 1993 apud Davies-Colley, 2001 para partículas individuais, utilizando-se a teoria de espalhamento de Mie para a determinação das eficiências de espalhamento. Diferenças no índice de refração e massa específica entre partículas de quartzo e orgânicas provocam deslocamento significativo da distribuição de b*, indicando que cada um dos tipos é mais efetivo em termos de dispersão de luz (por unidade de massa) em intervalos de diâmetro diferentes. Mais ainda, o fato de o perfil de cada tipo de partículas apresentar picos por si só sugere o impacto da distribuição granulométrica.

Não obstante, o efeito da distribuição granulométrica pode ser melhor apreciado reescrevendo-se a eq. 10 de modo a incluí-la explicitamente por meio de $N(d)$, o número de partículas com diâmetro $\mathrm{d}$, e supondo que as partículas sejam esferas perfeitas (eq. 11) (BOWERS et al, 2009). Considerando a massa específica $\rho$ dos sólidos como constante, $b^{*}$ passa a ser função da eficiência de espalhamento efetiva $Q_{\text {ef }}$ e o diâmetro efetivo $d_{\text {ef }}$ - que são tão somente as médias da eficiência de espalhamento e diâmetro das partículas ponderadas pela área projetada total ao longo dos intervalos granulométricos, respectivamente (eqs. 12 e 13): 


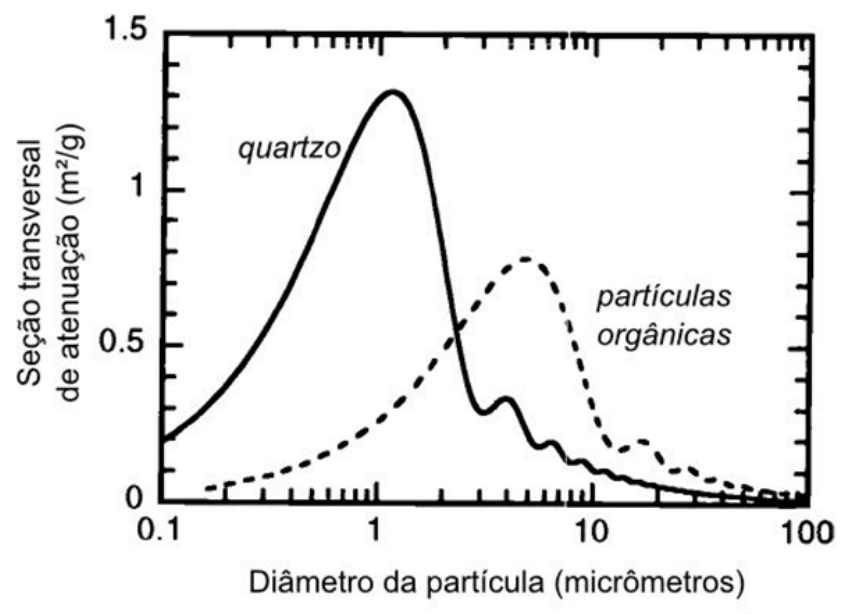

Figura 3.2 - Efeito do diâmetro e natureza de partículas em suspensão no meio líquido na atenuação da luz. A seção transversal de atenuação é dada pela razão entre coeficiente de atenuação e a concentração em massa das partículas; nos casos onde a absorção de luz é desprezível, a atenuação é governada pelo fenômeno de espalhamento.

Fonte: Davies-Colley, 2001.

$$
\begin{gathered}
b^{*}(\lambda)=\frac{3}{2} \cdot \frac{\int_{D_{0}}^{D} Q_{b}\left(m_{i}, \lambda, d\right) \cdot N(d) \cdot d^{2} d d}{\int_{D o}^{D} \rho(d) \cdot d^{3} d d}=\frac{3 \cdot Q_{e f}}{2 \cdot \rho \cdot d_{e f}} \\
Q_{e f}=\frac{\int_{D_{0}}^{D} Q_{b}\left(m_{i}, \lambda, d\right) \cdot N(d) \cdot d^{2} d d}{\int_{D_{o}}^{D} N(d) \cdot d^{2} d d} \\
d_{e f}=\frac{\int_{D_{0}}^{D} N(d) \cdot d^{3} d d}{\int_{D o}^{D} N(d) \cdot d^{2} d d}
\end{gathered}
$$

A eq. 13 pode ser generalizada para partículas não esféricas; sua utilidade como indicador da distribuição granulométrica permanece, apesar de perder sua ligação direta com a eq. 11 (PENG; EFFLER, 2012).

Observando a eq. 13, nota-se que caso a eficiência de espalhamento seja aproximadamente constante, $b^{*}$ será controlado fundamentalmente por $d_{e f}$, que é tanto maior quanto mais deslocada for a distribuição granulométrica em direção a diâmetros de partículas maiores. Evidências experimentais dessa relação foram 
obtidas por Peng e Effler (2012) em amostras coletadas antes, durante e após eventos de precipitação em um rio e reservatório. Durante tais eventos, a distribuição granulométrica das partículas foi substancialmente alterada; a composição foi pouco afetada, de modo que a eficiência de espalhamento $Q$ permaneceu constante. Apesar de apresentar algum ruído, foi encontrada a relação inversa entre $d_{\text {eff }}$ e $b^{*}$, conforme mostrado na Figura 3.3. Evidências mais indiretas e qualitativas acerca da dependência entre $b^{*}$ e a distribuição granulométrica também foram encontradas em outros trabalhos, especialmente para águas oceânicas, entre os quais aqueles por Baker e Lavelle (1984), Bowers e Binding (2006), Stramski et al (2007) e Wózniak et al (2010).

Combinados, todos esses fatores podem resultar em situações nas quais duas suspensões com a mesma concentração de partículas produzem efeitos óticos substancialmente diferentes. A depender da disparidade em termos dessas características, os impactos nas possibilidades de correlação entre SST e turbidez podem ser substanciais.

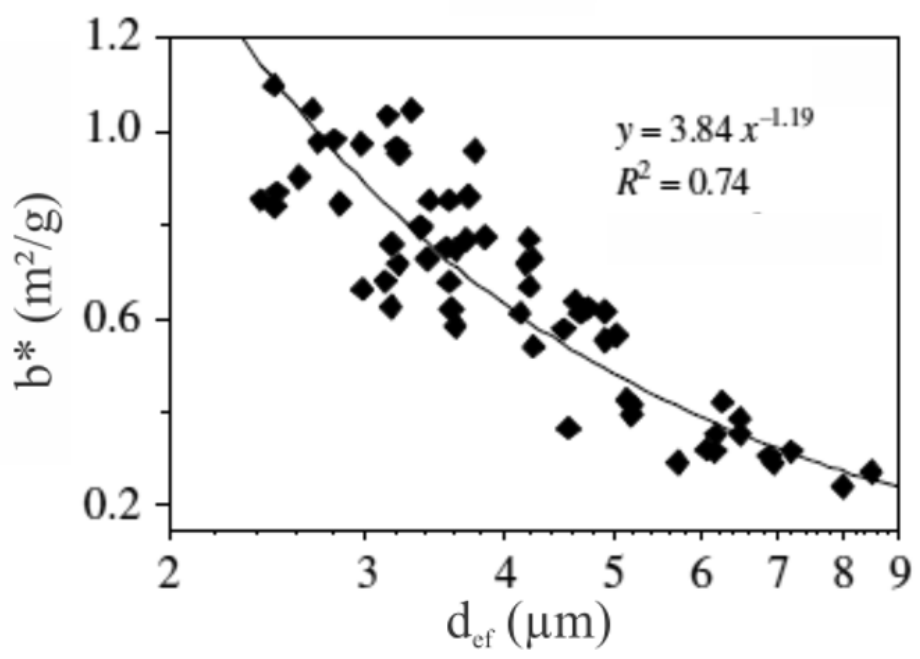

Figura 3.3 - Relação entre o coeficiente de espalhamento específico $b^{*}$ e o diâmetro efetivo $d_{\text {ef }}$ obtido para amostras coletas em rio e reservatório.

Fonte: PENG; EFFLER, 2012. 


\section{Correlações entre SST e Turbidez}

Conforme mencionado anteriormente, uma das principais dificuldades de se aplicar algumas das fórmulas empíricas é necessidade de se ter valores para a concentração de SST, um parâmetro que não é medido rotineiramente em ETAs (CORNWELL, 2006). Tradicionalmente, esse obstáculo é contornado modelando-se SST como função linear da turbidez - que é um parâmetro cuja medição é muito mais conveniente, por ser automatizada e realizável em tempo real (ANKCORN, 2003).

Muito do interesse por relações entre turbidez e sólidos em suspensão em corpos d'água está associado ao estudo de transporte de sedimentos em rios, uma vez que esse tipo de relação não está sujeita às limitações críticas - como a ocorrência de histerese - da forma mais tradicional de estimativa de carga de sedimentos por meio da correlação de concentração de sedimentos em suspensão (CSS) com a vazão (GIPPEL, 1995; GRAYSON et al, 1996). Apesar de CSS e SST constituírem medições metodologicamente diferentes e, de modo geral, produzirem valores não comparáveis (GRAY et al, 2000), a lógica subjacente à correlação entre turbidez e CSS é aplicável aos sólidos em suspensão totais (GRAYSON et al, 1996).

Uma revisão da literatura quanto à adequação tanto de correlações SST x Turbidez quanto CSS $\mathrm{x}$ Turbidez revelaram majoritariamente casos de sucesso e alguns de fracasso. O padrão que emerge desses trabalhos indica que a correlação entre SST e turbidez é altamente local: estudos focados em corpos d'água específicos (FRANCO, 2009; JASTRAM et al, 2010; JONES et al, 2011; LEWIS et al, 2002; MINELLA et al, 2008; LENHART et al, 2010; TEIXIERA; SENHORELO, 2000; TOMAZONI et al, 2005; STUBBLEFIELD et al, 2007; SUSFALK et al, 2008; ULRICH; BRAGG, 2003; WASS et al, 1997; WILLIAMSON; CRAWFORD, 2011) têm maior chance de chegar em correlações significativas do que estudos nos quais o conjunto de dados, apesar de grande, seja composto por uma miscelânea de poucas medições em muitos corpos d'água (LEWIS et al, 2002; SPEAR et al, 2008; HUl et al, 2011; WILLIAMSON; CRAWFORD, 2011).

Rasmussen et al (2009) enfatizam, no manual empregado pelo USGS para o desenvolvimento de modelos de regressão para relação entre concentração de sólidos e turbidez, que os coeficientes desses modelos devem ser considerados 
estritamente específicos para a dada localidade para o qual foram desenvolvidos - a extrapolação para outro corpo d'água, ou mesmo outro ponto do mesmo corpo d'água, traz consigo incertezas que não podem ser quantificadas a priori.

Dada a sensibilidade do espalhamento de luz a diversas características das partículas que compõe os sólidos em suspensão, discutida anteriormente, isto não é surpreendente. Um exemplo de como a dispersão espacial na coleta de dados pode resultar na dispersão dos dados de turbidez e concentração de sólidos é dado pelo trabalho de Spear et al (2008), no qual 56 amostras simples foram coletadas em 24 pontos diferentes do estuário de Elkhorn Slough, Califórnia, no qual a grande maioria das locações foi amostrada apenas duas vezes, durante duas campanhas de amostragem, realizadas no intervalo de aproximadamente um mês.

O modelo de regressão obtido, mostrado na Figura 3.4, explica somente uma pequena fração da variância da concentração de sedimentos em suspensão, conforme expresso pelo valor de $\mathrm{R}^{2}$; valores próximos de turbidez - principalmente na extremidade inferior do espectro de valores - estão associados a valores de CSS comparativamente muito diferentes.

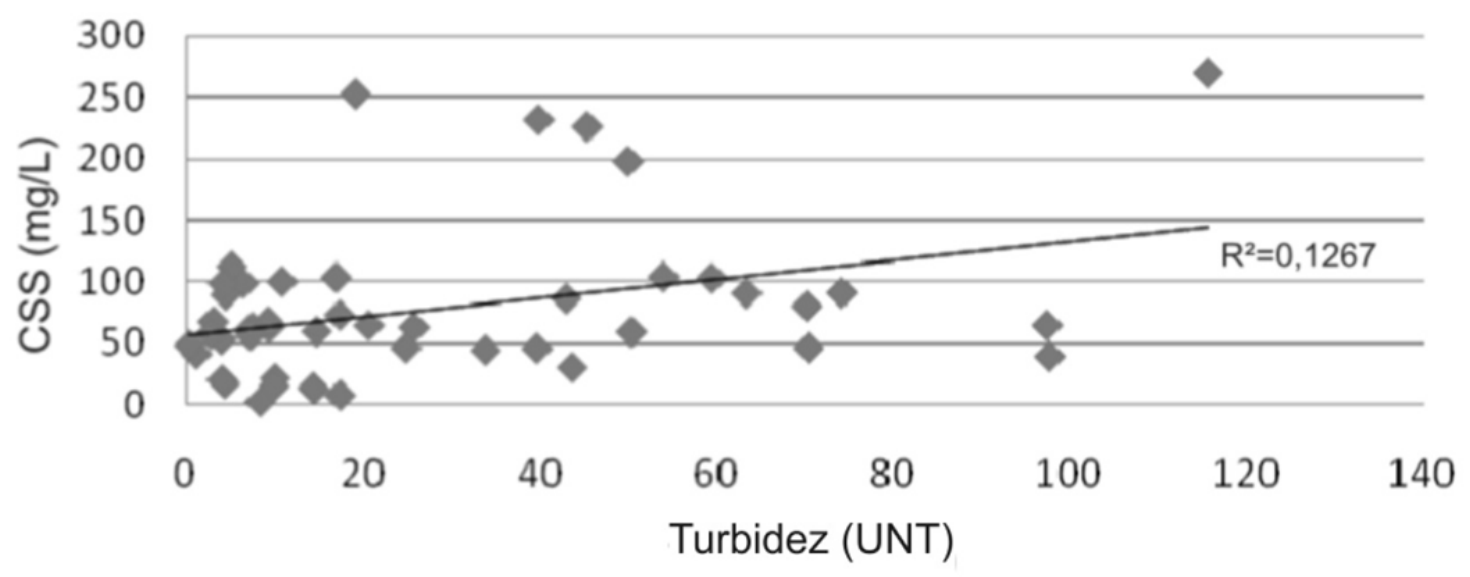

Figura 3.4 - Gráfico de dispersão de turbidez e concentração de sedimentos em suspensão obtido para o estuário de Elkhorn Slough. Fonte: Spear et al (2008).

Coeficientes de determinação à parte, a evidência mais convincente do efeito da localidade vem das imagens das membranas utilizadas durante a determinação de CSS de amostras coletadas em pontos diferentes do estuário, apresentadas na Figura 3.5; nela, é aparente a grande diferença em aspecto dos sólidos, que indica 
que, no mínimo, são oriundos de populações de partículas substancialmente distintas em termos de composição - particularmente os sólidos coletados em Struve Pond, que, a julgar pela cor, são compostos predominantemente por algas.

Há, ainda, algumas evidências de variações temporais de curto prazo na relação entre turbidez e concentração de sólidos em rios, relacionada à vazão. Pfannkuche e Schmidt (2003) e Wass et al (1997), estudando tal relação nos rios Elbe (Alemanha) e Swale (Inglaterra), respectivamente, identificaram flutuações nos coeficientes dos modelos de regressão linear devido à vazão, especialmente durante picos de escoamento provocados por chuvas intensas; em ambos os casos, a segmentação da série de dados, seja em intervalos de vazão (PFANNKUCHE; SCHMIDT, 2003) ou por eventos de precipitação (WASS et al, 1997), reduziu substancialmente a dispersão em torno das retas de regressão.

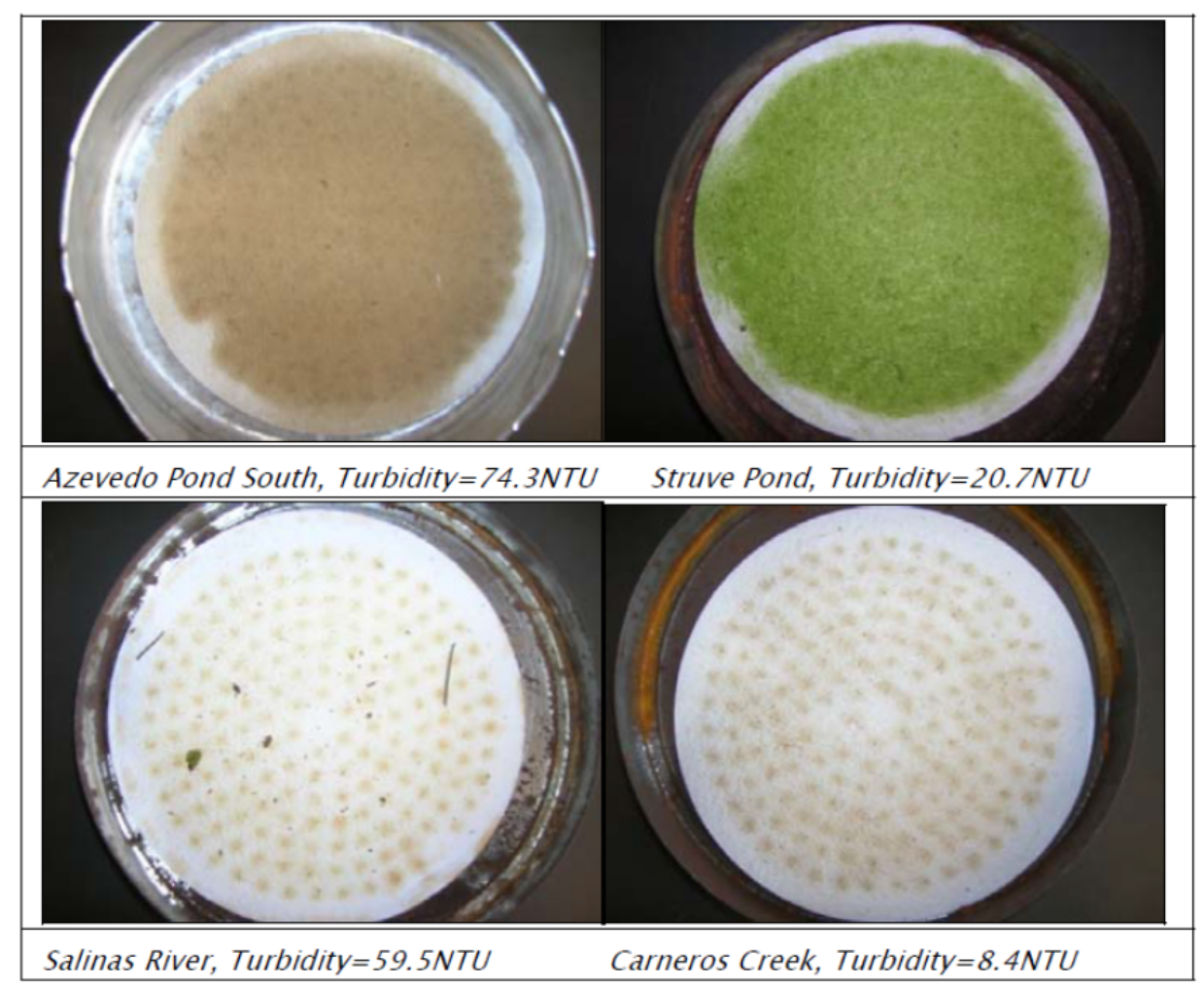

Figura 3.5 - Imagens das membranas usadas para filtração de amostras coletadas em Elkhorn Slough durante o procedimento de determinação da concentração de sedimentos em suspensão. Fonte: Spear et al (2008). 
Nos dois trabalhos, mudanças na distribuição granulométrica das partículas em suspensão com o aumento da vazão foram implicadas. Em particular, Pfannkuche e Schmidt (2003) identificaram, indiretamente e qualitativamente, a mesma dependência entre espalhamento e distribuição granulométrica predicada pela eq. 11. Em seu caso, os autores observaram relação positiva entre diâmetro médio das partículas e vazão; e inversa entre a vazão e o coeficiente angular da reta de regressão do modelo obtido para turbidez e concentração de SST (Figura 3.6). Apesar da função encontrada para o coeficiente angular não ser da mesma forma do que a eq. 11, implicitamente sua implicação é fundamentalmente a mesma - isto é, que a massa de sólidos necessária para a produção de um dado valor de turbidez aumenta com a vazão.

A importância da vazão como variável explicativa adicional é reconhecida por Rasmussen et al (2009), que recomendam seu uso caso a turbidez por si só seja insuficiente como variável explicativa, particularmente quando a fração de sólidos no intervalo granulométrico da areia (ou de diâmetros superiores) possa ser substancial.

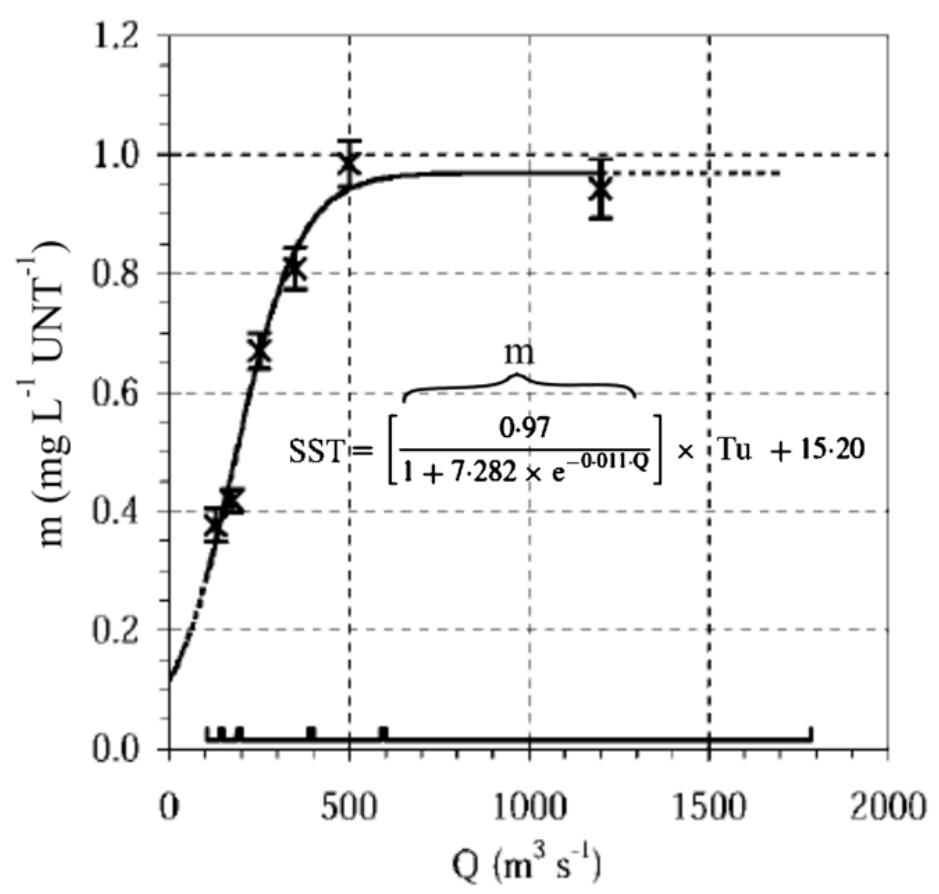

Figura 3.6 - Relação entre vazão e coeficiente angular da reta de regressão obtida por Pfannkuche e Schmidt (2003) para amostras coletadas no rio Elbe (Alemanha). Fonte: PFANNKUCHE; SCHMIDT, 2003. 
A relação entre SST e turbidez pode ser afetada ainda por limitações da medição da turbidez, em particular pela cor real da água. Constituintes dissolvidos ou particulados causadores de cor podem absorver luz, que, caso contrário, poderia ser espalhada, levando à subestimação da turbidez da amostra e distorcendo a relação dessa variável com a concentração de sólidos (CORNWELL, 2006; RASMUSSEN et al, 2009).

Em geral, dados coletados por Williamson e Crawford (2011) sugerem que o grau de correlação entre SST e turbidez sofra progressivamente menos o efeito deletério das diferenças entre as características das partículas conforme os valores de turbidez aumentem. Os autores compilaram dados de 10 pontos de monitoramento no estado norte-americano de Kentucky mantidos pelo Serviço Geológico dos Estados Unidos (USGS, no acrônimo em inglês) e com mais de 25 medições simultâneas de SST e turbidez, distribuídos ao longo de cinco bacias hidrográficas e cinco ecorregiões com coberturas de solo significantemente distintas, e coletados ao longo de 18 anos (1978-1995).

Os autores observaram que, a partir de um determinado valor de turbidez denominado breakpoint - a dispersão dos pares turbidez-SST diminui e converge para uma correlação linear distinta, conforme mostrado na Figura 3.7; no caso, o breakpoint foi estimado em cerca de 6 UNT. Uma das possibilidades aventadas para explicar esse fenômeno é a variedade tecnológica dos turbidímetros usados para a coleta dos dados ao estudo. Outra possibilidade explorada muito superficialmente é de que diversas configurações das propriedades óticas citadas anteriormente podem produzir baixa turbidez, com uma baixa dependência sobre a concentração de SST individualmente. Por outro lado, a influência da concentração numérica de partículas, é dominante para produção de valores altos de turbidez, uma vez que a população de partículas é grande o suficiente para que o feixe de luz que seja espalhado pela amostra efetivamente colha a média das demais características óticas de partículas individuais que definem $Q$ (a eficiência de espalhamento) - o efeito da variabilidade dessas características será, portanto, reduzido. 


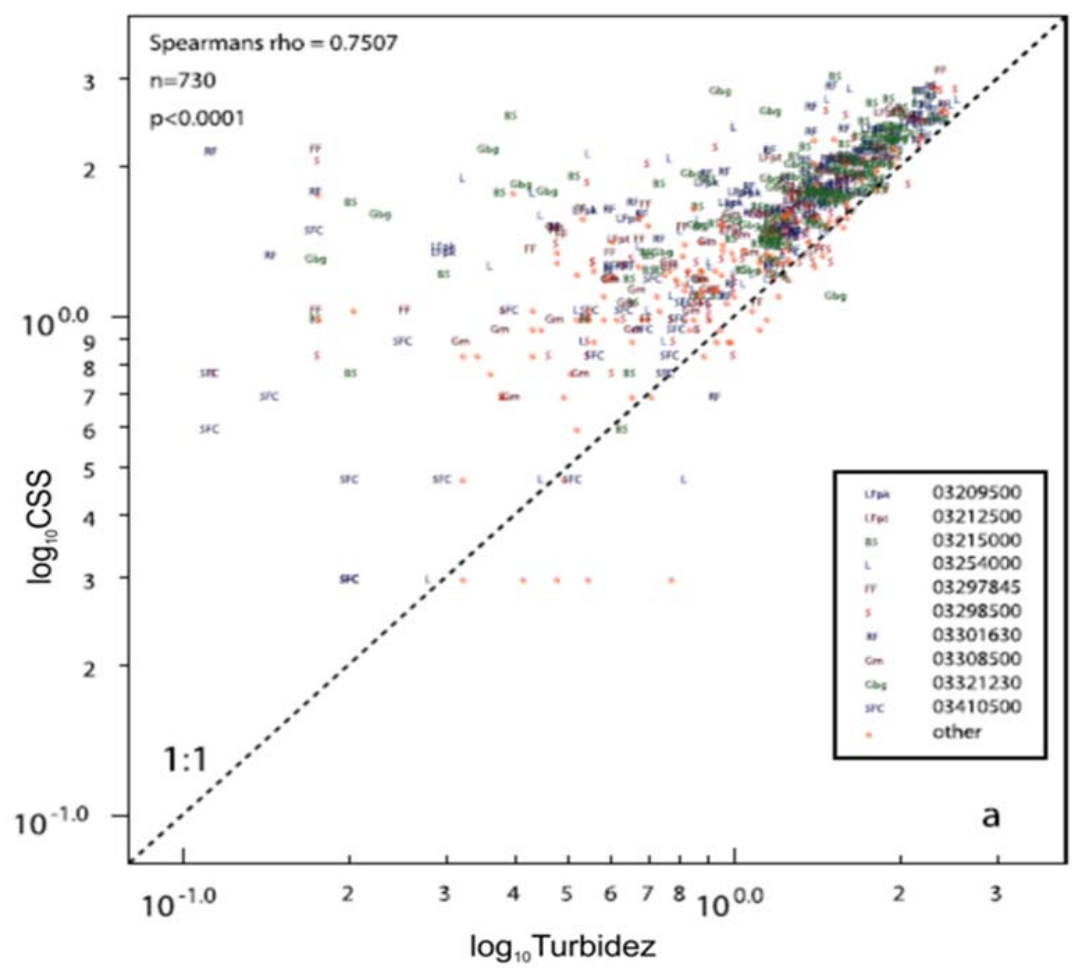

Figura 3.7 - Gráfico de dispersão de valores medidos de $\log _{10}$ CSS versus $\log _{10}$ da turbidez, obtido por Williamson e Crawford (2010) em estudo regional no estado de Kentucky. Fonte:

Williamson; Crawford, 2010.

\subsubsection{Conteúdo de água dos resíduos de ETAs}

O principal componente de resíduos de ETAs in natura é água. Em ETAs de ciclo completo, o processo de coagulação-floculação provoca a aglomeração das partículas presentes na água bruta em estruturas organizadas em três níveis cluster, agregado e floco, conforme mostrado na Figura 3.8.

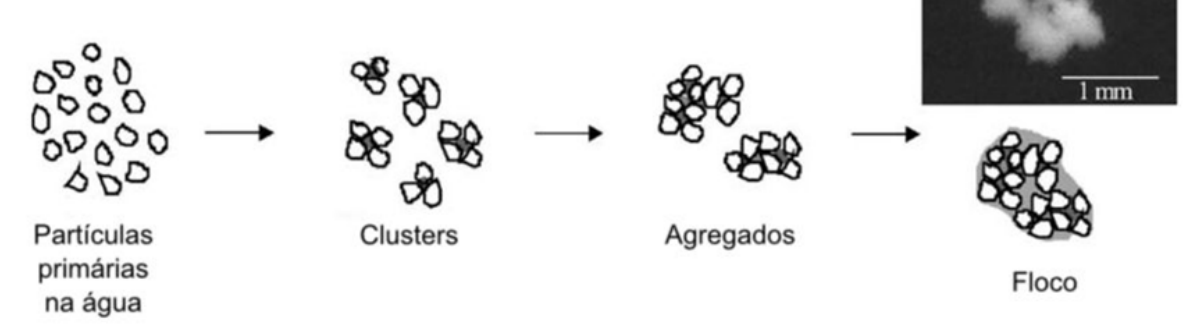

Figura 3.8 - Unidades básicas de organização de um floco de coagulação-floculação. Fonte: Turchiuli; Fargues , 2004. 
Em cada um desses domínios estruturais, a área superficial específica das partículas em contato com a massa de água contida naquela escala é diferente, de modo que a influência das forças intermoleculares atuantes na interface água-sólido é distinta. Assim, o comportamento da água contida nos flocos não é homogêneo, apresentando variações em cada nível - principalmente no que tange à facilidade de extração. Vesilind (1994) sugere um esquema de classificação dessa água baseado em quatro tipos, originalmente tomando em conta lodos de tratamento de esgoto:

- Água livre, não associada e não influenciada pelas partículas de sólidos;

- Água intersticial, aprisionada nos interstícios formados pelas partículas que compõe os flocos de sólidos;

- Água vicinal, vinculada às superfícies dos sólidos por forças intermoleculares atrativas; e

- Água de hidratação, ligada quimicamente à superfície dos sólidos.

Alternativamente, para lodos de alumínio e ferro, Cornwell (1978) apud Cornwell (2006) propôs uma classificação do conteúdo de água em três categorias, definidas como:

- Água livre, que pode ser removida por drenagem ou métodos mecânicos de baixa pressão;

- Água ligada ao floco por pontes de hidrogênio, cuja energia de interação é da ordem de $0,13 \mathrm{kcal} / \mathrm{mol}$; e

- Água ligada quimicamente ao floco por meio de ligações covalentes;

Como a determinação de massa de cada um dos tipos em ambos esquemas de classificação é trabalhosa e imprecisa, para fins operacionais o esquema de classificação é reduzido a duas categorias: a água livre - aquela que se comporta como água pura - e a água ligada - cujas propriedades são diferentes da água pura devido à interação com as superfícies sólidas (TURCHIULI; FARGUES, 2004).

Ao definir a distribuição interna e volume total de vazios, a estrutura do floco exerce papel fundamental na distribuição da água do floco entre os diversos tipos (BACHE; PAPAVASILOPOULOS, 2003; ZHAO, 2003; GORCZYCA; GANCZARCZYK, 2001); dado que a água de hidratação é praticamente não removível pelas tecnologias de desaguamento tipicamente aplicadas a lodos de ETAs, a distribuição entre os tipos de água influi sobre a massa "seca" de sólidos. 
As fórmulas empíricas em geral fazem pressuposições implícitas em relação a essa estrutura, impondo um valor para a quantidade de água que permanece ligada ao lodo após o desaguamento (exceção deve ser feita a eq. 5, que explicitamente deixa esse aspecto em aberto). Por exemplo, a eq. 6, de autoria da American Water Works Association (1999), considera que o alumínio coagulante na forma de sulfato de alumínio produz hidróxido na proporção molar de $1: 1$, segundo a seguinte reação global para a formação pelo mecanismo de varredura:

$$
\mathrm{Al}_{2}\left(\mathrm{SO}_{4}\right)_{3} \cdot 14 \mathrm{H}_{2} \mathrm{O}+6 \mathrm{HCO}_{3}^{-} \rightleftarrows 2 \mathrm{Al}(\mathrm{OH})_{3}+6 \mathrm{CO}_{2}+14 \mathrm{H}_{2} \mathrm{O}+3 \mathrm{SO}_{4}^{-2}
$$

Assume-se que, uma vez formado, o hidróxido seja hidratado na razão média de três moléculas de água por molécula de hidróxido $\left(\mathrm{Al}(\mathrm{OH})_{3} \cdot 3 \mathrm{H}_{2} \mathrm{O}\right.$, massa molar $=132$ $\mathrm{g} / \mathrm{mol}$ ). Sob essas condições, chega-se ao coeficiente de $4,89 \mathrm{mg}$ de sólido gerado por mg dosado de sulfato de alumínio (dado em termos de $\mathrm{Al}^{3+}$, massa molar = $26,98 \mathrm{~g} / \mathrm{mol}$ ); considerações análogas são subjacentes à eq. 7 , considerando cloreto férrico como coagulante. As eqs. 2 e 3 não consideram o fenômeno de hidratação, enquanto que, na eq. 1, as premissas não são rastreáveis a partir dos coeficientes sendo fruto de um exercício bruto de ajuste de dados a curvas, seus coeficientes provavelmente não possuem significado físico.

É muito improvável que essas pressuposições rígidas possam ser adequadas a todas as condições operacionais possíveis de ETAs. Primeiramente, por provocar colisões randômicas entre partículas de tamanhos variados, o processo de coagulação-floculação produz flocos com estrutura altamente intricada. Para a descrição desta estrutura, geralmente lança-se mão do fato de que flocos formados pelo processo de coagulação-floculação são fractais - isto é, estruturalmente são caracterizados pela ocorrência de padrões auto-similares (LI; GANCZARCZYK, 1989).

De acordo com a teoria de fractais (MANDELBROT, 1983), propriedades que, segundo a geometria euclidiana, possuem relação de proporcionalidade com uma propriedade espacial elevada a uma potência inteira (e.g. massa $\propto$ comprimento $^{3}$ ), em objetos descritos como fractais podem ser proporcionais a potências não inteiras 
(e.g. massa $\propto$ comprimento $\left.{ }^{1,5}\right)$. O expoente é denominado dimensão fractal $\left(D_{F}\right), e$, quanto maior seu valor, mais compacto é o arranjo das partículas no floco.

Resultados obtidos por Turchiuli e Fargues (2004) em experimentos de coagulação por varredura indicam que a dimensão fractal do floco e a fração de água na forma ligada estão de fato positivamente relacionadas - quanto maior a dimensão fractal, maior o teor de água ligada por unidade de massa de sólido seco (Figura 3.9); ainda, deve ser notada que a relação aparentemente independe do coagulante usado (sulfato de alumínio ou cloreto férrico).

Contudo, diversos fatores reconhecidamente afetam o processo de formação da estrutura de flocos, entre os quais as condições operacionais de coagulação e floculação ( $\mathrm{pH}$, dosagem, e gradientes médios de velocidade aplicados), temperatura, e concentração de sólidos em suspensão e matéria orgânica dissolvida na água (BACHE; PAPAVASILOPOULOS, 2003; BACHE et al, 1997; DUAN; GREGORY, 2003; FURRER et al, 2002; GREGORY; DUPON, 2001; JARVIS; JEFFERSON; PARSONS, 2005; LI et al, 2006; McCURDY; CARLSON; GREGORY, 2001; TURCHIULI ; FARGUES, 2004; VAN BENSCHOTEN; EDZWALD, 1990). Por exemplo, Li et al (2006), ao avaliar a coagulação e floculação de suspensões de caulinita utilizando sulfato de alumínio como coagulante, observou que a dimensão fractal dos flocos é sensível tanto ao gradiente de velocidades aplicado durante a floculação, assim como ao mecanismo de coagulação (varredura ou neutralização de cargas), conforme mostrado na Figura 3.10. 


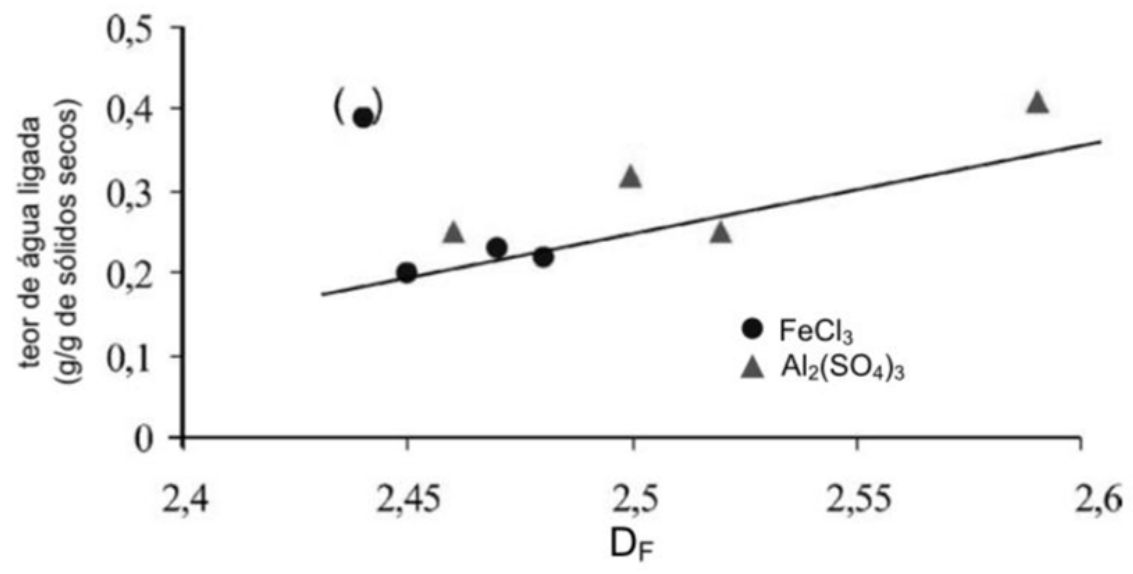

Figura 3.9 - Relação entre teor de água ligada e dimensão fractal em três dimensões de flocos produzidos com sulfato de alumínio e cloreto férrico.

Fonte: Turchiuli e Fargues, 2004.

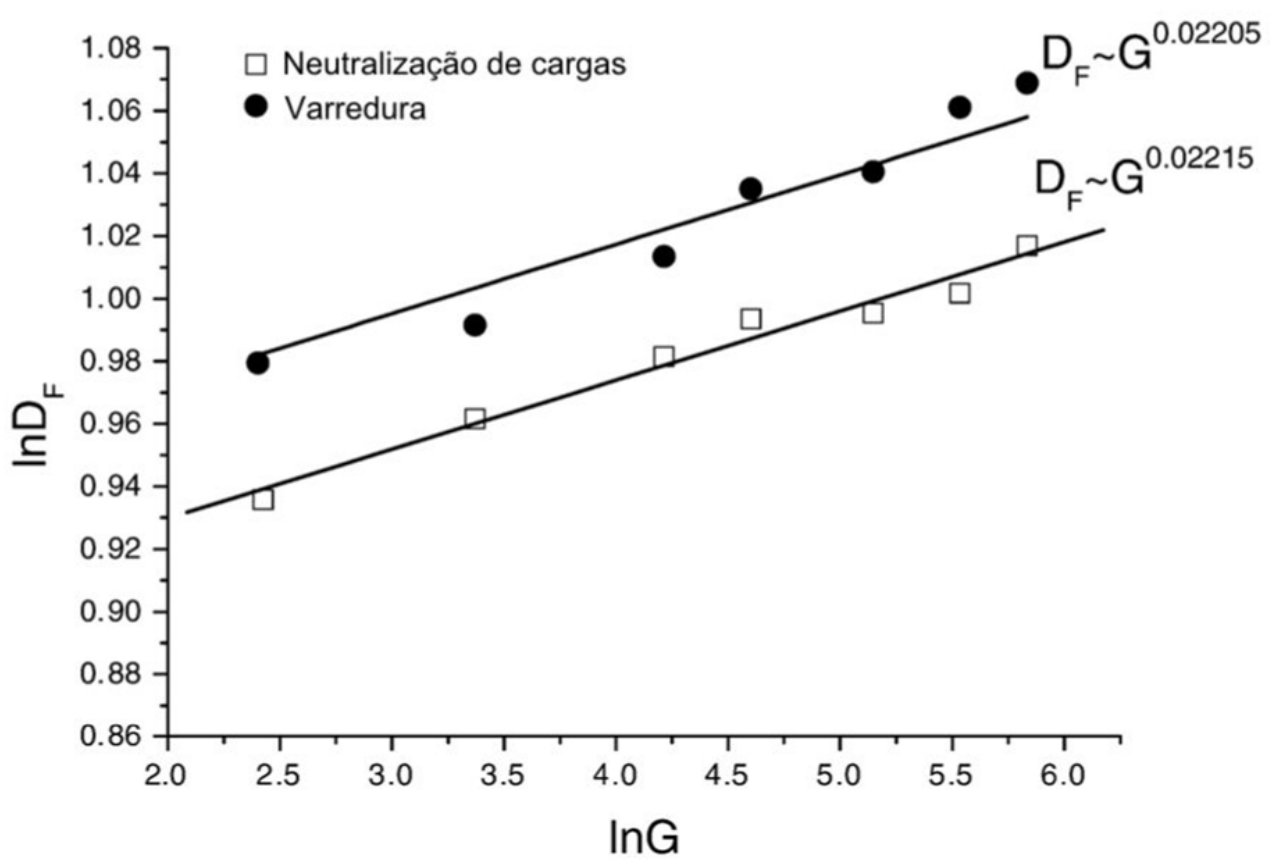

Figura 3.10 - Dimensão fractal de flocos de caulinita coagulados por diferentes mecanismos de coagulação e sob diferentes gradientes de velocidade, utilizando-se sulfato de alumínio como coagulante e polímero como auxiliar de floculação. Fonte: Li et al, 2006.

Deve ser observado que os resultados apresentados anteriormente são tão somente exemplos pontuais de como a interação de alguns fatores individuais afetam a formação e retenção de água no floco, muito provavelmente refletindo as condições específicas dos respectivos experimentos. No entanto, apesar de não representarem 
uma descrição universal e quantitativa que possa ser usada para prever o teor de água ligada, eles apontam para a imprecisão na qual se incorre ao se aceitar a hipótese de um teor de umidade fixo para os sólidos gerados pelo coagulante, com importantes implicações no uso das fórmulas empíricas.

\subsubsection{Quantificação de lodo em projetos de ETAs existentes}

Para ETAs existentes, o método mais adequado é o balanço de massa. Há diversas formas de configuração do modelo conceitual para aplicação desta metodologia. Basicamente, define-se um volume de controle, englobando certos processos e operações unitárias da ETA e, assim, analisa-se a vazão e a concentração de sólidos em dois momentos: na entrada e na saída do volume de controle; é considerada a técnica mais valiosa na quantificação dos resíduos gerados em ETAs existentes, segundo AWWA; ASCE (2005).

Este método pode ser aplicado para um poluente específico (e.g. sólidos, metais) globalmente ou a cada processo/operação unitária (SOUZA, 2004). A Figura 3.11 ilustra o balanço da quantidade de sólidos produzidos nos decantadores e nos filtros, definido pelas equações 15, 16e 17.

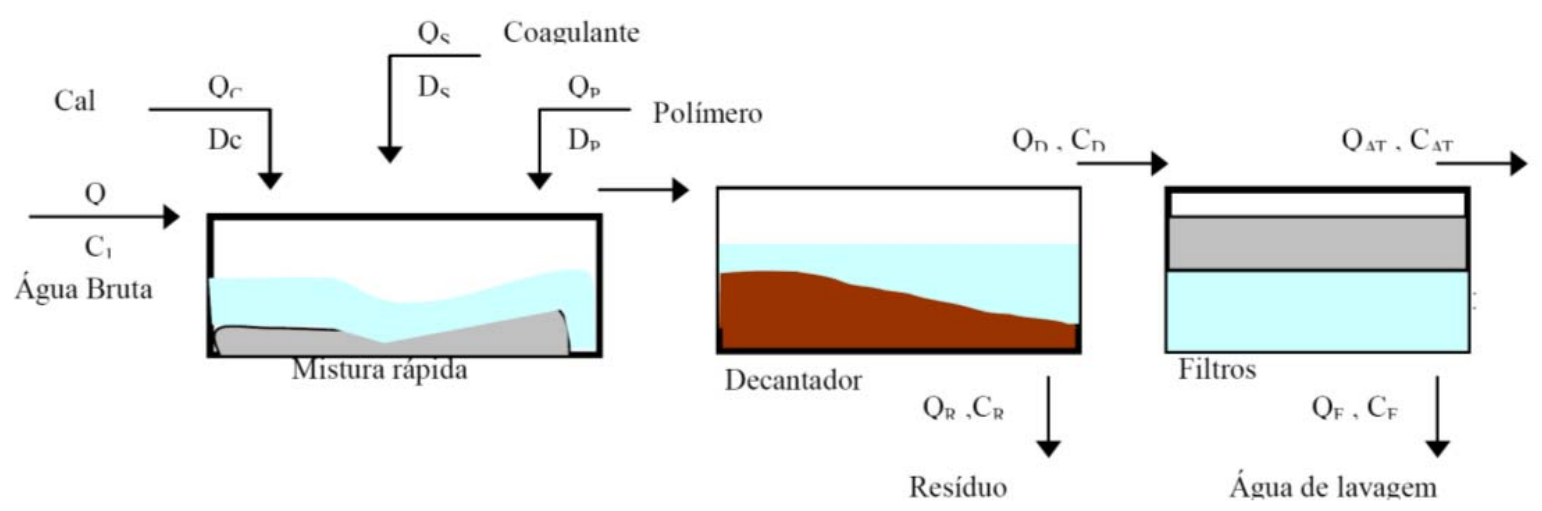

Figura 3.11 - Balanço de massa nos decantadores e filtros de ETAs de ciclo completo. Fonte: SOUZA, 2004.

Neste estudo, a contribuição devido à adição de produtos químicos foi calculada com base nos valores teóricos apresentados por REALI (1999). A estimativa da 
produção total de sólidos foi feita pela aplicação da eq. 15, considerando-se que $1 \mathrm{~g}$ de sulfato de alumínio produz 0,26 g de sólidos (ETA São Carlos), $1 \mathrm{~g}$ de cloreto férrico produz 0,66 $\mathrm{g}$ de sólidos (ETA Fonte Luminosa) e $1 \mathrm{~g}$ de cal produz 0,1 g de sólidos. A estimativa da produção de sólidos nos decantadores e filtros foi realizada por meio eq. 16 e 17, respectivamente.

$$
W=\left[\left(S S T_{A B} \times Q_{A B}\right)+\left(0,26 \times D_{S A}+0,1 \times D_{S C}\right)-\left(S S T_{A T} \times Q_{A T}\right)\right] \times 0,0864
$$

Em que:

$\mathrm{SST}_{\mathrm{AB}}$ - Concentração de sólidos em suspensão em mg/L na água bruta;

$Q_{A B}-$ Vazão de água bruta em L/s;

$\mathrm{D}_{\mathrm{SA}}$ - Adição diária de coagulante (sulfato de alumínio) em mg/s;

$\mathrm{D}_{\mathrm{SC}}$ - Adição diária de cal em mg/s;

$\mathrm{SST}_{\mathrm{AT}}$ - Concentração de sólidos em suspensão em mg/L na água tratada;

$\mathrm{Q}_{\mathrm{AT}}-$ Vazão de água tratada em L/s.

$$
W_{D}=\left[S S T_{A B} \times Q_{A B}+\left(0,26 \times D_{S A}+0,1 \times D_{S C}\right)-S S T_{A D} \times Q_{A D}\right] \times 0,0864
$$

Em que:

$\mathrm{SST}_{\mathrm{AD}}$ - concentração de sólidos em suspensão em mg/L na água decantada;

$Q_{A D}$ - vazão de água decantada em L/s.

$$
W_{F}=\left(S S T_{A D} \times Q_{A D}-S S T_{A F} \times Q_{A F}\right) \times 0,0864
$$

Em que:

$\mathrm{SST}_{\mathrm{AF}}$ - concentração de sólidos em suspensão em mg/L na água filtrada;

$Q_{A F}$ - vazão de água filtrada em L/s. 
Os gráficos da Figura 3.12 mostram o caminhamento dos sólidos ao longo do tratamento, no qual se observa a tendência de acréscimo de sólidos totais na saída do tratamento, sob influência marcante dos sólidos dissolvidos. E, segundo o autor, estes acréscimos podem ser explicados pela adição de sólidos, na forma de produtos químicos, e liberação ou ressolubilização de compostos dissolvidos no fundo dos decantadores. Este último aspecto (ressolubilização) pode estar associado às características operacionais dos decantadores, em função do volume e tempo (idade) dos resíduos retidos.
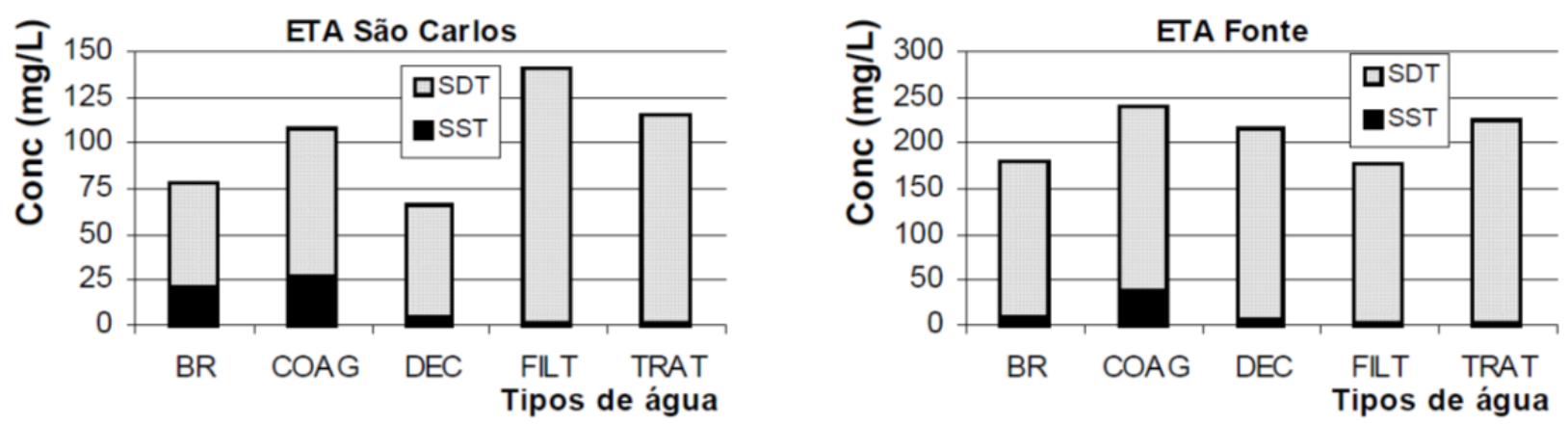

Figura 3.12 - Valores médios de SST e SD ao longo das ETAs. Fonte: SOUZA; 2004. 


\section{MATERIAL E MÉTODOS}

Neste trabalho, os métodos de quantificação de lodo (fórmulas empíricas e balanço de massa) foram avaliados comparativamente, utilizando-se dados das seguintes ETAs de ciclo completo e tipologias distintas, operadas pela Companhia de Saneamento Básico do Estado de São Paulo - SABESP:

- ETA Presidente Prudente (PPR), que capta água, em rio, com alta cor e alta turbidez;

- ETA Alto Cotia (ALC), que trata água de mananciais protegidos com baixa cor e turbidez;

- ETA Guaraú (GUA), que realiza captação em reservatórios e cuja água bruta é de boa qualidade;

- ETA Cubatão (CUB), que trata água de mananciais de serra;

- ETA Alto da Boa Vista (ABV), que trata água de reservatórios eutrofizados;

- ETA Franca (FRA), que trata água de rio.

A ETA Alto da Boa Vista (ETA ABV) faz parte do Sistema Guarapiranga/Billings de abastecimento da Região Metropolitana de São Paulo (RMSP). Seu manancial, a Represa Guarapiranga, é alimentado pelos rios Embu-Mirim, Embu-Guaçu, Cipó, Vermelho, Ribeirão Itaim, Capivari e Parelheiros - além da transposição por bombeamento das águas da Billings (através de braço do rio Taquacetuba) - que compõem uma bacia de $640 \mathrm{~km}^{2}$.

A qualidade da água do manancial está comprometida pela poluição difusa advinda da ocupação territorial desordenada no entorno da represa, que causa diversos problemas operacionais na ETA. Episódios de florações de algas associadas ao estado eutrófico do reservatório provocam picos de concentração de sólidos e carbono orgânico total na água bruta, além da degradação de sua qualidade organoléptica. À época da coleta de amostras, a ETA utilizava sulfato férrico como coagulante e poliamida como auxiliar de coagulação; conforme exigido principalmente durante eventos de floração de algas - aplica-se ainda carvão ativado para redução de gosto e odor. A lavagem dos decantadores é realizada manualmente a cada 15 dias em média, e o lodo é descartado na rede de coleta de 
esgoto doméstico e encaminhado para a ETE Barueri. A água de lavagem dos filtros é encaminhada para um tanque de equalização e bombeada ao início da linha de tratamento.

A ETA Alto Cotia pertence ao sistema produtor Alto Cotia, que também abastece RMSP. A água que o abastece é proveniente da represa Pedro Beicht, formada pelos rios Capivari e Cotia, e localizada dentro dos 10.000 hectares da reserva florestal do Morro Grande. A captação da água bruta é feita na Represa das Graças. Apesar de historicamente ser considerado um dos mananciais de melhor qualidade do sistema integrado de abastecimento da RMSP, a tendência recente é de degradação da água bruta devida à ação antrópica. Os decantadores da ETA Alto Cotia são lavados manualmente a cada 150-180 dias. A estação é desprovida de sistemas de recirculação, e, portanto, tanto a água de esgotamento dos decantadores em limpeza quanto a de lavagem dos filtros são descarregados no corpo d'água.

A ETA Guaraú é a de maior capacidade do sistema integrado da RMSP, abastecendo aproximadamente $40 \%$ da população da região com cerca de $33 \mathrm{~m} / \mathrm{s}$ de água tratada. Pertence ao Sistema Cantareira, um complexo de seis grandes represas, 48 quilômetros de túneis e canais, e uma elevatória de 80.000 HP. A água que alimenta a estação provém das barragens dos rios Jaguari, Jacareí, Cachoeira, Atibainha e Paiva Castro e chega à Elevatória Santa Inês, de onde é bombeada para a Represa de Águas Claras, construída no alto da Serra da Cantareira.

O coagulante mais frequentemente usado é o sulfato de alumínio, com uso ocasional de cloreto de polialumínio (PACl). A ETA possui um sistema de remoção de lodo dos decantadores automatizado e contínuo, que arrasta constantemente a camada de fundo dos decantadores pela ação de removedores circulares, com tempo de ciclo de 3 horas. O lodo segue para um poço no centro do decantador e é bombeado para o canal de águas residuárias da estação. A água de lavagem dos filtros é conduzida para um tanque de decantação específico. O sobrenadante retorna ao processo e o lodo é descartado na ETE Barueri.

A ETA Cubatão abastece a população dos municípios de Guarujá, Praia Grande, Santos, São Vicente e Cubatão com água captada no Rio Cubatão, cuja bacia é caracterizada pela extensa cobertura de Mata Atlântica. Devido à operação do canal 
de fuga da Usina Hidroelétrica Henry Borden, realizado durante eventos de reversão do Rio Pinheiros para controle de cheias, o rio ocasionalmente recebe águas da Represa Billings, com impacto negativo na qualidade da água bruta.

A ETA emprega cloreto férrico como coagulante. Seus decantadores são lavados manualmente a cada 20 dias, aproximadamente. A água usada para lavagem dos filtros é encaminhada para bacias de sedimentação, onde sofre adensamento com o uso de polímeros. O sobrenadante do adensamento e a água de esgotamento dos decantadores são recirculados para o início da linha de tratamento, enquanto que os lodos são misturados, desaguados com centrífugas e encaminhados para disposição final em aterro sanitário.

A ETA Franca, também conhecida como ETA Norte, tem capacidade nominal de tratamento de $850 \mathrm{~L} / \mathrm{s}$ de água proveniente do rio Canoas. O coagulante utilizado é o cloreto férrico. A ETA possui cinco decantadores, sendo que os menores 1, 2, 3 e 4 não contam com equipamentos para a retirada contínua de lodos sedimentados, e portanto, são lavados manualmente em bateladas. O decantador 5, de maior volume, possui equipamentos de limpeza mecanizada. Todo o conteúdo dos decantadores é lançado na rede de coleta de esgotos, e segue para a ETE Franca. A água de lavagem dos filtros é retornada ao início da linha de tratamento.

A ETA Presidente Prudente tem capacidade nominal de tratamento de $760 \mathrm{~L} / \mathrm{s}$, captados do Rio do Peixe (cerca de 70\%) e do Riberão Santo Anastácio. Durante o período de chuvas, a água desses rios ganha cor marrom, devido à erosão do solo das respectivas bacias. A fração mais fina, constituída principalmente de argila, silte e areia fina, acaba sendo levada para a estação de tratamento e retida nos decantadores. A ETA utiliza sulfato de alumínio como coagulante. Quando da coleta dos dados, a estação lançava seus lodos diretamente na rede de coleta de esgotos, prática que foi posteriormente substituída pelo desaguamento em bags e disposição em aterro sanitário.

Tipologias diferentes foram escolhidas de modo a identificar eventuais impactos das características da água bruta sobre as estimativas de ambos os métodos.

Medições de cor, turbidez, carbono orgânico total e série de sólidos (sólidos totais, sólidos dissolvidos e sólidos em suspensão totais) foram realizadas em amostras de água bruta, água coagulada, água floculada e água decantada. As análises foram 
compostas, com coletas de alíquotas de 1 litro a cada 2 horas, durante 12 horas, 2 vezes por mês nos seguintes pontos de cada ETA:

- Agua bruta: diretamente do rio ou reservatório, a montante dos pontos nos quais ocorre a adição de produtos químicos - tais quais sulfato de cobre, cloro e carvão ativado em pó - e a mistura com água de recirculação de filtros;

- Água coagulada: canal de coagulação;

- Água floculada: saída do floculador;

- Água decantada: calha central dos decantadores ou no início da filtração.

Além dos cuidados básicos citados, observou-se ainda:

- As amostras de água floculada foram coletadas em locais com nível de agitação adequado, de modo a garantir homogeneidade; e

- Para eliminar as diferenças na operação dos decantadores, as amostras foram coletadas nos canais centrais que recebem águas de todas as unidades.

O conjunto de análises laboratoriais por tipo de amostra de cada ETA está relacionado na Tabela 4.1. Os procedimentos para a determinação de cor e turbidez e série de sólidos foram realizados segundo a $21^{a}$ edição do Stardard Methods (APHA; AWWA; WEF, 2005). Algumas adaptações na determinação da série de sólidos foram realizadas em função das peculiaridades dos sólidos presentes nos diferentes tipos de águas. Devido à baixa concentração de sólidos, a determinação de concentração de SST em algumas amostras exigiu a filtração de um volume maior que o $1 \mathrm{~L}$, especificado como máximo para obtenção da massa mínima de 2,5 mg de sólido seco na membrana; para as ETAs ABV, Alto Cotia e Guaraú, o volume filtrado foi de 2 L, e, para as demais, de 1 a 1,5 L. Ainda, para a secagem dos sólidos durante a determinação de ST e SST, as amostras foram aquecidas a $140^{\circ} \mathrm{C}$ por $12 \mathrm{~h}$ (ao invés de $103-105^{\circ} \mathrm{C}$ ). 
Tabela 4.1 - Conjunto de variáveis avaliadas por tipo de água amostrada e para cada tipologia de ETA

\begin{tabular}{cc}
\hline Tipo de & Variável a ser analisada \\
\hline Turbidez & Cor \\
\hline Água Bruta & Sólidos em Suspensão Totais (SST) \\
& Sólidos em Dissolvidos Totais (SDT) \\
& Sólidos Totais (ST) \\
Carbono Orgânico Total (COT) & Samanho e Distribuição Granulométrica \\
\hline Água & Sólidos em Suspensão Totais (SST) \\
Sólidos em Dissolvidos Totais (SDT) & Sólidos Totais (ST) \\
\hline Água & Sólidos em Suspensão Totais (SST) \\
Decantada & Sólidos em Dissolvidos Totais (SDT) \\
& Sólidos Totais (ST) \\
\hline & Sólidos em Suspensão Totais (SST) \\
\hline &
\end{tabular}

\section{Carbono orgânico total}

Para a determinação de Carbono Orgânico Total foi utilizado analisador de TOC modelo TOCV da Shimadzu Corporation.

\section{Fórmulas empíricas}

Dados de cor, turbidez, carbono orgânico total e SST na água bruta das estações foram utilizados para verificar a existência de correlação entre SST e as demais variáveis, tanto par a par quanto se assumindo múltiplas variáveis explicativas, por 
meio de regressão linear pelo método dos mínimos quadrados, utilizando-se o software MATLAB R2009a.

Foram analisadas de modo análogo séries históricas de cor, turbidez, carbono orgânico total e SST de 130 estações de monitoramento operadas pela Companhia Ambiental de São Paulo (CETESB), abrangendo o período entre 1979 e 2011. Foram selecionadas somente estações localizadas em mananciais e com mais de 30 medições simultâneas de todas as variáveis. O rol de todas as estações de monitoramento avaliadas consta do Anexo A.

\section{Balanço de massa}

Utilizando-se os dados de concentração de SST coletados da linha de tratamento das ETAs, realizou-se o balanço de massa. De modo a evitar os obstáculos de balanços mais teóricos, as seguintes premissas foram adotadas na definição dos volumes de controle:

- Evitar a difícil prática de amostragem da água de lavagem de filtros e do lodo depositado nos decantadores;

- Simplificar o equacionamento, pela eliminação dos termos que representam as cargas dos produtos químicos, logo as imprecisões advindas de seus usos;

- Praticidade metodológica apropriada ao uso rotineiro.

As figuras a seguir ilustram os arranjos das ETAs estudadas, distinguindo, entre si, os caminhamentos das águas de lavagem dos decantadores e dos filtros para efeito do balanço. São apresentadas também as variáveis consideradas e os volumes de controle. O destino dos resíduos das ETAs na época da realização da campanha de amostragem era a rede de esgoto (ETA ABV, GUA, FRA e PPR), aterro sanitário (ETA CUB) ou corpo d'água mais próximo (ETA ALC). 


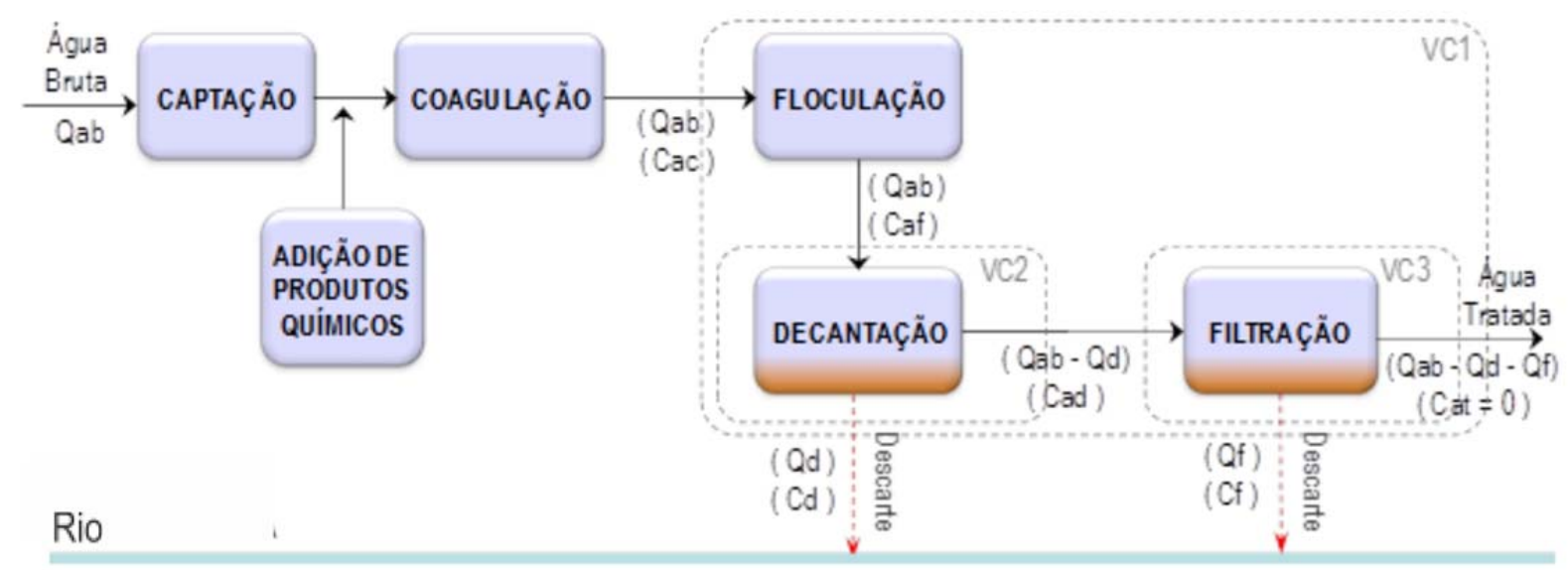

Legenda: Qab=vazão de água bruta; Qar=vazão de retorno; Qdd=vazão de descarga do decantador; Qdf=vazão de água de lavagem dos filtros; Cac=Concentração de SST na água coagulada; Caf=concentração de SST na água floculada; Cad=concentração de SST na água decantada; Cdd = concentração de SST na água de descarga dos decantadores; Cdf = Concentração de SST na água de descarga dos filtros; $\mathrm{Cr}=$ concentração de SST na água de retorno

Figura 4.1 - Volumes de controle considerados no Balanço de massa obtido para ETA Alto Cotia

Seguindo o fluxograma apresentado na Figura 4.1, é possível calcular as massas de lodo nos diferentes compartimentos do sistema de tratamento, segundo os volumes de controle indicados:

VC1: Massa de Lodo Total gerada na estação (MLODo)

$$
\mathrm{M}_{\mathrm{LODO}}=\mathrm{Q}_{\mathrm{ab}} \times \mathrm{C}_{\mathrm{ac}}
$$

\section{VC2: Massa de Lodo gerada nos Decantadores $\left(M_{\text {dec }}\right)$}

$$
\mathrm{M}_{\mathrm{dec}}=\mathrm{Q}_{\mathrm{ab}} \times \mathrm{C}_{\mathrm{ac}}-\left(\mathrm{Q}_{\mathrm{ab}}+\mathrm{Q}_{\mathrm{d}}\right) \mathrm{x}_{\mathrm{ad}}
$$

ou, quando da ocorrência de acúmulo de lodo nos floculadores,

$$
M_{\text {dec }}=Q_{a b} \times C_{a f}-\left(Q_{a b}-Q_{d}\right) \times C_{a d}
$$

VC3: Massa de Lodo gerada nos Filtros $\left(M_{\mathrm{fil}}\right)$

$$
\mathrm{M}_{\mathrm{fil}}=\left(\mathrm{Q}_{\mathrm{ab}}-\mathrm{Q}_{\mathrm{d}}\right) \times \mathrm{C}_{\mathrm{ad}}
$$

Devido a diferenças nos arranjos dos projetos das ETAs, outras dois fluxogramas para os balanços de massa são possíveis: 


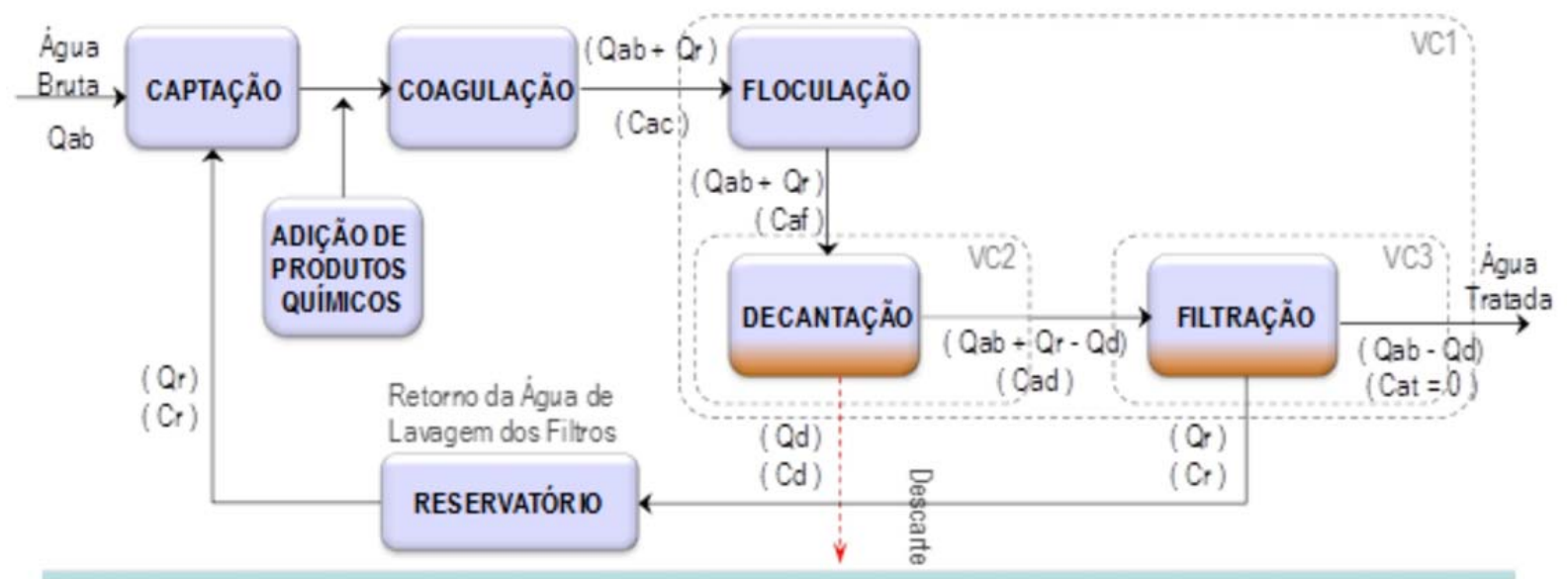

Rede de coleta de esgotos

Legenda: Qab=vazão de água bruta; Qr=vazão de retorno; Qd=vazão de descarga do decantador; Cac=Concentração de SST na água coagulada; Caf=concentração de SST na água floculada; Cad=concentração de SST na água decantada; Cdd = concentração de SST na água de descarga dos decantadores; $\mathrm{Cr}=$ concentração de SST na água de retorno; Cat=concentração da água tratada

Figura 4.2 - Balanço de massa das ETAs ABV, Guaraú, Presidente Prudente e Franca

Para tal conjunto de ETAs da Figura 4.2, a formulação das equações fica:

VC1: Massa de Lodo Total gerada na estação (MLODo)

$$
\mathrm{M}_{\mathrm{LODO}}=\left(\mathrm{Q}_{\mathrm{ab}}+\mathrm{Q}_{\mathrm{r}}\right) \mathrm{x} \mathrm{C}_{\mathrm{ac}}
$$

\section{VC2: Massa de Lodo gerada nos Decantadores $\left(M_{\mathrm{dec}}\right)$}

$$
\mathrm{M}_{\mathrm{dec}}=\left(\mathrm{Q}_{\mathrm{ab}}+\mathrm{Q}_{\mathrm{r}}\right) \times \mathrm{C}_{\mathrm{ac}}-\left(\mathrm{Q}_{\mathrm{ab}}+\mathrm{Q}_{\mathrm{r}}+\mathrm{Q}_{\mathrm{d}}\right) \times \mathrm{C}_{\mathrm{ad}}
$$

ou, quando da ocorrência de acúmulo de lodo nos floculadores,

$$
\mathrm{M}_{\mathrm{dec}}=\left(\mathrm{Q}_{\mathrm{ab}}+\mathrm{Q}_{\mathrm{r}}\right) \times \mathrm{C}_{\mathrm{af}}-\left(\mathrm{Q}_{\mathrm{ab}}+\mathrm{Q}_{\mathrm{r}}-\mathrm{Q}_{\mathrm{d}}\right) \times \mathrm{C}_{\mathrm{ad}}
$$

\section{VC3: Massa de Lodo gerada nos Filtros $\left(M_{\text {fil }}\right)$}

$$
\mathrm{M}_{\mathrm{fil}}=\left(\mathrm{Q}_{\mathrm{ab}}+\mathrm{Q}_{\mathrm{r}}-\mathrm{Q}_{\mathrm{d}}\right) \times \mathrm{C}_{\mathrm{ad}}
$$




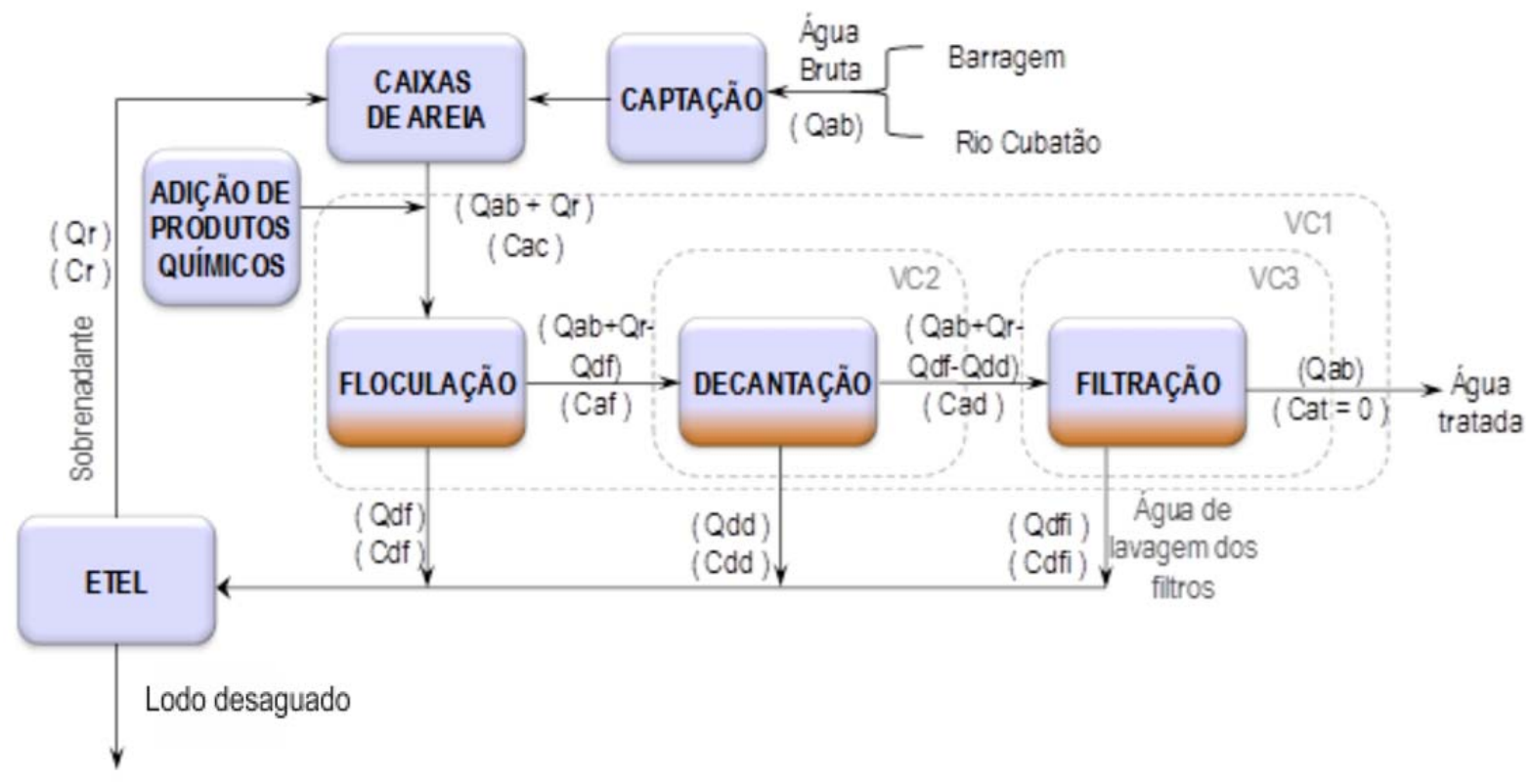

Legenda: Qab=vazão de água bruta; Qar=vazão de retorno; Qdd=vazão de descarga do decantador; Qdf=vazão de água de descarga dos floculadores; Qdfi=vazão de água de lavagem dos filtros; Cac=Concentração de SST na água coagulada; Caf=concentração de SST na água floculada; Cad=concentração de SST na água decantada; Cdd=concentração de SST na água de descarga dos decantadores; Cdf=Concentração de SST na água de descarga dos filtros; $\mathrm{Cr}=$ concentração de SST na água de retorno

Figura 4.3 - Balanço de massa da ETA Cubatão

Já para a ETA Cubatão (Figura 4.3), a formulação das equações fica:

VC1: Massa de Lodo Total gerada na estação (MLODo)

$$
\mathrm{M}_{\mathrm{LODO}}=\left(\mathrm{Q}_{\mathrm{ab}}+\mathrm{Q}_{\mathrm{r}}\right) \times \mathrm{C}_{\mathrm{ac}}
$$

VC2: Massa de Lodo gerada nos Decantadores $\left(M_{\text {dec }}\right)$

$$
\mathrm{M}_{\mathrm{dec}}=\left(\mathrm{Q}_{\mathrm{ab}}+\mathrm{Q}_{\mathrm{r}}\right) \times \mathrm{C}_{\mathrm{ac}}-\left(\mathrm{Q}_{\mathrm{ab}}+\mathrm{Q}_{\mathrm{r}}-\mathrm{Q}_{\mathrm{d}}-\mathrm{Q}_{\mathrm{d}}\right) \times \mathrm{C}_{\mathrm{ad}}
$$

ou, quando da ocorrência de acúmulo de lodo nos floculadores,

$\mathrm{M}_{\mathrm{dec}}=\left(\mathrm{Q}_{\mathrm{ab}}+\mathrm{Q}_{\mathrm{r}}-\mathrm{Q}_{\mathrm{df}}\right) \times \mathrm{C}_{\mathrm{af}}-\left(\mathrm{Q}_{\mathrm{ab}}+\mathrm{Q}_{\mathrm{r}}-\mathrm{Q}_{\mathrm{df}}-\mathrm{Q}_{\mathrm{dd}}\right) \times \mathrm{C}_{\mathrm{ad}}$

VC3: Massa de Lodo gerada nos Filtros $\left(M_{\text {fil }}\right)$

$$
\mathrm{M}_{\mathrm{fil}}=\left(\mathrm{Q}_{\mathrm{ab}}+\mathrm{Q}_{\mathrm{r}}-\mathrm{Q}_{\mathrm{df}}-\mathrm{Q}_{\mathrm{dd}}\right) \times \mathrm{C}_{\mathrm{ad}}
$$




\section{APRESENTAÇÃO E DISCUSSÃO DOS RESULTADOS}

Na Figura 5.1 são mostradas a distribuição dos valores medidos de turbidez, cor real, COT e concentração de SST na água bruta de cada ETA; os resultados completos das análises (incluindo a contagem de partículas por diâmetro) constam do Anexo B. Observa-se que a ETA Presidente Prudente se destaca das demais em termos de turbidez, cor e concentração de SST, apresentando medianas muito superiores àquelas das demais, sendo que, em relação à cor, o nível mínimo supera os máximos de todas as outras ETAs estudadas. Nota-se que tanto a dispersão quanto os valores máximos de concentração de SST e turbidez nos mananciais lóticos (ETAs FRA e PPR) é muito superior ao observado em mananciais lênticos, fato que deve ser observado durante o projeto da linha de tratamento de lodo.
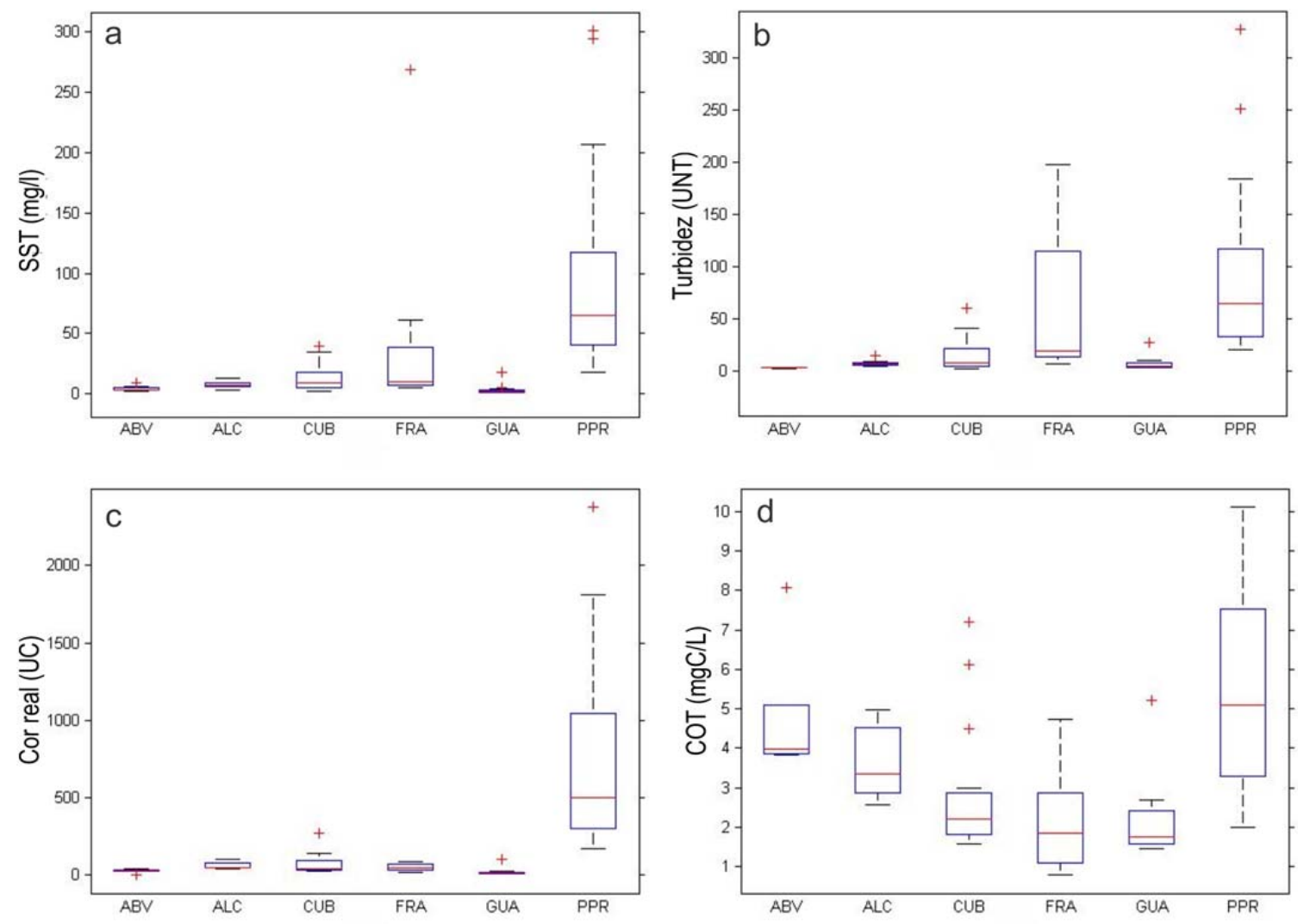

ETA

Figura 5.1 - Boxplots dos valores medidos das variáveis (a) SST, (b) turbidez, (c) cor e (d), COT, discriminados por ETA. 
Isso se deve ao fato de que rios não possuem a mesma capacidade de amortecimento de cargas de sedimento que ambientes lênticos - tais quais reservatórios e lagos - possuem, fator que é tão mais crítico quanto mais suscetíveis à erosão sejam as bacias dos rios. Em Presidente Prudente, cujos mananciais - o Rio do Peixe e o Ribeirão Santo Anastácio - drenam áreas classificadas como altamente vulneráveis à erosão (IPT, 1997), verificou-se, por meio de dados da estação pluviométrica D8-003 do Departamento de Águas e Energia Elétrica (DAEE), uma tendência visual de correlação entre a média mensal da série de precipitação do decênio 1994-2004 (o último ano com dados disponíveis) e turbidez, cor e concentração de SST, conforme mostrado na Figura 5.2.

Outro aspecto digno de nota é que, mesmo apresentando no decorrer da campanha de amostragem uma das melhores qualidades em termos de turbidez e concentração de sólidos em suspensão totais, na ETA ABV, foram medidas concentrações comparativamente altas de COT, cuja mediana foi inferior somente àquela da ETA PPR. Salienta-se que, das ETAs estudadas, esta é que historicamente apresenta maior frequência de florações algais, o que pode explicar tal fato.

A resolução temporal da campanha de amostragem foi baixa (com alguns meses, principalmente aqueles de alta precipitação, amostrados somente uma vez), e sua duração curta demais, para a identificação precisa de outliers nos dados de todas as variáveis, especialmente nas séries das ETAs FRA e PPR, que captam sua água em rios. Mesmo seguindo em linhas gerais às recomendações mínimas sugeridas por Cornwell (2006) e Di Bernardo (2005) - segundo as quais as amostragens devem ser feitas por um ano hidrológico de maneira progressivamente esparsa, inicialmente com frequência semanal e posteriormente mensal -, não foi possível distinguir se um valor aparentemente extremo foi fruto de uma condição sazonal que provoca médias sistematicamente mais altas - tal qual se verifica na época chuvosa -, ou se foi provocado por um evento esporádico - como um episódio de pico de vazão ou, ainda, no caso da ETA CUB, a operação do canal de fuga da UHE Henry Borden para controle de cheias na RMSP.

Para fins de representação gráfica na Figura 5.1, adotou-se como referência arbitrária o intervalo interquartil, sendo denotados como outliers superiores aqueles 
valores maiores que o terceiro quartil mais 1,5 vezes o espaço interquartil, e outliers inferiores aqueles menores que o primeiro quartil menos 1,5 vezes o espaço interquartil. Para fins das análises de regressão linear, todos os dados foram utilizados, com o efeito dos outliers analisado conforme necessário, conforme será discutido a seguir.
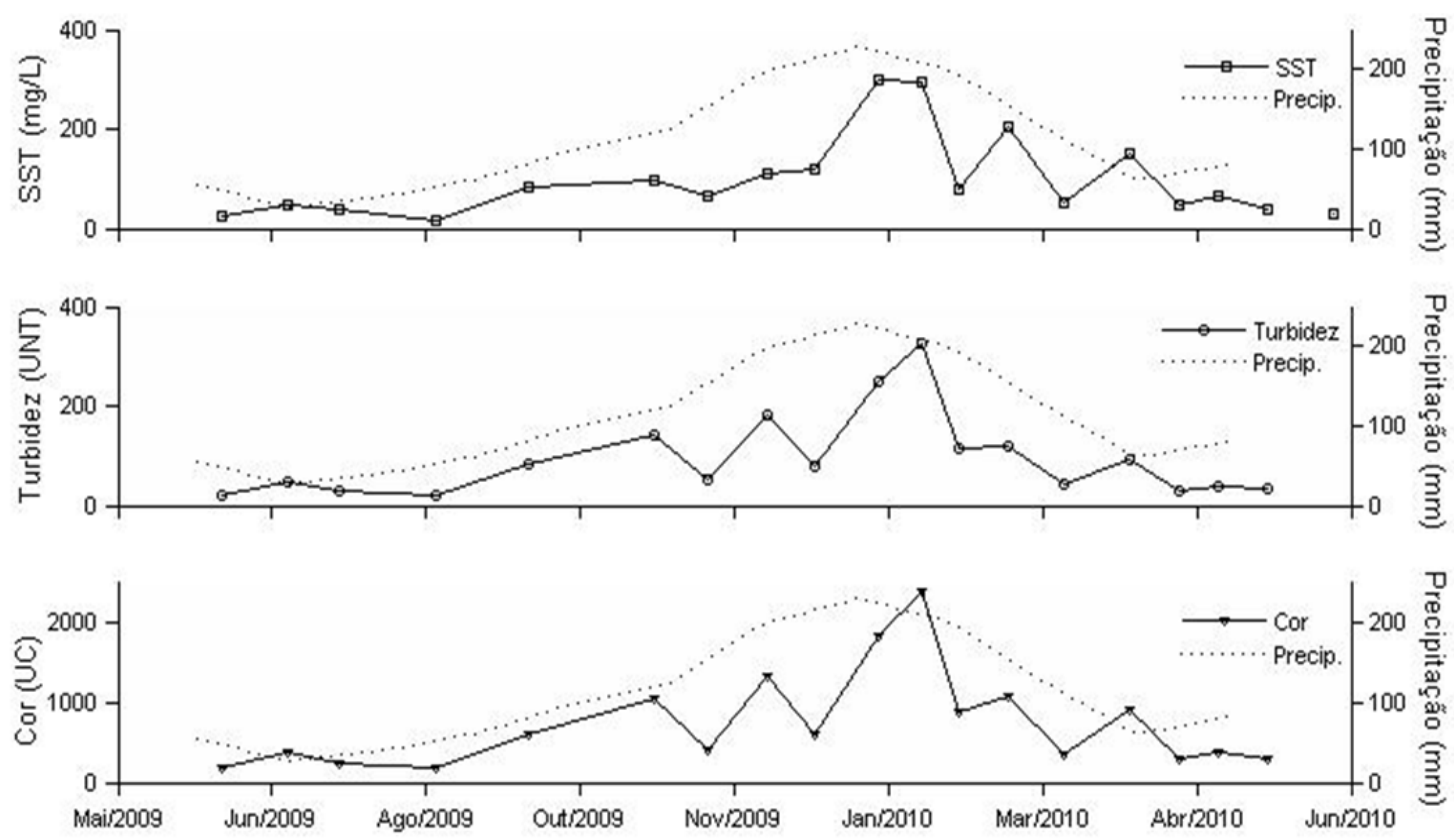

Figura 5.2 - Séries de valores de turbidez, cor e concentração de SST medidos na água bruta da ETA PPR, e precipitação média dos meses das medições.

\subsection{Relação Turbidez x SST}

\subsubsection{Dados da rede de monitoramento da CETESB}

A avaliação de se a concentração de SST é adequadamente descrita por um modelo linear com base na turbidez foi feita inicialmente com a série completa de dados de monitoramento de águas superficiais doces da CETESB, abrangendo um período que se estende de 1979 até 2011. De um universo de 244 pontos de monitoramento 
com dados disponíveis, foram selecionados 130 que possuíam mais de 30 medições simultâneas de turbidez e concentração de SST.

Adotou-se inicialmente o modelo sem constante da forma $S S T=b_{1} \cdot T u$, que é aquele tradicionalmente usado em conjunto com as fórmulas empíricas (AFEE, 1983; AWWA, 1999; CORNWELL, 2006; DI BERNARDO; DANTAS, 2005; KAWAMURA, 1991). Contudo, os resultados obtidos indicam que possivelmente esse modelo não seja o mais apropriado para descrever a variação da concentração de SST, dado que, para os dados de aproximadamente metade dos pontos de monitoramento, sua aplicação resultou em valores negativos de $\mathrm{R}^{2}$ (Figura 5.3). Mesmo que a natureza desse e de qualquer outro modelo linear que relacione as duas variáveis seja essencialmente fenomenológica, a supressão da constante tira muito do significado físico do modelo, uma vez que a turbidez pode ser provocada por partículas coloidais com diâmetro inferior a $1 \mu \mathrm{m}$ - que não são capturadas pelos métodos convencionais de medição de sólidos (ou sedimentos) em suspensão, e são, portanto, consideradas como sólidos dissolvidos.

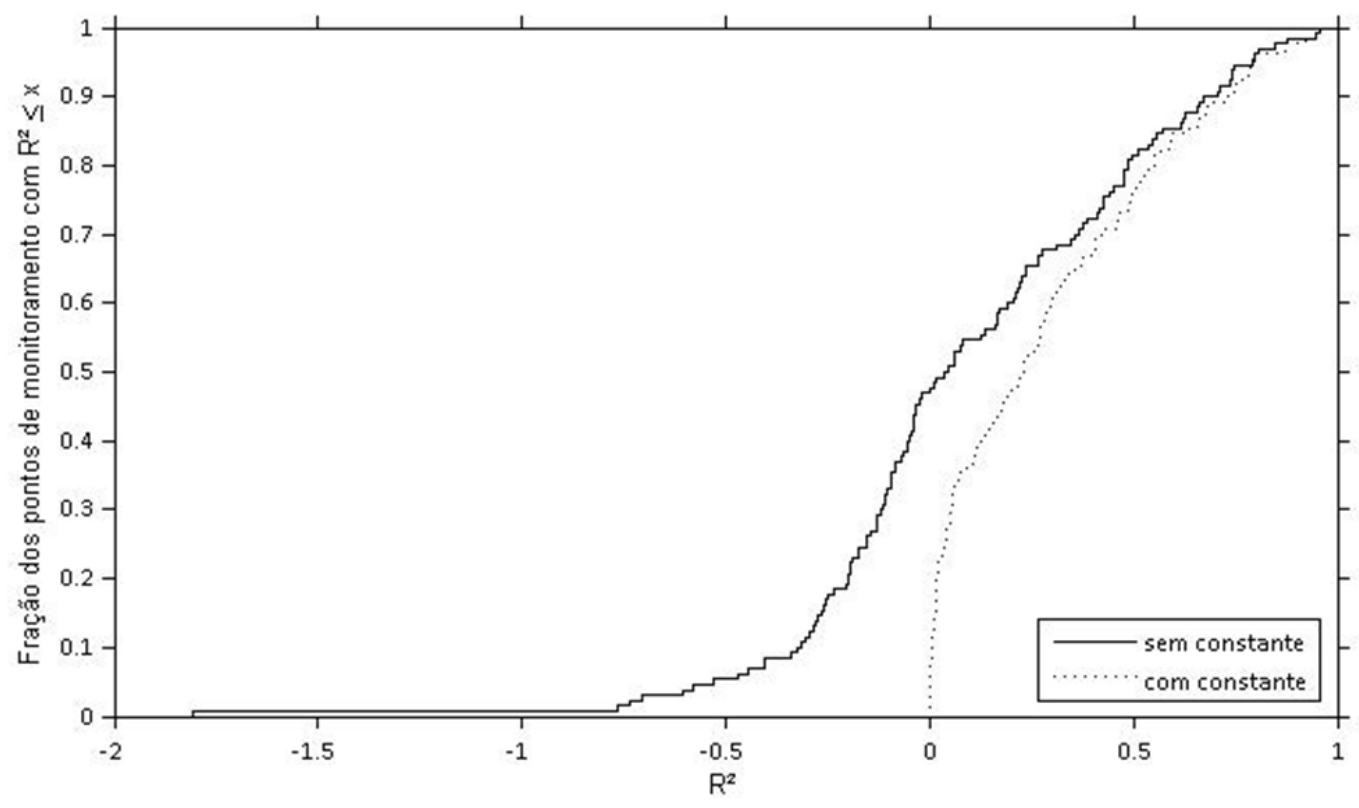

Figura 5.3 - Frequência acumulada de valores de $R^{2}$ das regressões lineares em função da turbidez obtidas para os pontos de monitoramento selecionados, assumindo-se modelo com $\mathrm{e}$ sem constante. 
Ademais, não há benefício prático em impor, a priori, um modelo sem constante; ao contrário, do ponto de vista estatístico, essa imposição só impõe uma restrição adicional ao processo de ajuste aos dados, acrescentando uma fonte artificial de viés e diminuindo a flexibilidade do modelo. No estudo de transporte de sedimentos - onde, conforme apresentado na Revisão Bibliográfica, maior parte da atividade na investigação sobre a relação entre concentração de sólidos e turbidez reside invariavelmente utiliza-se modelos com constante (vide referências daquela seção). De fato, Helsel e Hirsch (2002) apontam que a adoção de modelos lineares sem constante somente é justificável se todas as seguintes condições forem atendidas:

- Os dados da variável independente cobrem diversas ordens de magnitude;

- A relação entre as variáveis do modelo claramente aparenta ser linear desde zero até os valores extremos da variável independente;

- A hipótese nula de que o valor da constante é igual a zero não é rejeitada; e

- Há algum benefício econômico ou científico de se suprimir a constante.

Por essas razões, adotou-se para a análise de regressão linear modelo com constante, da forma $S S T=b_{1} \cdot S S T+b_{0}$. Contudo, mesmo com a inclusão da constante, o modelo foi inapropriado para explicar a variabilidade nos valores de concentração de SST observados. De acordo com os resultados obtidos, em somente 7 desses pontos obteve-se inicialmente um bom ajuste com o modelo linear, com coeficiente de determinação superior a 0,8 (Tabela 5.1). Na maior parte dos pontos, o modelo foi capaz de explicar somente metade ou menos da variabilidade da concentração de SST, conforme mostrado na Figura 5.4.

Tabela 5.1 - Pontos de monitoramento com $R^{2} \geq 0,8$, e respectivos valores da quantidade de dados ( $n$ ) e coeficiente do modelo de regressão (b).

\begin{tabular}{cccc}
\hline Nome & $\mathrm{n}$ & $\mathrm{R}^{2}$ & $\mathrm{~b}$ \\
\hline UNNA02800 & 36 & 0,96 & 0,98 \\
STAN04400 & 46 & 0,95 & 0,65 \\
LENS02500 & 33 & 0,92 & 0,30 \\
SAGU02100 & 50 & 0,88 & 0,39 \\
SORO02070 & 34 & 0,87 & 2,42 \\
PARB02530 & 30 & 0,80 & 0,68 \\
BAGU02700 & 33 & 0,80 & 0,45
\end{tabular}


Uma análise mais minuciosa da dispersão dos dados revelou a existência de alguns pontos com valores extremos de turbidez, concentração de SST ou ambos, muito superiores à mediana dos demais, tais quais aqueles indicados na Figura 5.5. Visualmente, o grande desvio em relação à tendência de covariância dos demais pontos sugere que se trata de fato de outliers.

Dado que as médias tanto de turbidez quanto de concentração de SST apresentam variação sazonal - correlacionada positivamente com a variação da vazão em corpos d'água lóticos (apesar dessa relação não ser unívoca, vide, por exemplo, Droppo e Jaskot (1995), Lenzi e Marchi (2000) e Stubblefield et al (2007)) - avaliouse a possibilidade de aqueles outliers em relação à tendência de correlação entre turbidez e concentração de SST corresponderem aos outliers em relação à tendência sazonal: isto é, se eventos anormais causadores desses outliers sazonais são mais propensos a provocar relações anormais entre turbidez e a concentração de SST. Os outliers sazonais foram identificados mês a mês, de modo a evitar que um valor anormalmente alto para o período seco seja mascarado pelo conjunto de valores normalmente altos do período chuvoso.

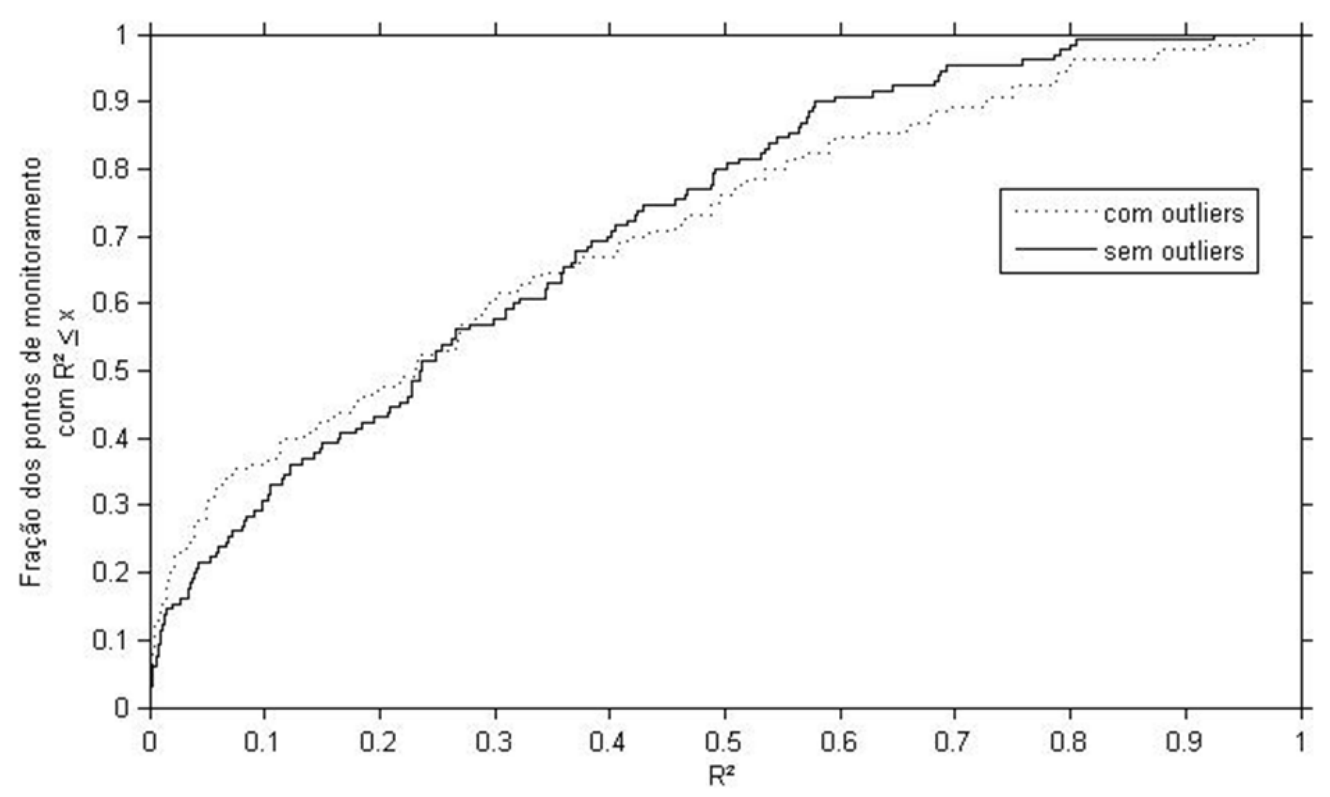

Figura 5.4 - Frequência acumulada de valores de $R^{2}$ das regressões lineares em função da turbidez, obtidas para os pontos de monitoramento selecionados. 
Uma vez que, mesmo para os pontos de monitoramento com mais medições, a quantidade de dados mensais é insuficiente para se identificar a distribuição de probabilidade de ambas as variáveis, adotou-se arbitrariamente o critério de se classificar como outlier sazonal aqueles valores (a) maiores que o terceiro quartil mais 1,5 vezes o intervalo interquartil, ou (b) inferiores ao primeiro quartil menos 1,5 vezes o intervalo interquartil.

Foram marcados como outliers sazonais aqueles pontos do conjunto de dados nos quais ou o valor de turbidez ou de concentração de SST ou ambos tenham obedecido ao critério. O impacto da eliminação desses pontos do conjunto de dados é mostrado na Figura 5.4. Observa-se que o efeito é misto: pontos de monitoramento com modelos de regressão no intervalo inferior do espectro de coeficientes de determinação tiveram sua qualidade aumentada, enquanto que pontos na extremidade superior tiveram sua qualidade reduzida. Em particular, verifica-se que o rol de pontos de monitoramento com $R^{2}$ superior a 0,8 diminui sensivelmente, para 3 (Tabela 5.2). Desse modo, com esse refinamento dos dados, em grande maioria dos pontos de monitoramento verificou-se que o modelo de regressão baseado unicamente na turbidez foi em geral inapropriado para explicar a variabilidade das concentrações de SST.

Os coeficientes obtidos para os pontos de monitoramento com melhor ajuste ao modelo, após a remoção de outliers sazonais constam da Tabela 5.2. Devido ao desconhecimento de qual é a distribuição de probabilidade do resíduo das regressões, intervalos de confiança não foram calculados; apesar dos trabalhos na literatura, em geral, assumirem implicitamente que essa distribuição é normal (SUSFALK et al, 2008; TOMLINSON; CARLO, 2003; WASS et al, 1997), a aplicação do teste de aderência de Kolmogorv-Smirnov rejeitou essa hipótese para os dados de todos os pontos de monitoramento em questão, considerando-se nível de confiança de $95 \%$.

Alguns pontos de monitoramento apresentaram queda acentuada dos coeficientes de determinação com a remoção de outliers sazonais. Destacam-se entre estes os pontos LENS02500 (instalado no Rio Lençóis, município de Lençóis Paulista) e STAN04400 (instalado no Rio Santo Anastácio, município de Alvares Machado), cujos valores de $R^{2}$, originalmente de 0,92 e 0,95 respectivamente, caíram para 0,03 
e 0,58 após a remoção desses outliers. O que ocorreu nesses pontos de monitoramento é exemplo particularmente instrutivo de como a má distribuição dos dados pode elevar artificialmente o valor dessa estatística, e levar à elaboração de modelos falhos em termos de poder explicativo. De maneira análoga ao que ocorre graficamente (Figura 5.6), os pontos marcados distorcem a escala da variância da concentração de SST: os valores extremamente altos (em comparação com os demais) e com alta alavanca aumentam substancialmente a média global dessa variável, e provocam uma distribuição desigual dos valores de concentração de SST. O resíduo da regressão associado ao restante dos valores de SST medidos (expressos em termos da soma dos quadrados dos erros) ficam comparativamente pequenos, e o resultado é um valor alto para $R^{2}$. Uma vez removidos esses outliers, a real variância dos dados emerge, e o valor de $\mathrm{R}^{2}$ cai.
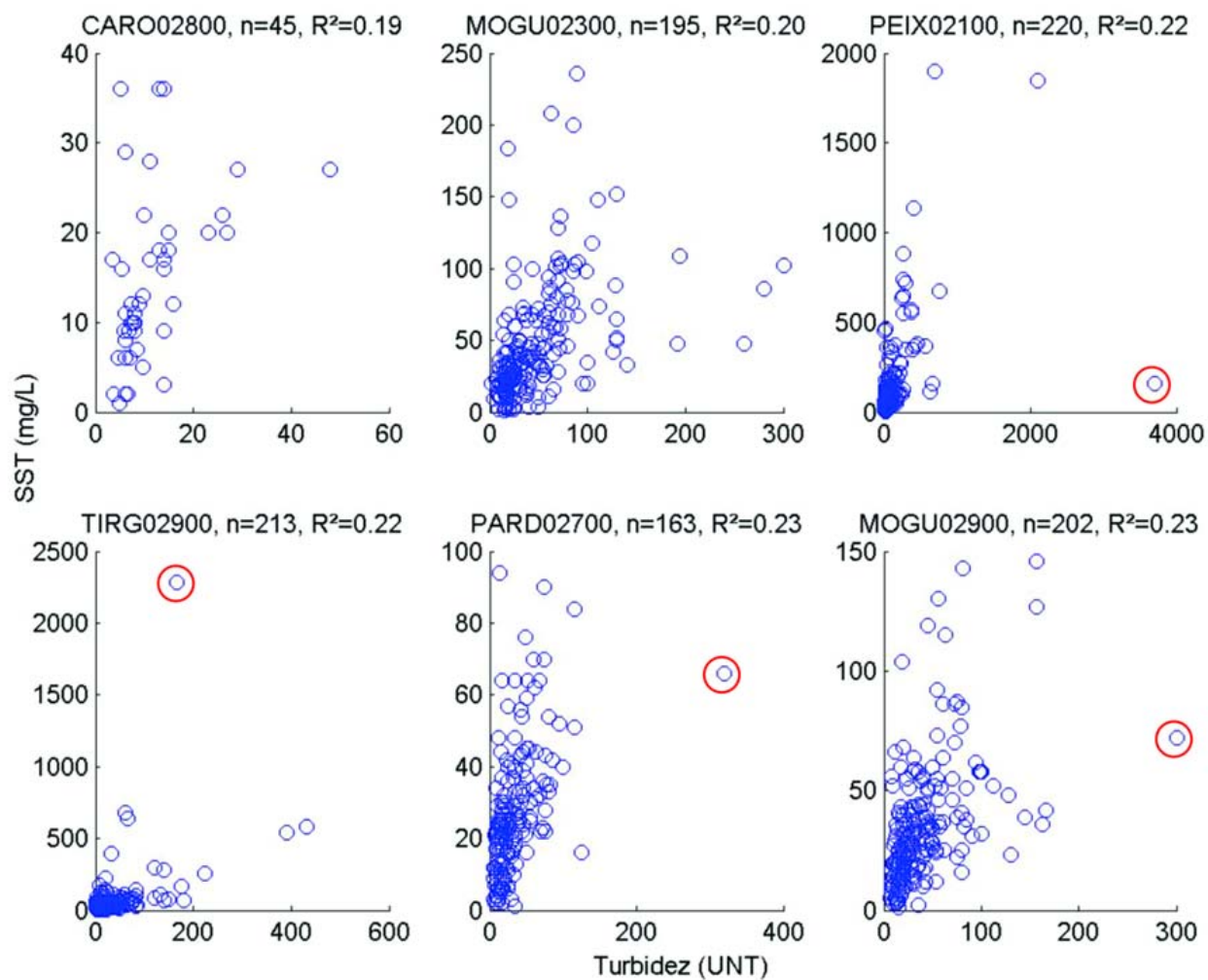

Figura 5.5 - Possíveis outliers nos dados de 6 pontos de monitoramento, marcados em vermelho. 
Tabela 5.2 - Pontos de monitoramento com $R^{2} \geq 0,8$ após remoção de possíveis outliers, e respectivos valores da quantidade de dados (n) e coeficiente do modelo de regressão (b).

\begin{tabular}{cccc}
\hline Nome & $\mathrm{n}$ & $\mathrm{R}^{2}$ & $\mathrm{~b}$ \\
\hline UNNA02800 & 36 & 0,92 & 0,98 \\
PARB02530 & 30 & 0,80 & 0,68 \\
TIET02450 & 105 & 0,80 & 1,07
\end{tabular}
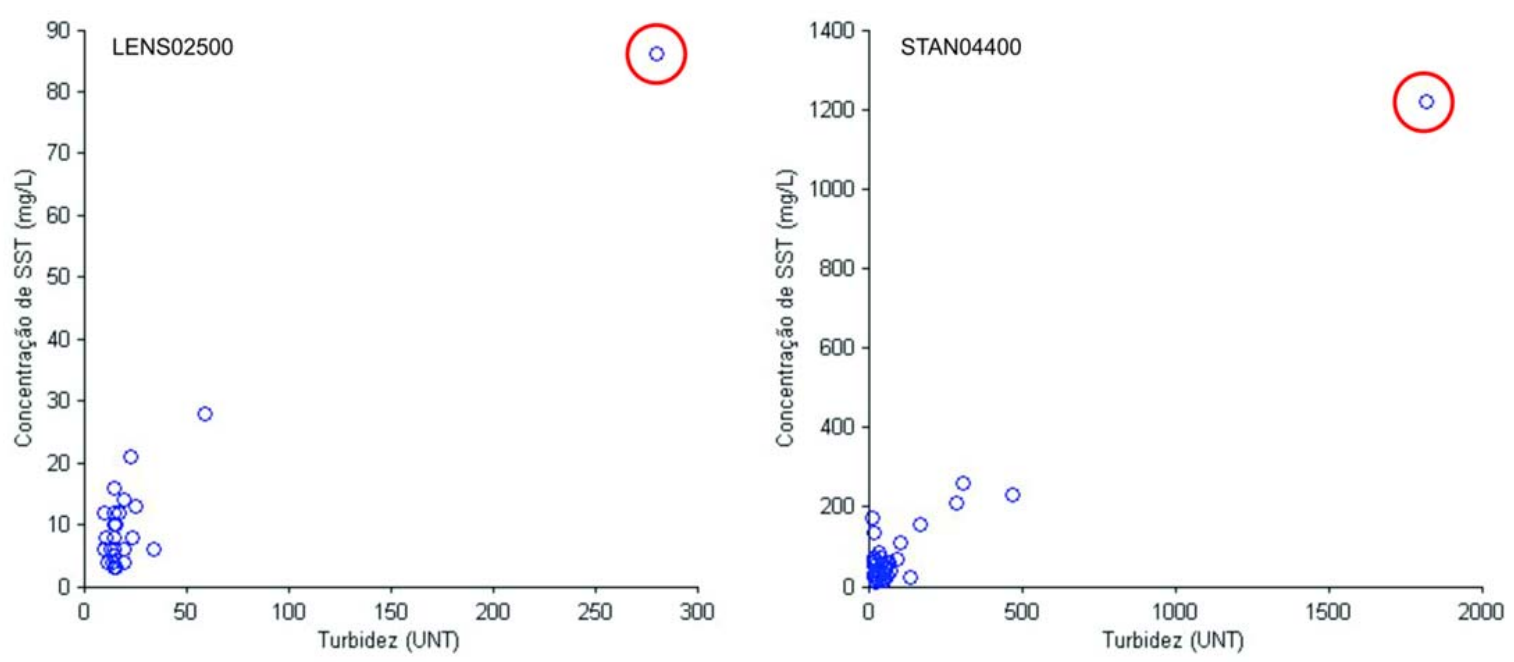

Figura 5.6 - Valores extremos com alta alavanca e alta influência nos dados dos pontos de monitoramento LENS02500 e STAN04400.

Deve-se enfatizar que o critério de detecção de outliers sazonais empregado é arbitrário, e consequentemente, pode ter eliminado medições válidas e não tão raras como sugerido pelo conjunto de dados. Para dados com distribuição normal, o critério de 1,5 vezes o espaço interquartil abrange valores localizados dentro do intervalo de +/- 2,7 $\sigma$ ao redor da média, com 99,3\% de confiança; contudo, conforme mencionado anteriormente, os dados disponíveis são insuficientes para a determinação da real distribuição de probabilidades dos valores de turbidez e concentração de SST em cada mês, e, consequentemente, é impossível a estimativa de quão frequentes são de fato os valores considerados extremos.

De qualquer maneira, ainda que os outliers sazonais identificados sejam de fato a eventos anormais, o fato de sua remoção da série de dados não propiciar melhoria na qualidade do ajuste do modelo linear indica que a dispersão em torno das retas de regressão obtidas não é devida só a anomalias intra-sazonais. 
Desse modo, a incapacidade do modelo de regressão baseado na turbidez de descrever a variação na concentração de SST possivelmente pode ser atribuída a dois fatores intimamente relacionados:

(i) os corpos d'água não são bem comportados em termos da relação entre turbidez e concentração de sólidos - isto é, são sujeitos a variações temporais nas características dos sólidos em suspensão suficientemente grandes para perturbar substancialmente sua correlação com a turbidez; e

(ii) a estratégia de amostragem adotada pelo programa de monitoramento da CETESB é inapropriada;

Em relação ao primeiro, é sabido que - conforme discutido na seção anterior outras características dos sólidos em suspensão afetam a geração de turbidez, tais quais a distribuição granulométrica e o índice de refração (este último relacionado à composição das partículas), que, por sua vez, respondem a uma miríade de fenômenos responsáveis pelo transporte de sólidos da litosfera e atmosfera para a hidrosfera.

Em rios, a distribuição granulométrica de partículas é sujeita a variações significativas em diversas escalas de tempo. Em todos os casos, verifica-se no corpo d'água a transição de condições erosivas a deposicionais (ou vice-versa), e/ou alteração das fontes dos sedimentos que aportam ao corpo d'água, que podem resultar no enriquecimento ou empobrecimento da concentração de partículas de um dado intervalo granulométrico com consequentes efeitos na relação entre turbidez e sólidos em suspensão.

Em termos de escalas de tempo grandes, essa transição é associada principalmente ao impacto de intervenções antropogênicas no uso e ocupação do solo das bacias hidrográficas, principalmente devido à urbanização e agricultura, que interferem na fonte de sedimentos (e.g., DEARING AND JONES, 2003; HENGSTUM et al, 2006; JOHNSON et al, 1997; KARR; SCHLOSSER, 1979; LECCE E PAVLOWSKY, 2004; OWENS et al, 1999; PROSSER et al, 2001). Um exemplo claro do impacto sedimentológico da transformação antropogênica de paisagens naturais é dado pelo trabalho de Hengstum et al (2006), no qual a granulometria de núcleos de sedimentos retirados de uma baía refletiu as diversas etapas de ocupação do solo da bacia drenada (vegetação natural, agricultura e urbanização); no caso, o 
tamanho das partículas de sedimento progressivamente diminuiu, como consequência do favorecimento de condições erosivas na bacia.

Já escalas de tempo inferiores, tais variações resultam principalmente do regime hidrológico da bacia, que determina a intensidade e frequência das chuvas, e, por conseguinte, o hidrograma do corpo d'água (FLORSHEIM et al, 2011; SUl et al, 2009; LENZI; MARCHI, 2000; STONE; SANDERSON, 1992; SUTHERLAND; BRIAN, 1989; WALLING; MOOREHEAD, 1987; XU, 2002). A dinâmica subjacente é complexa, e diferentes desfechos em termos de enriquecimento ou empobrecimento de uma dada fração granulométrica são possíveis, a depender de fatores como o nível de sedimentos armazenados no leito e a susceptibilidade da bacia a processos erosivos (WALLING; MOOREHEAD, 1987; SUTHERLAND; BRYAN, 1989; SUl et al, 2009). Os trabalhos de Pfannkuche e Schmidt (2003) e Wass et al (1997), discutidos na seção anterior, oferecem evidências diretas dessas flutuações nos modelos de regressão para turbidez e concentração de SST.

Outro aspecto da qualidade das águas dos corpos d'água que altera a relação entre turbidez e concentração de SST e é potencialmente variável ao longo do tempo é a participação de partículas orgânicas na massa total de sólidos em suspensão (LONGWORTH et al, 2007; NADEU et al, 2012; VAN OOST et al, 2007), que pode ser diminuída com a remoção de vegetação nativa, principalmente a ripária (FARELLA et al, 2001) e aumentada com o aporte de águas residuárias (LOUCHOUARN et al, 1999), e, possivelmente, esgoto doméstico.

Em relação às limitações da estratégia de coleta de amostras do monitoramento da CETESB, alguns aspectos críticos para a estimação da concentração de SST por meio de medições turbidez devem ser ressaltados. O procedimento de amostragem empregado pela CETESB é baseado na coleta de amostras simples, pontuais, com frequência fixa - que, apesar de haverem alguns lapsos na regularidade da série de dados de alguns pontos de monitoramento, tende a ser bimestral.

Em relação à representatividade das amostras simples, não foi encontrada documentação que a comprovasse, ou mesmo que relatasse o processo de definição das posições dos pontos em geral. Segundo Martin et al (1992), amostras coletadas em um único ponto de rios podem ter distribuição granulométrica de partículas e concentração de sólidos significantemente diferentes daquelas 
coletadas com técnicas de integração horizontal (ao longo da largura do corpo d'água) e vertical (ao longo da profundidade). Apesar de amostragens simples poderem render dados representativos, devem ser devidamente validadas com técnicas de integração.

Quanto à questão da frequência fixa, é amplamente documentado na literatura que tal estratégia é limitada quando aplicada ao monitoramento de turbidez e concentração de SST - e variáveis de qualidade d'água sensíveis a condicionantes hidrológicas em geral -, exigindo intervalos entre coletas extremamente pequenos para que sejam integralmente capturadas as grandes flutuações que ocorrem durante eventos de curta duração, como, no caso de rios, picos de vazão que sucedem episódios de precipitação intensa (DROPPO; JASKOT, 1995; HARMEL et al, 2006; JONES et al, 2012). Mais ainda, além da frequência de coleta de amostras ser baixa, a pouca sobreposição entre as redes fluviométrica do DAEE e de monitoramento da CETESB resulta na indisponibilidade de dados de vazão para maior parte dos pontos de monitoramento avaliados, impedindo a separação de dados de turbidez e concentração de SST associados com picos de vazão (que, conforme discutido anteriormente, apresentam relações diferenciadas entre essas duas variáveis) dos demais, procedimento que poderia ajudar na melhoria da qualidade dos modelos de regressão.

Limitações de monitoramento à parte, mesmo que maior parte dos trabalhos reportem sucessos na obtenção de modelos de regressão relacionando turbidez e concentração de SST (e.g. JASTRAM et al, 2010; JONES et al, 2011; LEWIS et al, 2002; MINELLA et al, 2008; LENHART et al, 2010; TEIXIERA; SENHORELO, 2000; TOMAZONI et al, 2005; SANTOS, 2009; STUBBLEFIELD et al, 2007; SUSFALK et al, 2008; ULRICH; BRAGG, 2003; WASS et al, 1997; WILLIAMSON; CRAWFORD, 2011), é difícil determinar a partir da literatura se a baixa incidência de altos níveis de correlação verificada neste trabalho é representativa da realidade física de corpos d'água em geral, uma vez que a cultura editorial de periódicos científicos e outras mídias acadêmicas muitas vezes acabam impedindo que fracassos sejam relatados. Por fim, avaliando-se coletivamente todos os dados de sólidos em suspensão e turbidez, a mesma tendência de convergência da correlação entre essas duas variáveis observada por Williamson e Crawford (2011) foi encontrada (Figura 5.7). 
Observa-se que a relação entre turbidez e concentração de SST é particularmente ambígua para baixos valores de turbidez, e que fica mais precisa com o aumento da turbidez. Possivelmente, isto sugere que um número menor de combinações das variáveis da eq. 8 pode ser associada a altos valores de turbidez - ao menos, no que diz respeito a partículas naturais. Mais especificamente, altos níveis de espalhamento de luz provavelmente só são possíveis em suspensões naturais com alta área total projetada pelas partículas na direção do feixe de luz - variável esta que se relacionada mais proximamente com a concentração das partículas situação na qual outras características ópticas das partículas são menos pronunciadas, diminuindo assim o efeito de sua variabilidade na relação entre turbidez e concentração de SST.

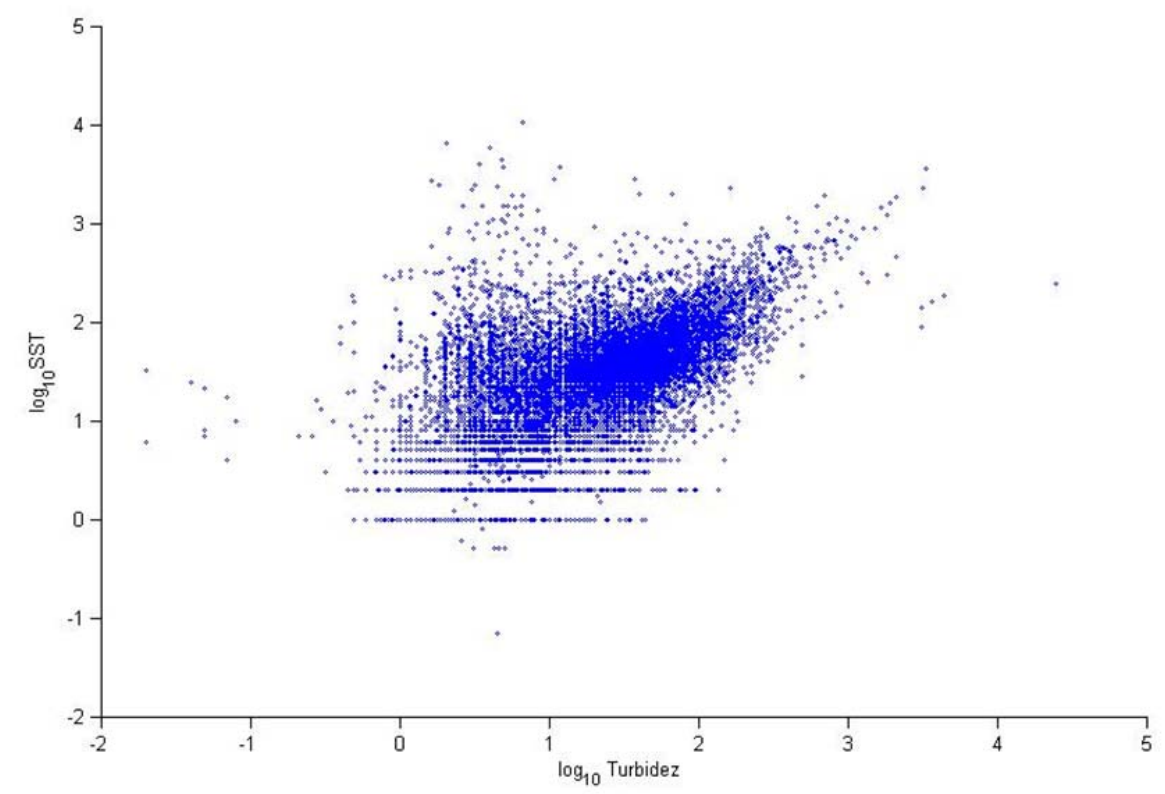

Figura 5.7 - Gráfico de dispersão de todos os pares de valores de turbidez e concentração de SST, na forma logarítmica.

\section{Outros modelos}

$\mathrm{Na}$ busca de respostas, outras covariantes além da turbidez foram investigadas, quais sejam: cor real, vazão (para os pontos próximos a estações fluviométricas), tipo de ambiente aquático (lêntico ou lótico) e mês. Diversos modelos foram avaliados, combinando-se as variáveis entre si e com turbidez, tanto de modo aditivo 
quanto interativo. Apesar de Cornwell (2006) sugerir a exclusão da constante do modelo baseado na exclusivamente na cor, optou-se por considerar uma constante no modelo, pela mesma razão expressa anteriormente na análise de regressão baseada na turbidez.

Em relação à cor, somente 15 dos pontos de monitoramento possuíam mais que 30 medições simultâneas de cor e concentração de SST. Os modelos obtidos apresentaram um ajuste muito inferior ao que se verificou com a turbidez, sendo capazes, no melhor dos casos, de explicar somente cerca de $37 \%$ da variação total da concentração de SST (Tabela 5.3).

Tabela 5.3 - Valores de $\mathbf{R}^{2}$ obtidos para modelos de regressão linear simples baseados na variável cor real.

\begin{tabular}{ccc}
\hline Nome & $\mathrm{n}$ & $\mathrm{R}^{2}$ \\
\hline PARD02500 & 33 & 0,37 \\
PARB02600 & 32 & 0,25 \\
MOGU02100 & 32 & 0,22 \\
PARD02800 & 37 & 0,20 \\
PARB02490 & 32 & 0,12 \\
PARB02310 & 32 & 0,11 \\
MOGU02300 & 43 & 0,09 \\
PARD02600 & 30 & 0,07 \\
MOGU02900 & 34 & 0,07 \\
MOGU02200 & 38 & 0,07 \\
PARB02200 & 32 & 0,02 \\
RPRE02200 & 43 & 0,02 \\
UNNA02800 & 35 & 0,01 \\
TIBT02500 & 45 & 0,01 \\
PADO02600 & 42 & 0,00
\end{tabular}

Dado a interferência que a absorção de luz pela cor exerce sobre medições de turbidez, sua inclusão como variável complementar também foi avaliada. Foram avaliados tanto modelos interativos quanto aditivos. Conforme mostrado na Tabela 5.4, também nesses casos seu efeito é marginal, aumentando desprezivelmente a variância da concentração de SST explicada pelo modelo. 
Tabela 5.4 - Valores do coeficiente de determinação obtidos para diferentes modelos de regressão multilinear envolvendo as variáveis cor real e turbidez.

\begin{tabular}{cccccc} 
& \multicolumn{5}{c}{$\mathbf{R}^{2}$ do modelo } \\
\cline { 2 - 5 } Nome & $\mathbf{1}$ & $\mathbf{2}$ & $\mathbf{3}$ & $\mathbf{4}$ & $\mathbf{n}$ \\
& & & & \\
MOGU02100 & 0,75 & 0,78 & 0,30 & 0,33 & 32 \\
MOGU02200 & $-0,08$ & 0,16 & $-0,34$ & $-0,14$ & 38 \\
MOGU02300 & 0,17 & 0,18 & $-0,20$ & 0,00 & 43 \\
MOGU02900 & $-0,36$ & $-0,33$ & $-1,13$ & 0,06 & 34 \\
PADO02600 & $-0,39$ & $-0,21$ & $-0,69$ & $-0,27$ & 42 \\
PARB02200 & 0,39 & 0,39 & 0,11 & 0,17 & 32 \\
PARB02310 & 0,21 & 0,25 & $-0,06$ & 0,09 & 32 \\
PARB02490 & 0,58 & 0,59 & 0,44 & 0,45 & 32 \\
PARB02600 & 0,54 & 0,56 & 0,18 & 0,42 & 32 \\
PARD02500 & 0,25 & 0,37 & $-0,10$ & 0,22 & 33 \\
PARD02600 & $-0,28$ & $-0,25$ & $-1,12$ & $-0,36$ & 30 \\
PARD02800 & 0,23 & 0,23 & $-0,33$ & 0,10 & 37 \\
RPRE02200 & $-0,26$ & $-0,25$ & $-0,57$ & $-0,27$ & 43 \\
TIBT02500 & $-0,07$ & 0,01 & $-0,14$ & $-0,01$ & 45 \\
UNNA02800 & 0,96 & 0,97 & 0,46 & 0,47 & 35 \\
Nota : Modelo $1-S S T=b_{1} \cdot$ Turbidez $+b_{0}$ \\
modelo $2-S S T=b_{2} \cdot$ Turbidez $+b_{1} \cdot$ Cor $+b_{0}$ \\
modelo $3-S S T=b_{1} \cdot$ Turbidez $\cdot$ Cor $+b_{0}$ \\
modelo $4-S S T=b_{1} \cdot$ Turbidez $\cdot$ Cor $+b_{1} \cdot$ Cor $+b_{0}$
\end{tabular}

Para avaliação do efeito da vazão, foram usados dados pluviométricos de estações operadas pelo Departamento de Águas e Energia Elétrica do Estado de São Paulo (DAEE). Os dados disponíveis com maior resolução temporal em todas as estações consultadas eram de vazão média diária $\left(Q_{\text {med }}\right)$. Dos 8 pontos de monitoramento com estações pluviométricas suficientemente próximas - dentro de um raio de $5 \mathrm{~km}$ - somente 6 possuíam mais de 30 medições de concentração de SST, turbidez e vazão realizadas no mesmo dia. Além da regressão linear simples entre concentração de SST e $Q_{\text {med }}$, foram avaliados modelos aditivos e interativos com a turbidez e vazão média diária como variáveis explicativas. Foram testados modelos das seguintes formas: (i) $S S T=b_{1} \cdot Q+b_{0}$; (ii) $S S T=b_{2} \cdot Q+b_{1} \cdot T u+b_{0}$; (iii) $S S T=b_{1} \cdot Q \cdot T u+b_{0}$; e (iv) $S S T=b_{3} \cdot Q \cdot T u+b_{2} \cdot Q+b_{1} \cdot T u+b_{0}$.

Para a obtenção dos modelos, optou-se por não realizar a detecção e remoção de outliers, uma vez que os desvios considerados anômalos nos modelos dependentes 
exclusivamente da turbidez poderiam ser explicados pela adição da vazão como segunda variável explicativa.

Os respectivos valores de $R^{2}$ são mostrados na Tabela 5.5. Pode-se observar que a adição da vazão média mensal nos modelos de regressão oferece, no melhor dos casos, uma melhora desprezível à sua capacidade de explicar variações na concentração de SST. Apesar de qualitativamente a correlação entre essas duas variáveis ser aparente (Figura 5.8), individualmente, $Q_{\text {med }}$ é um péssimo preditor para a concentração de SST. Isto não é surpreendente pelo fato de que, além de a média não informar a vazão no momento de coleta das amostras de SST, revela muito pouco sobre o hidrograma do corpo d'água - o que é extremamente relevante, dado que a relação entre vazão e concentração de sólidos apresenta histerese.

Tabela 5.5 - Valores de $\mathbf{R}^{2}$ obtidos pelos modelos aditivos e interativos de vazão e turbidez.

\begin{tabular}{ccccccc}
\hline \multirow{2}{*}{ Nome } & \multirow{n}{c}{$\mathrm{n}$} & \multicolumn{5}{c}{$\mathrm{R}^{2}$ obtido pelo modelo } \\
& & 1 & 2 & 3 & 4 & 5 \\
\hline MOGU02900 & 122 & 0,32 & 0,10 & 0,32 & 0,02 & 0,32 \\
ONCA02500 & 139 & 0,42 & 0,34 & 0,43 & 0,00 & 0,43 \\
PARD02500 & 175 & 0,54 & 0,22 & 0,54 & 0,01 & 0,56 \\
PARD02800 & 164 & 0,29 & 0,19 & 0,29 & 0,02 & 0,29 \\
PEIX02100 & 157 & 0,21 & 0,08 & 0,21 & 0,00 & 0,21 \\
RIIG02500 & 82 & 0,41 & 0,29 & 0,42 & 0,08 & 0,43
\end{tabular}

Nota: Modelo $1-S S T=b_{1} \cdot$ Turbidez $+b_{0}$

Modelo $2-S S T=b_{1} \cdot Q+b_{0}$

Modelo $3-S S T=b_{2} \cdot Q+b_{1} \cdot T u+b_{0}$

Modelo $4-S S T=b_{1} \cdot Q \cdot T u+b_{0}$

Modelo $5-S S T=b_{3} \cdot Q \cdot T u+b_{2} \cdot Q+b_{1} \cdot T u+b_{0}$.

O caráter lêntico ou lótico do corpo d'água também aparentemente não afeta a obtenção de melhores modelos de regressão. Conforme mostrado na Tabela 5.6, o modelo linear baseado na turbidez mostrou-se inadequado em todos os pontos de monitoramento localizados em ambientes lênticos com mais de 30 observações. 


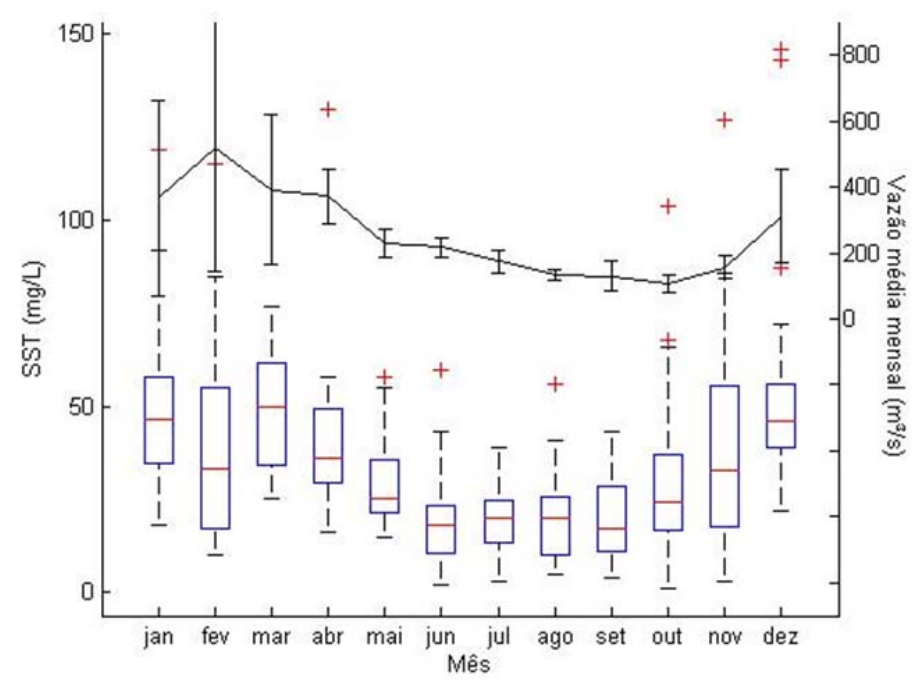

Figura 5.8 - Boxplot da concentração de SST e vazão média mensal do ponto de monitoramento MOGU02900.

Tabela 5.6 - Valores de $R^{2}$ obtidos para o modelo de regressão baseado na turbidez para ambientes lênticos.

\begin{tabular}{lcc}
\multicolumn{1}{c}{ Nome } & $\mathbf{n}$ & $\mathbf{R}^{\mathbf{2}}$ \\
\hline JAGJ00200 & 72 & 0,68 \\
TIPR02400 & 131 & 0,33 \\
CASC02050 & 43 & 0,28 \\
TIRG02900 & 213 & 0,22 \\
GUAR00900 & 195 & 0,12 \\
TIBB02100 & 73 & 0,11 \\
RPRE02200 & 170 & 0,11 \\
CAM000900 & 42 & 0,06 \\
TIBB02700 & 97 & 0,04 \\
TITR02100 & 126 & 0,02 \\
ARPE02800 & 34 & 0,01 \\
TITR02800 & 213 & 0,01 \\
SOIT02100 & 70 & 0,00 \\
SANT00100 & 46 & 0,00 \\
TIBB02900 & 39 & 0,00 \\
JURU02500 & 54 & 0,00 \\
GUAR00100 & 54 & 0,00 \\
SOIT02900 & 69 & 0,00
\end{tabular}

O mês no qual as medições de turbidez e concentração de SST foram feitas foi adicionado ao modelo de turbidez como uma variável categórica, de modo a avaliar 
se a relação entre essas duas variáveis exibe algum tipo de sazonalidade. O modelo adotado foi parcialmente interativo, considerando-se, par a par, as interações entre a turbidez e cada um dos meses, além de uma componente associada somente ao mês. Foram ignorados termos correspondentes a interações entre pares de meses e entre mais de três variáveis. Dessa maneira, conforme indicado pela eq. 18, buscouse identificar se os coeficientes do modelo de regressão linear de turbidez e concentração de SST variam com o mês.

$$
S S T=\left(\sum b_{1, i} \cdot M_{i}\right) \cdot T u+b_{2, i} \cdot M_{i}
$$

Para 54 dos pontos de monitoramento, estimativas dos coeficientes não puderam ser computadas, devido à produção de matrizes de delineamento mal condicionadas pelas 12 variáveis dummy criadas para representar cada um dos meses. Nesses casos, o determinante da matriz foi suficientemente próximo de zero para que o software usado - MATLAB versão 2009a - não conseguisse obter aproximações pelo método dos mínimos quadrados da solução do sistema de equações cujas incógnitas são os coeficientes da regressão.

Para aqueles para os quais a análise de regressão foi possível, esse modelo produziu resultados positivos (Figura 5.9). Em comparação com o modelo unicamente dependente da turbidez, observa-se que, em geral, a capacidade de explicar as variações da concentração de SST aumentou. Em alguns casos, esse aumento foi significativo, indicando que, de fato, a relação entre concentração de SST e turbidez possa mudar em escalas menores de tempo, ciclicamente, provavelmente devido a alterações sazonais na distribuição granulométrica da população de partículas que compõe os sólidos.

Entretanto, mesmo nos casos dos pontos de monitoramento com maior número absoluto de medições, a quantidade de dados mensais é pequena demais - da ordem de, no máximo, uma dezena de pontos - para a identificação conclusiva de alguma tendência sazonal, ou correlação com séries de precipitação ou vazão. A distribuição heterogênea dos dados no intervalo de valores observados, que já distorcia o processo de regressão linear com o conjunto completo de dados de cada 
ponto de monitoramento, é mais prejudicial ainda para subconjuntos substancialmente menores de dados. Tais limitações se manifestam na ocorrência de coeficientes com valores negativos (Tabela 5.7).

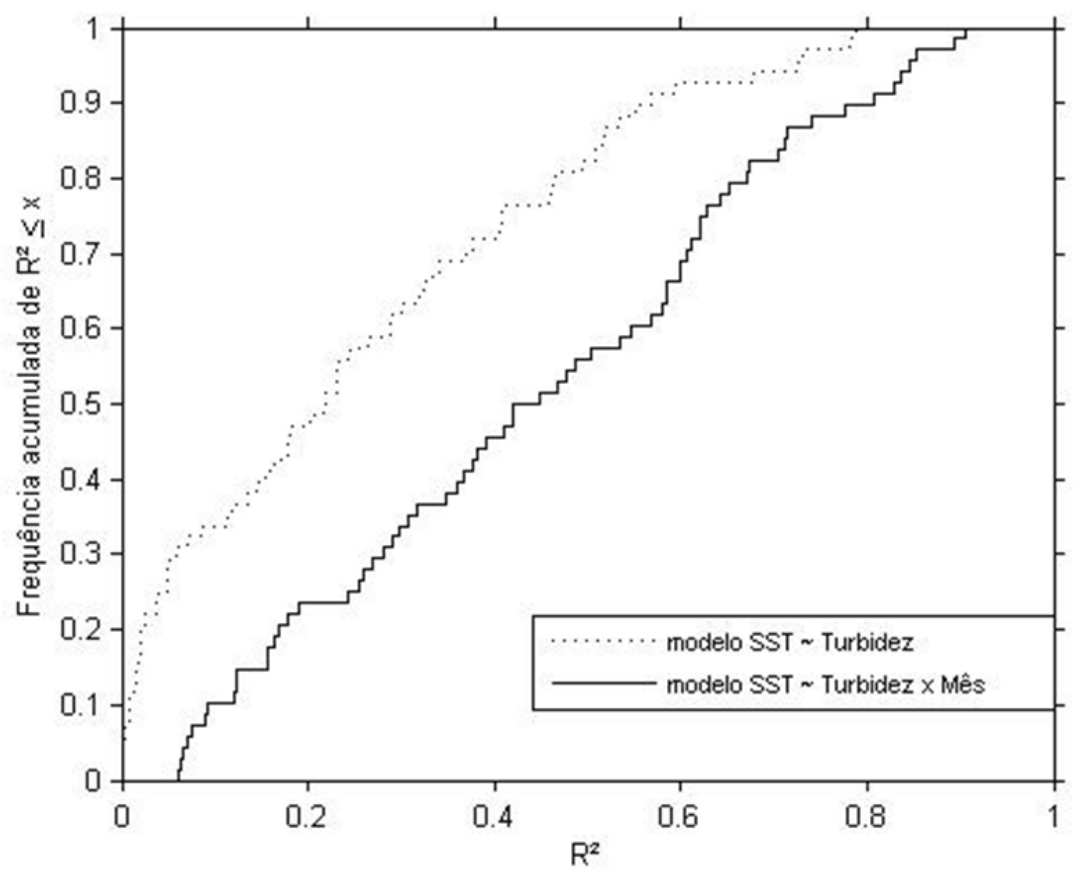

Figura 5.9 - Frequência acumulada de $\mathbf{R}^{2}$ para modelo de regressão simples, baseado na turbidez, e modelo interativo de turbidez e mês. Foram omitidos dados de pontos de monitoramento para os quais o modelo interativo não foi obtido ou retornou valores negativos de $\mathbf{R}^{2}$.

Coletivamente, os resultados apresentados indicam que a obtenção de modelos robustos que permitam a estimativa da concentração de SST a partir de medições de turbidez de modo confiável é extremamente desafiadora, principalmente quando se usam dados secundários não coletados para esse fim.

Tabela 5.7 - Coeficientes dos termos mensais do modelo SST Turbidez $\times$ Mês

\begin{tabular}{lccccccccccccc}
\hline \multicolumn{1}{c}{ Nome } & $\mathrm{n}$ & jan & fev & mar & abr & mai & jun & jul & ago & set & out & nov & dez \\
\hline RIIG02900 & 57 & 1,46 & 0,21 & $-7,13$ & $-1,08$ & 0,64 & 1,04 & 1,55 & 1,43 & 3,27 & 0,15 & 0,06 & $-0,04$ \\
TIBT02100 & 47 & 2,95 & 1,05 & $-0,13$ & $-1,43$ & 1,41 & 0,19 & 0,17 & 2,20 & 1,96 & 0,31 & 7,88 & $-0,14$ \\
BAGR04500 & 152 & 1,80 & 0,28 & 0,15 & 0,87 & 0,96 & 0,73 & 0,70 & $-0,04$ & 1,92 & 0,86 & 1,00 & 0,21 \\
SAPU02400 & 146 & 0,98 & 0,01 & 0,10 & 0,02 & $-0,17$ & 0,07 & 0,61 & 0,05 & 0,64 & 0,46 & 1,83 & 0,11 \\
TIET02350 & 169 & 1,87 & 0,95 & 3,41 & 1,15 & 1,02 & 0,64 & 0,96 & $-0,08$ & 1,08 & 0,01 & 1,72 & 0,80 \\
PEIX02800 & 213 & 2,32 & 0,68 & $-0,38$ & 0,43 & 0,15 & 0,44 & 0,22 & 2,79 & 0,52 & 0,59 & 1,18 & 0,04 \\
STAN02700 & 215 & 0,86 & 0,71 & $-0,13$ & 0,06 & 0,10 & 0,94 & 0,08 & 0,79 & 1,19 & 0,66 & 1,12 & 0,06
\end{tabular}




\subsubsection{Dados das medições realizadas na água bruta das ETAs}

Para as ETAs estudadas, foram avaliados modelos de regressão para a relação entre turbidez e concentração de SST com e sem constante. Apesar de modelos com constante serem, do ponto de vista estatístico - e mesmo físico, conforme discutido anteriormente - mais apropriados, a análise de regressão foi realizada também com modelos sem constante para fins de comparação com o intervalo de valores desses coeficientes reportados por Cornwell (2006) e Di Bernardo e Dantas (2005) para este tipo de modelo..

Tanto modelos com e sem constante foram em geral mal sucedidos, conforme mostrado na Tabela 5.8, especialmente para ETA ALC, para o qual o valor negativo de $R^{2}$ indica que o modelo linear sem constante é absolutamente inadequado. $A$ única exceção é a ETA PPR, que apresentou $R^{2}=0,79$ (modelo sem constante) e 0,81 (modelo com constante). Cabe notar que os níveis distintivamente altos de turbidez verificados na água bruta dessa ETA ao longo da campanha de amostragem, estão dentro do intervalo no qual correlações lineares significativas entre turbidez e concentração de SST são mais prováveis, conforme mostrado na Figura 5.7 .

Observa-se que cada ETA apresenta uma correlação aparentemente diferente entre concentração de SST e turbidez (Figura 5.10). Tal qual com os dados da rede de monitoramento da CETESB, a quantidade de dados por ETA foi insuficiente para a identificação de qual distribuição de probabilidade melhor descreve o resíduo do modelo de regressão, sendo impossível, portanto, a estimativa precisa dos intervalos de confiança dos parâmetros do modelo. A título ilustrativo, foram calculados os intervalos de confiança supondo-se uma distribuição normal e nível de confiança de 95\%, mostrados na Tabela 5.8. Sob essa suposição, observa-se que as distribuições de probabilidade dos coeficientes apresentam sobreposição considerável, o que não é surpreendente dada a dispersão dos dados. Ademais, a largura dos intervalos de confiança sugere que para maior parte das ETAs os valores dos coeficientes do modelo não sejam significativos, o que foi de fato indicado (ainda assumindo a normalidade da distribuição dos dados) pelos altos valores de $p$ obtidos, principalmente para as ETAs ALC e ABV (Tabela 5.9). 

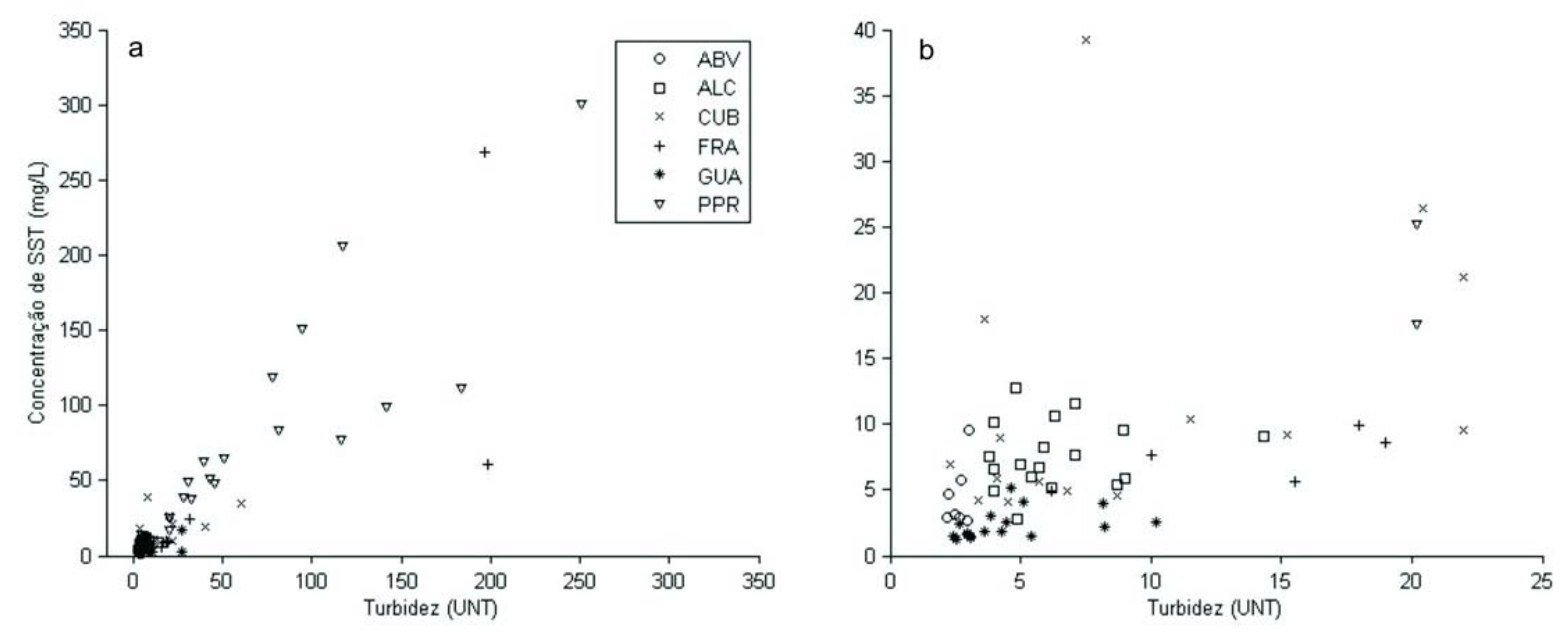

Figura 5.10 - Gráfico de dispersão de concentração de SST e turbidez para medidos nas ETAs (a), e detalhe para o intervalo de turbidez $\leq 25$ UNT (b).

Tabela $5.8-\mathrm{N}^{\circ}$ de medições, coeficiente de determinação, e coeficiente das regressões lineares da forma SST $=b_{1}{ }^{*}$ Turbidez de cada ETA estudada.

\begin{tabular}{|c|c|c|c|c|c|}
\hline \multirow[t]{2}{*}{ ETA } & \multirow[t]{2}{*}{$n$} & \multirow[t]{2}{*}{$\mathrm{R}^{2}$} & \multirow{2}{*}{$b_{1}$} & \multicolumn{2}{|c|}{$\begin{array}{l}\text { intervalo de } \\
\text { conf. }(\alpha=5 \%)\end{array}$} \\
\hline & & & & inferior & superior \\
\hline$A B V$ & 7 & 0,17 & 1,76 & 0,95 & 2,56 \\
\hline ALC & 18 & $-0,99$ & 1,05 & 0,79 & 1,32 \\
\hline CUB & 17 & 0,05 & 0,67 & 0,41 & 0,94 \\
\hline FRA & 8 & 0,62 & 0,83 & 0,36 & 1,30 \\
\hline GUA & 19 & 0,40 & 0,39 & 0,25 & 0,53 \\
\hline PPR & 18 & 0,79 & 1,00 & 0,85 & 1,16 \\
\hline
\end{tabular}

Tabela $5.9-\mathrm{N}^{\circ}$ de medições, coeficiente de determinação, e coeficientes das regressões lineares da forma SST $=b_{1}{ }^{*}$ Turbidez $+b_{0}$ de cada ETA estudada.

\begin{tabular}{|c|c|c|c|c|c|c|c|c|c|c|}
\hline \multirow{2}{*}{ ETA } & \multirow{2}{*}{$\mathrm{n}$} & \multirow{2}{*}{$\mathrm{R}^{2}$} & \multirow{2}{*}{ b1 } & \multicolumn{2}{|c|}{ intervalo de conf. $(\alpha=5 \%)$} & \multirow{2}{*}{$p$} & \multirow{2}{*}{ b0 } & \multicolumn{2}{|c|}{ intervalo de conf. $(\alpha=5 \%)$} & \multirow{2}{*}{$p$} \\
\hline & & & & inferior & superior & & & inferior & superior & \\
\hline ABV & 7 & 0,23 & 3,53 & $-3,97$ & 11,04 & 0,51 & $-4,69$ & $-24,37$ & 14,99 & 0,73 \\
\hline ALC & 18 & 0,02 & 0,13 & $-0,39$ & 0,65 & 0,81 & 6,82 & 3,25 & 10,40 & 0,01 \\
\hline CUB & 17 & 0,33 & 0,41 & 0,09 & 0,73 & 0,02 & 7,84 & 1,22 & 14,46 & 0,02 \\
\hline FRA & 8 & 0,62 & 0,85 & 0,19 & 1,52 & 0,03 & $-3,86$ & $-70,21$ & 62,49 & 0,42 \\
\hline GUA & 19 & 0,43 & 0,33 & 0,13 & 0,52 & 0,01 & 0,88 & $-1,02$ & 2,79 & 0,46 \\
\hline PPR & 18 & 0,81 & 0,90 & 0,66 & 1,13 & $1,18 \mathrm{E}-06$ & 17,64 & $-11,61$ & 46,88 & 0,24 \\
\hline
\end{tabular}

Avaliou-se ainda a possibilidade das demais variáveis (cor e COT) servirem de preditores para a concentração de SST, tanto individualmente quanto em 
combinação entre si e com a turbidez. Novamente, foram aplicados aqui somente modelos de regressão com constante.

Da mesma maneira pela qual se procedeu na análise dos dados da CETESB, a variável cor foi combinada aditivamente $\left(S S T=b_{2} \cdot\right.$ Turbidez $\left.+b_{1} \cdot \operatorname{Cor}+b_{0}\right)$ e interativamente $\left(S S T=b_{1} \cdot\right.$ Turbidez $\left.\cdot \operatorname{Cor}+b_{0}\right)$ com a turbidez, de modo a avaliar se a cor das amostras exerceu algum grau de interferência nas medições de turbidez. Os coeficientes de determinação obtidos são apresentados na Tabela 5.10.

Tabela 5.10 - $\mathrm{N}^{\circ}$ de medições e coeficientes de determinação obtidos para modelos de regressão linear da concentração de SST em função das varáveis cor real e COT, e para modelos interativo e aditivo dependentes de tanto turbidez e quanto cor. Coeficientes para modelo baseado na turbidez e mostrado para comparação.

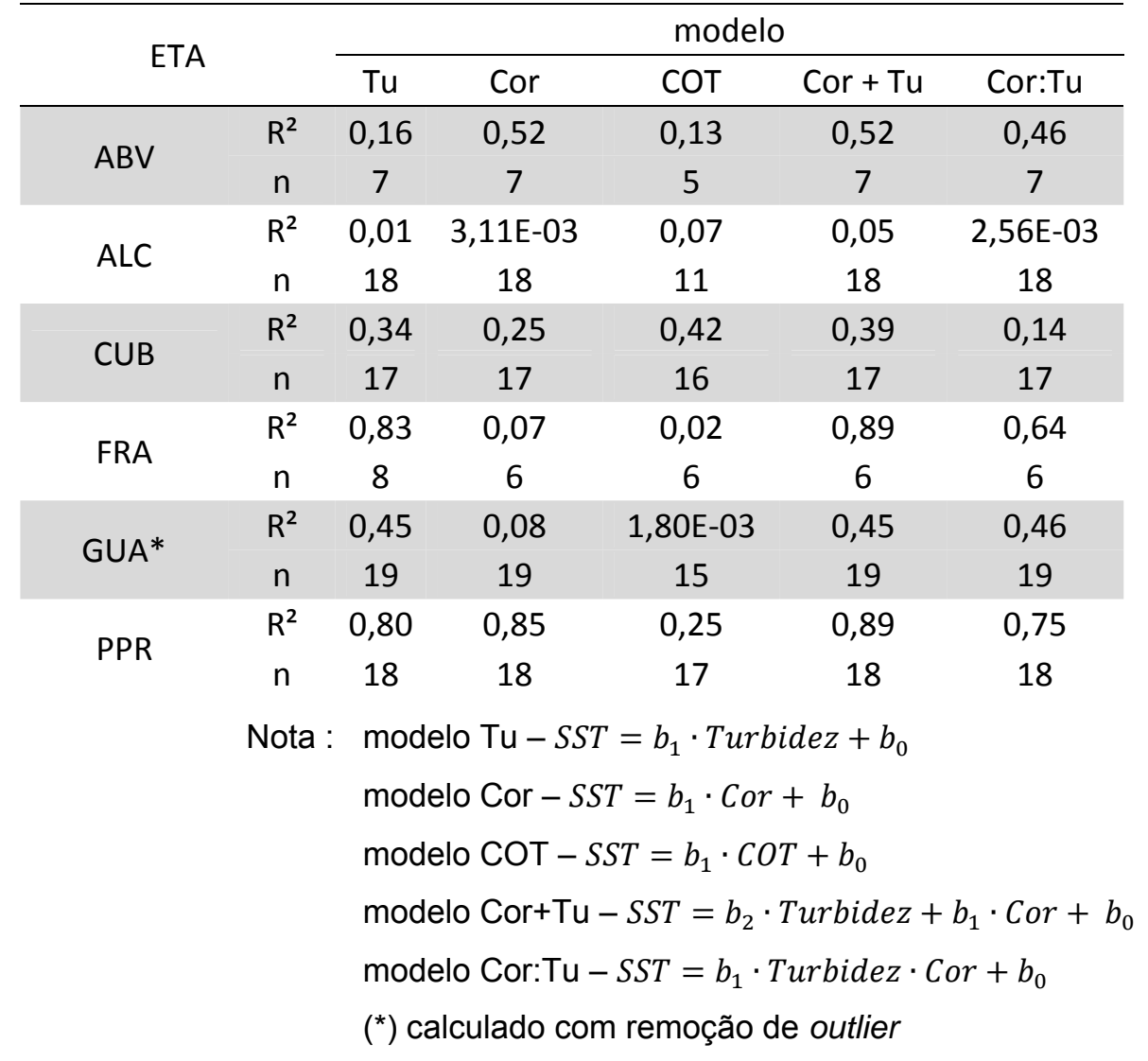

Em geral, o modelo dependente da cor não foi adequado aos dados das diferentes ETAs, com somente as ETAs GUA e PPR apresentando inicialmente valores de $\mathrm{R}^{2}$ superiores a 0,8 (Tabela 5.10 e Figura 5.11). No caso da ETA GUA, o valor de $\mathrm{R}^{2}$ calculado é substancialmente aumentado pelo ponto marcado na Figura 5.1(c), alcançando valor de 0,95; quando removido esse ponto, esse valor é reduzido a 
0,08. Para a ETA PPR, além do modelo baseado na cor ser capaz de explicar uma proporção maior da variação da concentração de SST do aquele dependente da turbidez, seu coeficiente possui um intervalo de confiança sutilmente mais estreito (Tabela 5.11).

Tabela $5.11-\mathrm{N}^{\circ}$ de medições, coeficiente de determinação, e coeficientes das regressões lineares SST $=b_{1}{ }^{*}$ Cor $+b_{0}$ de cada ETA estudada.

\begin{tabular}{|c|c|c|c|c|c|c|c|}
\hline \multirow{2}{*}{ ETA } & \multicolumn{2}{|c|}{ intervalo de conf.( $\alpha=5 \%)$} & \multirow{2}{*}{ Valor $\mathrm{p}$} & \multirow{2}{*}{$\mathrm{b}$} & \multicolumn{2}{|c|}{ intervalo de conf. $(\alpha=5 \%)$} & \multirow{2}{*}{ Valor $p$} \\
\hline & inferior & superior & & & inferior & superior & \\
\hline$A B V$ & $-0,20$ & 0,26 & 0,17 & 3,70 & $-3,22$ & 10,61 & 0,41 \\
\hline ALC & $-0,07$ & 0,07 & 0,87 & 7,74 & 3,25 & 12,22 & 0,03 \\
\hline CUB & $3,06 \mathrm{E}-03$ & 0,17 & 0,05 & 7,51 & $-0,34$ & 15,35 & 0,06 \\
\hline FRA & $-0,29$ & 0,47 & 0,66 & 5,51 & $-16,10$ & 27,13 & 0,60 \\
\hline GUA & $-0,93$ & 3,05 & 0,27 & $-0,69$ & $-0,04$ & 0,18 & 0,18 \\
\hline PPR & 0,10 & 0,16 & $1,36 \mathrm{E}-07$ & 7,00 & $-19,72$ & 33,71 & 0,60 \\
\hline
\end{tabular}

$\left(^{*}\right)$ calculado com remoção de possível outlier
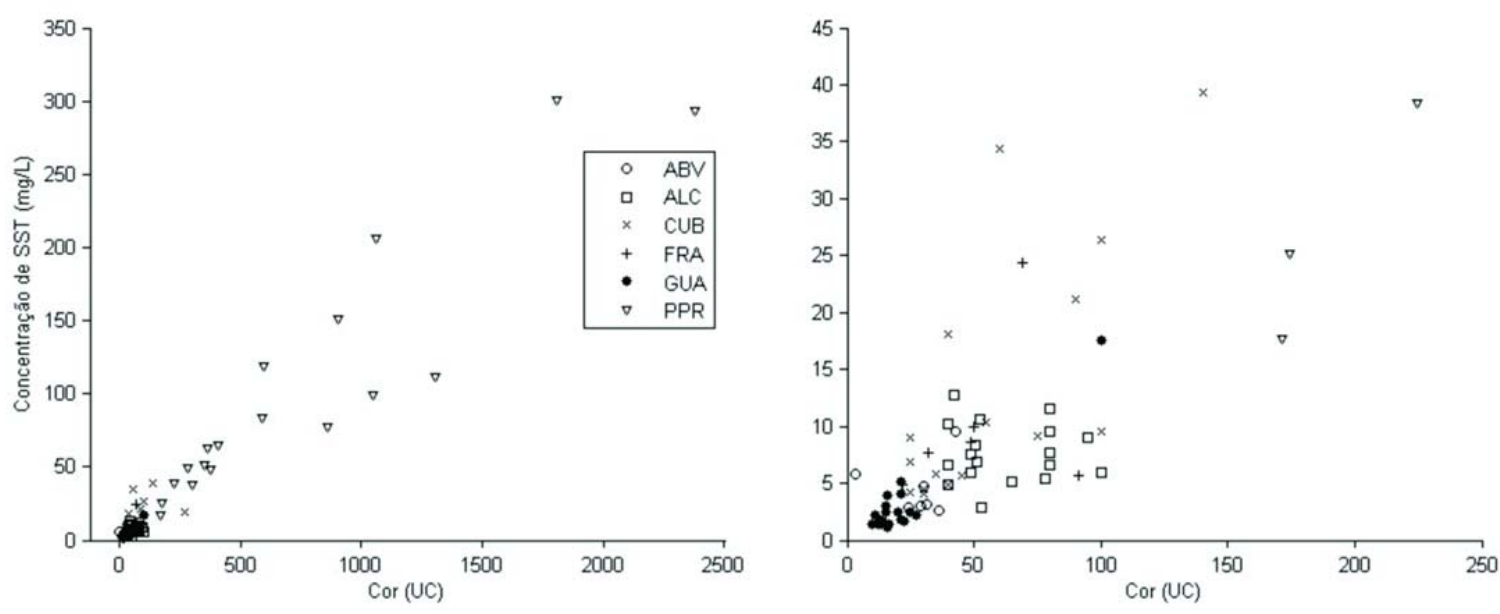

Figura 5.11 - Gráfico de dispersão de concentração de SST e cor para medidos nas ETAs (a), e detalhe para o intervalo de cor $\leq 250 \mathrm{UC}(\mathrm{b})$. 


\subsection{Balanço de massa e fórmulas empíricas}

A comparação entre a produção total de lodo obtida pela realização de balanço de massa e aquela estimada pela fórmula empírica elaborada pela AWWA (1999) para cada ETA é mostrada nas Figuras 5.13 a 5.17; os dados brutos podem ser encontrados no Anexos A e B. A ETA ABV foi excluída dessa etapa de análise devido ao pequeno número de medições de concentração de sólidos nas águas coagulada e floculada, essenciais para a realização do balanço de massa.

Devido à má qualidade das correlações entre concentração de SST e turbidez obtidas para as ETAs, optou-se por aplicar nas fórmulas empíricas as concentrações de SST efetivamente medidas nas respectivas águas brutas.

Durante a realização dos balanços de massa, verificou-se que em todas as ETAs, esporadicamente, ocorre acúmulo de sólidos nas unidades de floculação, observação prontamente confirmada por relatos das equipes operacionais das estações. Como em grande maioria dos casos a diferença entre as concentrações de SST da água floculada e coagulada indicou que a massa acumulada diariamente poderia ser substancial, esse lodo foi incluído no cômputo da produção diária de sólidos, junto com aqueles oriundos dos decantadores e filtros. Ressalta-se assim a importância da amostragem de água floculada para a realização de balanço massa, principalmente devido à prática comum de desligamento dos floculadores por parte dos operadores das ETAs.

A análise visual dos gráficos de dispersão sugere que há algum grau de concordância entre a produção de lodo medida por balanço de massa e aquela estimada pela fórmula empírica (Figuras 5.13 a 5.17, gráfico B), com a última sendo capaz de explicar boa parte da variância da produção de lodo medida (com exceção da ETA GUA, caso esse discutido adiante).

Contudo, em termos porcentuais, desvios substanciais foram obtidos (Tabela 5.12). Não foi encontrada uma tendência universal para esses desvios. Nas ETAs PPR e FRA, a fórmula empírica em geral superestimou a produção de lodo; nessa ETA, a mediana dos desvios (em relação à geração de sólidos medida) atingiu 129\%. $\mathrm{Na}$ ETA PPR, o desempenho da fórmula empírica foi substancialmente melhor, com a 
mediana dos desvios na ordem de $11 \%$. Para a ETA FRA - a única a utilizar cloreto férrico no período estudado -- uma possível explicação para a superestimação por parte da fórmula empírica diz respeito à quantidade de moléculas de água ligadas aos precipitados de hidróxido de ferro. Conforme mostrado na Figura 5.12, a alteração do número especificado de moléculas de água ligadas afeta substancialmente a estimativa da fórmula empírica. Entretanto, mesmo adotando a suposição não realística de que as moléculas de hidróxidos de ferro não possuem nenhuma molécula de água fisicamente adsorvida a sua superfície, ainda se obtém valores de produção de lodo em geral superestimadas, com mediana dos desvios igual a aproximadamente $58 \%$. Outra possibilidade é de que o cloreto férrico utilizado pela estação à época (fornecido na forma líquida) estivesse fora de especificação, com concentrações inferiores às nominais - o que levaria à superestimação das doses e, consequentemente, da produção de lodo calculada pela fórmula.

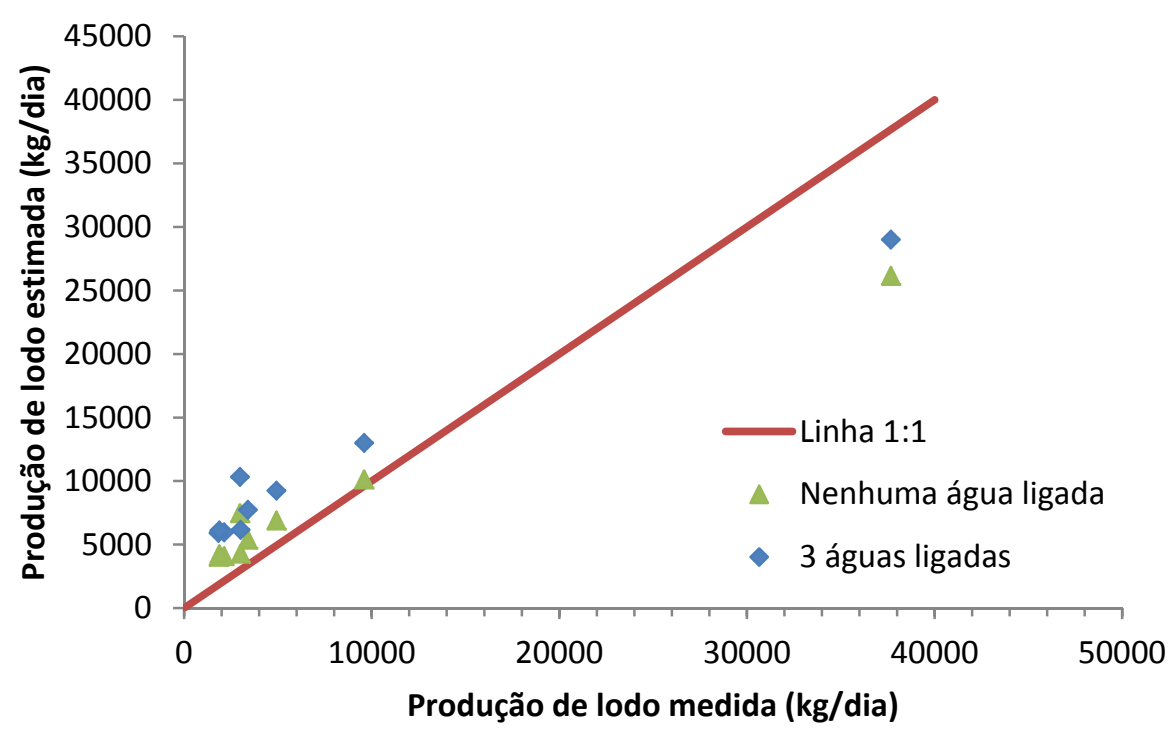

Figura 5.12 - Comparação da produção de lodo estimada pela fórmula empírica da AWWA (1999) para a ETA FRA supondo-se três ou nenhuma água ligada aos precipitados de $\mathrm{Fe}(\mathrm{OH})_{3}$.

Para as demais ETAs (ALC, CUB e GUA), a fórmula empírica proveu, em geral, subestimativas da produção de lodo (Tabela 5.12). Em particular, a ETA GUA se destaca das demais por se desviar sistematicamente das previsões da fórmula 
empírica, com o erro de estimativa aumentando concomitantemente com a produção de lodo estimada. A análise de regressão linear revelou, por meio de um modelo sem constante de ajuste excelente $\left(R^{2}=0,89\right)$, que a fórmula empírica dá conta de só aproximadamente $53 \%$ dos sólidos produzidos pela ETA (fração correspondente ao valor da constante do modelo). Tabela 5.12 - Estatísticas dos desvios da produção de lodo medida em relação à produção
estimada pela fórmula empírica.

\begin{tabular}{lcccccc} 
ETA & ALC & CUB & FRA & GUA & PPR & Geral \\
\hline mediana & 16,96 & 53,33 & $-55,96$ & 93,68 & $-6,43$ & 10,11 \\
mínimo & $-29,93$ & $-48,60$ & $-71,10$ & 33,69 & $-27,85$ & $-71,10$ \\
máximo & 84,98 & 211,68 & 29,86 & 158,97 & 130,45 & 211,68 \\
média & 19,74 & 64,09 & $-47,03$ & 97,79 & 0,49 & 14,72 \\
desv. padrão & 26,83 & 72,62 & 32,18 & 37,39 & 37,06 & 13,10
\end{tabular}

Muito provavelmente, isso pode ser atribuído a dois aspectos em relação aos quais a água bruta da ETA GUA se distingue das demais. Conforme mostrado na Figura 5.18, observou-se que nessa ETA os sólidos dissolvidos (SD) responderam por uma fração comparativamente alta dos sólidos totais, e que essa fração permaneceu essencialmente constante - resultando, consequentemente, em uma razão aproximadamente fixa entre concentração de SST e SD.

A fórmula empírica da AWWA (1999) não possui nenhum termo que contabilize diretamente os sólidos dissolvidos; apesar de passíveis de coagulação (como no caso de remoção de cor ou de compostos orgânicos precursores de produtos de desinfecção), assume-se que componham uma fração desprezível da massa de hidróxidos metálicos precipitados pelo mecanismo de varredura. Contudo, deve ser notado que neste trabalho membranas de 1,2 $\mu \mathrm{m}$ foram utilizadas na determinação da concentração de SST e que, portanto, partículas coloidais - que são o objeto natural da coagulação - eventualmente presentes nas amostras foram mensuradas como SD. 



\section{ETA Alto de Cotia}

A

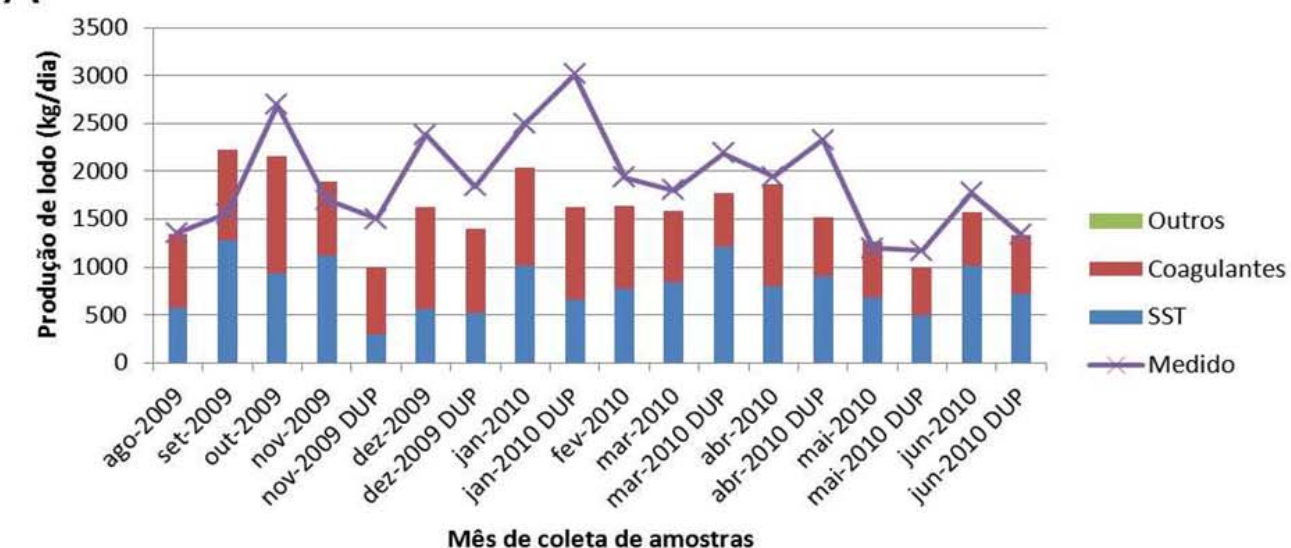

D

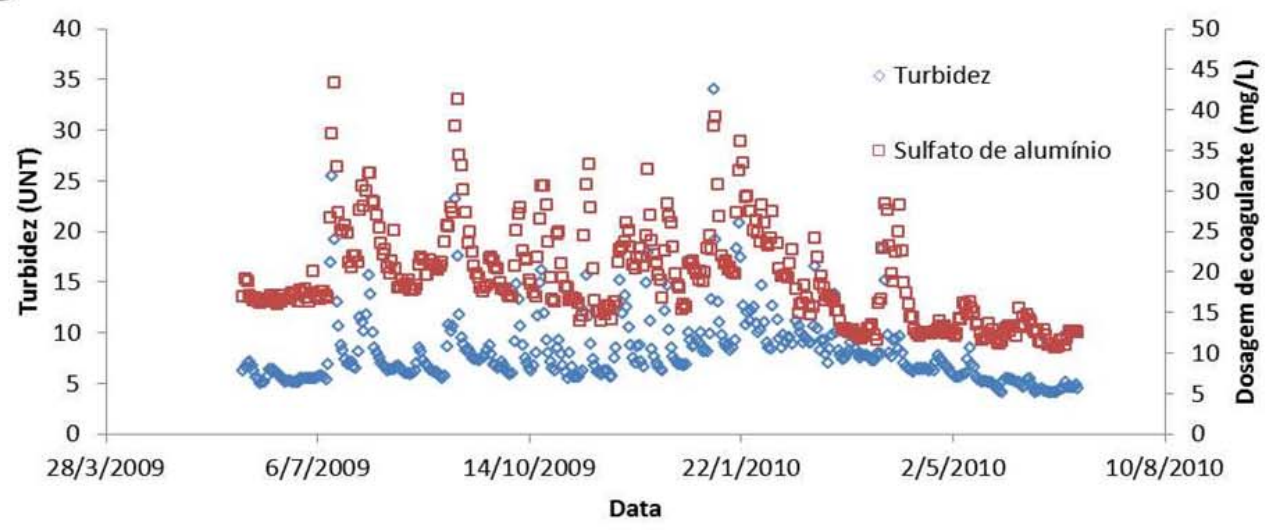

B

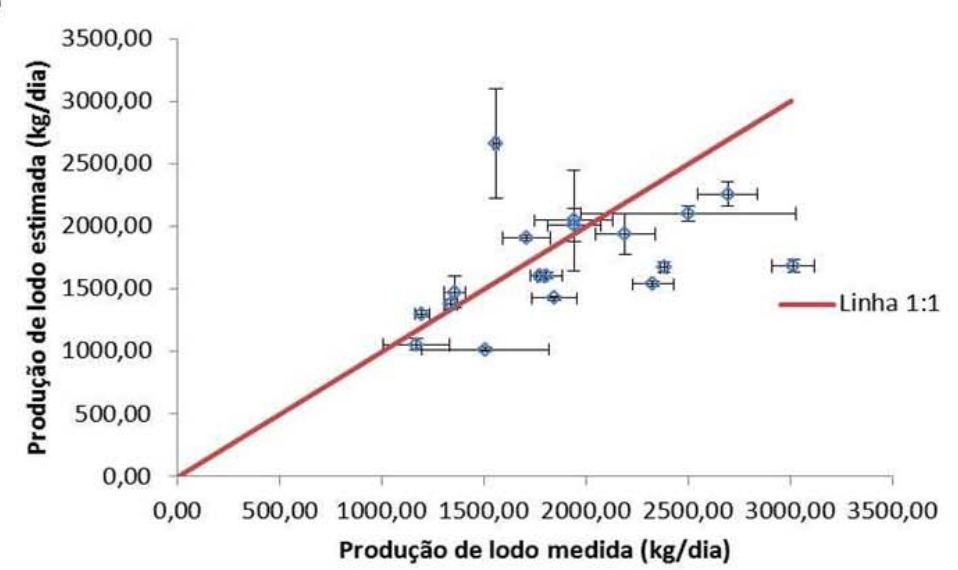

C

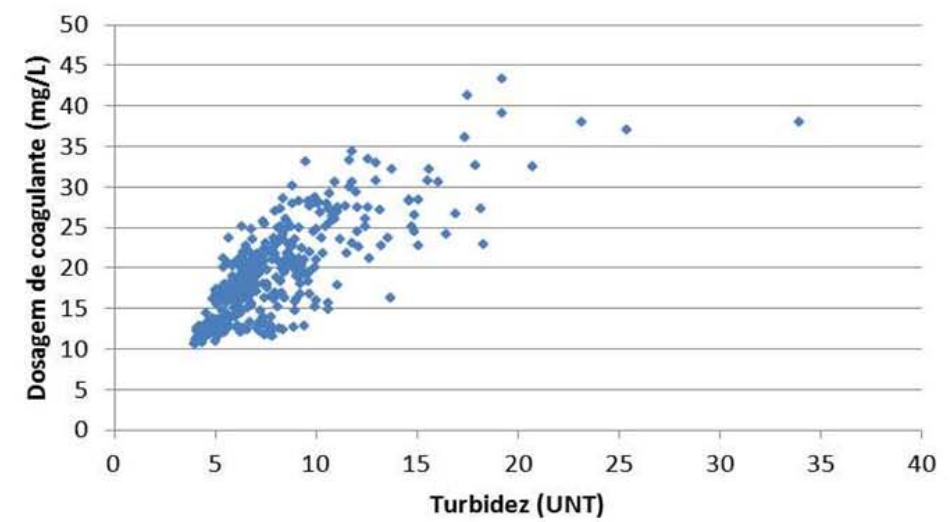

Figura 5.13 - Para a ETA ALC: (A) Comparação entre produção de lodo obtida por balanço de massa e pela aplicação da fórmula empírica da AWWA (1999); (B) gráfico de dispersão de produção de lodo medida (pelo balanço de massa) e estimada (pela fórmula empírica) - barras de erros correspondem a um desvio padrão; (C) Gráfico de dispersão de turbidez e dosagem de coagulante; (D) Série temporal de medições de turbidez e dosagem de coagulante. 


\section{ETA Cubatão}

A

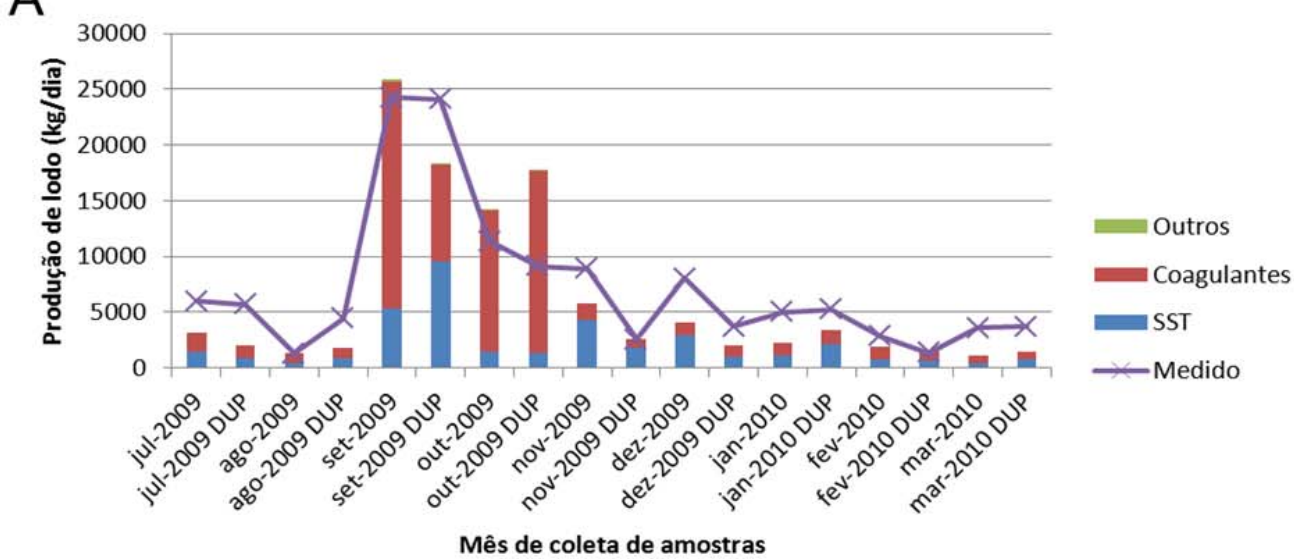

D

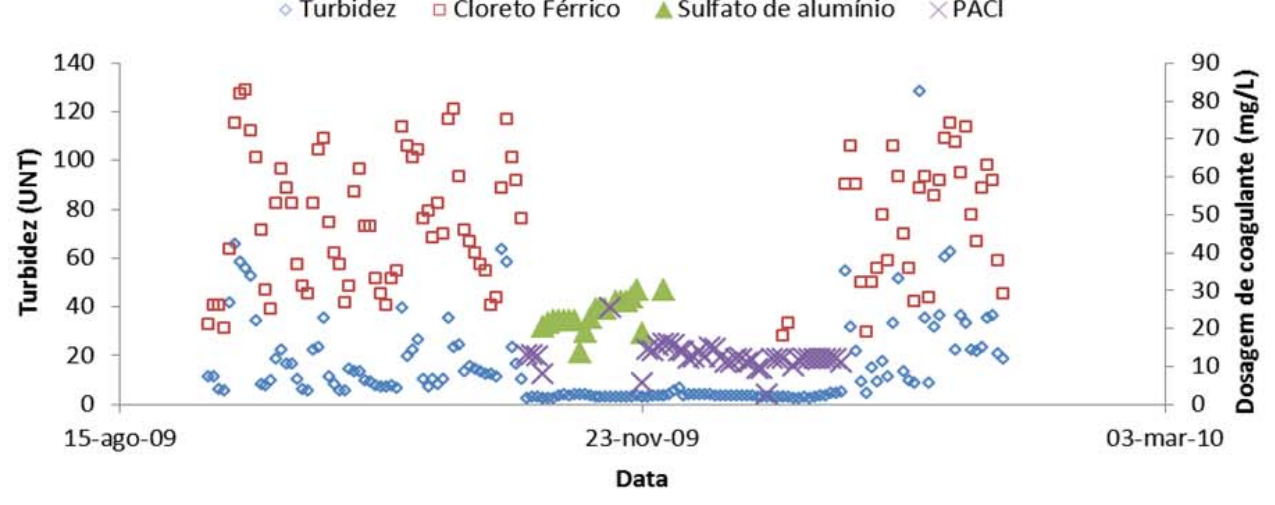

B

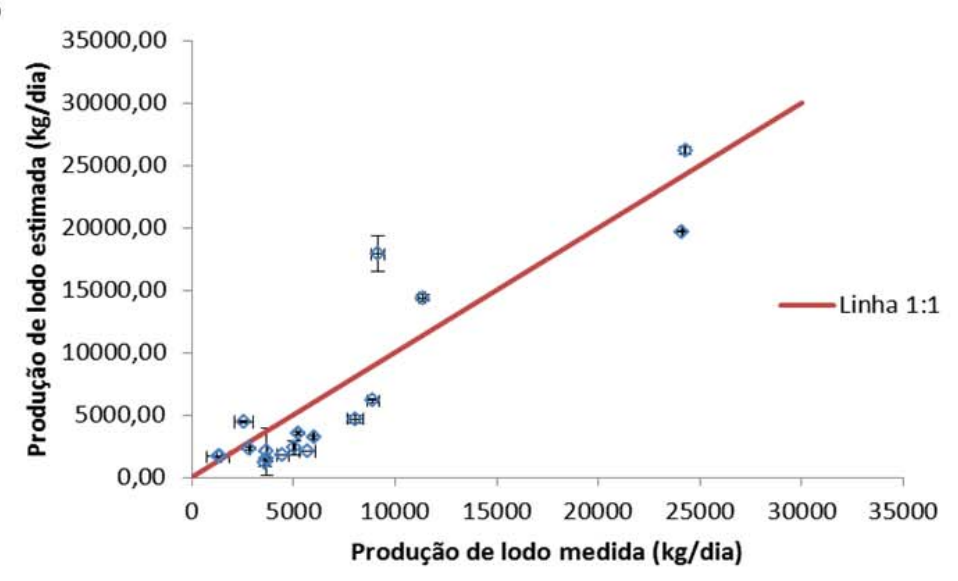

C

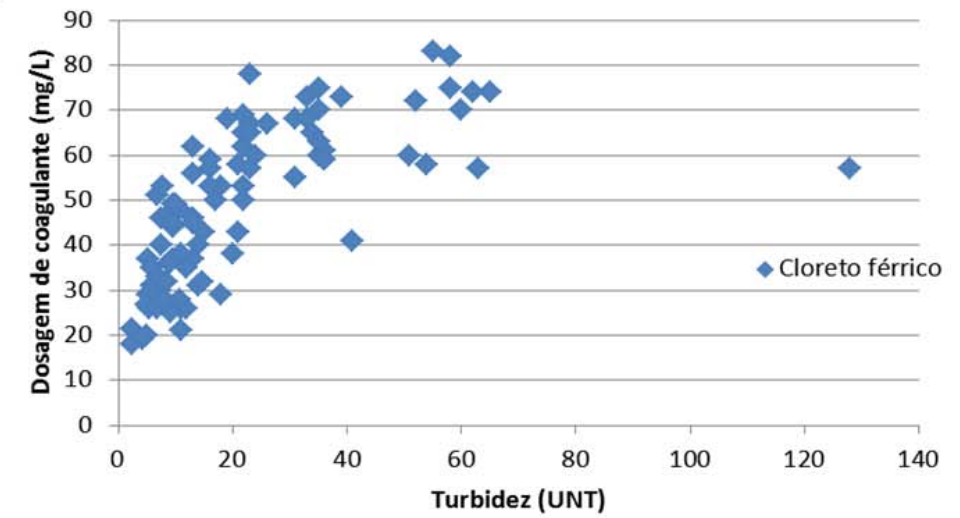

Figura 5.14- Para a ETA CUB: (A) Comparação entre produção de lodo obtida por balanço de massa e pela aplicação da fórmula empírica da AWWA (1999); (B) gráfico de dispersão de produção de lodo medida (pelo balanço de massa) e estimada (pela fórmula empírica) - barras de erros correspondem a um desvio padrão; (C) Gráfico de dispersão de turbidez e dosagem de coagulante; (D) Série temporal de medições de turbidez e dosagem de coagulante. 


\section{ETA Franca}

A

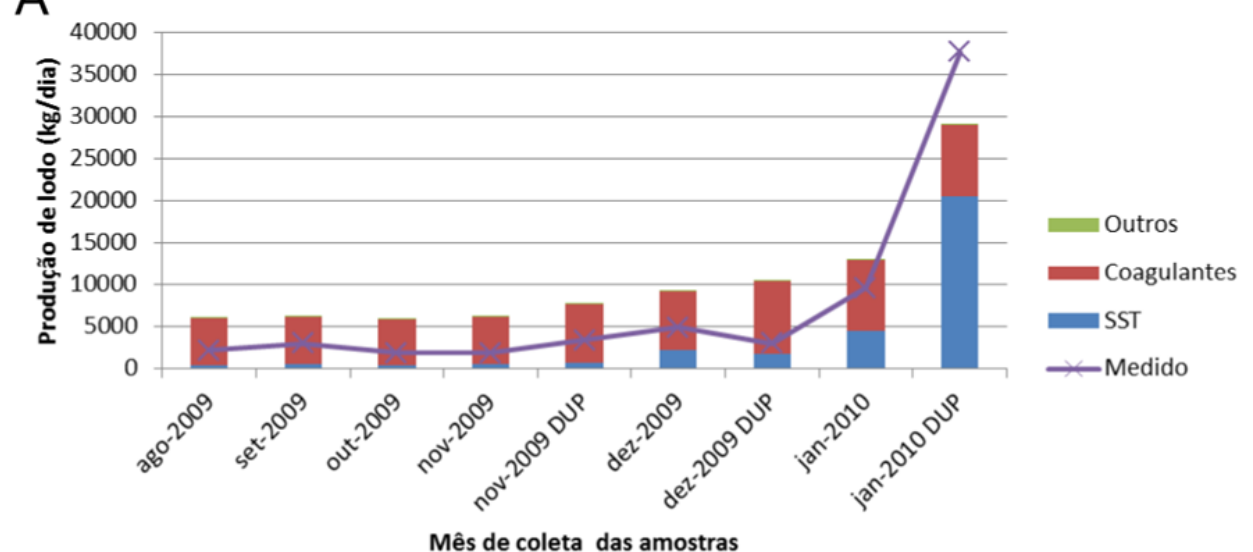

D

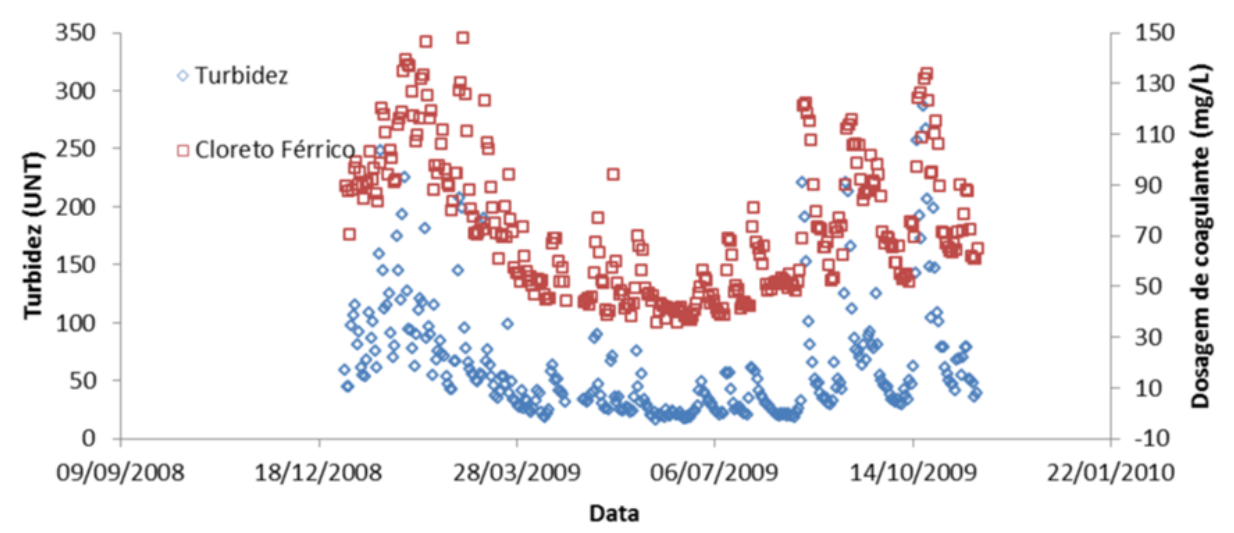

B

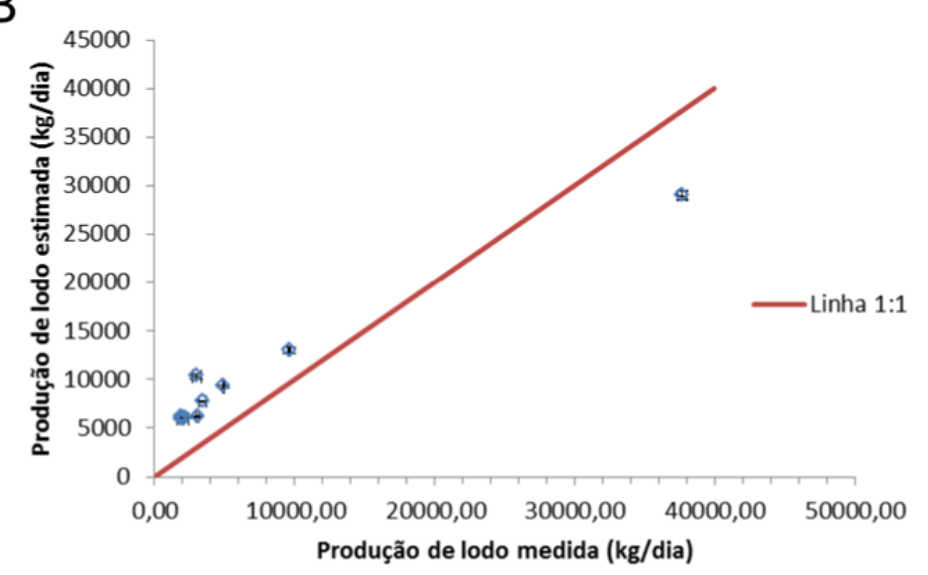

C

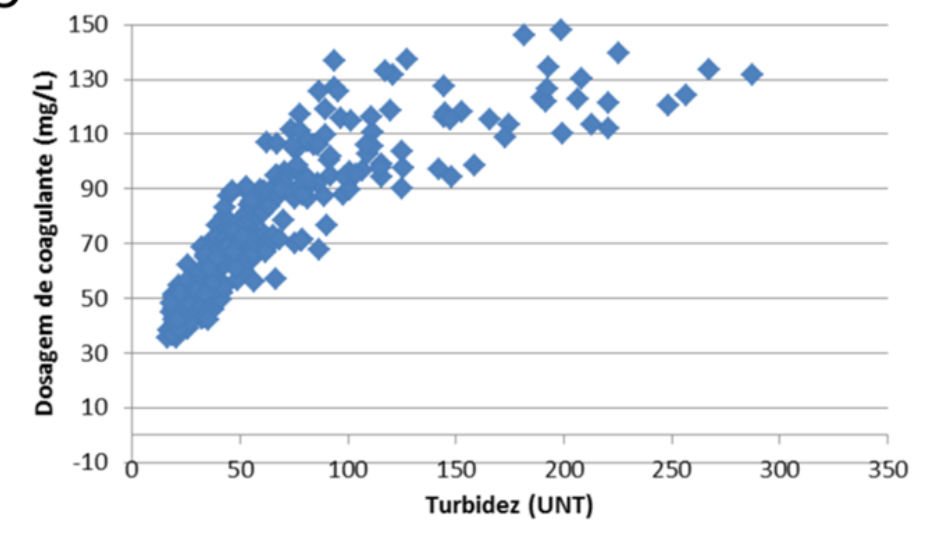

Figura 5.15 - Para a ETA FRA: (A) Comparação entre produção de lodo obtida por balanço de massa e pela aplicação da fórmula empírica da AWWA (1999); (B) gráfico de dispersão de produção de lodo medida (pelo balanço de massa) e estimada (pela fórmula empírica) - barras de erros correspondem a um desvio padrão; (C) Gráfico de dispersão de turbidez e dosagem de coagulante; (D) Série temporal de medições de turbidez e dosagem de coagulante. 


\section{ETA Guaraú}

A

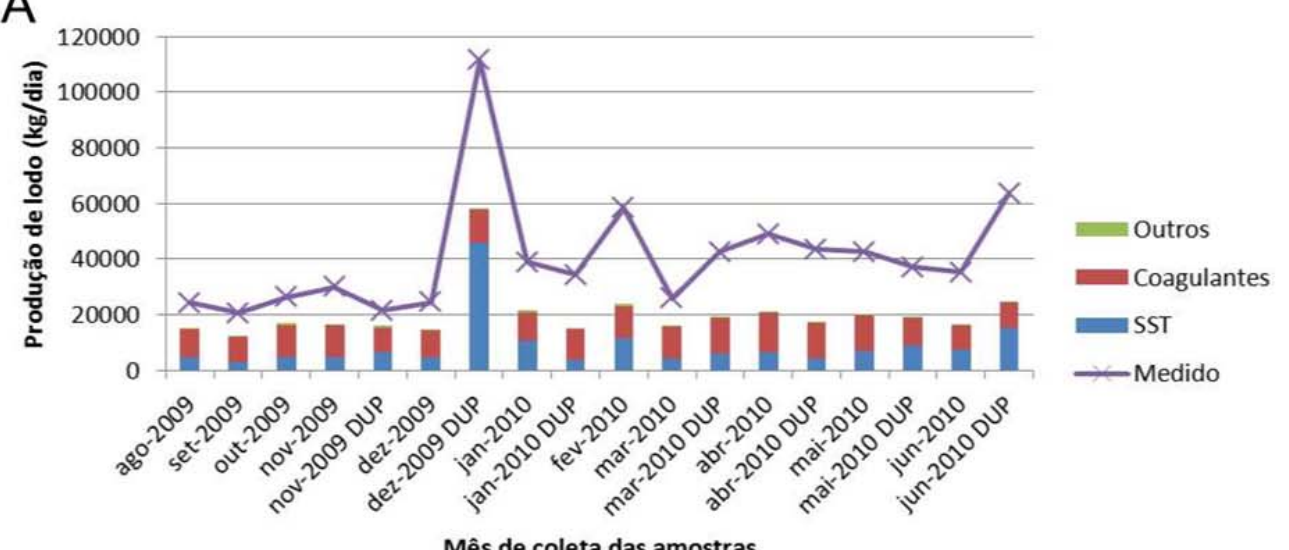

D

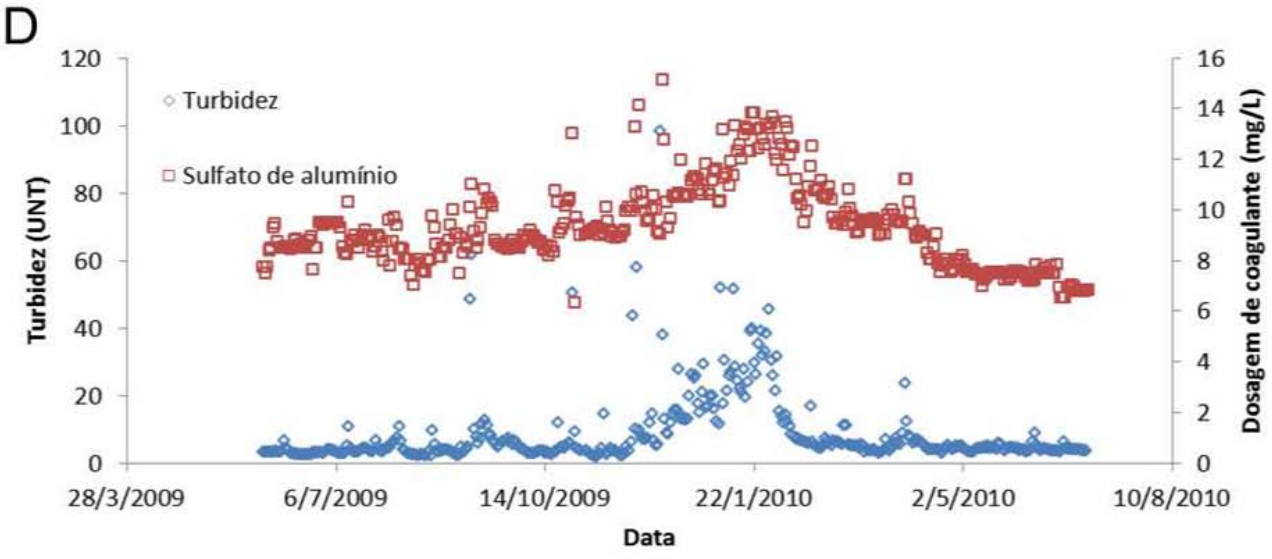

B

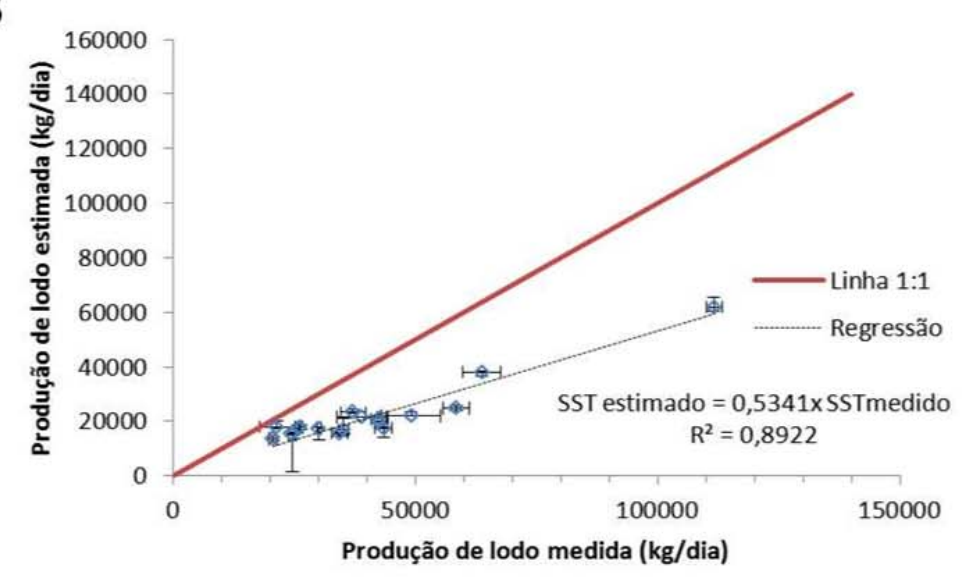

C

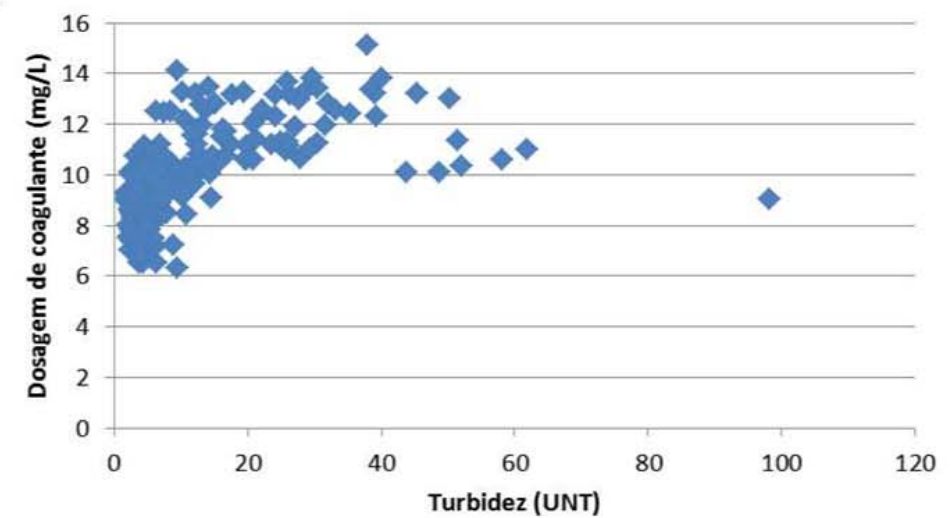

Figura 5.16 - Para a ETA GUA: (A) Comparação entre produção de lodo obtida por balanço de massa e pela aplicação da fórmula empírica da AWWA (1999); (B) gráfico de dispersão de produção de lodo medida (pelo balanço de massa) e estimada (pela fórmula empírica) - barras de erros correspondem a um desvio padrão; (C) Gráfico de dispersão de turbidez e dosagem de coagulante; (D) Série temporal de medições de turbidez e dosagem de coagulante. 


\section{ETA Presidente Prudente}

A

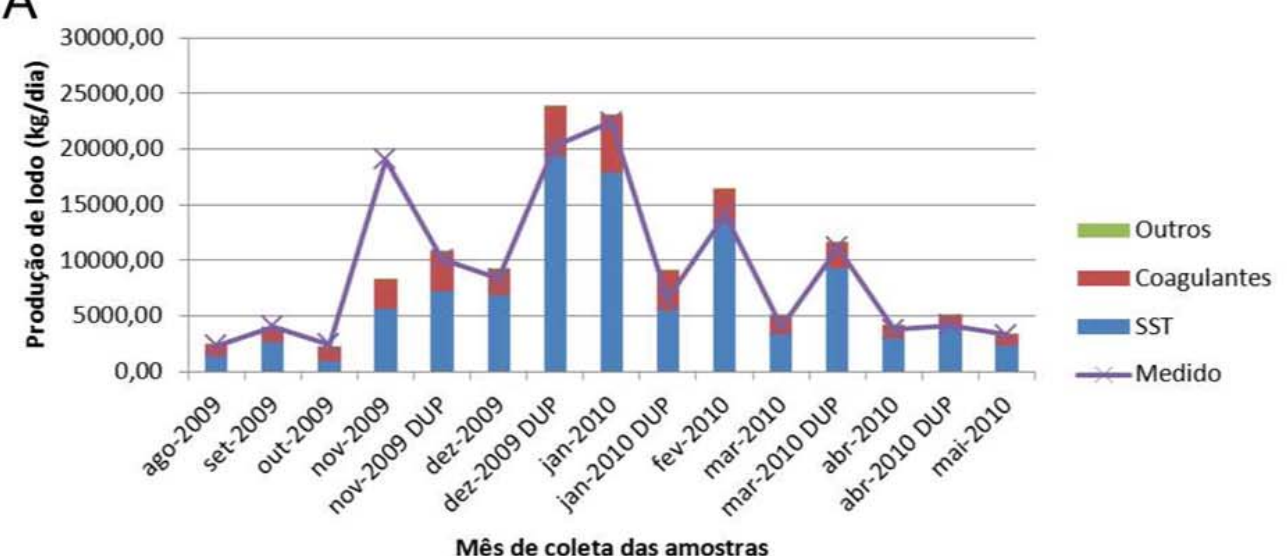

D

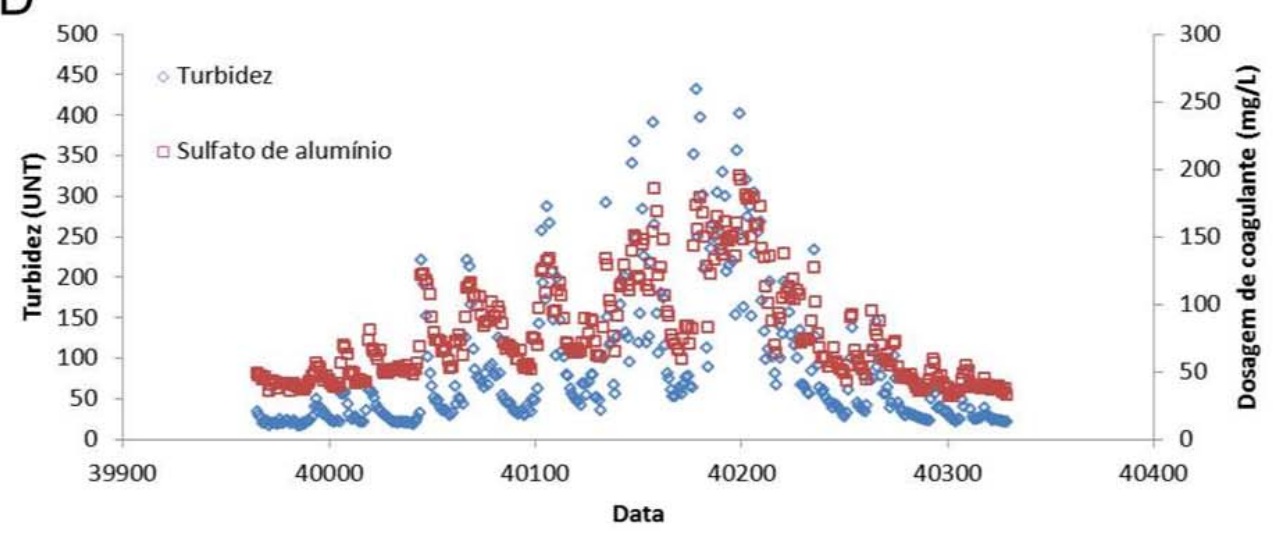

B

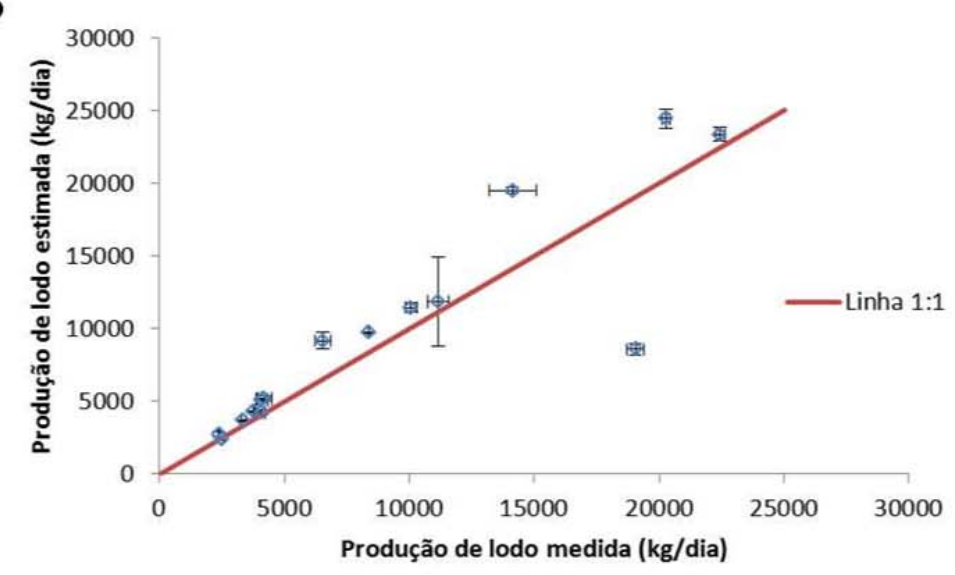

C

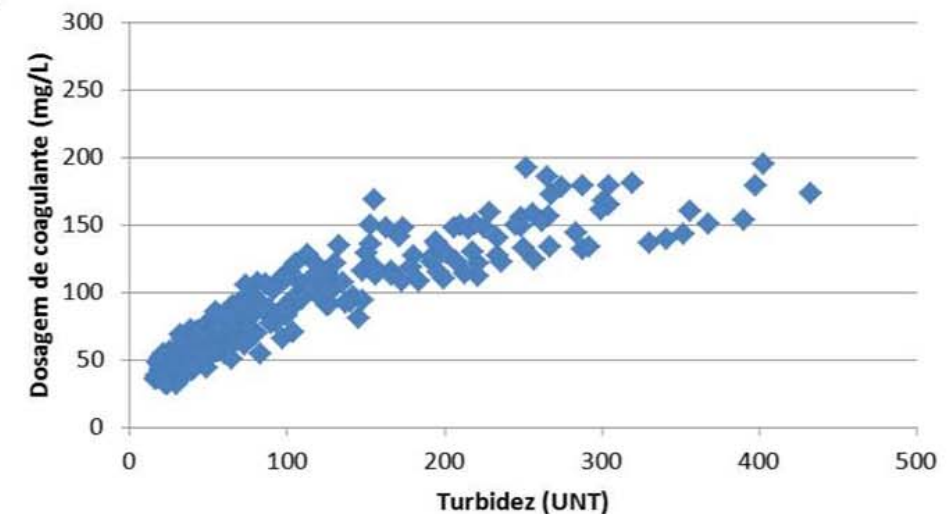

Figura 5.17 - Para a ETA PPR: (A) Comparação entre produção de lodo obtida por balanço de massa e pela aplicação da fórmula empírica da AWWA (1999); (B) gráfico de dispersão de produção de lodo medida (pelo balanço de massa) e estimada (pela fórmula empírica) - barras de erros correspondem a um desvio padrão; (C) Gráfico de dispersão de turbidez e dosagem de coagulante; (D) Série temporal de medições de turbidez e dosagem de coagulante. 
Desse modo, se uma fração considerável dos sólidos dissolvidos na ETA GUA corresponder a coloides, a fórmula empírica evidentemente subestimará a produção de lodo, e o fará de maneira sistemática se a participação de colóides nos sólidos totais for consistentemente alta. Cornwell (2006) aponta que, em águas com alta concentração de carbono orgânico dissolvido, pode ser necessária a inclusão de um termo adicional em fórmulas empíricas.

Comparando-se a relação SD/SST da água bruta (Figura 5.18) com o fator $1-S S T_{\text {estimado }} / S S T_{\text {medido }}$ - que equivaleria à massa de lodo associada aos coloides medidos com SD (Figura 5.16, B) - obtém-se que aproximadamente 4\% da massa de SD é incorporada ao lodo gerado na ETA.

Esses mesmos fatores podem ser responsáveis pela subestimação da produção de lodo nas ETAs CUB e ALC, nas quais os SD também correspondem à boa parte da concentração de sólidos totais. Nesses casos, o efeito dos coloides na fração dissolvida dos sólidos não se expressou tão claramente devido à variação mais randômica da razão entre as concentrações de SD e SST (Figura 5.18).

Um segundo fator que pode levar a subestimação é a presença de impurezas nos insumos das ETAs.

Mesmo que os resultados reunidos aqui sejam insuficientes para que novas variáveis possam ser inseridas de maneira apropriada na fórmula empírica, qualitativamente ignorar os fatores mencionados até agora e tratá-los simplesmente como componentes de erro aleatórios podem levar a estimativas excessivamente grosseiras da produção de lodo de uma ETA. 

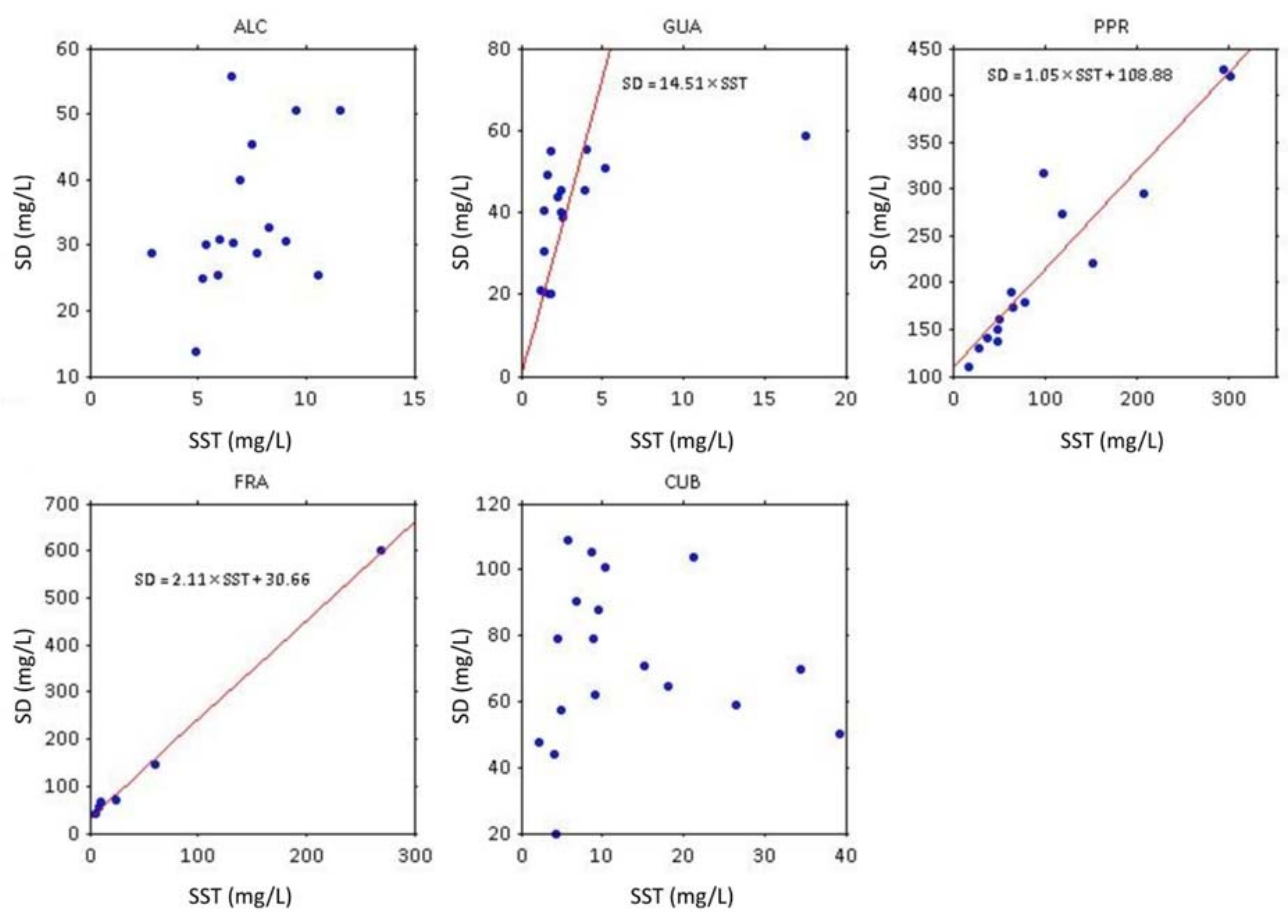

Figura 5.18 - Gráfico de dispersão das concentrações de SST e SD na água bruta das diversas ETAs.

O potencial de erro pode ser avaliado do ponto de vista estatístico por meio de intervalos de confiança, tratando a relação entre a produção de lodo medida e aquela estimada pela fórmula empírica de maneira análoga a um modelo de regressão linear simples (sem constante, com valor médio do coeficiente é igual a 1). De fato, através de análise de regressão linear (excluindo-se os dados relativos à ETA GUA) obteve-se coeficiente igual a $0,92\left(R^{2}=0,8\right)$, sugerindo que essas hipóteses são aceitáveis.

Os dados da ETA GUA foram excluídos da análise pelo fato de que, em termos de vazão tratada e quantidade de lodo produzido, essa estação poder ser considerada excepcional. Mais especificamente, seus dados possuem grade alavanca e grande influência, devido ao fato de ocuparem, de maneira quase isolada, o intervalo superior de valores de produção medida de lodo e apresentarem grande viés observado em relação à produção estimada - viés esse não verificado, na mesma escala, nas demais ETAs. Portanto, intervalos de confiança obtidos considerando-se esses dados seriam distorcidos e possivelmente não representativos da população geral de estações de tratamento de água. 


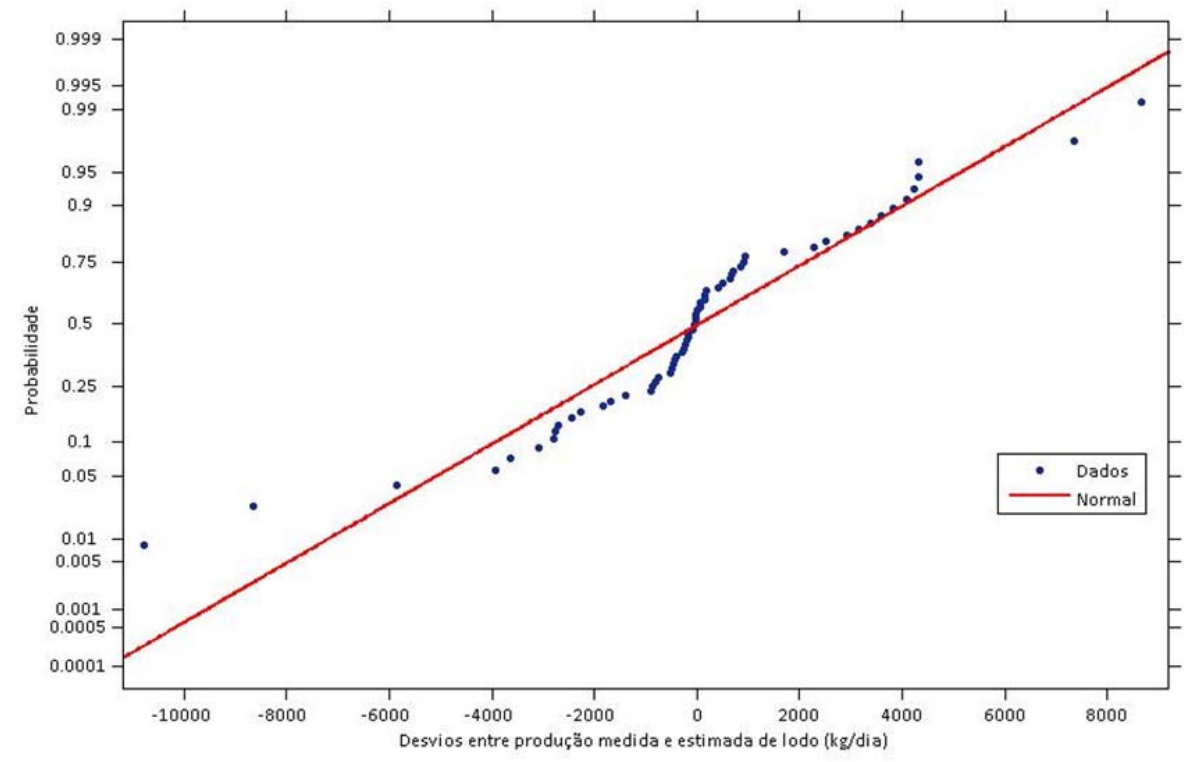

Figura 5.19 - Distribuição de probabilidade dos desvios entre produção estimada e medida de lodo nas ETAs ALC, CUB, FRA e PPR.

Excluindo-se os dados da ETA GUA, observou-se que os resíduos do modelo apresentam distribuição aparentemente normal (Figura 5.19, comprovada por teste de Kolmogorov-Smirnov, com nível de confiança de 5\%). A distribuição irregular dos dados ao longo do intervalo de valores de produção estimada de lodo dificulta a verificação de homocedasticidade (Figura 5.20).

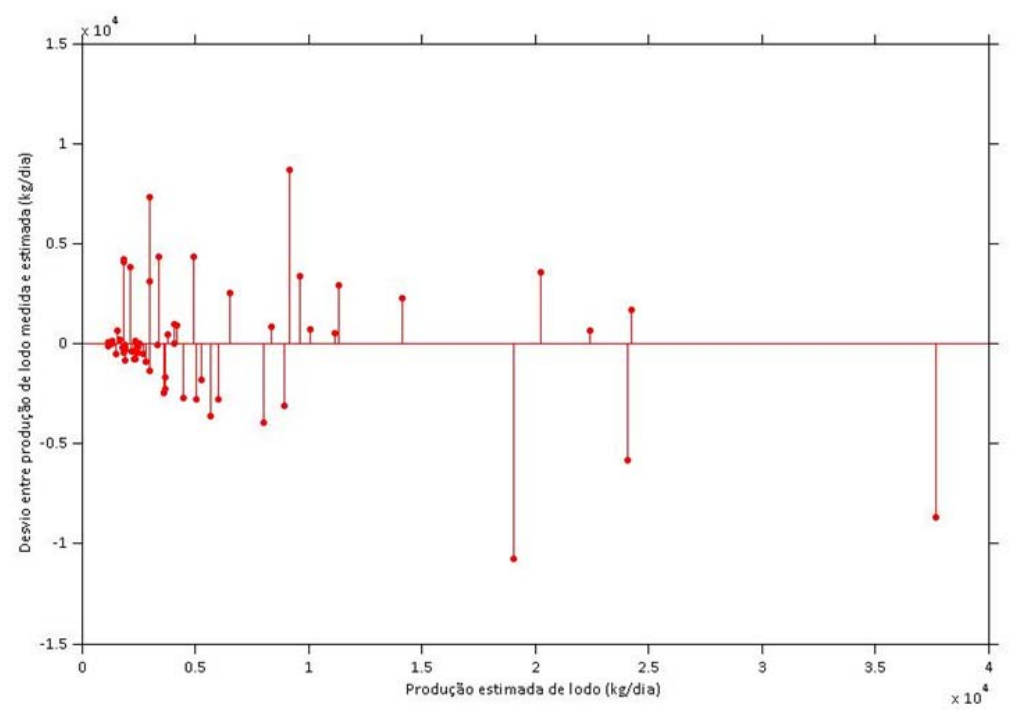

Figura 5.20 - Desvios entre produção estimada e produzida de lodo para as ETAs ALC, CUB, FRA e PPR. 
O intervalo de confiança para a previsão de valores individuais de produção de lodo obtidos é mostrado na Figura 5.21. Pode ser observado que, sem se avaliar peculiaridades da água bruta e da realidade operacional (prevista para ETAs em projeto e existente em ETAs já construídas), uma grande amplitude de valores pode ser encontrada ao redor da média fornecida pela fórmula empírica, com $95 \%$ dos valores ocorrendo no intervalo de $+/-5300 \mathrm{~kg} /$ dia, o que é uma estimativa inaceitável do ponto de vista de engenharia. Assim, se aplicada indiscriminadamente e sem critério, a fórmula empírica pode levar a sistemas de tratamento de sólidos substancialmente mal dimensionados.

Ainda deve-se observar que, para o projeto de novas ETAs, um condicionante adicional para obtenção de estimativas precisas por meio da fórmula empírica é a previsão de qual será o coagulante usado e sua dosagem nas condições de projeto. Apesar de isto ser evidente e devidamente ressaltado em manuais de projeto (e.g., KAWAMURA, 2000), não raro reporta-se que as dosagens ótimas obtidas por meio de jar-tests não são efetivamente aplicadas durante a operação, devido a não representatividade das condições de ensaio em relação a circunstâncias operacionais, o que impede o scale-up daquilo determinado em bancada (e.g. BRATBY, 2006). Nessas situações, o regime de dosagem acaba sendo definido pela prática e experiência operacional dos operadores da estação. Caso a diferença entre a dosagem ótima e a operacional seja grande, o erro na estimação da produção de lodo será proporcionalmente grande.

A recomendação de se realizar ensaios de bancada e/ou instalações piloto não é gratuita. A avaliação dos dados de dosagem obtidos para as cinco ETAs analisadas aqui e de outras 108 estações operadas pela SABESP revela que não existe uma relação universal explícita entre qualidade da água bruta (indicada pela turbidez) e dosagem (Figura 5.22).

Desse modo, os resultados apresentados até aqui sugerem que o acoplamento da fórmula empírica da AWWA com modelos de regressão de SST e turbidez possa não configurar uma boa prática de projeto de novas ETAs. Combinadas, as fontes de erros de uma e outro tornam a processo de estimação da produção de lodo uma tarefa muito trabalhosa, dado os cuidados necessários no planejamento 
experimental e execução das coletas de amostras para obtenção dos modelos de regressão entre SST e turbidez.

No âmbito do projeto de novas ETAs convencionais, uma parte do apelo prático de fórmulas empíricas é esvaziada ao se eliminar a perspectiva do uso de correlações entre SST e turbidez - principalmente em situações nas quais o coeficiente do modelo seja retirado da literatura - já que se passa a ser necessária a realização de campanhas de amostragem para a determinação da concentração de SST.

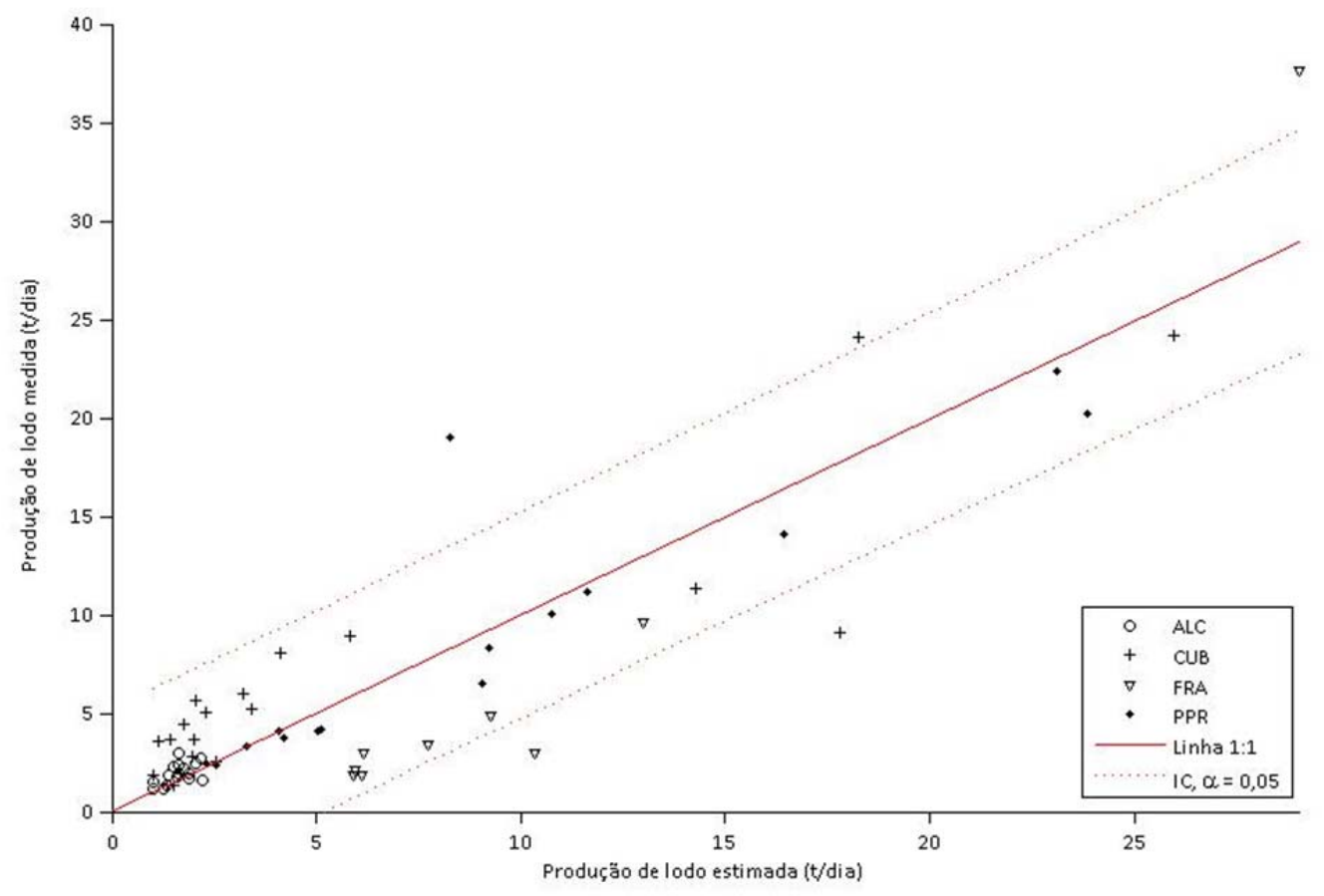

Figura 5.21 - Gráfico de dispersão da produção de lodo medida e estimada para as diversas ETAs com exceção da ETA GUA, com a reta 1:1 (equivalente à reta do modelo de regressão $S_{S T} T_{\text {MEDIDO }}=S_{\text {ESTIMADO }}$ e o respectivo intervalo de confiança $(\alpha=0,05)$.

Mais ainda, pode ser mais vantajoso para o dimensionamento das unidades de tratamento de lodo se, ao invés de se realizar as medições de concentração de SST e aplicá-las na fórmula, executar séries de jar-tests ao longo de (no mínimo) um ano hidrológico para a determinação direta do valor de produção de lodo a ser usado como parâmetro de projeto, seja ele a média, mediana ou qualquer outra medida de localização dos dados de geração de sólidos. Ao revelar simultaneamente a dosagem ótima de coagulante e a produção de sólidos associada, essa abordagem 
é possivelmente mais precisa que o uso da fórmula empírica com dados de dosagem e sólidos obtidos separadamente - a situação mais provável no contexto de projeto de ETAs novas. O uso de jar-tests para esse fim já é recomendada pela EPA no contexto do tratamento químico de águas residuárias (EPA, 1987).

Para ETAs já existentes, raciocínio similar se aplica. Descartada a possibilidade de uso de modelos de regressão baseados em turbidez para a estimativa de SST, a realização de balanço de massa oferece precisão e representatividade na estimativa superiores a das fórmulas empíricas, a um custo marginalmente maior, em termos de esforço experimental.

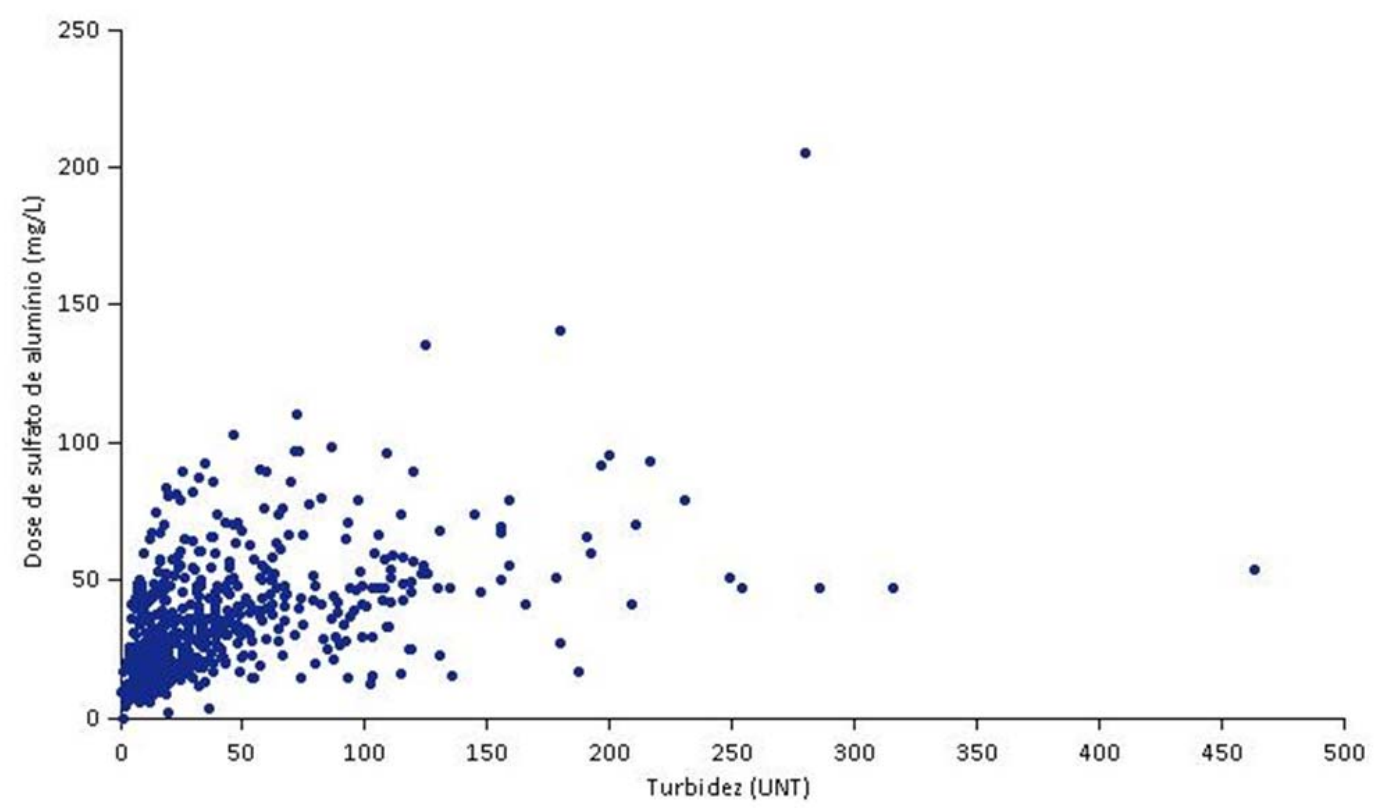

Figura 5.22 - Gráfico de dispersão de turbidez e dosagem de sulfato de alumínio para as ETAs ALC, CUB, GUA, FRA e PPR, além de outras 108 ETAs operadas pela SABESP. 


\section{CONCLUSÕES}

Assim como no caso dos dados de monitoramento da CETESB, os resultados obtidos para as ETAs destoam do que é reportado na literatura, confirmando que a identificação de correlações entre concentração de SST e turbidez é elusiva, e não constitui tarefa trivial.

Os resultados apresentados no neste trabalho sugerem que o acoplamento da fórmula empírica da AWWA com modelos de regressão de SST e turbidez possa não configurar uma boa prática de projeto de novas ETAs. Combinadas, as fontes de erros de uma e outro tornam a processo de estimação da produção de lodo uma tarefa muito trabalhosa, dado os cuidados necessários no planejamento experimental e execução das coletas de amostras para obtenção dos modelos de regressão.

No âmbito do projeto de novas ETAs convencionais, uma parte do apelo prático de fórmulas empíricas é esvaziada ao se eliminar a perspectiva do uso de correlações entre SST e turbidez - principalmente em situações nas quais o coeficiente do modelo seja retirado da literatura - já que passa a ser necessária a realização de campanhas de amostragem para a determinação mais precisa da concentração de SST.

Para ETAs já existentes, raciocínio similar se aplica. Descartada a possibilidade de uso de modelos de regressão baseados em turbidez para a estimativa de SST, a realização de balanço de massa oferece precisão e representatividade de estimativa superiores ao que se obtém com as fórmulas empíricas. 


\section{REFERÊNCIAS BIBLIOGRÁFICAS}

AMERICAN PUBLIC HEALTH ASSOCIATION; AMERICAN WATER WORKS ASSOCIATION; WATER ENVIRONMENT FEDERATION - APHA; AWWA; WEF. Standard Methods for the examination of water and wastewater. Washington, D.C, 21a. ed., 2005.

AMERICAN WATER WORKS ASSOCIATION - AWWA. Water quality and treatment: a handbook of community water supplies. $5^{\text {th }}$ ed. New York: McGraw-Hill, 1999.

AMERICAN WATER WORKS ASSOCIATION - AWWA; AMERICAN SOCIETY OF CIVIL ENGINEERS - ASCE. Water Treatment Plant Design. New York: McGrawHill, 2005.

ANDRADE, Patrícia de Souza. Avaliação do impacto ambiental da utilização de resíduos de estações de tratamento de água em indústrias de cerâmica vermelha: estudo de caso. Campinas, 2005. Dissertação (Mestrado) - Universidade Estadual de Campinas, Faculdade de Engenharia Civil, Arquitetura e Urbanismo.

ANDREOLI, Cleverson Vitório; PINTO, Marcelo A. Teixeira. Introdução. In: ANDREOLI, Cleverson Vitório (org.). Resíduos sólidos do saneamento: processamento, reciclagem e disposição final. Rio de Janeiro: RiMa, ABES, 2001.

ANKCORN, Paul D. Clarifying turbidity - the potential and limitations of turbidity as a surrogate for water-quality monitoring. In: Georgia Water Resources Conference, 2003, Athens, GA. Proceedings... Athens: University of Georgia, 2003.

ASSOCIAÇÃO BRASILEIRA DE NORMAS TÉCNICAS - ABNT. NBR 10004 Resíduos sólidos: classificação. Rio de Janeiro: ABNT, 2004.

ASSOCIATION FRANÇAISE POUR L'ÉTUDE DES EAUX - AFEE. Traitment des boues de stations de production d'eau potable. [S.I.]: AFEE, 1993.

BABATUNDE, A O. et al. Performance evaluation and prediction for a pilot two-stage on-site constructed wetland system employing dewatered alum sludge as main substrate. Bioresource technology, v. 102, n. 10, p. 5645-52, 2011. DOI: 10.1016/j.biortech.2011.02.065. 
BABIN, M. et al. Light scattering properties of marine particles in coastal and open ocean waters as related to the particle mass concentration. Limnology and Oceanography, v. 48, n. 2, p. 843-859, 2003.

BACHE, D. et al. A conceptual view of floc structure in the sweep floc domain. Water Science and Technology. [S.I.]: IWA, v. 36, n. 4, p. 49-56, 1997. DOI: 10.1016/S0273-1223(97)00418-6.

BACHE, D. H.; PAPAVASILOPOULOS, E. N. Dewatering of alumino-humic sludge: impacts of hydroxide. Water Research. [S.I.]: IWA, v. 37, n. 14, p. 3289-98, 2003. DOI:10.1016/S0043-1354(03)00174-X.

BAKER, E. T.; LAVELLE, J. W. The effect of particle size on the light attenuation coefficient of natural suspensions. Journal of Geophysical Research, v. 89, pp. 8197-8203, 1984.

BARBOSA, R. M. Avaliação do Impacto de Lodos de Estações de Tratamento de Água à Biota Aquática Através de Estudos Ecotoxicológicos. Tese (Doutorado) - Escola de Engenharia de São Carlos, Universidade de São Paulo. São Carlos, 2000.

BOHREN, C. F.; HUFFMAN, D. R. Absorption and Scattering of Light by Small Particles. 2nd. ed. Weinheim: Wiley-VCH, 2007.

BOWERS, D. G. et al. Light scattering by particles suspended in the sea: The role of particle size and density. Continental Shelf Research, v. 29, n. 14, p. 1748-1755, jul. 2009.

BOWERS, D. G.; BINDING, C. E. The optical properties of mineral suspended particles: A review and synthesis. Estuarine, Coastal and Shelf Science, v. 67, n. 1-2, p. 219-230,2006. DOI: 10.1016/j.ecss.2005.11.010.

BRASIL. Lei $n^{\circ}$ 12305, de 02/08/2010. Disponível em: <http://www.mma.gov.br/port/conama/legiabre.cfm?codlegi=636>. Acesso em: 11/12/2012.

CHAO, lara Regina Soares. ; YABROUDI, S. C. ; MORITA, D. M. . Remoción de fósforo de efluentes de lagunas de estabilización empleando lodo de estaciones de tratamiento de agua. Interciencia (Caracas), v. 36, p. 774-778, 2011. 
CHAO, lara Regina Soares. Remoção de fósforo de efluentes de estações de tratamento biológico de esgotos utilizando lodo de estação de tratamento de água. Dissertação (Mestrado em Engenharia Civil) - Escola Politécnica, Universidade de São Paulo. São Paulo, 2006.

CORDEIRO, J.S. Importância do tratamento e disposição adequada dos lodos de ETAs. In: REALI, M.A.P., coord. Noções Gerais de Tratamento e Disposição Final de Lodos de Estações de Tratamento de Água. Rio de Janeiro: ABES, 1999.

CORNWELL, David. A.; MUTTER, R. N.; VANDERMEYDEN, C. Commercial Application and Marketing of Water Plant Residuals. Denver: American Water Works Association, 2000.

CORNWELL, David A. et al. Water treatment plant waste management. Denver: AWWARF, 1987.

CORNWELL, David A. Alum sludge characteristics. In: Joint Meeting of the Connecticut Water Works Association and the Connecticut Section AWWA, New Haven, 1978. Proceedings... [S.I.]:AWWA, 1978.

CORNWELL, David A. Water treatment residuals engineering. Denver: AWWA Research Foundation and American Water Works Association, 2006.

DAVIES-COLLEY, R. J.; SMITH, D. G. Turbidity, suspended sediment, and water clarity: a review. Journal of the American Water Resources Association. [S.I.]: AWRA, v. 37, n. 5, p. 1085-1101, 2001. DOI: 10.1111/j.1752-1688.2001.tb03624.x.

DAVIES-COLLEY, R. J.; VANT, W. N.; SMITH, D. G. Colour and Clarity of Natural Waters. Ellis Horwood: New York, 1993 apud DAVIES-COLLEY, R. J.; SMITH, D. G. Turbidity, suspended sediment, and water clarity: a review. Journal of the American Water Resources Association. [S.I.]: AWRA, v. 37, n. 5, p. 1085-1101, 2001. DOI: 10.1111/j.1752-1688.2001.tb03624.x.

DEARING, J. A.; JONES, R. T. Coupling temporal and spatial dimensions of global sediment flux through lake and marine sediment records. Global and Planetary Change, v. 39, n. 1-2, p. 147-168, out. 2003.

DI BERNARDO, Luiz; DANTAS, Ângela Di Bernardo. Métodos e técnicas de tratamento de água. São Carlos: Rima, 2005. 
DILLON, Glenn. Application Guide to Waterworks Sludge Treatment and Disposal. [S.I.]: WRc, 1996.

DROPPO, I. G.; JASKOT, C. Impact of river transport characteristics on contaminant sampling error and design. Environmental science \& technology, v. 29, n. 1, p. 161-70, 1995.

DUAN, J.; GREGORY, J. Coagulation by hydrolysing metal salts. Advances in Colloid and Interface Science, v. 100-102, p. 475-502, 2003. DOI: 10.1016/S00018686(02)00067-2.

EFFLER, S. W. Secchi Disc Transparency and Turbidity. Journal of Environmental Engineering. [S.I.]: ASCE, v. 114, p. 1436-1447, 1988.

FARELLA, N. et al. Deforestation modifying terrestrial organic transport in the Rio Tapajos, Brazilian Amazon. Organic Geochemistry, v. 32, p. 1443-1458, 2001.

FLORSHEIM, J. L. et al. From deposition to erosion: Spatial and temporal variability of sediment sources, storage, and transport in a small agricultural watershed. Geomorphology, v. 132, n. 3-4, p. 272-286, 2011. DOI: 10.1016/j.geomorph.2011.04.037.

FRANCO, Elton Santos. Avaliação da influência dos coagulantes sulfato de alumínio e cloreto férrico na remoção de turbidez e cor da água bruta e sua relação com sólidos na geração de lodo em estações de tratamento de água. Dissertação (Mestrado) - Universidade Federal de Ouro Preto, Instituto de Ciências Exatas e Biológicas. Ouro Preto, 2009.

FURRER, G. et al. The origin of aluminum flocs in polluted streams. Science, v. 297, n. 5590, p. 2245-7, 2002. DOI: 10.1126/science.1076505.

GIPPEL, C. J. Potential of turbidity monitoring for measuring the transport of suspended-solids in streams. Hydrological Processes. Chichester: John Wiley and Sons, v. 9, n. 1, p. 83-97, 1995. DOI: 10.1002/hyp.3360090108.

GODBOLD, P.; LEWIN, K.; GRAHAM, A.; BARKER, P. The Potential Reuse of Water Utility Products as Secondary Commercial Materials. [S.I.], 2003 apud ANDRADE, Patrícia de Souza. Avaliação do impacto ambiental da utilização de resíduos de estações de tratamento de água em indústrias de cerâmica 
vermelha: estudo de caso. Campinas, 2005. Dissertação (Mestrado) - Universidade Estadual de Campinas, Faculdade de Engenharia Civil, Arquitetura e Urbanismo GORCZYCA, B.; GANCZARCZYK, J. Fractal Analysis of Pore Distributions in Alum Coagulation and Activated Sludge Flocs. Water Quality Research Journal of Canada. [S.I.]: IWA, v. 36, n. 4, p. 687-700, 2001.

GRAY, John R. Water-Resources Investigation Report 00-4191: Comparability of suspended-sediment concentration and total suspended solids data. Reston: USGS, 2000.

GRAYSON, R. B. et al. The potential of field turbidity measurements for the computation of total phosphorus and suspended solids loads. Journal of Environmental Management. [S.I.]: Elsevier, v. 47, n. 3, p. 257-267, 1996. DOI: 10.1006/jema.1996.

GREGORY, J.; DUPON, V. Properties of flocs produced by water treatment coagulants. Water Science and Technology, v. 44, n. 10, p. 231-6, 2001.

HARMEL, R. D. et al. Cumulative uncertainty in measured streamflow and water quality data for small watersheds. Transactions of the ASABE, v. 49, n. 3, p. 689702, 2006.

HELSEL, D. R.; HIRSCH, R. M. Statistical Methods in Water Resources. In: Techniques of Water-Resources Investigations. Book 4, Hydrologic Analysis and Interpretation. [S.I.] United States Geological Service, 202AD. v. 36p. 323.

HENGSTUM, P. J. et al. Changing sedimentation patterns due to historical land-use change in Frenchman's Bay, Pickering, Canada: evidence from high-resolution textural analysis. Journal of Paleolimnology, v. 37, n. 4, p. 603-618, 21 out. 2006.

HUI, L. et al . Correlation between turbidity and total suspended solids in Singapore Rivers. Journal of Water Sustainability. [S.I.]:UTS-XAUAT, v. 1, n. 3, p. 313-322, 2011.

INTERNATIONAL ORGANIZATION FOR STANDARDIZATION. ISO 7097: Water quality - determination of turbidity. Genebra: ISO, 1999. 
INSTITUTO DE PESQUISAS TECNOLÓGICAS DO ESTADO DE SÃO PAULO IPT. Orientações para o combate à erosão no Estado de São Paulo - Síntese. São Paulo: IPT/DAEE. (IPT, Relatório 36071). 1997.

ISAAC, R. de L.; LUVIZOTTO Jr., E.; CHAVEZ, A. Clarificação de Água de Lavagem de Filtro e Lodo de Decantador Convencional para Recirculação em ETA. In: SIMPÓSIO LUSOBRASILEIRO DE ENGENHARIA SANITÁRIA E AMBIENTAL SILUBESA, 10., 2002a, Braga. Anais... Braga: APESB, APRH, ABES, 2002.

JARVIS, P.; JEFFERSON, B.; PARSONS, S. A. How the natural organic matter to coagulant ratio impacts on floc structural properties. Environmental Science \& Technology, v. 39, n. 22, p. 8919-24, 15, 2005. DOI: 10.1021/es0510616.

JASTRAM, J. D. et al . Increasing Precision of Turbidity-Based Suspended Sediment Concentration and Load Estimates. Journal of Environment Quality. [S.I.]: American Society of Agronomy, v. 39, n. 4, p. 1306-1316, 2010. DOI:10.2134/jeq2009.0280.

JONES, A. S., et al. Surrogate measures for providing high frequency estimates of total suspended solids and total phosphorus concentrations. Journal of the American Water Resources Association. [S.I.]: AWRA, v. 47, n. 2, p. 239-253, 2011. DOI:10.1111/j.1752-1688.2010.00505.x.

JONES, A. S. et al. Influence of Sampling Frequency on Estimation of Annual Total Phosphorus and Total Suspended Solids Loads1. JAWRA Journal of the American Water Resources Association, v. 5200, p. 1-18, 2012.

JOHNSON, L. et al. Landscape influences on water chemistry in Midwestern stream ecosystems. Freshwater Biology, v. 37, n. 1, p. 193-208, 1997.

KARR, J. R.; SCHLOSSER, I. J. Water resources and the land-water interface. Science, v. 201, n. 4352, p. 229-34, 21 jul. 1978.

KAWAMURA, Susumu. Integrated design and operation of water treatment facilities. $2^{\text {nd }}$ ed. New York: John Wiley \& Sons, 2000.

KAWAMURA, Susumu. Integrated design of water treatment facilities. [S.I.]: Wiley, 1991. 
KIRK, J. T. O. Light and photosynthesis in aquatic ecosystems. $2^{\text {nd }}$ ed., New York: Cambridge University Press, 1994.

KIRK, J. T. O. Relationship between nephelometric turbidity and scattering coefficients in certain Australian waters. Marine and Freshwater Research. [S.I.]:CSIRO, v. 31, n. 1, p. 1-12, 1980. DOI:10.1071/MF9800001.

KOREVAAR, Gijsbert. Sustainable Chemical Processes and Products: New Design Methodology and Design Tools. Delft: Eburon B V, 2004.

LAWLER, D. M. et al. Turbidity dynamics during spring storm events in an urban headwater river system: the Upper Tame, West Midlands, UK. The Science of the Total Environment, v. 360, n. 1-3, p. 109-26, 1 maio. 2006. DOI: 10.1016/j.scitotenv.2005.08.032.

LECCE, S. A; PAVLOWSKY, R. T. Spatial and temporal variations in the grain-size characteristics of historical flood plain deposits, Blue River, Wisconsin, USA. Geomorphology, v. 61, n. 3-4, p. 361-371, ago. 2004.

LENHART, C. F., (2010). Spatial and temporal variation in suspended sediment, organic matter, and turbidity in a Minnesota prairie river: implications for TMDLs. Environmental Monitoring and Assessment. [S.I.]: Springer, v. 165, n. 1-4, p. 43547. DOI:10.1007/s10661-009-0957-y.

LENZI, M.; MARCHI, L. Suspended sediment load during floods in a small stream of the Dolomites (northeastern Italy). Catena, v. 39, p. 267-282, 2000. DOI: 10.1016/S0341-8162(00)00079-5.

LEWIS, D.; TATE, K.; DAHLGREN, R. (2002). Turbidity and total suspended solid concentration dynamics in streamflow from California oak woodland watersheds. [S.I.]: USDA, p. 107-118, 2002. (USDA Forest Service General Technical Report PSW-GTR-184). Disponível em: < http://www.yubashed.org/biblio/rvrprocess_lewisetal_2002_turb_prj.pdf>. Acessado em: 24 jul. 2012.

LI, D. H.; GANCZARCZYK, J. Fractal geometry of particle aggregates generated in water and wastewater treatment processes. Environmental Science \& Technology. [S.I.]: ACS, v. 23, n. 11, p. 1385-1389, 1989. DOI: 10.1021/es00069a009. 
LI, T. et al. Characterization of floc size, strength and structure under various coagulation mechanisms. Powder Technology, v. 168, n. 2, p. 104-110, 2006. DOI: 10.1016/j.powtec.2006.07.003.

LONGWORTH, B. E. et al. Linking lithology and land use to sources of dissolved and particulate organic matter in headwaters of a temperate, passive-margin river system. Geochimica et Cosmochimica Acta, v. 71, n. 17, p. 4233-4250, 2007.

LOUCHOUARN, P.; LUCOTTE, M.; FARELLA, N. Historical and geographical variations of sources and transport of terrigenous organic matter within a large-scale coastal environment. Organic Geochemistry, v. 30, n. 7, p. 675-699, 1999.

MAKRIS, Konstantinos C. et al. Aluminum-based drinking-water treatment residuals: a novel sorbent for perchlorate removal. Environmental Pollution. [S.I.] : Elsevier, v. 140, p. 9-12, 2006.

MANDELBROT, Benoit B. The fractal geometry of nature. New York: W. H. Freeman, 1983.

MARTIN, G.; SMOOT, J.; WHITE, K. A comparison of surface-grab and cross sectionally integrated stream-water-quality sampling methods. Water Environment Research, v. 64, n. 7, p. 866-876, 1992.

MCCURDY, K.; CARLSON, K.; GREGORY, D. Floc morphology and cyclic shearing recovery: comparison of alum and polyaluminum chloride coagulants. Water Research, v. 38, n. 2, p. 486-94,2004. DOI: 10.1016/j.watres.2003.10.005.

MINELLA, J. P. G. et al (2008). Estimating suspended sediment concentrations from turbidity measurements and the calibration problem. Hydrological Processes. [S.I.]: Elsevier, v. 22, n. 12, p. 1819-1830, 2008. DOI:10.1002/hyp.6763.

NADEU, E. et al. Erosion, deposition and replacement of soil organic carbon in Mediterranean catchments: a geomorphological, isotopic and land use change approach. Biogeosciences, v. 9, n. 3, p. 1099-1111, 2012.

OWENS, P. N.; WALLING, D. E.; LEEKS, G. J. . Use of floodplain sediment cores to investigate recent historical changes in overbank sedimentation rates and sediment sources in the catchment of the River Ouse, Yorkshire, UK. Catena, v. 36, n. 1-2, p. 21-47, jun. 1999. 
PAULSRUD, B.; STORHAUG, R.; HEM L. J. Management of Wastes from Drinking Water Treatment in Norway. In: MANAGEMENT OF WASTES FROM DRINKING WATER TREATMENT, 2002, London. Procedings... London: The Chartered Institution of Water and Environmental Management, 2002. p. 21-8.

PENG, Feng et al. Light-scattering features of turbidity-causing particles in interconnected reservoir basins and a connecting stream. Water Research. [S.I.]: IWA, v. 43, n. 8, p. 2280-2292, 2009. DOI: 10.1016/j.watres.2009.02.018.

PENG, F.; EFFLER, S. W. Mass-specific scattering coefficient for natural minerogenic particle populations: particle size distribution effect and closure analyses. Applied optics, v. 51, n. 13, p. 2236-49, 2012. DOI:

PENG, F. et al. Role of minerogenic particles in light scattering in lakes and a river in central New York. Applied optics, v. 46, n. 26, p. 6577-94, 2007.

PFANNKUCHE, J.; SCHMIDT, A. Determination of suspended particulate matter concentration from turbidity measurements: particle size effects and calibration procedures. Hydrological Processes, v. 17, n. 10, p. 1951-1963, 2003.

PROSSER, I.; RUTHERFURD, I.; OLLEY, J. Large-scale patterns of erosion and sediment transport in river networks, with examples from Australia. Marine and Freshwater ..., v. 52, 2001.

RASMUSSEN, P. P. et al. Guidelines and Procedures for Computing Time-Series Suspended-Sediment Concentrations and Loads from In-Stream Turbidity-Sensor and Streamflow Data. In: SERVICE, U. S. G. (Ed.). Book 3, Applications of Hydraulics, Section C, Sediment and Erosion Techniques. [S.I.] United States Geological Service, 2009. .

REALI, Marco Antônio Penalva. Noções gerais de tratamento e disposição final de lodos de estações de tratamento de água. Rio de Janeiro: PROSAB, 1999.

RICHTER, Carlos A. Água: métodos e tecnologias de tratamento. São Paulo: Blucher, 2009.

SADAR, Mike. Making sense of turbidity measurements - advantages in establishing traceability between measurements and technology. In: National Monitoring Conference, 2004, 1., Chattanoga. Proceedings... [S.I.]: NWQMC, 2004. 
SARON, Alexandre; LEITE, Vera Maria Barbosa. Quantificação de lodo em estação de tratamento de água. In: Congresso Brasileiro de Engenharia Sanitária e Ambiental, 21., 2001, João Pessoa. Anais... Rio de Janeiro: ABES, 2001, p. 1-11.

SOTERO-SANTOS, Rosana B. et al. Toxicity of ferric chloride sludge to aquatic organisms. Chemosphere. Elsevier, v. 68, p. 628-636, 2007.

SOUZA, F. G. C.; BARROSO, M. M.; CORDEIRO, J. S. Estudo comparativo da geração de sólidos em estação de tratamento de água convencional de ciclo completo e ETA ciclo completo com decantador de alta taxa. In: Congreso Interamericano de Ingenieria Sanitaria y Ambiental, 29., San Juan, 2004. Anais... San Juan: AIDIS, 2004.

SPEAR, B. et al (2008). Turbidity as a surrogate measure for suspended sediment concentration in Elkhorn Slough, CA. Seaside: The Watershed Institute, 2008. (Publication No. WI-2008-04).

STACKELBERG, Paul E. et al. Efficiency of conventional drinking-water-treatment processes in removal of pharmaceuticals and other organic compounds. Science of the Total Environment, v. 377, n. 2-3, p. 255-272, 2007.

STONE, M.; SAUNDERSON, H. Particle size characteristics of suspended sediment in Southern Ontario rivers tributary to the great lakes. Hydrological Processes, v. 6, n. 2, p. 189-198, 1992. DOI: 10.1002/hyp.3360060207.

STRAMSKI, D. et al. The role of seawater constituents in light backscattering in the ocean. Progress In Oceanography, v. 61, n. 1, p. 27-56, 2004. DOI: 10.1016/j.pocean.2004.07.001.

STRAMSKI, D.; BABIN, M.;WOZNIAK, S. B. Variations in the optical properties of terrigenous mineral-rich particulate mat- ter suspended in seawater. Limnology and Oceanography, v. 52, pp. 2418-2433, 2007).

STUBBLEFIELD, A. P. et al (2007). Use of turbidometry to characterize suspended sediment and phosphorus fluxes in the Lake Tahoe basin, California, USA. Hydrological Processes. [S.I.]: Elsevier, v. 291, September 2006, p. 281-291. DOI:10.1002/hyp. 
SUI, J.; HE, Y.; LIU, C. Changes in sediment transport in the Kuye River in the Loess Plateau in China. International Journal of Sediment Research, v. 24, n. 2, p. 201213, 2009. DOI: 10.1016/S1001-6279(09)60027-5.

SUSFALK, R. B.; FITZGERALD, B.; KNUST, A. M. Characterization of turbidity and total suspended solids in the Upper Carson River, Nevada. [S.I.]: Desert Research Institute, 2008. (DHS Publication No. 41242).

SUTHERLAND, R. A.; BRYAN, R. B. Variability of particle size characteristics of sheetwash sediments and fluvial suspended sediment in a small semiarid catchment, Kenya. Catena, v. 16, n. 2, p. 189-204, 1989. DOI: 10.1016/0341-8162(89)90040-4.

TEIXEIRA, Edmilson Costa; SENHORELO, Adriano Possé. Avaliação de correlação entre turbidez e concentração de sólidos suspensos em bacias hidrográficas com uso e ocupação diferenciada. In: Congresso Interamericano de Engenharia Sanitária e Ambiental, 27, 2000., Porto Alegre. Anais... Rio de Janeiro: ABES, 2000.

TOMAZONI, Julio Caetano et al. Utilização de medidas de turbidez na quantificação da movimentação de sólidos por veiculação hídrica nas bacias dos Rios Anta Gorda, Brinco, Coxilha Rica e Jirau - sudoeste do Estado do Paraná. Boletim Paranaense de Geociências. Curitiba: UFPR, n. 57, p. 49-56, 2005.

TOMLINSON, M.; CARLO, E. The need for high resolution time series data to characterize Hawaiian streams. JAWRA Journal of the American ..., v. 39, n. 1, p. 113-123, 2003.

TURCHIULI, C.; FARGUES, C. Influence of structural properties of alum and ferric flocs on sludge dewaterability. Chemical Engineering Journal. [S.I.]: Elsevier, v. 103, n. 1-3, p. 123-131, 2004. DOI:10.1016/j.cej.2004.05.013.

UHRICH, Mark A; BRAGG, Heather M. Monitoring instream turbidity to estimate continuous suspended-sediment loads and yields and clay-water volumes in the Upper North Santiam River Basin, Oregon, 1998-2000. Portland: USGS, 2003. (Water-Resources Investigations Report 03-4098).

UNITED STATES ENVIRONMENTAL PROTECTION AGENCY - USEPA. Design Manual - Dewatering Municipal Wastewater Sludges. Cincinnati: USEPA, 1987. 
. Method 180.1 - Determination of turbidity by nephelometry (revision 2.0). Cincinnati: USEPA, 1993.

VAN BENSCHOTEN, J. E.; EDZWALD, J. K. Chemical aspects of coagulation using aluminum salts-l. Hydrolytic reactions of alum and polyaluminum chloride. Water Research, v. 24, n. 12, p. 1519-1526, 1990. DOI: 10.1016/0043-1354(90)90086-L.

VAN OOST, K. et al. The impact of agricultural soil erosion on the global carbon cycle. Science, v. 318, n. 5850, p. 626-9, 2007.

VESILIND, P. A. Capillary measure suction of time sludge as a fundamental dewaterability. Journal (Water Pollution Control Federation), v. 60, n. 2, p. 215220, 1988.

WASS, P. et al. Monitoring and preliminary interpretation of in-river turbidity and remote sensed imagery for suspended sediment transport studies in the Humber catchment. Science of the Total Environment. [S.I.]: Elsevier, v. 194-195, n. 96, p. 263-283, 1997. DOI: 10.1016/S0048-9697(96)05370-3.

WALLING, D. E.; MOOREHEAD, P. W. Spatial and temporal variation the particlesize characteristics of fluvial suspended sediment. Geografiska Annaler, v. 69, n. 1, p. 47-59, 1987.

WILLIAMS, N. D.; WALLING, D. E.; LEEKS, G. J. L. High temporal resolution in situ measurement of the effective particle size characteristics of fluvial suspended sediment. Water Research, v. 41, n. 5, p. 1081-93, 2007. DOI: 10.1016/j.watres.2006.11.010.

WILLIAMSON, T. N.; CRAWFORD, C. G. (2011). Estimation of suspended-sediment concentration from total suspended solids and turbidity data for Kentucky, 19781995. Journal of the American Water Resources Association. [S.I.]: AWRA, v. 47, n. 4, p. 739-749. DOI:10.1111/j.1752-1688.2011.00538.x.

WOZNIAK, S. B. et al. Optical variability of seawater in relation to particle concentration, composition, and size distribution in the nearshore marine environment at Imperial Beach, California. Journal of Geophysical Research, v. 115, C08027, 2010. 
$\mathrm{XU}$, J. Implication of relationships among suspended sediment size, water discharge and suspended sediment concentration: the Yellow River basin, China. Catena, v. 49, n. 4, p. 289-307, 2002. DOI: 10.1016/S0341-8162(02)00064-4.

YUZHU, W. Condicionamento de Lodo de Estações de Tratamento de Água: Estudo de Caso. São Paulo, 1996. Dissertação (Mestrado em Engenharia Civil) Escola Politécnica, Universidade de São Paulo apud ANDRADE, Patrícia de Souza. Avaliação do impacto ambiental da utilização de resíduos de estações de tratamento de água em indústrias de cerâmica vermelha: estudo de caso. Dissertação (Mestrado) - Universidade Estadual de Campinas, Faculdade de Engenharia Civil, Arquitetura e Urbanismo. Campinas, 2005.

ZHAO, Y. Q. Correlations between floc physical properties and optimum polymer dosage in alum sludge conditioning and dewatering. Chemical Engineering Journal. [S.I.]: Elsevier, v. 92, n. 1-3, p. 227-235, 2003. DOI: 10.1016/S13858947(02)00253-X.

ZHAO, Y. Q.; BABATUNDE, A. O. (2007). Constructive approaches toward water treatment works sludge management: an international review of beneficial reuses. Critical Review in Environmental Science and Technology, v. 37, p. 129-164.

ZHAO, Y. Q.; ZHAO, X. H.; BABATUNDE, A O. Use of dewatered alum sludge as main substrate in treatment reed bed receiving agricultural wastewater: long-term trial. Bioresource technology, v. 100, n. 2, p. 644-8, jan. 2009. DOI: 10.1016/j.biortech.2008.07.040.

ZIEGLER, Andrew C. Issues related to use of turbidity measurements as a surrogate for suspended sediment. In: Turbidity and Other Sediment Surrogates Workshop, 1., 2002, Reno. Proceedings... Denver: USGS, 2002. 
ANEXO A

PONTOS DE MONITORAMENTO DA CETESB

AVALIADOS 


$\begin{array}{ll}\text { AGUA02010 } & \text { Rio Aguapeí } \\ \text { AGUA02100 } & \text { Rio Aguapeí } \\ \text { AGUA02800 } & \text { Rio Aguapeí } \\ \text { ARPE02800 } & \text { Reservatório do Arrependido } \\ \text { BAGR04500 } & \text { Ribeirão dos Bagres } \\ \text { BAGR04600 } & \text { Ribeirão dos Bagres } \\ \text { BAGU02700 } & \text { Ribeirão Baguaçu } \\ \text { BATA02050 } & \text { Rio Batalha } \\ \text { BATA02800 } & \text { Rio Batalha } \\ \text { BUNA02900 } & \text { Rio Una -UGRHI 10 } \\ \text { CAM000900 } & \text { Reservatório Capivari-Monos } \\ \text { CAR002800 } & \text { Rio Claro - UGRHI 03 } \\ \text { CASC02050 } & \text { Reservatório Cascata } \\ \text { CFUG02900 } & \text { Canal de Fuga II da UHE Henry Borden } \\ \text { CUBA02700 } & \text { Rio Cubatão } \\ \text { CUBA03900 } & \text { Rio Cubatão } \\ \text { GRAN02400 } & \text { Rio Grande -UGRHI 03 } \\ \text { GRAN02800 } & \text { Rio Grande -UGRHI 03 } \\ \text { GRDE02300 } & \text { Rio Grande -UGRHI 08 e 15 } \\ \text { GRDE02500 } & \text { Rio Grande -UGRHI 08 e 15 } \\ \text { GUAR00100 } & \text { Reservatório do Guarapiranga } \\ \text { GUAR00900 } & \text { Reservatório do Guarapiranga } \\ \text { IPAN02500 } & \end{array}$

\begin{tabular}{|c|c|}
\hline ITAP02800 & Rio Itapetininga \\
\hline ITAR02500 & Rio Itararé \\
\hline JAGI02900 & Rio Jaguari - UGRHI 02 \\
\hline JAGJ00200 & Reservatório do Jaguari - UGRHI 02 \\
\hline JAPI02100 & Rio Jacupiranga \\
\hline JCGU03400 & Rio Jacaré-Guaçu \\
\hline JCGU03900 & Rio Jacaré-Guaçu \\
\hline JIBU02900 & Rio Pirajibú \\
\hline JPEP03500 & Rio Jacaré-Pepira \\
\hline JUQI00800 & Rio Juquiá \\
\hline JUQI02900 & Rio Juquiá \\
\hline JURU02500 & Reservatório Jurumirim \\
\hline LAGE02500 & Ribeirão Lageado \\
\hline LENS02500 & Rio Lençóis \\
\hline MOGU02100 & Rio Mogi-Guaçu \\
\hline MOGU02200 & Rio Mogi-Guaçu \\
\hline MOGU02300 & Rio Mogi-Guaçu \\
\hline MOGU02500 & Rio Mogi-Guaçu \\
\hline MOGU02900 & Rio Mogi-Guaçu \\
\hline MOJI02800 & Rio Moji-UGRHI 07 \\
\hline ONCA02500 & Ribeirão da Onça \\
\hline PADO02500 & Rio Pardo - UGRHI 17 \\
\hline PADO02600 & Rio Pardo - UGRHI 17 \\
\hline
\end{tabular}




\begin{tabular}{ll} 
PARB02100 & Rio Paraíba do Sul \\
PARB02200 & Rio Paraíba do Sul \\
PARB02300 & Rio Paraíba do Sul \\
PARB02310 & Rio Paraíba do Sul \\
PARB02400 & Rio Paraíba do Sul \\
PARB02490 & Rio Paraíba do Sul \\
PARB02530 & Rio Paraíba do Sul \\
PARB02600 & Rio Paraíba do Sul \\
PARB02700 & Rio Paraíba do Sul \\
PARB02900 & Rio Paraíba do Sul \\
PARD02010 & Rio Pardo - UGRHIs 4 e 12 \\
PARD02100 & Rio Pardo - UGRHIs 4 e 12 \\
PARD02500 & Rio Pardo - UGRHIs 4 e 12 \\
PARD02600 & Rio Pardo - UGRHIs 4 e 12 \\
PARD02700 & Rio Pardo - UGRHIs 4 e 12 \\
PARD02800 & Rio Pardo - UGRHIs 4 e 12 \\
PARN02100 & Rio Paraná \\
PARN02900 & Rio Paraná \\
PARP02100 & Rio Paranapanema \\
PARP02500 & Rio Paranapanema \\
PARP02750 & Rio Paranapanema \\
PARP02900 & Rio Paranapanema \\
PEIX02100 & Rio do Peixe-UGRHI 21 \\
\hline
\end{tabular}

\begin{tabular}{ll} 
PEIX02800 & Rio do Peixe-UGRHI 21 \\
PIAC02700 & Rio Piaçaguera \\
PRET02800 & Rio Preto-UGRHI 15 \\
PRET04300 & Rio Preto-UGRHI 15 \\
PTEI02900 & Rio Paratei \\
RIBE02500 & Rio Ribeira \\
RIIG02500 & Rio Ribeira de Iguape \\
RIIG02900 & Rio Ribeira de Iguape \\
RPRE02200 & Reservatório do Rio Preto \\
SAFO00300 & Rio São Francisco \\
SAGU02100 & Rio Sapucaí Guaçu \\
SANT00100 & Reservatório Santa Branca \\
SAPU02300 & Rio Sapucaí-UGRHI 08 \\
SAPU02400 & Rio Sapucaí-UGRHI 08 \\
SAPU02800 & Rio Sapucaí-UGRHI 08 \\
SAUI02900 & Rio Sarapuí \\
SDOM03700 & Ribeirão São Domingos \\
SDOM03900 & Ribeirão São Domingos \\
SDOM04500 & Ribeirão São Domingos \\
SDOM04600 & Ribeirão São Domingos \\
SJDO02500 & Rio São José dos Dourados \\
SMIG02800 & Rio São Miguel Arcanjo \\
SOBU02800 & Rio Sorocabuçu \\
\hline
\end{tabular}




\begin{tabular}{ll} 
SOIT02100 & Reservatório Itupararanga \\
SOIT02900 & Reservatório Itupararanga \\
SOMI02850 & Rio Sorocamirim \\
SORO02070 & Rio Sorocaba \\
SORO02100 & Rio Sorocaba \\
SORO02200 & Rio Sorocaba \\
SOR002500 & Rio Sorocaba \\
SORO02700 & Rio Sorocaba \\
SORO02900 & Rio Sorocaba \\
STAN02700 & Rio Santo Anastácio \\
STAN04400 & Rio Santo Anastácio \\
TAQR02400 & Rio Taquari \\
TAUI04900 & Rio Tatuí \\
TBIR02700 & Rio Tibiriçá \\
TBIR03300 & Rio Tibiriçá \\
TIBB02100 & Reservatório de Barra Bonita \\
TIBB02700 & Reservatório de Barra Bonita \\
TIBB02900 & Reservatório de Barra Bonita \\
TIBT02100 & Braço do Rio Tietê \\
TIBT02500 & Braço do Rio Tietê \\
TIET02250 & Rio Tietê \\
TIET02300 & Rio Tietê \\
TIET02350 & Rio Tietê \\
\hline
\end{tabular}

$\begin{array}{ll}\text { TIET02400 } & \text { Rio Tietê } \\ \text { TIET02450 } & \text { Rio Tietê } \\ \text { TIET02500 } & \text { Rio Tietê } \\ \text { TIET02550 } & \text { Rio Tietê } \\ \text { TIET02600 } & \text { Rio Tietê } \\ \text { TIET02700 } & \text { Rio Tietê } \\ \text { TIPR02400 } & \text { Reservatório de Promissão } \\ \text { TIRG02900 } & \text { Reservatório de Rasgão } \\ \text { TITR02100 } & \text { Reservatório de Três Irmãos } \\ \text { TITR02800 } & \text { Reservatório de Três Irmãos } \\ \text { TOCA02900 } & \text { Córrego das Tocas } \\ \text { TURV02500 } & \text { Rio Turvo } \\ \text { TURV02800 } & \text { Rio Turvo } \\ \text { UNNA02800 } & \text { Rio Una -UGRHI 02 } \\ \text { XOTE02500 } & \text { Córrego do Baixote }\end{array}$




\section{ANEXO B \\ CARACTERIZAÇÃO DA ÁGUA BRUTA DAS ETAS}




\begin{tabular}{|c|c|c|c|c|c|c|c|c|c|c|c|c|c|c|c|c|c|c|c|c|}
\hline \multirow{2}{*}{ ETA } & \multirow{2}{*}{ Data } & \multicolumn{2}{|c|}{ ST (mg/L) } & \multicolumn{2}{|c|}{$\mathrm{SD}$ (mg/L) } & \multicolumn{2}{|c|}{ SST (mg/L) } & \multicolumn{2}{|c|}{ TOC (mgC/L) } & \multirow{2}{*}{$\begin{array}{l}\text { Turbidez } \\
\text { (UNT) }\end{array}$} & \multirow{2}{*}{$\begin{array}{l}\text { Cor } \\
\text { (UC) }\end{array}$} & \multirow{2}{*}{$\mathrm{pH}-$} & \multicolumn{8}{|c|}{$\begin{array}{l}\text { concentração numérica de partículas com diâmetro igual a } \\
\qquad\left(\mathrm{n}^{\circ} \text { partículas/L) }\right.\end{array}$} \\
\hline & & média & $\begin{array}{l}\text { desv. } \\
\text { pad. }\end{array}$ & média & $\begin{array}{l}\text { desv. } \\
\text { pad. }\end{array}$ & média & $\begin{array}{l}\text { desv. } \\
\text { pad. }\end{array}$ & média & $\begin{array}{l}\text { desv. } \\
\text { pad. }\end{array}$ & & & & $50 \mathrm{um}$ & $40 \mathrm{um}$ & $20 \mathrm{um}$ & $10 \mathrm{um}$ & $8 \mathrm{um}$ & $4 \mathrm{um}$ & $2 \mathrm{um}$ & $1,2 \mathrm{um}$ \\
\hline \multirow{10}{*}{ 高 } & jun-2009 & 100,00 & 10,00 & 76,67 & 5,77 & 5,76 & 0,53 & -- & -- & 2,73 & 3,12 & 8,10 & -- & -- & -- & -- & -- & -- & -- & -- \\
\hline & jul-2009 & -- & -- & -- & -- & -- & -- & -- & -- & -- & -- & -- & -- & -- & -- & -- & -- & -- & -- & -- \\
\hline & jul-2009 DUP & 80,00 & -- & 80,00 & 0,00 & 2,87 & 0,38 & 8,08 & -- & 2,67 & 24,12 & 7,04 & 9 & 8 & 84 & 2011 & 2012 & 32768 & 43330 & 121580 \\
\hline & ago-2009 & 93,33 & 5,77 & 100,00 & 0,00 & 4,68 & 0,84 & 4,11 & 0,07 & 2,23 & 30,00 & 7,55 & 208 & 295 & 3074 & 9561 & 4557 & 61938 & 66117 & 93710 \\
\hline & out-2009 & 101,67 & 2,89 & -- & -- & 3,40 & 1,08 & 4,48 & 0,39 & 1,68 & 23,90 & 7,22 & 64 & 68 & 1271 & 7755 & 4399 & 39916 & 45416 & 75672 \\
\hline & out-2009 DUP & 98,33 & 5,77 & -- & -- & 3,12 & 0,31 & 3,89 & 0,10 & 2,46 & 31,60 & 7,38 & 40 & 59 & 820 & 7844 & 5794 & 51212 & 73077 & 170142 \\
\hline & nov-2009 & 66,67 & 11,55 & -- & -- & 2,63 & 0,55 & 3,97 & 0,03 & 2,94 & 36,42 & 7,00 & 57 & 87 & 1116 & 18710 & 14277 & 102711 & 114119 & 139382 \\
\hline & nov-2009 DUP & -- & -- & -- & -- & -- & -- & -- & -- & 2,92 & 27,30 & 7,74 & -- & -- & -- & -- & -- & -- & -- & -- \\
\hline & dez-2009 & 138,33 & 2,89 & -- & -- & 9,53 & 6,99 & 3,83 & 0,03 & 3,03 & 42,58 & -- & 430 & 589 & 4259 & 12781 & 7503 & 67548 & 55594 & 88784 \\
\hline & dez-2009 DUP & 86,67 & 2,89 & -- & -- & 2,95 & 0,13 & -- & -- & 2,16 & 28,79 & -- & -- & -- & -- & -- & - & -- & -- & -- \\
\hline \multirow{17}{*}{ 岁 } & ago-2009 & 36,67 & 5,77 & -- & -- & 6,00 & 1,35 & 3,36 & 0,02 & 5,40 & 49,00 & 6,20 & 32 & 39 & 590 & 5401 & 4551 & 72841 & 94227 & 184899 \\
\hline & set-2009 & 30,00 & -- & 40,00 & 0,00 & 12,73 & 4,39 & 3,29 & 0,03 & 4,80 & 42,00 & 6,20 & 34 & 40 & 505 & 4915 & 4283 & 68754 & 85452 & 148580 \\
\hline & out-2009 & 38,33 & 7,64 & -- & -- & 9,05 & 0,94 & 4,54 & 0,05 & 14,30 & 95,00 & 6,00 & 26 & 38 & 472 & 3781 & 2979 & 50844 & 81342 & 204460 \\
\hline & nov-2009 & 28,33 & 2,89 & -- & -- & 10,60 & 0,17 & -- & -- & 6,30 & 52,21 & -- & -- & -- & -- & -- & -- & -- & -- & -- \\
\hline & nov-2009 DUP & 31,67 & 2,89 & -- & -- & 2,83 & 0,12 & 3,11 & 0,13 & 4,90 & 53,00 & 6,12 & 24 & 24 & 260 & 2075 & 1385 & 18745 & 39806 & 145289 \\
\hline & dez-2009 & 35,00 & 5,00 & -- & -- & 5,38 & 0,39 & 4,97 & 0,12 & 8,73 & 78,00 & -- & 32 & 56 & 574 & 2840 & 2239 & 41726 & 89854 & 221627 \\
\hline & dez-2009 DUP & 35,00 & 10,00 & -- & -- & 5,20 & 0,17 & -- & -- & 6,16 & 64,88 & -- & -- & -- & -- & -- & -- & -- & -- & -- \\
\hline & jan-2010 & 53,33 & 2,89 & -- & -- & 9,57 & 0,55 & -- & -- & 8,92 & 80,00 & 5,57 & -- & -- & -- & -- & -- & -- & -- & -- \\
\hline & jan-2010 DUP & 28,33 & 2,89 & -- & -- & 5,92 & 0,48 & 4,79 & 0,12 & 9,00 & 100,00 & 5,50 & 108 & 240 & 2171 & 4752 & 1921 & 19175 & 33663 & 138954 \\
\hline & fev-2010 & -- & -- & -- & -- & -- & -- & -- & -- & -- & -- & -- & -- & -- & -- & -- & -- & -- & -- & -- \\
\hline & fev-2010 DUP & 33,33 & 2,89 & -- & -- & 6,65 & 3,47 & 4,50 & 0,03 & 5,69 & 80,00 & 6,06 & 3 & 3 & 55 & 771 & 553 & 9288 & 16686 & 49226 \\
\hline & mar-2010 & 31,67 & 2,89 & -- & -- & 7,70 & 0,20 & -- & -- & 7,10 & 80,00 & 5,90 & -- & -- & -- & -- & -- & -- & -- & -- \\
\hline & mar-2010 DUP & 53,33 & 2,89 & -- & -- & 11,57 & 1,56 & 2,80 & 0,03 & 7,10 & 80,00 & -- & 9 & 12 & 331 & 3294 & 2349 & 31629 & 44423 & 132526 \\
\hline & abr-2010 & 48,33 & 2,89 & -- & -- & 7,50 & 1,25 & 3,36 & 0,14 & 3,80 & 49,00 & 6,00 & 57 & 89 & 2124 & 15627 & 9591 & 76601 & 62195 & 104966 \\
\hline & abr-2010 DUP & 38,33 & 5,77 & -- & -- & 8,30 & 0,17 & 2,66 & 0,04 & 5,87 & 50,71 & -- & 10 & 3 & 56 & 539 & 440 & 7223 & 19111 & 131443 \\
\hline & mai-2010 & 40,00 & 0,00 & -- & -- & 6,93 & 0,29 & 2,57 & 0,03 & 4,98 & 51,04 & -- & 2 & 2 & 31 & 366 & 284 & 6699 & 18897 & 87029 \\
\hline & mai-2010 DUP & 16,67 & 2,89 & -- & -- & 4,90 & 0,44 & -- & -- & 3,96 & 39,79 & -- & -- & -- & -- & -- & -- & -- & -- & -- \\
\hline
\end{tabular}




\begin{tabular}{|c|c|c|c|c|c|c|c|c|c|c|c|c|c|c|c|c|c|c|c|c|}
\hline \multirow{2}{*}{ ETA } & \multirow{2}{*}{ Data } & \multicolumn{2}{|c|}{ ST (mg/L) } & \multicolumn{2}{|c|}{$\mathrm{SD}$ (mg/L) } & \multicolumn{2}{|c|}{ SST (mg/L) } & \multicolumn{2}{|c|}{ TOC (mgC/L) } & \multirow{2}{*}{$\begin{array}{l}\text { Turbidez } \\
\text { (UNT) }\end{array}$} & \multirow{2}{*}{$\begin{array}{l}\text { Cor } \\
\text { (UC) }\end{array}$} & \multirow{2}{*}{$\mathrm{pH}$} & \multicolumn{8}{|c|}{$\begin{array}{l}\text { concentração numérica de partículas com diâmetro igual a } \\
\qquad\left(n^{\circ} \text { partículas/L) }\right.\end{array}$} \\
\hline & & média & $\begin{array}{l}\text { desv. } \\
\text { pad. }\end{array}$ & média & $\begin{array}{l}\text { desv. } \\
\text { pad. }\end{array}$ & média & $\begin{array}{l}\text { desv. } \\
\text { pad. }\end{array}$ & média & $\begin{array}{l}\text { desv. } \\
\text { pad. }\end{array}$ & & & & $50 \mathrm{um}$ & $40 \mathrm{um}$ & $20 u m$ & $10 \mathrm{um}$ & 8 um & $4 \mathrm{um}$ & $2 \mathrm{um}$ & $1,2 \mathrm{um}$ \\
\hline & jun-2010 & -- & -- & -- & -- & 10,20 & 0,26 & -- & -- & 3,96 & 39,79 & -- & -- & -- & -- & -- & -- & -- & -- & -- \\
\hline & jun-2010 DUP & 63,33 & 7,64 & -- & -- & 6,57 & 0,38 & -- & -- & 3,96 & 39,79 & -- & -- & -- & -- & -- & -- & -- & -- & -- \\
\hline \multirow{20}{*}{$\stackrel{9}{\mathcal{U}}$} & jun-2009 & 116,67 & 11,55 & 66,67 & 11,55 & 8,67 & 0,83 & 2,24 & 0,31 & -- & -- & -- & 82 & 158 & 1989 & 5534 & 1857 & 20804 & 40529 & 68762 \\
\hline & jun-2009 DUP & 53,33 & 5,77 & 56,67 & 5,77 & 2,18 & 0,20 & 1,59 & 0,04 & -- & -- & -- & 6 & 11 & 150 & 862 & 838 & 19813 & 35460 & 76513 \\
\hline & jul-2009 & 76,67 & 5,77 & 16,67 & 5,77 & 15,23 & 0,34 & -- & -- & -- & -- & -- & 0 & 0 & 7 & 54 & 37 & 2620 & 6127 & 22249 \\
\hline & jul-2009 DUP & 73,33 & 11,55 & 53,33 & 5,77 & 9,17 & 0,28 & -- & -- & 15,20 & 75,00 & 7,10 & 2 & 11 & 339 & 5649 & 4366 & 63146 & 104496 & 196526 \\
\hline & ago-2009 & 30,00 & 10,00 & 36,67 & 5,77 & 4,27 & 2,98 & 1,63 & 0,04 & 3,40 & 25,00 & 7,10 & 1 & 2 & 48 & 636 & 598 & 14023 & 28635 & 84222 \\
\hline & ago-2009 DUP & 93,33 & 5,77 & 70,00 & 10,00 & 9,58 & 0,30 & 2,50 & 0,08 & 22,00 & 100,00 & 6,70 & 60 & 79 & 1101 & 4964 & 2407 & 33438 & 68011 & 233288 \\
\hline & set-2009 & 90,00 & -- & 43,33 & 5,77 & 18,85 & 0,75 & 7,19 & 0,19 & 40,00 & 270,00 & 7,00 & 3 & 4 & 165 & 2785 & 3188 & 96251 & 168626 & 230365 \\
\hline & set-2009 DUP & 80,00 & 10,00 & 36,67 & 5,77 & 34,43 & 5,13 & 6,13 & 0,62 & 60,00 & 60,00 & 6,70 & 35 & 54 & 573 & 6110 & 5539 & 95252 & 139355 & 204211 \\
\hline & out-2009 & 63,33 & 5,77 & 6,25 & 0,40 & 4,93 & 0,40 & 1,83 & 0,12 & 6,80 & 40,00 & 7,20 & 89 & 103 & 1520 & 5261 & 2383 & 33869 & 70337 & 167202 \\
\hline & out-2009 DUP & 81,67 & 2,89 & 43,33 & 2,89 & 4,53 & 0,33 & 1,76 & 0,04 & 8,70 & 30,00 & 6,80 & 72 & 90 & 1300 & 5935 & 3188 & 35259 & 51052 & 145112 \\
\hline & nov-2009 & 50,00 & 0,00 & 80,00 & 0,00 & 39,27 & 2,81 & 4,50 & 0,15 & 7,50 & 140,00 & 7,50 & 425 & 1022 & 9965 & 52563 & 28318 & 218733 & 129048 & 117926 \\
\hline & nov-2009 DUP & 93,33 & 28,87 & 51,67 & 7,64 & 18,03 & 18,74 & 2,49 & 0,08 & 3,60 & 40,00 & 7,20 & 227 & 203 & 1617 & 6054 & 3228 & 37778 & 57515 & 131243 \\
\hline & dez-2009 & 61,67 & 2,89 & 93,33 & 28,87 & 26,43 & 5,23 & 2,98 & 0,02 & 20,40 & 100,00 & 7,10 & 609 & 729 & 7170 & 20623 & 7396 & 49268 & 54631 & 111168 \\
\hline & dez-2009 DUP & 81,67 & 2,89 & 40,00 & 0,00 & 9,00 & 0,82 & 2,11 & 0,04 & 4,20 & 25,00 & 7,00 & 27 & 36 & 959 & 2641 & 750 & 4816 & 7080 & 31173 \\
\hline & jan-2010 & 106,67 & 5,77 & 53,33 & 5,77 & 10,40 & 0,75 & 2,86 & 0,14 & 11,50 & 55,00 & 7,10 & 186 & 188 & 3052 & 9535 & 4895 & 72398 & 77964 & 152793 \\
\hline & jan-2010 DUP & 106,67 & 2,89 & -- & -- & 21,17 & 0,64 & 1,57 & 0,29 & 22,00 & 90,00 & 7,20 & 193 & 344 & 5268 & 26644 & 15014 & 129046 & 118012 & 145599 \\
\hline & fev-2010 & 111,67 & 2,89 & 48,33 & 2,89 & 5,83 & 2,49 & 2,15 & 0,10 & 4,10 & 35,00 & 7,10 & 34 & 66 & 1045 & 4849 & 2602 & 33122 & 52161 & 118652 \\
\hline & fev-2010 DUP & 110,00 & -- & -- & -- & 5,63 & 1,11 & 2,51 & 0,08 & 5,70 & 45,00 & 7,80 & 2 & 2 & 105 & 1912 & 1277 & 33158 & 53394 & 135341 \\
\hline & mar-2010 & 46,67 & 2,89 & 91,67 & 2,89 & 4,13 & 0,21 & 2,13 & 0,04 & 4,50 & 30,00 & 6,90 & 3 & 1 & 30 & 269 & 202 & 4850 & 13310 & 103120 \\
\hline & mar-2010 DUP & 93,33 & 2,89 & 48,33 & 2,89 & 6,90 & 0,10 & 1,82 & 0,07 & 2,28 & 25,00 & 7,30 & 13 & 8 & 102 & 870 & 662 & 9497 & 24733 & 85493 \\
\hline \multirow{5}{*}{$\underset{\nwarrow}{ঞ}$} & jun-2009 & 46,67 & 5,77 & 6,67 & 11,55 & 5,67 & 0,08 & 0,79 & 0,04 & 15,50 & 91,00 & 7,30 & 16 & 14 & 95 & 405 & 245 & 8610 & 38360 & 198385 \\
\hline & jun-2009 DUP & 63,33 & 5,77 & 56,67 & 11,55 & 8,57 & 1,23 & 1,94 & 0,07 & 19,00 & 49,00 & 7,20 & 22 & 66 & 1133 & 5074 & 2563 & 46238 & 104791 & 238544 \\
\hline & ago-2009 & 30,00 & -- & 26,67 & 5,77 & 4,92 & 0,23 & 0,97 & 0,03 & 6,20 & 22,00 & 7,40 & 5 & 7 & 125 & 1509 & 1233 & 23588 & 44895 & 180849 \\
\hline & ago-2009 DUP & 60,00 & -- & 60,00 & 10,00 & 7,65 & 0,49 & -- & -- & 10,00 & 32,00 & 7,40 & -- & -- & -- & -- & -- & -- & -- & -- \\
\hline & set-2009 & 70,00 & 5,00 & 66,67 & 11,55 & 9,88 & 0,90 & 4,75 & 0,03 & 18,00 & 50,00 & 7,30 & 101 & 111 & 869 & 3212 & 2050 & 33475 & 68561 & 189609 \\
\hline
\end{tabular}




\begin{tabular}{|c|c|c|c|c|c|c|c|c|c|c|c|c|c|c|c|c|c|c|c|c|}
\hline \multirow{10}{*}{ ETA } & \multirow{2}{*}{ Data } & \multicolumn{2}{|c|}{ ST (mg/L) } & \multicolumn{2}{|c|}{$\mathrm{SD}(\mathrm{mg} / \mathrm{L})$} & \multicolumn{2}{|c|}{ SST (mg/L) } & \multicolumn{2}{|c|}{ TOC (mgC/L) } & \multirow{2}{*}{$\begin{array}{c}\text { Turbidez } \\
\text { (UNT) }\end{array}$} & \multirow{2}{*}{$\begin{array}{l}\text { Cor } \\
\text { (UC) }\end{array}$} & \multirow{2}{*}{$\mathrm{pH}$} & \multicolumn{8}{|c|}{$\begin{array}{l}\text { concentração numérica de partículas com diâmetro igual a } \\
\qquad\left(n^{\circ} \text { partículas/L) }\right.\end{array}$} \\
\hline & & média & $\begin{array}{l}\text { desv. } \\
\text { pad. }\end{array}$ & média & $\begin{array}{l}\text { desv. } \\
\text { pad. }\end{array}$ & média & $\begin{array}{l}\text { desv. } \\
\text { pad. }\end{array}$ & média & $\begin{array}{l}\text { desv. } \\
\text { pad. }\end{array}$ & & & & $50 \mathrm{um}$ & 40 um & 20 um & $10 \mathrm{um}$ & 8 um & $4 \mathrm{um}$ & $2 \mathrm{um}$ & $1,2 \mathrm{um}$ \\
\hline & set-2009 DUP & 90,00 & -- & 53,33 & 5,77 & 30,57 & 1,95 & 1,21 & 0,05 & -- & -- & -- & 10 & 36 & 1559 & 8204 & 4805 & 68955 & 112507 & 204172 \\
\hline & nov-2009 & -- & -- & -- & -- & -- & -- & 2,00 & 0,38 & -- & -- & -- & -- & -- & -- & -- & -- & -- & -- & -- \\
\hline & nov-2009 DUP & -- & -- & -- & -- & -- & -- & -- & -- & -- & -- & -- & -- & -- & -- & -- & -- & -- & -- & -- \\
\hline & dez-2009 & -- & -- & -- & -- & -- & -- & -- & -- & -- & -- & -- & -- & -- & -- & -- & -- & -- & -- & -- \\
\hline & dez-2009 DUP & -- & -- & -- & -- & -- & -- & -- & -- & -- & -- & -- & -- & -- & -- & -- & -- & -- & -- & -- \\
\hline & jan-2010 & 73,33 & 2,89 & -- & -- & 24,37 & 3,12 & 1,76 & 0,13 & 31,00 & 69,00 & 7,30 & 17 & 28 & 282 & 2118 & 1758 & 41114 & 107337 & 259225 \\
\hline & jan-2010 DUP & 153,33 & 5,77 & -- & -- & 61,07 & 3,95 & 3,73 & 0,23 & 198,00 & -- & -- & -- & -- & -- & -- & -- & -- & -- & -- \\
\hline & mar-2010 & 606,67 & 5,77 & -- & -- & 268,77 & 6,14 & -- & -- & 197,00 & -- & -- & -- & -- & -- & -- & -- & -- & -- & -- \\
\hline \multirow{19}{*}{ 䢔 } & jun-2009 & 54,97 & 5,84 & 53,33 & 5,77 & 1,64 & 0,07 & 2,64 & 0,00 & 2,95 & 14,05 & -- & 66 & 78 & 678 & 3117 & 1875 & 26456 & 51581 & 135218 \\
\hline & jun-2009 DUP & 26,67 & 5,77 & 10,00 & 0,00 & 1,20 & 0,36 & 2,68 & 0,04 & 2,56 & 16,13 & -- & 10 & 2 & 46 & 330 & 372 & 10006 & 28805 & 122550 \\
\hline & jul-2009 & 30,00 & 10,00 & -- & -- & 1,72 & 0,31 & -- & -- & 2,94 & 22,45 & -- & -- & -- & -- & -- & -- & -- & -- & -- \\
\hline & jul-2009 DUP & 66,67 & 11,55 & 10,00 & 10,00 & 1,78 & 0,20 & 5,20 & -- & 4,25 & 21,35 & -- & 3 & 0 & 12 & 129 & 105 & 2375 & 8750 & 86158 \\
\hline & ago-2009 & 40,00 & 0,00 & 36,67 & 5,77 & 2,45 & 0,74 & 1,46 & 0,02 & 2,68 & 15,10 & -- & 4 & 4 & 50 & 816 & 687 & 9689 & 24822 & 110396 \\
\hline & ago-2009 DUP & 25,00 & 5,00 & 46,67 & 11,55 & 1,80 & 0,09 & 1,53 & 0,02 & 3,60 & 13,10 & -- & 14 & 19 & 255 & 1764 & 1366 & 22856 & 52468 & 156053 \\
\hline & set-2009 & 61,67 & 2,89 & 36,67 & 5,77 & 17,52 & 1,38 & 2,50 & 0,22 & 26,66 & 100,25 & -- & 7 & 4 & 95 & 2825 & 3630 & 110981 & 179278 & 223367 \\
\hline & set-2009 DUP & 58,33 & 2,89 & 43,33 & 5,77 & 4,07 & 0,03 & 1,55 & 0,03 & 5,12 & 21,00 & -- & 33 & 25 & 559 & 9618 & 6720 & 48031 & 52418 & 127388 \\
\hline & out-2009 & 33,33 & 2,89 & 43,33 & 5,77 & 1,38 & 0,13 & 1,53 & 0,05 & 3,08 & 16,40 & -- & 4 & 5 & 32 & 376 & 369 & 5169 & 9560 & 36318 \\
\hline & out-2009 DUP & 48,33 & 2,89 & -- & -- & 3,93 & 0,35 & 1,68 & 0,03 & 8,15 & 16,10 & -- & 57 & 48 & 379 & 1917 & 1197 & 23441 & 70725 & 248799 \\
\hline & nov-2009 & 43,33 & 2,89 & -- & -- & 1,45 & 0,57 & 1,73 & 0,07 & 2,39 & 13,50 & -- & 8 & 6 & 82 & 753 & 530 & 7158 & 15109 & 95856 \\
\hline & nov-2009 DUP & 45,00 & -- & -- & -- & 2,22 & 0,20 & 1,61 & 0,02 & 26,76 & 11,05 & -- & 5 & 1 & 22 & 348 & 322 & 4732 & 7589 & 23283 \\
\hline & dez-2009 & -- & -- & -- & -- & -- & -- & -- & -- & -- & -- & -- & -- & -- & -- & -- & -- & -- & -- & -- \\
\hline & dez-2009 DUP & -- & -- & -- & -- & -- & -- & -- & -- & -- & -- & -- & -- & -- & -- & -- & -- & -- & -- & -- \\
\hline & fev-2010 & 46,67 & 2,89 & -- & -- & 2,23 & 0,48 & -- & -- & 8,21 & 27,20 & -- & -- & -- & -- & -- & -- & -- & -- & -- \\
\hline & fev-2010 DUP & -- & -- & -- & -- & -- & -- & -- & -- & -- & -- & -- & -- & -- & -- & -- & -- & -- & -- & -- \\
\hline & mar-2010 & 23,33 & 2,89 & -- & -- & 1,45 & 0,05 & -- & -- & 5,42 & 12,50 & -- & -- & -- & -- & -- & -- & -- & -- & -- \\
\hline & mar-2010 DUP & 45,00 & -- & -- & -- & 1,45 & 0,23 & 1,98 & 0,03 & 3,07 & 10,00 & -- & 6 & 4 & 83 & 709 & 522 & 8990 & 24591 & 125038 \\
\hline & abr-2010 & 48,33 & 2,89 & -- & -- & 2,50 & 0,39 & 2,18 & 0,17 & 10,19 & 25,00 & -- & 2 & 2 & 15 & 152 & 73 & 3263 & 8402 & 41720 \\
\hline
\end{tabular}




\begin{tabular}{|c|c|c|c|c|c|c|c|c|c|c|c|c|c|c|c|c|c|c|c|c|}
\hline \multirow{2}{*}{ ETA } & \multirow{2}{*}{ Data } & \multicolumn{2}{|c|}{$\mathrm{ST}(\mathrm{mg} / \mathrm{L})$} & \multicolumn{2}{|c|}{$\mathrm{SD}(\mathrm{mg} / \mathrm{L})$} & \multicolumn{2}{|c|}{ SST (mg/L) } & \multicolumn{2}{|c|}{$\mathrm{TOC}$ (mgC/L) } & \multirow{2}{*}{$\begin{array}{c}\text { Turbidez } \\
\text { (UNT) }\end{array}$} & \multirow{2}{*}{$\begin{array}{l}\text { Cor } \\
\text { (UC) }\end{array}$} & \multirow{2}{*}{$\mathrm{pH}$} & \multicolumn{8}{|c|}{$\begin{array}{l}\text { concentração numérica de partículas com diâmetro igual a } \\
\left(\mathrm{n}^{\circ} \text { partículas/L) }\right.\end{array}$} \\
\hline & & média & $\begin{array}{l}\text { desv. } \\
\text { pad. }\end{array}$ & média & $\begin{array}{l}\text { desv. } \\
\text { pad. }\end{array}$ & média & $\begin{array}{l}\text { desv. } \\
\text { pad. }\end{array}$ & média & $\begin{array}{l}\text { desv. } \\
\text { pad. }\end{array}$ & & & & 50 um & $40 \mathrm{um}$ & 20 um & $10 \mathrm{um}$ & 8 um & 4 um & $2 \mathrm{um}$ & $1,2 \mathrm{um}$ \\
\hline \multirow{23}{*}{$\frac{a}{a}$} & abr-2010 DUP & 30,00 & -- & -- & -- & 3,03 & 1,46 & 1,77 & 0,06 & 3,86 & 15,00 & 6,70 & 10 & 2 & 9 & 177 & 230 & 5083 & 14727 & 88919 \\
\hline & mai-2010 & 41,67 & 2,89 & -- & -- & 2,53 & 0,16 & 1,92 & 0,02 & 4,43 & 20,00 & -- & 4 & 4 & 33 & 261 & 230 & 4091 & 11643 & 67934 \\
\hline & mai-2010 DUP & 56,67 & 5,77 & -- & -- & 5,17 & 4,62 & -- & -- & 4,63 & 21,00 & -- & -- & -- & -- & -- & -- & -- & -- & -- \\
\hline & jun-2009 & 120,00 & -- & 83,33 & 11,55 & 25,17 & 3,15 & 1,99 & 0,06 & 20,20 & 174,05 & 7,25 & 95 & 154 & 992 & 2056 & 788 & 8370 & 25340 & 190581 \\
\hline & jun-2009 DUP & 153,33 & 15,28 & 126,67 & 11,55 & 48,17 & 2,84 & 3,22 & 0,08 & 45,00 & 377,75 & 7,15 & 293 & 798 & 13271 & 60318 & 25470 & 150529 & 101082 & 107700 \\
\hline & jul-2010 & 140,00 & -- & 76,67 & 11,55 & 38,43 & 0,42 & 10,12 & -- & 27,85 & 224,75 & 7,20 & 0 & 0 & 2 & 17 & 29 & 804 & 10317 & 202901 \\
\hline & ago-2009 & 110,00 & 0,00 & 130,00 & 10,00 & 17,63 & 1,55 & 2,87 & 0,01 & 20,18 & 171,36 & 7,18 & 413 & 505 & 6509 & 28860 & 12538 & 84738 & 85284 & 142306 \\
\hline & set-2009 & 190,00 & -- & 100,00 & 0,00 & 84,08 & 6,53 & 5,50 & 0,04 & 81,55 & 591,25 & 6,95 & 312 & 418 & 7071 & 49822 & 26499 & 173591 & 119556 & 125946 \\
\hline & out-2009 & 323,33 & 5,77 & -- & -- & 98,87 & 5,35 & 7,27 & 0,14 & 141,44 & 1047,92 & 6,88 & -- & -- & -- & -- & -- & -- & -- & -- \\
\hline & nov-2009 & 176,67 & 2,89 & -- & -- & 65,27 & 0,55 & 4,62 & 0,07 & 51,00 & 408,30 & 6,95 & 1155 & 2466 & 18988 & 85331 & 33033 & 155052 & 80851 & 81822 \\
\hline & dez-2009 & 200,00 & -- & -- & -- & 112,10 & 10,54 & 5,10 & 0,24 & 183,85 & 1308,95 & 6,85 & -- & -- & -- & -- & -- & -- & -- & -- \\
\hline & dez-2009 DUP & 276,67 & 2,89 & -- & -- & 118,73 & 8,39 & 5,89 & 0,08 & 78,05 & 596,90 & 7,00 & -- & -- & -- & -- & -- & -- & -- & -- \\
\hline & jan-2010 & 426,67 & 5,77 & -- & -- & 300,93 & 8,42 & 8,30 & 0,30 & 250,85 & 1810,20 & 6,95 & -- & -- & -- & -- & -- & -- & -- & -- \\
\hline & jan-2010 DUP & 433,33 & 5,77 & -- & -- & 293,80 & 4,10 & 8,30 & 0,30 & 327,40 & 2377,20 & 6,90 & -- & -- & -- & -- & -- & -- & -- & -- \\
\hline & fev-2010 & 193,33 & 15,28 & -- & -- & 77,67 & 1,27 & 9,51 & 0,11 & 116,00 & 862,30 & 6,90 & -- & -- & -- & -- & -- & -- & -- & -- \\
\hline & fev-2010 DUP & 306,67 & 11,55 & -- & -- & 206,53 & 47,76 & 6,49 & 0,11 & 117,30 & 1059,10 & 6,90 & -- & -- & -- & -- & -- & -- & -- & -- \\
\hline & mar-2010 & 166,67 & 5,77 & -- & -- & 51,33 & 0,61 & -- & -- & 42,90 & 354,65 & 7,20 & -- & -- & -- & -- & -- & -- & -- & -- \\
\hline & mar-2010 DUP & 226,67 & 5,77 & -- & -- & 151,07 & 3,25 & 4,03 & 0,04 & 94,10 & 907,10 & 7,15 & -- & -- & -- & -- & -- & -- & -- & -- \\
\hline & abr-2010 & 150,00 & 0,00 & -- & -- & 49,07 & 1,03 & 3,25 & 0,12 & 30,30 & 284,00 & 7,30 & 881 & 2234 & 36912 & 83071 & 18913 & 64030 & 29651 & 36910 \\
\hline & abr-2010 DUP & 190,00 & 0,00 & -- & -- & 62,93 & 1,17 & 3,29 & 0,06 & 39,25 & 365,30 & 7,25 & 4 & 2 & 176 & 6053 & 4680 & 43736 & 59280 & 170389 \\
\hline & mai-2010 & 140,00 & 0,00 & -- & -- & 38,37 & 5,86 & 3,31 & 0,03 & 32,40 & 303,75 & 7,30 & 5 & 4 & 47 & 535 & 413 & 22269 & 101689 & 304200 \\
\hline & mai-2010 DUP & -- & -- & -- & -- & -- & -- & -- & -- & -- & -- & -- & -- & -- & -- & -- & -- & -- & -- & -- \\
\hline & jun-2010 & 140,00 & 10,00 & -- & -- & 28,23 & 3,42 & -- & -- & -- & -- & -- & -- & -- & -- & -- & -- & -- & -- & -- \\
\hline
\end{tabular}


ANEXO A

BALANÇOS DE MASSA 
ETA Alto de Cotia

\begin{tabular}{|c|c|c|c|c|c|c|c|c|c|c|c|c|c|c|c|c|c|c|c|}
\hline \multirow[b]{2}{*}{$\begin{array}{l}\text { TIPO } \\
\text { ÁGUA }\end{array}$} & \multirow[b]{2}{*}{ PARAM. } & \multicolumn{18}{|c|}{ PERÍODO } \\
\hline & & $\begin{array}{l}\text { ago- } \\
2009\end{array}$ & $\begin{array}{c}\text { set- } \\
2009\end{array}$ & $\begin{array}{l}\text { out- } \\
2009\end{array}$ & $\begin{array}{l}\text { nov- } \\
2009\end{array}$ & $\begin{array}{l}\text { nov- } \\
2009 \\
\text { DUP }\end{array}$ & $\begin{array}{l}\text { dez- } \\
2009\end{array}$ & $\begin{array}{l}\text { dez- } \\
2009 \\
\text { DUP }\end{array}$ & $\begin{array}{l}\text { jan- } \\
2010\end{array}$ & $\begin{array}{l}\text { jan- } \\
2010 \\
\text { DUP }\end{array}$ & $\begin{array}{c}\text { fev- } \\
2010\end{array}$ & $\begin{array}{l}\text { mar- } \\
2010\end{array}$ & $\begin{array}{l}\text { mar- } \\
2010 \\
\text { DUP }\end{array}$ & $\begin{array}{l}\text { abr- } \\
2010\end{array}$ & $\begin{array}{l}\text { abr- } \\
2010 \\
\text { DUP }\end{array}$ & $\begin{array}{l}\text { mai- } \\
2010\end{array}$ & $\begin{array}{l}\text { mai- } \\
2010 \\
\text { DUP }\end{array}$ & $\begin{array}{l}\text { jun- } \\
2010\end{array}$ & $\begin{array}{l}\text { jun- } \\
2010 \\
\text { DUP }\end{array}$ \\
\hline \multirow{2}{*}{ Bruta } & SST (mg/L) & 6,00 & 12,73 & 9,05 & 10,60 & 2,83 & 5,38 & 5,20 & 9,57 & 5,92 & 6,65 & 7,70 & 11,57 & 7,50 & 8,30 & 6,93 & 4,90 & 10,20 & 6,57 \\
\hline & desv. pad. & 1,35 & 4,39 & 0,94 & 0,17 & 0,12 & 0,39 & 0,17 & 0,55 & 0,48 & 3,47 & 0,20 & 1,56 & 1,25 & 0,17 & 0,29 & 0,44 & 0,26 & 0,38 \\
\hline \multirow{2}{*}{ Coagulada } & SST (mg/L) & 14,07 & 13,23 & 25,97 & 11,67 & 14,33 & 17,03 & 17,07 & 21,77 & 25,13 & 16,63 & 12,97 & 20,93 & 17,40 & 12,23 & 12,13 & 11,43 & 17,90 & 12,13 \\
\hline & desv. pad. & 0,57 & 0,15 & 0,68 & 1,10 & 1,14 & 0,15 & 1,08 & 4,97 & 0,95 & 0,83 & 0,72 & 0,65 & 1,22 & 0,93 & 0,35 & 0,12 & 10,45 & 0,31 \\
\hline \multirow{2}{*}{ Floculada } & SST (mg/L) & 11,50 & 15,53 & 19,67 & 16,17 & 11,87 & 22,80 & 18,23 & 23,63 & 27,30 & 16,13 & 16,47 & 18,03 & 18,13 & 21,20 & 12,17 & 11,20 & 4,77 & 12,20 \\
\hline & desv. pad. & 0,52 & 0,74 & 1,42 & 4,89 & 2,95 & 0,17 & 0,29 & 1,94 & 0,30 & 1,64 & 0,31 & 1,38 & 0,81 & 0,40 & 0,70 & 1,61 & 0,15 & 0,87 \\
\hline \multirow{2}{*}{ Decantada } & SST (mg/L) & 1,82 & 1,95 & 1,63 & 1,18 & 2,02 & 1,17 & 1,12 & 1,32 & 1,13 & 8,33 & 1,25 & 2,30 & 1,37 & 4,12 & 1,96 & 1,62 & 2,17 & 2,22 \\
\hline & desv. pad. & 0,23 & 0,13 & 0,26 & 0,03 & 0,25 & 0,03 & 0,19 & 0,13 & 0,13 & 0,41 & 0,18 & 0,22 & 0,42 & 4,84 & 0,14 & 0,18 & 1,41 & 0,04 \\
\hline
\end{tabular}

\begin{tabular}{|c|c|c|c|c|c|c|c|c|c|c|c|c|c|c|c|c|c|c|}
\hline \multicolumn{2}{|l|}{ VAZ ÕES (L/s) } & & & & & & & & & & & & & & & & & \\
\hline Vazão de recirculação média & 0 & & & & & & & & & & & & & & & & & \\
\hline Vazão de descarte decantadores & 49,38 & & & & & & & & & & & & & & & & & \\
\hline Vazão de lavagem filtros & 30,00 & & & & & & & & & & & & & & & & & \\
\hline PARÂMETROS & $\begin{array}{l}\text { ago- } \\
2009\end{array}$ & $\begin{array}{l}\text { set- } \\
2009\end{array}$ & $\begin{array}{l}\text { out- } \\
2009\end{array}$ & $\begin{array}{l}\text { nov- } \\
2009\end{array}$ & $\begin{array}{l}\text { nov- } \\
2009 \\
\text { DUP }\end{array}$ & $\begin{array}{l}\text { dez- } \\
2009\end{array}$ & $\begin{array}{c}\text { dez- } \\
2009 \\
\text { DUP }\end{array}$ & $\begin{array}{l}\text { jan- } \\
2010\end{array}$ & $\begin{array}{l}\text { jan- } \\
2010 \\
\text { DUP }\end{array}$ & $\begin{array}{l}\text { fev- } \\
2010\end{array}$ & $\begin{array}{l}\text { mar- } \\
2010\end{array}$ & $\begin{array}{l}\text { mar- } \\
2010 \\
\text { DUP }\end{array}$ & $\begin{array}{l}\text { abr- } \\
2010\end{array}$ & $\begin{array}{l}\text { abr- } \\
2010 \\
\text { DUP }\end{array}$ & $\begin{array}{l}\text { mai- } \\
2010\end{array}$ & $\begin{array}{l}\text { mai- } \\
2010 \\
\text { DUP }\end{array}$ & $\begin{array}{l}\text { jun- } \\
2010\end{array}$ & $\begin{array}{l}\text { jun- } \\
2010 \\
\text { DUP }\end{array}$ \\
\hline lodo no floculador (kg/dia) & 247 & -231 & 653 & -474 & 259 & -602 & -118 & -197 & -239 & 58 & -383 & 303 & -78 & -984 & -3 & 24 & 1301 & -7 \\
\hline lodo no decantador ( $\mathrm{kg} / \mathrm{dia})$ & 941 & 1370 & 1876 & 1585 & 1043 & 2263 & 1734 & 2366 & 2894 & 945 & 1672 & 1656 & 1800 & 1892 & 1012 & 986 & 267 & 1104 \\
\hline lodo no filtro (kg/dia) & 167 & 187 & 162 & 120 & 203 & 117 & 108 & 134 & 120 & 936 & 132 & 231 & 140 & 434 & 184 & 158 & 205 & 234 \\
\hline TOTAL gerado (kg/dia) & 1356 & 1557 & 2691 & 1705 & 1506 & 2380 & 1843 & 2499 & 3014 & 1939 & 1803 & 2190 & 1941 & 2327 & 1196 & 1169 & 1774 & 1339 \\
\hline desv. pad. do TOTAL (kg/dia) & 50 & 15 & 147 & 116 & 310 & 16 & 109 & 525 & 104 & 192 & 79 & 144 & 130 & 102 & 35 & 164 & 15 & 34 \\
\hline Vazão diária média (L/s) & 1116 & 1160 & 1199 & 1220 & 1216 & 1208 & 1170 & 1224 & 1278 & 1349 & 1268 & 1211 & 1239 & 1270 & 1137 & 1183 & 1147 & 1270 \\
\hline Vazão efluente decantadores (L/s) & 1067 & 1111 & 1150 & 1171 & 1167 & 1159 & 1120 & 1175 & 1228 & 1300 & 1218 & 1162 & 1189 & 1221 & 1088 & 1134 & 1098 & 1221 \\
\hline
\end{tabular}




\section{ETA Cubatão}

\begin{tabular}{|c|c|c|c|c|c|c|c|c|c|c|c|c|c|c|c|c|c|c|c|c|c|}
\hline \multirow[b]{2}{*}{$\begin{array}{l}\text { TIPO } \\
\text { ÁGUA }\end{array}$} & \multirow[b]{2}{*}{ PARAM. } & \multicolumn{20}{|c|}{ PERÍODO } \\
\hline & & $\begin{array}{l}\text { jun- } \\
2009\end{array}$ & $\begin{array}{l}\text { jun- } \\
2009 \\
\text { DUP }\end{array}$ & $\begin{array}{c}\text { jul- } \\
2009\end{array}$ & $\begin{array}{l}\text { jul- } \\
2009 \\
\text { DUP }\end{array}$ & $\begin{array}{l}\text { ago- } \\
2009\end{array}$ & $\begin{array}{l}\text { ago- } \\
2009 \\
\text { DUP }\end{array}$ & $\begin{array}{l}\text { set- } \\
2009\end{array}$ & $\begin{array}{l}\text { set- } \\
2009 \\
\text { DUP }\end{array}$ & $\begin{array}{l}\text { out- } \\
2009\end{array}$ & $\begin{array}{l}\text { out- } \\
2009 \\
\text { DUP }\end{array}$ & $\begin{array}{l}\text { nov- } \\
2009\end{array}$ & $\begin{array}{l}\text { nov- } \\
2009 \\
\text { DUP }\end{array}$ & $\begin{array}{l}\text { dez- } \\
2009\end{array}$ & $\begin{array}{l}\text { dez- } \\
2009 \\
\text { DUP }\end{array}$ & $\begin{array}{l}\text { jan- } \\
2010\end{array}$ & $\begin{array}{l}\text { jan- } \\
2010 \\
\text { DUP }\end{array}$ & $\begin{array}{l}\text { fev- } \\
2010\end{array}$ & $\begin{array}{l}\text { fev- } \\
2010 \\
\text { DUP }\end{array}$ & $\begin{array}{l}\text { mar- } \\
2010\end{array}$ & $\begin{array}{l}\text { mar- } \\
2010 \\
\text { DUP }\end{array}$ \\
\hline \multirow{2}{*}{ Bruta } & $\mathrm{SST}(\mathrm{mg} / \mathrm{L})$ & 8,67 & 2,18 & 15,23 & 9,17 & 4,27 & 9,58 & 18,85 & 34,43 & 4,93 & 4,53 & 39,27 & 18,03 & 26,43 & 9,00 & 10,40 & 21,17 & 5,83 & 5,63 & 4,13 & 6,90 \\
\hline & desv. pad. & 0,83 & 0,20 & 0,34 & 0,28 & 2,98 & 0,30 & 0,75 & 5,13 & 0,40 & 0,33 & 2,81 & 18,74 & 5,23 & 0,82 & 0,75 & 0,64 & 2,49 & 1,11 & 0,21 & 0,10 \\
\hline \multirow{2}{*}{ Coagulada } & SST (mg/L) & 10,93 & 17,73 & 64,23 & 55,17 & 13,07 & 48,50 & 57,23 & 86,30 & 38,97 & 30,33 & 81,00 & 23,23 & 72,97 & 30,80 & 49,23 & 49,03 & 20,03 & 11,73 & 34,00 & 20,93 \\
\hline & desv. pad. & 0,46 & 2,32 & 0,81 & 2,90 & 0,06 & 1,56 & 0,60 & 1,06 & 0,57 & 1,62 & 9,46 & 0,15 & 1,53 & 0,56 & 4,92 & 1,18 & 0,29 & 4,82 & 0,35 & 0,65 \\
\hline \multirow{2}{*}{ Floculada } & $\mathrm{SST}(\mathrm{mg} / \mathrm{L})$ & 18,20 & 17,63 & 64,00 & 59,93 & 12,23 & 44,67 & 85,07 & 64,90 & 36,60 & 31,53 & 75,23 & 25,47 & 53,07 & 32,73 & 48,07 & 51,30 & 21,65 & 10,37 & 29,20 & 32,67 \\
\hline & desv. pad. & 0,53 & 3,89 & 5,67 & 2,80 & 0,59 & 0,38 & 2,63 & 1,25 & 0,95 & 2,40 & 3,32 & 5,06 & 0,67 & 9,59 & 0,38 & 1,81 & 0,92 & 0,32 & 1,31 & 21,52 \\
\hline \multirow{2}{*}{ Decantada } & SST (mg/L) & 7,30 & 3,58 & 3,07 & 3,50 & 3,18 & 4,15 & 3,42 & 5,07 & 3,55 & 3,05 & 2,65 & 2,02 & 2,87 & 5,77 & 3,27 & 1,92 & 2,83 & 3,05 & 2,90 & 3,07 \\
\hline & desv. pad. & 0,17 & 0,06 & 0,10 & 0,40 & 0,18 & 0,13 & 0,72 & 0,51 & 0,17 & 0,48 & 0,70 & 0,39 & 0,80 & 1,30 & 0,81 & 0,08 & 0,03 & 0,07 & 0,17 & 0,29 \\
\hline
\end{tabular}

\begin{tabular}{|c|c|c|c|c|c|c|c|c|c|c|c|c|c|c|c|c|c|c|c|c|}
\hline \multicolumn{2}{|l|}{ VAZ ÕES (L/S) } & & & & & & & & & & & & & & & & & & & \\
\hline Vazão de recirculação média & 15,64 & & & & & & & & & & & & & & & & & & & \\
\hline Vazão de descarte decantadores & 14,00 & & & & & & & & & & & & & & & & & & & \\
\hline Vazão de lavagem filtros & 0 & & & & & & & & & & & & & & & & & & & \\
\hline PARÂMETROS & $\begin{array}{l}\text { jun- } \\
2009\end{array}$ & $\begin{array}{l}\text { jun- } \\
2009 \\
\text { DUP }\end{array}$ & $\begin{array}{c}\text { jul- } \\
2009\end{array}$ & $\begin{array}{c}\text { jul- } \\
2009 \\
\text { DUP }\end{array}$ & $\begin{array}{l}\text { ago- } \\
2009\end{array}$ & $\begin{array}{l}\text { ago- } \\
2009 \\
\text { DUP }\end{array}$ & $\begin{array}{l}\text { set- } \\
2009\end{array}$ & $\begin{array}{c}\text { set- } \\
2009 \\
\text { DUP }\end{array}$ & $\begin{array}{l}\text { out- } \\
2009\end{array}$ & $\begin{array}{l}\text { out- } \\
2009 \\
\text { DUP }\end{array}$ & $\begin{array}{l}\text { nov- } \\
2009\end{array}$ & $\begin{array}{l}\text { nov- } \\
2009 \\
\text { DUP }\end{array}$ & $\begin{array}{l}\text { dez- } \\
2009\end{array}$ & $\begin{array}{l}\text { dez- } \\
2009 \\
\text { DUP }\end{array}$ & $\begin{array}{c}\text { jan- } \\
2010\end{array}$ & $\begin{array}{l}\text { jan- } \\
2010 \\
\text { DUP }\end{array}$ & $\begin{array}{c}\text { fev- } \\
2010\end{array}$ & $\begin{array}{l}\text { fev- } \\
2010 \\
\text { DUP }\end{array}$ & $\begin{array}{l}\text { mar- } \\
2010\end{array}$ & $\begin{array}{l}\text { mar- } \\
2010 \\
\text { DUP }\end{array}$ \\
\hline lodo no floculador (kg/dia) & -762 & 11 & 22 & -453 & 83 & 354 & -7939 & 5979 & 690 & -348 & 635 & -225 & 2195 & -218 & 120 & -232 & -213 & 159 & 510 & -1327 \\
\hline lodo no decantador (kg/dia) & 1152 & 1498 & 5695 & 5370 & 903 & 3747 & 23293 & 16722 & 9642 & 8267 & 7996 & 2363 & 5541 & 3050 & 4601 & 5068 & 2479 & 856 & 2800 & 3352 \\
\hline lodo no filtro (kg/dia) & 765 & 381 & 286 & 333 & 316 & 383 & 975 & 1416 & 1035 & 885 & 292 & 203 & 316 & 651 & 335 & 197 & 373 & 355 & 308 & 347 \\
\hline TOTAL gerado (kg/dia) & 1908 & 1886 & 6000 & 5698 & 1298 & 4479 & 24264 & 24110 & 11363 & 9148 & 8920 & 2564 & 8049 & 3693 & 5052 & 5262 & 2848 & 1367 & 3615 & 3695 \\
\hline desvio padrão do TOTAL (kg/dia) & 48 & 414 & 530 & 276 & 58 & 35 & 172 & 349 & 278 & 470 & 366 & 15 & 73 & 63 & 39 & 122 & 38 & 37 & 139 & 74 \\
\hline Vazão diária média (L/s) & 1214 & 1231 & 1081 & 1100 & 1150 & 1069 & 3301 & 3234 & 3375 & 3358 & 1275 & 1165 & 1277 & 1306 & 1188 & 1187 & 1523 & 1349 & 1231 & 1309 \\
\hline Vazão efluente decantadores (L/s) & 1200 & 1217 & 1067 & 1086 & 1136 & 1055 & 3287 & 3220 & 3361 & 3344 & 1261 & 1151 & 1263 & 1292 & 1174 & 1173 & 1509 & 1335 & 1217 & 1295 \\
\hline
\end{tabular}




\section{ETA Franca}

\begin{tabular}{|c|c|c|c|c|c|c|c|c|c|c|}
\hline \multirow[b]{2}{*}{ TIPOÁGUA } & \multirow[b]{2}{*}{ PARAM. } & \multicolumn{9}{|c|}{ PERÍODO } \\
\hline & & $\begin{array}{l}\text { jun- } \\
2009\end{array}$ & $\begin{array}{l}\text { jun- } \\
2009 \\
\text { DUP }\end{array}$ & $\begin{array}{l}\text { ago- } \\
2009\end{array}$ & $\begin{array}{l}\text { ago- } \\
2009 \\
\text { DUP }\end{array}$ & $\begin{array}{l}\text { set- } \\
2009\end{array}$ & $\begin{array}{l}\text { set- } \\
2009 \\
\text { DUP }\end{array}$ & $\begin{array}{l}\text { jan- } \\
2010\end{array}$ & $\begin{array}{l}\text { jan- } \\
2010 \\
\text { DUP }\end{array}$ & $\begin{array}{l}\text { mar- } \\
2010\end{array}$ \\
\hline \multirow{2}{*}{ Bruta } & SST (mg/L) & 5,67 & 8,57 & 4,92 & 7,65 & 9,88 & 30,57 & 24,37 & 61,07 & 268,77 \\
\hline & desv. pad. & 0,08 & 1,23 & 0,23 & 0,49 & 0,90 & 1,95 & 3,12 & 3,95 & 6,14 \\
\hline \multirow{2}{*}{ Coagulada } & SST (mg/L) & 29,60 & 32,33 & 24,80 & 25,30 & 45,17 & 65,27 & 40,07 & 94,37 & 478,73 \\
\hline & desv. pad. & 3,61 & 1,31 & 0,95 & 0,36 & 5,18 & 4,11 & 1,42 & 1,70 & 4,41 \\
\hline \multirow{2}{*}{ Floculada } & $\mathrm{SST}(\mathrm{mg} / \mathrm{L})$ & 29,97 & 42,40 & 21,60 & 25,40 & 43,70 & 59,93 & 39,83 & 128,80 & 481,40 \\
\hline & desv. pad. & 0,97 & 1,35 & 2,72 & 0,72 & 3,46 & 1,01 & 4,56 & 0,80 & 5,63 \\
\hline \multirow{2}{*}{ Decantada } & SST (mg/L) & 4,50 & 3,45 & 7,85 & 4,88 & 13,02 & 1,98 & 2,45 & 13,62 & 6,56 \\
\hline & desv. pad. & 1,34 & 0,48 & 0,33 & 0,12 & 0,41 & 0,32 & 0,05 & 0,46 & 0,14 \\
\hline
\end{tabular}

\begin{tabular}{|l|c|}
\hline \multicolumn{2}{|c|}{ VAZ ÕES (L/s) } \\
\hline Vazão de recirculação média & 23,918 \\
\hline Vazão de descarte decantadores & 0 \\
\hline Vazão de lavagem filtros & 0 \\
\hline
\end{tabular}

\begin{tabular}{|l|c|c|c|c|c|c|c|c|c|}
\hline \multicolumn{1}{|c|}{ PARÂMETROS } & $\begin{array}{c}\text { jun- } \\
2009\end{array}$ & $\begin{array}{c}\text { jun- } \\
2009 \\
\text { DUP }\end{array}$ & $\begin{array}{c}\text { ago- } \\
2009\end{array}$ & $\begin{array}{c}\text { ago- } \\
2009 \\
\text { DUP }\end{array}$ & $\begin{array}{c}\text { set- } \\
2009\end{array}$ & $\begin{array}{c}\text { set- } \\
2009 \\
\text { DUP }\end{array}$ & $\begin{array}{c}\text { jan- } \\
2010\end{array}$ & $\begin{array}{c}\text { jan- } \\
2010 \\
\text { DUP }\end{array}$ & $\begin{array}{c}\text { mar- } \\
2010\end{array}$ \\
\hline lodo no floculador (kg/dia) & $-26,13$ & $-717,3$ & 237,5 & $-7,422$ & 110,61 & 402,21 & 17,392 & -2567 & $-208,7$ \\
lodo no decantador (kg/dia) & 1814,6 & 2775,3 & 1020,5 & 1522,7 & 2314 & 4370,3 & 2786,4 & 8585,3 & 37159 \\
lodo no filtro (kg/dia) & 320,64 & 245,82 & 582,62 & 362,44 & 981,65 & 149,57 & 182,61 & 1014,9 & 513 \\
TOTAL gerado (kg/dia) & 2135,2 & 3021,1 & 1840,6 & 1885,2 & 3406,2 & 4922,1 & 2986,4 & 9600,2 & 37672 \\
\hline desvio padrão do TOTAL (kg/dia) & 249,46 & 90,297 & 196,41 & 26,015 & 253,77 & 73,836 & 330,7 & 123,48 & 336,03 \\
\hline Vazão diária média (L/s) & 800,77 & 800,77 & 835,11 & 835,11 & 848,94 & 848,94 & 838,77 & 838,77 & 881,8 \\
Vazão efluente decantadores (L/s) & 824,69 & 824,69 & 859,02 & 859,02 & 872,86 & 872,86 & 862,68 & 862,68 & 905,72 \\
\hline
\end{tabular}




\section{ETA Guaraú}

\begin{tabular}{|c|c|c|c|c|c|c|c|c|c|c|c|c|c|c|c|c|c|c|c|}
\hline \multirow[b]{2}{*}{ TIPOÁGUA } & \multirow[b]{2}{*}{ PARAM. } & \multicolumn{18}{|c|}{ PERÍODO } \\
\hline & & $\begin{array}{l}\text { jun- } \\
2009\end{array}$ & $\begin{array}{l}\text { jun- } \\
2009 \\
\text { DUP }\end{array}$ & $\begin{array}{c}\text { jul- } \\
2009\end{array}$ & $\begin{array}{l}\text { jul- } \\
2009 \\
\text { DUP }\end{array}$ & $\begin{array}{l}\text { ago- } \\
2009\end{array}$ & $\begin{array}{l}\text { ago- } \\
2009 \\
\text { DUP }\end{array}$ & $\begin{array}{c}\text { set- } \\
2009\end{array}$ & $\begin{array}{c}\text { set- } \\
2009 \\
\text { DUP }\end{array}$ & $\begin{array}{l}\text { out- } \\
2009\end{array}$ & $\begin{array}{l}\text { out- } \\
2009 \\
\text { DUP }\end{array}$ & $\begin{array}{l}\text { nov- } \\
2009\end{array}$ & $\begin{array}{l}\text { nov- } \\
2009 \\
\text { DUP }\end{array}$ & $\begin{array}{c}\text { fev- } \\
2010\end{array}$ & $\begin{array}{l}\text { mar- } \\
2010\end{array}$ & $\begin{array}{l}\text { abr- } \\
2010\end{array}$ & $\begin{array}{l}\text { abr- } \\
2010 \\
\text { DUP }\end{array}$ & $\begin{array}{l}\text { mai- } \\
2010\end{array}$ & $\begin{array}{l}\text { mai- } \\
2010 \\
\text { DUP }\end{array}$ \\
\hline \multirow{2}{*}{ Bruta } & $\mathrm{SST}(\mathrm{mg} / \mathrm{L})$ & 1,64 & 1,20 & 1,72 & 1,78 & 2,45 & 1,80 & 17,52 & 4,07 & 1,38 & 3,93 & 1,45 & 2,22 & 2,23 & 1,45 & 2,50 & 3,03 & 2,53 & 5,17 \\
\hline & desv. pad. & 0,07 & 0,36 & 0,31 & 0,20 & 0,74 & 0,09 & 1,38 & 0,03 & 0,13 & 0,35 & 0,57 & 0,20 & 0,48 & 0,05 & 0,39 & 1,46 & 0,16 & 4,62 \\
\hline \multirow{2}{*}{ Coagulada } & $\mathrm{SST}(\mathrm{mg} / \mathrm{L})$ & 7,47 & 7,47 & 9,07 & 10,70 & 7,67 & 9,17 & 42,00 & 14,53 & 12,43 & 19,93 & 8,85 & 14,73 & 16,53 & 14,65 & 14,97 & 12,40 & 12,15 & 9,93 \\
\hline & desv. pad. & 0,15 & 0,31 & 0,15 & 0,10 & 1,36 & 0,15 & 7,71 & 0,72 & 0,25 & 1,27 & 0,07 & 1,96 & 0,12 & 1,34 & 0,81 & 1,31 & 1,06 & 2,22 \\
\hline \multirow{2}{*}{ Floculada } & $\mathrm{SST}(\mathrm{mg} / \mathrm{L})$ & 8,73 & 7,87 & 9,40 & 8,53 & 8,07 & 9,10 & 22,20 & 10,13 & 11,00 & 18,80 & 7,77 & 13,20 & 13,90 & 13,37 & 14,90 & 10,97 & 11,37 & 21,60 \\
\hline & desv. pad. & 0,75 & 0,32 & 0,00 & 0,12 & 3,06 & 0,26 & 0,61 & 1,93 & 0,62 & 0,95 & 0,12 & 0,36 & 2,07 & 0,57 & 0,90 & 0,38 & 1,39 & 12,37 \\
\hline \multirow{2}{*}{ Decantada } & $\mathrm{SST}(\mathrm{mg} / \mathrm{L})$ & 3,67 & 2,57 & 4,02 & 4,43 & 3,48 & 2,72 & 4,58 & 3,52 & 2,60 & 2,65 & 2,00 & 3,52 & 6,10 & 3,78 & 1,78 & 3,30 & 3,30 & 5,40 \\
\hline & desv. pad. & 0,21 & 0,20 & 0,06 & 0,38 & 0,25 & 0,45 & 0,16 & 0,08 & 0,10 & 0,05 & 0,07 & 1,10 & 0,53 & 0,93 & 0,14 & 0,53 & 1,09 & 1,64 \\
\hline
\end{tabular}

\begin{tabular}{|c|c|c|c|c|c|c|c|c|c|c|c|c|c|c|c|c|c|c|}
\hline \multicolumn{2}{|l|}{ VAZ ÕES (L/S) } & & & & & & & & & & & & & & & & & \\
\hline Vazão de recirculação média & 450 & & & & & & & & & & & & & & & & & \\
\hline Vazão de descarte decantadores & 0 & & & & & & & & & & & & & & & & & \\
\hline Vazão de lavagem filtros & 30 & & & & & & & & & & & & & & & & & \\
\hline PARÂMETROS & $\begin{array}{l}\text { jun- } \\
2009\end{array}$ & $\begin{array}{l}\text { jun- } \\
2009 \\
\text { DUP }\end{array}$ & $\begin{array}{c}\text { jul- } \\
2009\end{array}$ & $\begin{array}{l}\text { jul- } \\
2009 \\
\text { DUP }\end{array}$ & $\begin{array}{l}\text { ago- } \\
2009\end{array}$ & $\begin{array}{l}\text { ago- } \\
2009 \\
\text { DUP }\end{array}$ & $\begin{array}{l}\text { set- } \\
2009\end{array}$ & $\begin{array}{c}\text { set- } \\
2009 \\
\text { DUP }\end{array}$ & $\begin{array}{l}\text { out- } \\
2009\end{array}$ & $\begin{array}{l}\text { out- } \\
2009 \\
\text { DUP }\end{array}$ & $\begin{array}{l}\text { nov- } \\
2009\end{array}$ & $\begin{array}{l}\text { nov- } \\
2009 \\
\text { DUP }\end{array}$ & $\begin{array}{l}\text { fev- } \\
2010\end{array}$ & $\begin{array}{l}\text { mar- } \\
2010\end{array}$ & $\begin{array}{l}\text { abr- } \\
2010\end{array}$ & $\begin{array}{l}\text { abr- } \\
2010 \\
\text { DUP }\end{array}$ & $\begin{array}{l}\text { mai- } \\
2010\end{array}$ & $\begin{array}{l}\text { mai- } \\
2010 \\
\text { DUP }\end{array}$ \\
\hline lodo no floculador (kg/dia) & -3530 & -1049 & -932 & 6097 & -1066 & 179 & 52603 & 11794 & 3955 & 3323 & 3166 & 4428 & 7824 & 3802 & 190 & 4293 & 2272 & -34402 \\
\hline lodo no decantador (kg/dia) & 14118 & 13897 & 15047 & 11537 & 12218 & 17150 & 46802 & 17736 & 23179 & 47357 & 16853 & 27940 & 23173 & 28395 & 37288 & 22963 & 23401 & 47769 \\
\hline lodo no filtro (kg/dia) & 10427 & 7299 & 11422 & 12607 & 9905 & 7725 & 13033 & 10000 & 7394 & 7536 & 5687 & 10024 & 17346 & 10759 & 5071 & 9384 & 9384 & 15356 \\
\hline TOTAL gerado (kg/dia) & 24335 & 20628 & 26274 & 30109 & 21504 & 24628 & 111581 & 38956 & 34309 & 58451 & 25863 & 42547 & 49120 & 43407 & 42547 & 37140 & 35246 & 63692 \\
\hline $\begin{array}{l}\text { desvio padrão do TOTAL } \\
\text { (kg/dia) }\end{array}$ & 420 & 789 & 421 & 320 & 3567 & 701 & 1592 & 5097 & 1699 & 2760 & 333 & 1027 & 6059 & 1663 & 2524 & 1119 & 3969 & 6457 \\
\hline Vazão diária média (L/s) & 31801 & 29899 & 31900 & 32119 & 30404 & 30646 & 30299 & 30574 & 31488 & 33489 & 33374 & 32974 & 33936 & 33844 & 32453 & 34216 & 33126 & 33679 \\
\hline $\begin{array}{l}\text { Vazão efluente decantadores } \\
(\mathrm{L} / \mathrm{s})\end{array}$ & 32251 & 29899 & 31900 & 32119 & 30404 & 30646 & 30299 & 30574 & 31488 & 33489 & 33374 & 32974 & 33936 & 33844 & 32453 & 34216 & 33126 & 33679 \\
\hline
\end{tabular}




\section{ETA Presidente Prudente}

\begin{tabular}{|c|c|c|c|c|c|c|c|c|c|c|c|c|c|c|c|c|}
\hline \multirow[b]{2}{*}{$\begin{array}{l}\text { TIPO } \\
\text { ÁGUA }\end{array}$} & \multirow[b]{2}{*}{ PARAM. } & \multicolumn{15}{|c|}{ PERÍODO } \\
\hline & & $\begin{array}{l}\text { jun- } \\
2009\end{array}$ & $\begin{array}{l}\text { jun- } \\
2009 \\
\text { DUP }\end{array}$ & $\begin{array}{l}\text { ago- } \\
2009\end{array}$ & $\begin{array}{l}\text { out- } \\
2009\end{array}$ & $\begin{array}{l}\text { dez- } \\
2009\end{array}$ & $\begin{array}{l}\text { dez- } \\
2009 \\
\text { DUP }\end{array}$ & $\begin{array}{l}\text { jan- } \\
2010\end{array}$ & $\begin{array}{l}\text { jan- } \\
2010 \\
\text { DUP }\end{array}$ & $\begin{array}{l}\text { fev- } \\
2010\end{array}$ & $\begin{array}{l}\text { fev- } \\
2010 \\
\text { DUP }\end{array}$ & $\begin{array}{l}\text { mar- } \\
2010\end{array}$ & $\begin{array}{l}\text { mar- } \\
2010 \\
\text { DUP }\end{array}$ & $\begin{array}{l}\text { abr- } \\
2010\end{array}$ & $\begin{array}{l}\text { abr- } \\
2010 \\
\text { DUP }\end{array}$ & $\begin{array}{l}\text { mai- } \\
2010\end{array}$ \\
\hline \multirow{2}{*}{ Bruta } & $\mathrm{SST}(\mathrm{mg} / \mathrm{L})$ & 25,17 & 48,17 & 17,63 & 98,87 & 112,10 & 118,73 & 300,93 & 293,80 & 77,67 & 206,53 & 51,33 & 151,07 & 49,07 & 62,93 & 38,37 \\
\hline & desv. pad. & 3,15 & 2,84 & 1,55 & 5,35 & 10,54 & 8,39 & 8,42 & 4,10 & 1,27 & 47,76 & 0,61 & 3,25 & 1,03 & 1,17 & 5,86 \\
\hline \multirow{2}{*}{ Coagulada } & $\mathrm{SST}(\mathrm{mg} / \mathrm{L})$ & 38,07 & 65,50 & 36,23 & 305,00 & 146,47 & 133,93 & 324,80 & 359,20 & 104,73 & 222,07 & 65,60 & 161,73 & 60,53 & 67,20 & 53,67 \\
\hline & desv. pad. & 2,02 & 2,46 & 1,26 & 1,60 & 2,41 & 2,44 & 9,37 & 18,91 & 0,58 & 6,22 & 2,27 & 4,98 & 1,01 & 1,93 & 1,89 \\
\hline \multirow{2}{*}{ Floculada } & $\mathrm{SST}(\mathrm{mg} / \mathrm{L})$ & 30,13 & 47,10 & 39,73 & 295,73 & 161,20 & 118,10 & 295,33 & 321,93 & 87,50 & 226,20 & 61,80 & 178,50 & 54,47 & 67,20 & 53,20 \\
\hline & desv. pad. & 0,42 & 2,25 & 0,67 & 4,06 & 3,86 & 3,11 & 4,64 & 15,69 & 3,54 & 3,80 & 0,53 & 5,23 & 1,21 & 1,93 & 0,53 \\
\hline \multirow{2}{*}{ Decantada } & $\mathrm{SST}(\mathrm{mg} / \mathrm{L})$ & 1,92 & 4,95 & 2,83 & 2,17 & 5,73 & 1,95 & 1,02 & 2,18 & 2,07 & 4,57 & 32,63 & 1,67 & 1,60 & 1,68 & 1,69 \\
\hline & desv. pad. & 0,03 & 0,35 & 0,23 & 0,16 & 4,99 & 0,05 & 0,10 & 0,57 & 0,28 & 5,57 & 3,15 & 0,33 & 0,30 & 0,13 & 0,14 \\
\hline
\end{tabular}

\begin{tabular}{|c|c|c|c|c|c|c|c|c|c|c|c|c|c|c|c|}
\hline \multicolumn{2}{|l|}{ VAZ ÕES (L/S) } & & & & & & & & & & & & & & \\
\hline Vazão de recirculação média & 38,9 & & & & & & & & & & & & & & \\
\hline Vazão de descarte decantadores & 5,5 & & & & & & & & & & & & & & \\
\hline Vazão de lavagem filtros & 0 & & & & & & & & & & & & & & \\
\hline PARÂMETROS & $\begin{array}{c}\text { jun- } \\
2009\end{array}$ & $\begin{array}{c}\text { jun- } \\
2009 \\
\text { DUP }\end{array}$ & $\begin{array}{l}\text { ago- } \\
2009\end{array}$ & $\begin{array}{l}\text { out- } \\
2009\end{array}$ & $\begin{array}{l}\text { dez- } \\
2009\end{array}$ & $\begin{array}{c}\text { dez- } \\
2009 \\
\text { DUP }\end{array}$ & $\begin{array}{c}\text { jan- } \\
2010\end{array}$ & $\begin{array}{l}\text { jan- } \\
2010 \\
\text { DUP }\end{array}$ & $\begin{array}{l}\text { fev- } \\
2010\end{array}$ & $\begin{array}{l}\text { fev- } \\
2010 \\
\text { DUP }\end{array}$ & $\begin{array}{l}\text { mar- } \\
2010\end{array}$ & $\begin{array}{l}\text { mar- } \\
2010 \\
\text { DUP }\end{array}$ & $\begin{array}{l}\text { abr- } \\
2010\end{array}$ & $\begin{array}{l}\text { abr- } \\
2010 \\
\text { DUP }\end{array}$ & $\begin{array}{l}\text { mai- } \\
2010\end{array}$ \\
\hline lodo no floculador ( $\mathrm{kg} / \mathrm{dia})$ & 461 & 1070 & -204 & 539 & -857 & 921 & 1714 & 2168 & 1002 & -240 & 221 & -975 & 353 & 0 & 27 \\
\hline lodo no decantador ( $\mathrm{kg} / \mathrm{dia}$ ) & 1642 & 2484 & 2084 & 17607 & 10613 & 7105 & 19958 & 20551 & 6341 & 15060 & 2028 & 11432 & 3418 & 4328 & 3241 \\
\hline lodo no filtro (kg/dia) & 111 & 289 & 159 & 129 & 389 & 118 & 68 & 139 & 152 & 308 & 2235 & 107 & 103 & 110 & 105 \\
\hline TOTAL gerado (kg/dia) & 2377 & 4091 & 2482 & 19049 & 10068 & 8365 & 20285 & 22434 & 6541 & 14127 & 4097 & 11148 & 3781 & 4197 & 3352 \\
\hline $\begin{array}{l}\begin{array}{l}\text { desvio padrão do TOTAL } \\
\text { (kg/dia) }\end{array} \\
\end{array}$ & 23 & 125 & 67 & 230 & 156 & 180 & 299 & 956 & 250 & 402 & 35 & 305 & 74 & 121 & 32 \\
\hline Vazão diária média (L/s) & 634 & 643 & 614 & 655 & 751 & 669 & 746 & 705 & 820 & 747 & 759 & 709 & 709 & 725 & 689 \\
\hline $\begin{array}{l}\text { Vazão efluente decantadores } \\
\text { (L/s) }\end{array}$ & 668 & 676 & 648 & 689 & 784 & 702 & 779 & 738 & 853 & 781 & 793 & 743 & 743 & 759 & 723 \\
\hline
\end{tabular}


ANEXO B

APLICAÇÃO DA FÓRMULA EMPÍRICA 
ETA Alto de Cotia

\begin{tabular}{|c|c|c|c|c|c|c|c|c|c|c|c|c|c|c|c|c|}
\hline \multirow{2}{*}{ Data } & \multirow{2}{*}{$\underset{\left(\mathrm{m}^{3} / \mathrm{h}\right)}{\mathrm{Q}}$} & \multicolumn{6}{|c|}{ Dosagem (mg/L) } & \multirow{2}{*}{$\begin{array}{c}\text { SST } \\
\text { medida } \\
(\mathrm{mg} / \mathrm{L})\end{array}$} & \multicolumn{5}{|c|}{ Produção de lodo por componente } & \multirow{2}{*}{$\begin{array}{l}\text { Produção } \\
\text { total } \\
\text { estimada } \\
\text { (kg/dia) }\end{array}$} & \multirow{2}{*}{$\begin{array}{c}\text { Produção } \\
\text { total } \\
\text { (kg/dia) }\end{array}$} & \multirow{2}{*}{$\begin{array}{l}\text { desvio em } \\
\text { relação ao } \\
\text { estimado } \\
\text { (\%) }\end{array}$} \\
\hline & & SA & $\mathrm{CF}$ & $\mathrm{PACl}$ & $P$ & Cal & CAP & & $\begin{array}{c}\text { SST } \\
\text { (kg/dia) }\end{array}$ & $\begin{array}{l}\text { SST } \\
(\%)\end{array}$ & $\begin{array}{l}\text { Coag. } \\
\text { (kg/dia) }\end{array}$ & $\begin{array}{l}\text { Coag. } \\
(\%)\end{array}$ & Outros & & & \\
\hline ago-2009 & 4017,49 & 17,85 & 0 & 0 & 0 & 55,42 & 0 & 6,00 & 578,52 & 43,08 & 764,48 & 56,92 & 0,00 & 1343,00 & 1356,30 & 0,99 \\
\hline set-2009 & 4176,21 & 21,24 & 0 & 0 & 0 & 64,86 & 0 & 12,73 & 1276,25 & 57,44 & 945,51 & 42,56 & 0,00 & 2221,76 & 1556,89 & $-29,93$ \\
\hline out-2009 & 4317,69 & 26,51 & 0 & 0 & 0 & 82,41 & 0 & 9,05 & 937,80 & 43,45 & 1220,52 & 56,55 & 0,00 & 2158,33 & 2690,79 & 24,67 \\
\hline nov-2009 & 4393,30 & 16,47 & 0 & 0 & 0 & 60,76 & 0 & 10,60 & 1117,65 & 59,16 & 771,53 & 40,84 & 0,00 & 1889,19 & 1704,60 & $-9,77$ \\
\hline nov-2009 DUP & 4377,69 & 15,12 & 0 & 0 & 0 & 62,04 & 0 & 2,83 & 297,68 & 29,67 & 705,78 & 70,33 & 0,00 & 1003,46 & 1505,93 & 50,07 \\
\hline dez-2009 & 4348,57 & 23,05 & 0 & 0 & 0 & 87,71 & 0 & 5,38 & 561,26 & 34,44 & 1068,57 & 65,56 & 0,00 & 1629,83 & 2379,54 & 46,00 \\
\hline dez-2009 DUP & 4210,52 & 19,65 & 0 & 0 & 0 & 71,43 & 0 & 5,20 & 525,47 & 37,34 & 881,90 & 62,66 & 0,00 & 1407,38 & 1842,52 & 30,92 \\
\hline jan-2010 & 4406,27 & 21,98 & 0 & 0 & 0 & 92,24 & 0 & 9,57 & 1011,68 & 49,49 & 1032,38 & 50,51 & 0,00 & 2044,05 & 2499,24 & 22,27 \\
\hline jan-2010 DUP & 4600,00 & 19,90 & 0 & 0 & 0 & 78,02 & 0 & 5,92 & 653,20 & 40,09 & 976,10 & 59,91 & 0,00 & 1629,30 & 3013,92 & 84,98 \\
\hline fev-2010 & 4856,17 & 16,75 & 0 & 0 & 0 & 79,72 & 0 & 6,65 & 775,04 & 47,19 & 867,34 & 52,81 & 0,00 & 1642,38 & 1938,58 & 18,03 \\
\hline mar-2010 & 4563,10 & 15,21 & 0 & 0 & 0 & 72,60 & 0 & 7,70 & 843,26 & 53,27 & 739,84 & 46,73 & 0,00 & 1583,10 & 1803,34 & 13,91 \\
\hline mar-2010 DUP & 4359,79 & 12,12 & 0 & 0 & 0 & 64,30 & 0 & 11,57 & 1210,28 & 68,24 & 563,39 & 31,76 & 0,00 & 1773,67 & 2190,36 & 23,49 \\
\hline abr-2010 & 4459,29 & 22,50 & 0 & 0 & 0 & 81,23 & 0 & 7,50 & 802,67 & 42,87 & 1069,62 & 57,13 & 0,00 & 1872,29 & 1940,68 & 3,65 \\
\hline abr-2010 DUP & 4572,68 & 12,47 & 0 & 0 & 0 & 59,49 & 0 & 8,30 & 910,88 & 59,98 & 607,74 & 40,02 & 0,00 & 1518,62 & 2326,58 & 53,20 \\
\hline mai-2010 & 4094,85 & 13,49 & 0 & 0 & 0 & 56,89 & 0 & 6,93 & 681,38 & 53,63 & 589,07 & 46,37 & 0,00 & 1270,45 & 1195,70 & $-5,88$ \\
\hline mai-2010 DUP & 4258,46 & 11,18 & 0 & 0 & 0 & 51,13 & 0 & 4,90 & 500,79 & 49,66 & 507,59 & 50,34 & 0,00 & 1008,38 & 1168,52 & 15,88 \\
\hline jun-2010 & 4128,85 & 12,83 & 0 & 0 & 0 & 46,17 & 0 & 10,20 & 1010,74 & 64,15 & 564,83 & 35,85 & 0,00 & 1575,57 & 1773,76 & 12,58 \\
\hline jun-2010 DUP & 4572,46 & 12,60 & 0 & 0 & 0 & 50,25 & 0 & 6,57 & 720,62 & 53,98 & 614,29 & 46,02 & 0,00 & 1334,91 & 1338,82 & 0,29 \\
\hline média & 4372,97 & & & & & & & & média & 49,28 & média & 50,72 & & & média & 19,74 \\
\hline desv. pad. & 210,77 & & & & & & & & mediana & 49,58 & mediana & 50,42 & & & desv. pad. & 26,83 \\
\hline \multirow[t]{3}{*}{ CV } & 0,05 & & & & & & & & & & & & & & mín. & $-29,93$ \\
\hline & & & & & & & & & & & & & & & máx. & 84,98 \\
\hline & & & & & & & & & & & & & & & mediana & 16,96 \\
\hline
\end{tabular}




\section{ETA Cubatão}

Dosagem $(\mathrm{mg} / \mathrm{L})$

Produção de lodo por componente

Produção $\begin{array}{lllllllllllll}\text { SA } & \text { CF } & \text { PACl } & P & \text { Cal } & \text { CAP } & \begin{array}{c}\text { medida } \\ (\mathrm{mg} / \mathrm{L})\end{array} & \begin{array}{c}\text { SST } \\ (\mathrm{kg} / \mathrm{dia})\end{array} & \begin{array}{c}\text { SST } \\ (\%)\end{array} & \begin{array}{c}\text { Coag. } \\ (\mathrm{kg} / \mathrm{dia})\end{array} & \begin{array}{c}\text { Coag. } \\ (\%)\end{array} & \begin{array}{c}\text { Outros } \\ \text { estimada } \\ (\mathrm{kg} / \mathrm{dia})\end{array}\end{array}$

\begin{tabular}{lcccc}
\hline jun-2009 & 4368,88 & 16,21 & 0 \\
\hline jun-2009 DUP & 4430,81 & 16,63 & 0 \\
\hline jul-2009 & 3892,07 & 43,33 & 0 \\
\hline jul-2009 DUP & 3961,64 & 28,04 & 0 \\
\hline ago-2009 & 4139,46 & 21,31 & 0 \\
\hline ago-2009 DUP & 3848,08 & 21,44 & 0 \\
\hline set-2009 & 11884,58 & 0,00 & 72 \\
\hline set-2009 DUP & 11640,83 & 0,00 & 31 \\
\hline out-2009 & 12150,00 & 0,00 & 44 \\
\hline out-2009 DUP & 12088,33 & 0,00 & 57 \\
\hline nov-2009 & 4588,27 & 30,74 & 0 \\
\hline nov-2009 DUP & 4194,94 & 16,28 & 0 \\
\hline dez-2009 & 4596,02 & 24,43 & 0 \\
\hline dez-2009 DUP & 4701,37 & 19,75 & 0 \\
\hline jan-2010 & 4275,22 & 26,83 & 0 \\
\hline jan-2010 DUP & 4273,71 & 27,53 & 0 \\
\hline fev-2010 & 5482,01 & 20,46 & 0 \\
\hline fev-2010 DUP & 4856,17 & 16,75 & 0 \\
\hline mar-2010 & 4430,26 & 15,25 & 0 \\
\hline mar-2010 DUP & 4713,32 & 12,94 & 0 \\
\hline média & 5925,80 & & \\
\hline
\end{tabular}

desv. pad $\quad 3108,57$

0,52 total

Produção desvio em

relação ao

(kg/dia) estimado (\%)

$\begin{array}{lll}1663,78 & 1908,33 & 14,70\end{array}$

$1017,75 \quad 1885,75 \quad 85,29$

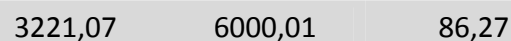

$2055,95 \quad 5698,43 \quad 177,17$

$1364,35 \quad 1298,13 \quad-4,85$

$1764,80 \quad 4479,16 \quad 153,80$

$25948,40 \quad 24263,57 \quad-6,49$

$18250,74 \quad 24110,49 \quad 32,11$

0,79

$\begin{array}{lllllllll} & 0 & 18,85 & 5376,59 & 20,72 & \# \# \# \# \# \# \quad 78,41 & 225,00 & 25948,4\end{array}$

$\begin{array}{llllll}4,43 & 9619,98 & 52,71 & 8580,76 & 47,02 & 50,00\end{array}$

14275,41

17799,26

5827,90

2543,58

4112,58

2005,24

2289,8

3425,51

1963,28

1523,89

1159,8

1430,76

$\begin{array}{lllll}780,53 & 54,55 & 650,24 & 45,45 & 0,00\end{array}$

média 44,39 média 55,48

mediana 45,39 mediana 54,61

$9148,45 \quad-48,60$

$8919,59-53,05$

$2563,95 \quad 0,80$

$8048,54 \quad 95,71$

$3693,40 \quad 84,19$

$5051,60 \quad 120,61$

$5261,79 \quad 53,61$

$2848,45 \quad 45,09$

$1367,50 \quad-10,26$

$3615,09 \quad 211,68$

média 64,09

desv. pad. $\quad 72,62$

mín. $\quad-48,60$

máx. $\quad 211,68$

mediana

53,33

$11362,68 \quad-20,40$

$3695,24 \quad 158,27$ 


\section{ETA Franca}

Dosagem (mg/L)

Produção de lodo por componente

Produção

total

Produção desvio em SST SST SST Coag. Coag. Outros estimada total elação ao $\begin{array}{llllllll}\text { Data } & \mathrm{Q}\left(\mathrm{m}^{3} / \mathrm{h}\right) & \mathrm{SA} & \mathrm{CF} & \mathrm{PACl} & \mathrm{P} & \text { Cal } & \text { CAP }\end{array}$ $(\mathrm{mg} / \mathrm{L}) \quad(\mathrm{kg} / \mathrm{dia}) \quad(\%)$

(kg/dia) (kg/dia)

\begin{tabular}{|c|c|c|c|c|c|c|c|c|c|c|c|c|c|c|c|c|}
\hline jun-2009 & 2882,79 & 0,00 & 80,926 & 0 & 0,2891 & 28,91 & 0 & 5,67 & 392,06 & 6,58 & 5547,27 & 93,09 & 20,00 & 5959,33 & 2135,23 & $-64,17$ \\
\hline jun-2009 DUP & 2882,79 & 0,00 & 80,926 & 0 & 0,2891 & 28,91 & 0 & 8,57 & 592,70 & 9,62 & 5547,27 & 90,05 & 20,00 & 6159,97 & 3021,14 & $-50,96$ \\
\hline ago-2009 & 3006,38 & 0,00 & 77,564 & 0 & 0,1967 & 30,40 & 0 & 4,92 & 354,75 & 6,00 & 5544,81 & 93,76 & 14,19 & 5913,75 & 1840,65 & $-68,88$ \\
\hline ago-2009 DUP & 3006,38 & 0,00 & 77,564 & 0 & 0,1967 & 30,40 & 0 & 7,65 & 551,97 & 9,03 & 5544,81 & 90,74 & 14,19 & 6110,97 & 1885,18 & $-69,15$ \\
\hline set-2009 & 3056,18 & 0,00 & 96,162 & 0 & 0,2999 & 36,36 & 0 & 9,88 & 724,93 & 9,37 & 6988,13 & 90,34 & 22,00 & 7735,06 & 3406,24 & $-55,96$ \\
\hline set-2009 DUP & 3056,18 & 0,00 & 96,162 & 0 & 0,2999 & 36,36 & 0 & 30,57 & 2242,01 & 24,23 & 6988,13 & 75,53 & 22,00 & 9252,14 & 4922,07 & $-46,80$ \\
\hline jan-2010 & 3019,56 & 0,00 & 118,92 & 0 & 0,4117 & 46,29 & 0 & 24,37 & 1765,84 & 17,09 & 8538,44 & 82,62 & 29,84 & 10334,11 & 2986,40 & $-71,10$ \\
\hline jan-2010 DUP & 3019,56 & 0,00 & 118,92 & 0 & 0,4117 & 46,29 & 0 & 61,07 & 4425,46 & 34,06 & 8538,44 & 65,71 & 29,84 & 12993,74 & 9600,22 & $-26,12$ \\
\hline mar-2010 & 3174,49 & 0,00 & 112,47 & 0 & 0,5504 & 41,92 & 0 & 268,77 & \#\#\#\#\#\#\# & 70,59 & 8489,86 & 29,27 & 41,94 & 29008,49 & 37671,55 & 29,86 \\
\hline média & 3036,42 & & & & & & & & média & 20,73 & média & 79,01 & & & média & $-47,03$ \\
\hline desv. pad & 98,18 & & & & & & & & mediana & 9,62 & mediana & 90,05 & & & desv. pad. & 32,18 \\
\hline \multirow[t]{3}{*}{ CV } & 0,03 & & & & & & & & & & & & & & mín. & $-71,10$ \\
\hline & & & & & & & & & & & & & & & máx. & 29,86 \\
\hline & & & & & & & & & & & & & & & mediana & $-55,96$ \\
\hline
\end{tabular}


ETA Guaraú

Dosagem (mg/L)

Produção de lodo por componente

Produção

SST

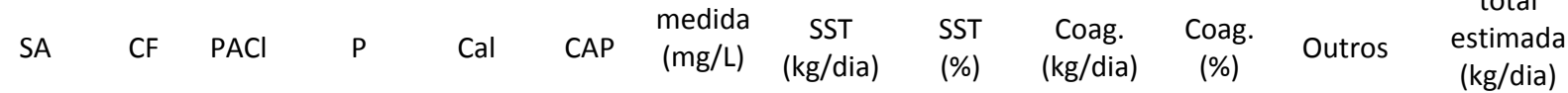

Produção

total relação ao

Data

$\mathrm{Q}\left(\mathrm{m}^{3} / \mathrm{h}\right)$

$\begin{array}{lllllll}1,64 & 4506 & 29,30 & 10331 & 67,16 & 544,57 & 15381\end{array}$

jun-2009 114483

8,46

jun-2009 DUP

107637

$\begin{array}{lll}0 & 0,20 & 0,00\end{array}$

1,20

jul-2009

3100

$\begin{array}{llll}24,57 & 8774 & 69,56 & 740,21\end{array}$

jul-2009 DUP

9,47

0

$\begin{array}{llll}\text { ago-2009 } & 109455 & 7,37 & 0 \\ \text { ago-2009 DUP } & 110326 & 8,12 & 0\end{array}$

set-2009

$\begin{array}{ll}0,24 & 0,82 \\ 0,28 & 0,00\end{array}$

1,72

\begin{tabular}{|l|l|l|l|l}
\hline 731 & 27,87 & 11590 & 68,26 & 658,03 \\
\hline
\end{tabular}

12615

$\begin{array}{lllllll}1,78 & 4949 & 29,56 & 11024 & 65,84 & 769,81 & 16743\end{array}$

\begin{tabular}{|l|l|l|l|l|l|l|}
\hline 2,45 & 6436 & 40,01 & 8598 & 53,45 & 1050,79 & 16084 \\
\hline
\end{tabular}

$\begin{array}{lllllll}1,80 & 4766 & 32,11 & 9552 & 64,34 & 526,94 & 14845\end{array}$

$\begin{array}{ccccc}0,20 & 0,00 & 0 & 1,80 & 4766 \\ 0,24 & 0,00 & 0 & 17,52 & 45855\end{array}$

$\begin{array}{llrl}\text { set-2009 DUP } & 110065 & 8,64 & 0 \\ \text { out-2009 } & 113356 & 8,96 & 0\end{array}$

$\begin{array}{llll}\text { out-2009 DUP } & 120560 & 9,10 & 0 \\ \text { nov-2009 } & 120147 & 8,91 & 0\end{array}$

nov-2009

nov-2009 DUP $118705 \quad 10,10 \quad 0$

$\begin{array}{lllllll}\text { nov-2009 } & 120147 & 8,91 & 0 & 0 & 0,02 & 0,00 \\ \text { nov-2009 DUP } & 118705 & 10,10 & 0 & 0 & 0,02 & 0,00 \\ \text { fev-2010 } & 122170 & 10,75 & 0 & 0 & 0,04 & 0,00 \\ \text { mar-2010 } & 121837 & 10,03 & 0 & 0 & 0,04 & 0,00\end{array}$

$\begin{array}{lll}\text { abr-2010 } & 116830 & 10,28\end{array}$

$\begin{array}{llll}\text { abr-2010 DUP } & 123177 & 7,53 & 0 \\ \text { mai-2010 } & 119252 & 7,00 & 0\end{array}$

\begin{tabular}{lccc} 
mai-2010 DUP & 121243 & 7,00 & 0 \\
\cline { 1 - 2 } média & 116863,42 & & 0
\end{tabular}

desv.pad 5050,22

cV

0,04

\begin{tabular}{|c|c|c|c|c|c|c|}
\hline ,52 & 45855 & 78,72 & 11754 & 20,18 & 638,94 & 58 \\
\hline 4,07 & 10742 & 49,92 & 10140 & 47,12 & 635,40 & \\
\hline 1,38 & 3763 & 24,68 & 10831 & 71,01 & 657,44 & \\
\hline 3,93 & 11381 & 47,87 & 11695 & 49,19 & 697,58 & \\
\hline 1,45 & 4181 & 26,71 & 11416 & 72,92 & 58,39 & \\
\hline 2,22 & 6315 & 32,97 & 12782 & 66,73 & 58,05 & \\
\hline 2,23 & 6548 & 31,71 & 13996 & 67,78 & 105,92 & \\
\hline 1,45 & 4240 & 24,41 & 13022 & 74,98 & 105,51 & \\
\hline 2,50 & 7010 & 35,20 & 12798 & 64,27 & 103,63 & \\
\hline 3,03 & 8967 & 47,28 & 9893 & 52,16 & 106,79 & \\
\hline 2,53 & 7251 & 44,70 & 8900 & 54,87 & 69,17 & \\
\hline \multirow[t]{3}{*}{5,17} & 15034 & 61,13 & 9484 & 38,56 & \multirow[t]{3}{*}{75,53} & \\
\hline & média & 37,64 & média & 60,07 & & \\
\hline & mediana & 32,11 & mediana & 65,84 & & \\
\hline
\end{tabular}

$\begin{array}{ll}0,24 & 0,00 \\ 0,24 & 0,00\end{array}$

mediana 32,11 mediana 65,84

(kg/dia)

\begin{tabular}{|c|c|}
\hline 24335 & 58,21 \\
\hline 20628 & 63,52 \\
\hline 26274 & 54,74 \\
\hline 30109 & 79,84 \\
\hline 21504 & 33,69 \\
\hline 24628 & 65,90 \\
\hline 111581 & 91,56 \\
\hline 38956 & 81,04 \\
\hline 34309 & 124,95 \\
\hline 58451 & 145,86 \\
\hline 25863 & 65,20 \\
\hline 42547 & 122,12 \\
\hline 49120 & 137,86 \\
\hline 43407 & 149,94 \\
\hline 42547 & 113,68 \\
\hline 37140 & 95,81 \\
\hline 35246 & 117,31 \\
\hline 63692 & 158,97 \\
\hline média & 97,79 \\
\hline desv. pad. & 37,39 \\
\hline
\end{tabular}

33,69

máx. 158,97

mediana $\quad 93,69$ 
ETA Presidente Prudente

\begin{tabular}{|c|c|c|c|c|c|c|c|c|c|c|c|c|c|c|c|c|}
\hline \multirow[b]{2}{*}{ Data } & \multirow[b]{2}{*}{$\mathrm{Q}\left(\mathrm{m}^{3} / \mathrm{h}\right)$} & \multicolumn{6}{|c|}{ Dosagem (mg/L) } & \multirow{2}{*}{$\begin{array}{c}\mathrm{SST} \\
\text { medida } \\
(\mathrm{mg} / \mathrm{L})\end{array}$} & \multicolumn{5}{|c|}{ Produção de lodo por componente } & \multirow{2}{*}{$\begin{array}{l}\text { Produção } \\
\text { total } \\
\text { estimada } \\
\text { (kg/dia) }\end{array}$} & \multirow{2}{*}{$\begin{array}{l}\text { Produção } \\
\text { total } \\
\text { (kg/dia) }\end{array}$} & \multirow{2}{*}{$\begin{array}{l}\text { desvio em } \\
\text { relação ao } \\
\text { estimado (\%) }\end{array}$} \\
\hline & & SA & $\mathrm{CF}$ & $\mathrm{PACl}$ & $\mathrm{P}$ & Cal & CAP & & $\begin{array}{c}\text { SST } \\
\text { (kg/dia) }\end{array}$ & $\begin{array}{l}\text { SST } \\
(\%)\end{array}$ & $\begin{array}{l}\text { Coag. } \\
\text { (kg/dia) }\end{array}$ & $\begin{array}{c}\text { Coag. } \\
(\%)\end{array}$ & Outros & & & \\
\hline jun-2009 & 2283,80 & 43,00 & 0 & 0 & 0 & 0,00 & 1,9 & 25,17 & 1379,42 & 54,51 & 1046,98 & 41,37 & 104,14 & 2530,54 & 2377,46 & $-6,05$ \\
\hline jun-2009 DUP & 2313,05 & 56,30 & 0 & 0 & 0 & 0,00 & 0 & 48,17 & 2673,89 & 65,82 & 1388,36 & 34,18 & 0,00 & 4062,26 & 4090,82 & 0,70 \\
\hline ago-2009 & 2211,46 & 51,80 & 0 & 0 & 0 & 0,00 & 3 & 17,63 & 935,89 & 40,40 & 1221,29 & 52,72 & 159,23 & 2316,40 & 2481,56 & 7,13 \\
\hline out-2009 & 2358,85 & 105,90 & 0 & 0 & 0,1 & 0,00 & 0 & 98,87 & 5597,07 & 67,71 & 2663,21 & 32,22 & 5,66 & 8265,94 & 19048,86 & 130,45 \\
\hline dez-2009 & 2703,61 & 120,70 & 0 & 0 & 0,1 & 3,60 & 0 & 112,10 & 7273,80 & 67,60 & 3479,05 & 32,34 & 6,49 & 10759,34 & 10067,79 & $-6,43$ \\
\hline dez-2009 DUP & 2408,33 & 91,20 & 0 & 0 & 0,1 & 1,00 & 0 & 118,73 & 6862,79 & 74,51 & 2341,64 & 25,42 & 5,78 & 9210,21 & 8364,84 & $-9,18$ \\
\hline jan-2010 & 2685,42 & 156,00 & 0 & 0 & 0,1 & 10,40 & 0 & 300,93 & \#\#\#\#\#\# & 81,26 & 4466,28 & 18,71 & 6,45 & 23867,88 & 20285,47 & $-15,01$ \\
\hline jan-2010 DUP & 2537,92 & 191,70 & 0 & 0 & 0,1 & 9,50 & 0 & 293,80 & \#\#\#\#\#\# & 77,51 & 5186,91 & 22,47 & 6,09 & 23088,36 & 22433,94 & $-2,83$ \\
\hline fev-2010 & 2951,88 & 112,80 & 0 & 0 & 0,2 & 2,70 & 0 & 77,67 & 5502,29 & 60,69 & 3549,90 & 39,15 & 14,17 & 9066,37 & 6541,15 & $-27,85$ \\
\hline fev-2010 DUP & 2690,83 & 107,10 & 0 & 0 & 0,1 & 4,50 & 0 & 206,53 & \#\#\#\#\#\# & 81,25 & 3072,46 & 18,72 & 6,46 & 16416,84 & 14127,38 & $-13,95$ \\
\hline mar-2010 & 2733,75 & 57,20 & 0 & 0 & 0,1 & 0,00 & 0 & 51,33 & 3367,98 & 66,80 & 1667,11 & 33,07 & 6,56 & 5041,65 & 4097,07 & $-18,74$ \\
\hline mar-2010 DUP & 2553,47 & 87,10 & 0 & 0 & 0,1 & 0,00 & 0 & 151,07 & 9257,86 & 79,57 & 2371,15 & 20,38 & 6,13 & 11635,14 & 11148,27 & $-4,18$ \\
\hline abr-2010 & 2553,46 & 43,70 & 0 & 0 & 0,1 & 0,00 & 0 & 49,07 & 3006,95 & 71,55 & 1189,65 & 28,31 & 6,13 & 4202,73 & 3780,63 & $-10,04$ \\
\hline abr-2010 DUP & 2611,67 & 41,80 & 0 & 0 & 0,1 & 0,00 & 0 & 62,93 & 3944,66 & 77,12 & 1163,87 & 22,75 & 6,27 & 5114,80 & 4196,99 & $-17,94$ \\
\hline mai-2010 & 2481,25 & 38,60 & 0 & 0 & 0,1 & 0,00 & 0 & 38,37 & 2284,73 & 68,99 & 1021,10 & 30,83 & 5,96 & 3311,79 & 3351,77 & 1,21 \\
\hline média & 2512,60 & & & & & & & & média & 68,91 & média & 34,21 & & & média & 0,49 \\
\hline desv. pad & 202,50 & & & & & & & & mediana & 68,99 & mediana & 30,83 & & & desv. pad. & 37,06 \\
\hline \multirow[t]{3}{*}{$\mathrm{cV}$} & 0,08 & & & & & & & & & & & & & & mín. & $-27,85$ \\
\hline & & & & & & & & & & & & & & & máx. & 130,45 \\
\hline & & & & & & & & & & & & & & & mediana & $-6,43$ \\
\hline
\end{tabular}

